\title{
Anwendung der Fluoreszenz-Korrelations-Spektroskopie zur Untersuchung dynamischer Prozesse in lebenden Zellen
}

\author{
Dissertation \\ zur Erlangung des Doktorgrades \\ der Mathematisch-Naturwissenschaftlichen Fakultäten \\ der Georg-August-Universität zu Göttingen
}

vorgelegt von

Randolf Jordan

aus Aurich

Göttingen 2000 
D 7

Referent:

Prof. Dr. J. Troe

Korreferent:

Prof. Dr. A. Zeeck

Tag der mündlichen Prüfung: $\quad 31.10 .2000$ 


\section{Inhaltsverzeichnis}

1 EINLEITUNG

1.1 Synaptische Transmission

$12^{2}$ Wirkung von Benzodiazepinen

1.3 ${ }^{1}$ Calciumchèatoren in Chromaffinzellen

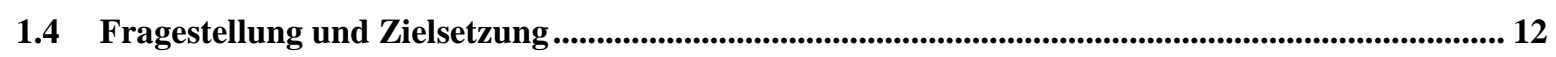

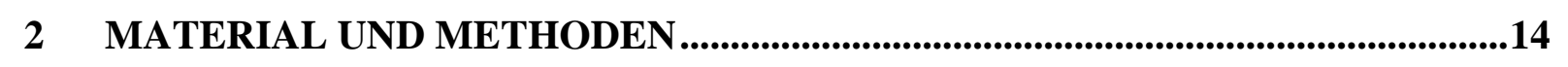

p.1 Konfokales Mikroskop

$\overline{2} .2$ Berechnung von Autokorrelationsfunktion und Leistungsspektrum

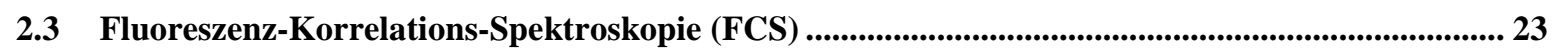

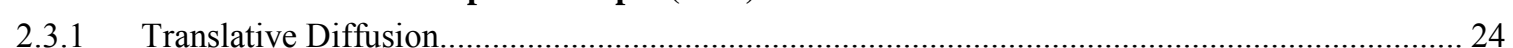

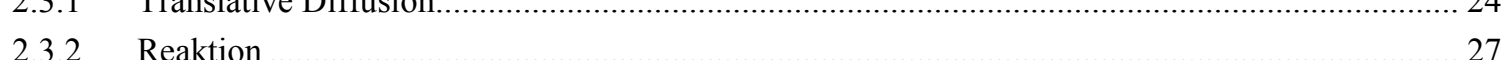

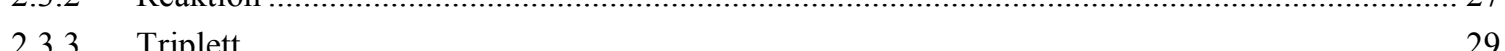

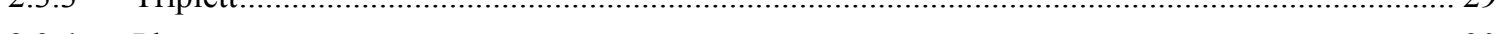

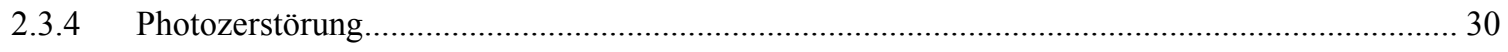

12.3.

2.4 4 Fluoreszenzrǘckkehr nach Photozerstörung (FRAP)

2.5 Experimenteller Aufbau

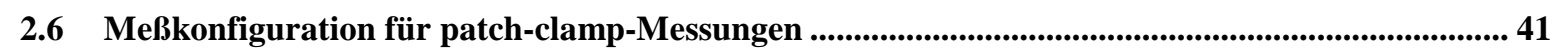

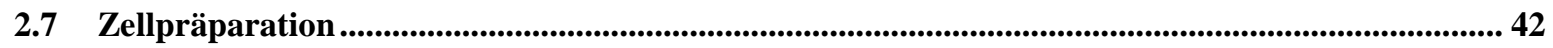

12.1 Neuronale Primärkulturen des Hippocampus

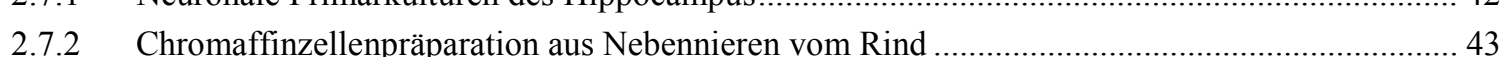

20.

2.8

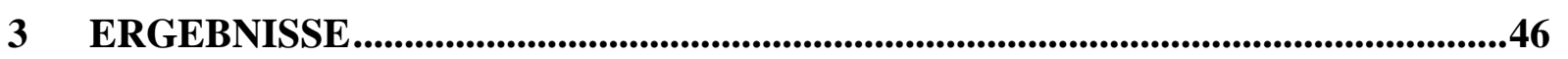

3.1 Autofluoreszenz in Chromaffinzellen und hippocampalen Neuronen ...........................................

3.2 Diffusion und Kinetik von Calciumfarbstoffen in einfachen Elektrolyten und

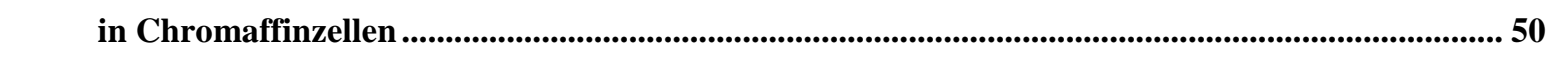

3.1 Diffusion und Kinetik von Calciumfarbstoffen im Elektrolyten

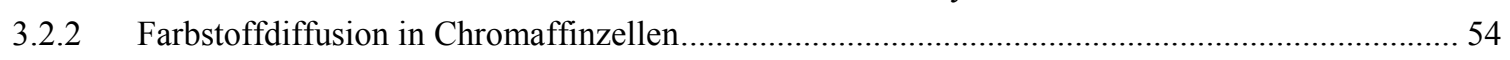

3.3. Benzodiazepin-Rezeptor-Wechselwirkung in der Membran hippocampaler Neurone..................58

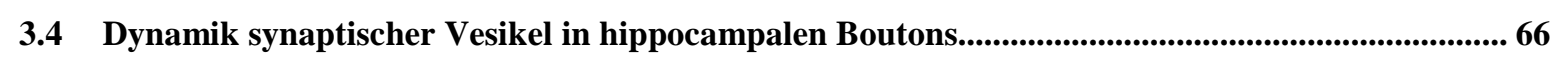

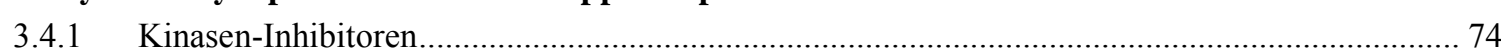

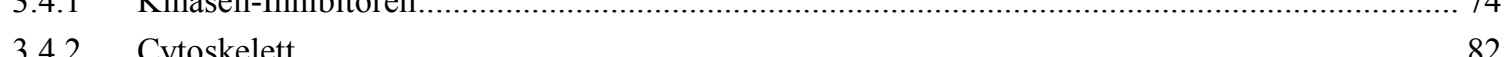

$43.4 .0=0=$

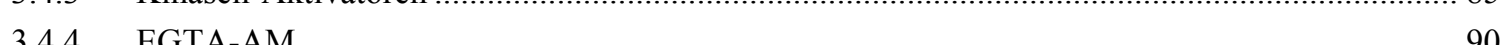

13.44 EGTA-AM

13.

13. 4 . AP-Stimulation........

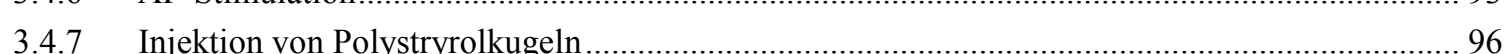




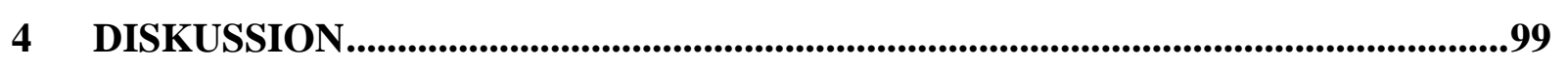

4.1 Autofluoreszenz in Chromaffinzellen und hippocampalen Neuronen

4.2 Diffusion und Kinetik von Calciumfarbstoffen in einfachen Elektrolyten und

1-

4.3. Benodiazepin-Rezeptor-Wechselwirkung in der Membran hippocampaler Neurone.................102

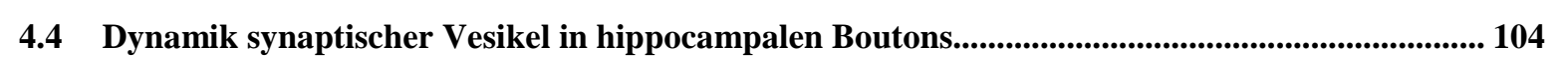

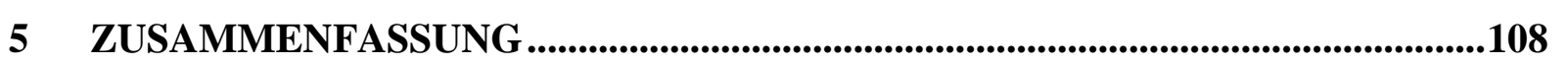

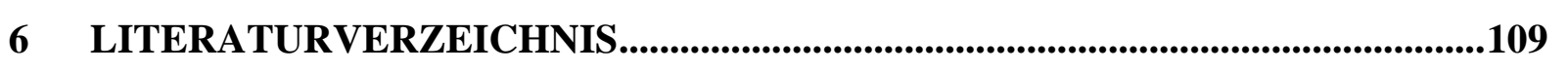

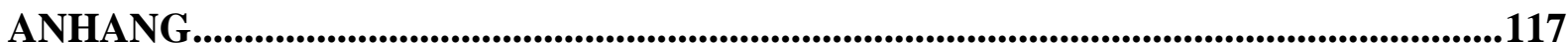




\section{Abkürzungsverzeichnis}

AM

AP

ATP

BAPTA

Bisindolylmaleimid I

Colchicin

cps

Cytochalasin D

Forskolin

GTP

HEPES

kcps

$\mathrm{KN}-62$

Latrunculin B

ML-7

NA

OGB1

OGB2

Okadasäure

PMA

Rp-8-Br-cAMPS

TTX
Acetoxymethylester

Aktionspotential

Adenosin-5'-triphosphat

1,2-Bis-2-aminophenoxy)-ethan-N,N,N',N'-tetraessigsäure(

GF 109203X; Gö6850; 2-[1-(3-dimethylaminopropyl)-1H-indol-

3-yl]-3-(1H-indol-3-yl)-maleimid

Colchicum autumnale

Zählrate pro Sekunde (counts per second)

Zygusporium mansonii

Coleus forskohlii; $7 \beta$-Acetoxy-8,13-exoxy-1 $\alpha, 6 \beta, 9 \alpha-\mathrm{t}$

rihydroxy-labd-14-en-11-on; colforsin

Guanosin-5'-triphosphat

4-(2-Hydroxyethyl)-piperazin-1-ethansulfonsäure

Zählrate pro Sekunde $\cdot 10^{3}$

1-[N,O-bis-(5-Isoquinolinsulfonyl)-N-methyl-L-tyrosyl]-4-

phenylpiperazin

Latrunculia magnifica

(5-Iodonaphthalen-1-sulfonyl)homopiperazine, $\mathrm{HCl}$

Numerische Apertur

Oregon Green 488 BAPTA-1

Oregon Green 488 BAPTA-2

Prorocentrum concavum

Phorbol-12-myristat-13-acetat

Andenosin 3',5'-cyclo Monophosphorothioat, 8-Bromo-, RpIsomer, $\mathrm{Na}-\mathrm{Salz}$

Tetrodotoxin; Fugu sp. 


\section{Einleitung}

Die Fluoreszenz-Korrelations-Spektroskopie (FCS) ist eine vielseitige Methode zur Untersuchung dynamischer Prozesse. Die FCS-Technik beruht auf der Beobachtung und Analyse von Fluoreszenzfluktuationen, die in einem kleinen offenen Volumenelement innerhalb einer Probe mit fluoreszierenden Molekülen auftreten. Im thermodynamischen Gleichgewicht schwankt die aus dem Volumenelement detektierte Fluoreszenz, indem beispielsweise neue Teilchen in das Volumenelement hineindiffundieren oder Teilchen unter Fluoreszenzänderung chemische Reaktionen eingehen. Die Fluktuationsdauer enthält Informationen über die Geschwindigkeit der untersuchten Vorgänge, die Fluktuationsamplitude ist ein Maß für die Anzahl der Teilchen im Volumenelement. Ausgewertet werden die Fluoreszenzsignale durch Autokorrelation, die über die vielen beobachteten Fluoreszenzfluktuationen mittelt und so den Rauschlevel reduziert.

Zum ersten Mal wurde die Fluoreszeszenz-Korrelations-Spektroskopie Anfang der siebziger Jahre angewandt [1 14 ] technische Verbesserungen ständig erhöht. Durch Objektive mit hoher numerischer Apertur zusammen mit konfokaler Detektion der emittierten Fluoreszenz wurden immer kleinere Detektionsvolumina mit Rauminhalten von bis zu einer Größenordnung von $10^{-15} 1$ erreicht. Bei gleichzeitiger Entwicklung von immer empfindlicheren Fluoreszenzdetektoren können heute dynamische Prozesse von einzelnen Molekülen im Detektionsvolumen beobachtet werden $[5$

Im Vergleich zum Detektionsvolumen hat eine typische lebende Säugerzelle mit einen Radius von $7 \mu \mathrm{m}$ bei annähernd sphärischer Gestalt einen ungefähr 1000fach größeren Rauminhalt. Mit der FCS-Methode sind also Experimente in einzelnen Zellkompartimenten denkbar. In diesen Kompartimenten könnte die FCS-Methode dann zur Klärung von dynamischen Prozessen auf Einzelmolekülebene genutzt werden. Das Studium würde im Unterschied zu anderen Methoden nichtinvasiv und im thermodynamischen Gleichgewicht der Zelle erfolgen.

Von besonderem Interesse sind hierbei Diffusions- und Reaktionsprozesse. Die Reaktionskinetik wird von der Geschwindigkeitskonstanten des Reaktionsschrittes bestimmt. Die Mobilität der Reaktionspartner und des Reaktionsproduktes wird durch die Viskosität der Umgebung mitbestimmt. Messung von Diffusion und Reaktion von Teilchen direkt an dem Ort in der Zelle, in der sie ihre relevante Funktion ausüben, kann somit zur Klärung von Mechanismus und Geschwindigkeit einzelner Reaktionsschritte beitragen und somit helfen, die komplexen Vorgänge in der Zelle besser zu verstehen.

Eine Grundvoraussetzung für FCS-Experimente ist die Fluoreszenz der zu untersuchenden Teilchen. Nichtfluoreszierende biologisch relevante Moleküle müssen also erst mit Farbstoffen markiert werden. Andere nicht zu untersuchende Teilchen sollten möglichst nicht zur Fluoreszenz beitragen, da sie das Meßsignal stören. In der Zelle ist aber von Fluoreszenz 
endogener Zellbestandteile (Autofluoreszenz) auszugehen $\left[\begin{array}{ll}10 \\ 1\end{array} 11\right]$. Die Absorptions- und Emissionseigenschaften der endogenen Zellbestandteile bestimmen dabei die Fluoreszenzintensität. Neben der Signalhöhe der Autofluoreszenz ist in FCS-Messungen die Autokorrelationsfunktion besonders wichtig. Damit also FCS-Experimente in lebenden Zellen ausgeführt werden können, müssen die Eigenschaften der Autofluoreszenz vorher hinsichtlich Signalintensität und Autokorrelation charakterisiert werden.

Anhand ausgewählter Projekte, deren biologische Grundlagen in den folgenden Kapiteln der Einleitung skizziert werden, soll in der vorliegenden Dissertation die FCS auf dynamische Prozesse in lebenden Zellen bzw. in Teilen davon, d. h. in einzelnen Kompartimenten, angewandt werden.

\subsection{Synaptische Transmission}

Die Basis für die enorme Leistungsfähigkeit des menschlichen Gehirns beruht auf der komplexen Interaktion von Nervenzellen (Neuronen). Die im Nervensystem verarbeiteten Signale bestehen aus elektrischen Strömen, die durch Ionenfluß durch in die Zellmembran eingelagerte Kanäle hervorgerufen werden. Der Signaltransfer zwischen den Neuronen erfolgt dabei über eine hochspezialisierte Kontaktstelle, die Synapse. Neben der elektrischen Synapse, in der direkt ein Strom zwischen den Cytoplasmata der Zellen fließt, wird im Nervensystem vor allem die chemische Synapse gefunden. In der chemischen Synapse sind die Nervenzellen nicht direkt miteinander verbunden, sondern sind durch den synaptischen Spalt voneinander getrennt (cf. 'Ẩb bildung 1). Damit der Signaltransfer von der Senderzelle (Präsynapse) zur Empfängerzelle (Postsynapse) erfolgen kann, muß dieser ca. $20 \mathrm{~nm}$ breite Spalt zunächst überwunden werden. Zu diesem Zweck sind in der präsynaptischen Nervenendigung Vesikel eingelagert, die in einer hohen Konzentration eine chemische Substanz, den Neurotransmitter, enthalten. Erreicht das elektrische Signal die Nervenendigung der Präsynapse, so führt ein Einstrom von Calciumionen zur Freisetzung des Neurotransmitters in den synaptischen Spalt, indem die Vesikel mit der Plasmamembran verschmelzen. Die Fusion erfolgt dabei in einem genau festgelegten Bereich der Membran, der aktive Zone genannt wird. Der Neurotransmitter bindet nach Diffusion durch den Spalt an Rezeptoren der postsynaptischen Zelle und bewirkt damit einen Ionenfluß durch die Membran der postsynaptischen Zelle. In Abhängigkeit vom Neurotransmitter und den postsynaptischen Rezeptoren kann es entweder zu einem erregenden (exzitatorischen) oder einem hemmenden (inhibitorischen) postsynaptischen Potential kommen.

Der Vorteil der chemischen Synapse gegenüber der schnelleren elektrischen Synapse liegt in der Modulierbarkeit des Signals. Aufgrund der vielen Schritte bis zur vollständigen synaptischen Übertragung ergibt sich vom Öffnen des Calciumkanals bis zum Binden des Neurotransmitters an den Rezeptoren der postsynaptischen Membran an vielen Stellen eine Einflußnahme auf das zu übertragende Signal, und somit eine Anpassung der Signalstärke an 
unterschiedlichste Situationen. Diese Modulation der synaptischen Übertragung ist die Basis für die höheren Leistungen des Gehirns.

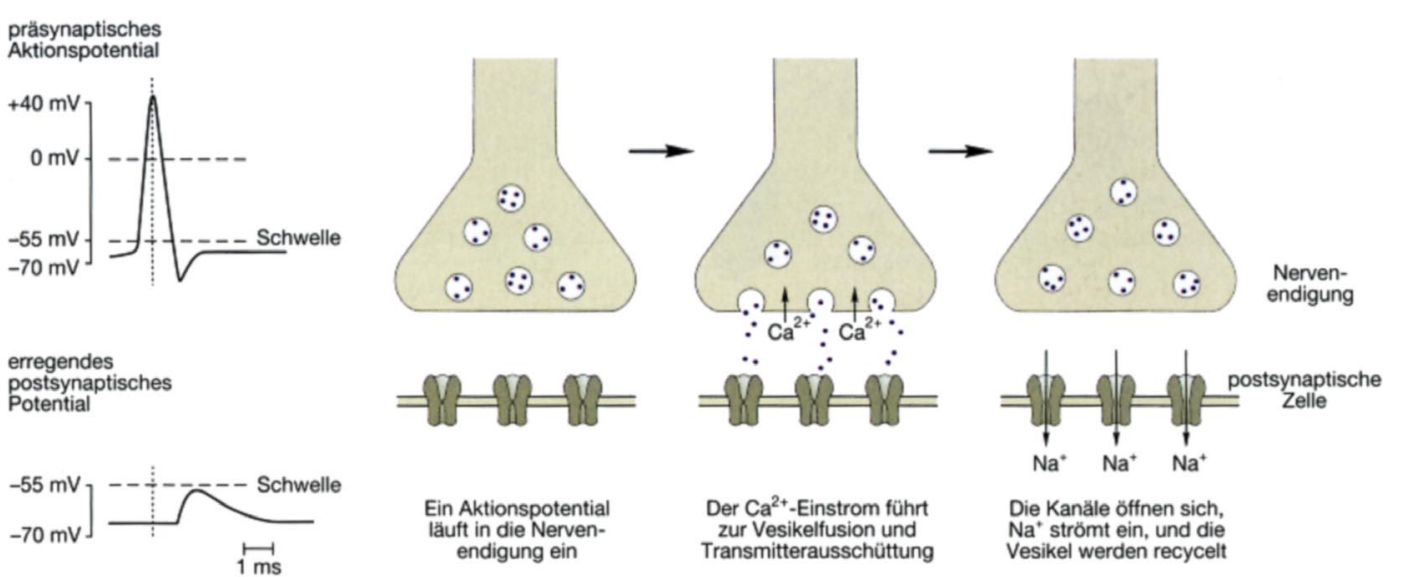

Abbildung 1: Schematische Darstellung der synaptischen Übertragung zwischen Neuronen. Ein präsynaptisches Aktionspotential führt zum Einfluß von $\mathrm{Ca}^{2+}$ in die Nervenendigung sowie zur Transmitterausschüttung durch Vesikelfusion. Nach Bindung des Neurotransmitters an den postsynaptischen Rezeptoren kommt es zur einer Änderung des postsynaptischen Potentials (nach' ${ }^{\prime}\left[\overline{1} \overline{6}_{-}\right]$).

In einem typischen hippocampalen Bouton, der präsynaptische Nervenendigung von Neuronen des Hippocampus, befinden sich etwa $10^{2}$ Vesikel $[171]$, wobei etwa ein Dutzend Vesikel an der aktiven Zone fusionsbereit gedockt sind (cf. AAbbildung 2) [1 1800$]$.

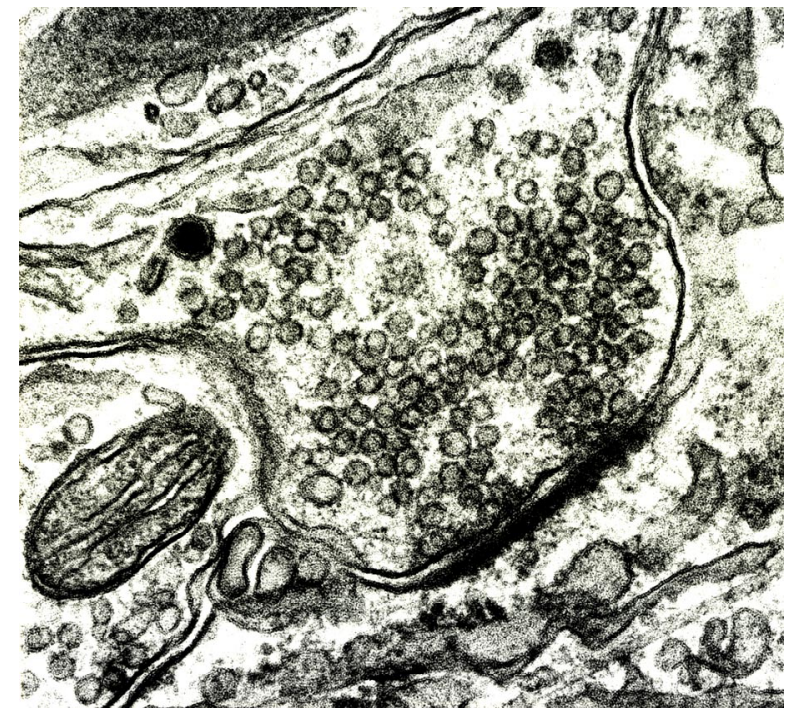

Abbildung 2: Elektronenmikroskopische Aufnahme einer Synapse zwischen zwei hippocampalen Neuronen. Die synaptischen Vesikel und die aktive Zone zusammen mit der postsynaptischen Membran sind deutlich als dunkle Bereiche zu erkennen. Das präsynaptische Bouton ist in seiner größten Ausdehnung etwa $1 \mu \mathrm{m}$ groß. (14 Tage in vitro, Glutaraldehyd-fixiert, Färbung mit $1 \%$ Osmiumtetraoxid, Nachfärbung mit $2 \%$ Uranylacetat. $50 \mathrm{~mm}$ Schnittdicke, aufgenommen mit einem Phillips CM-12 Transmissionsmikroskop; mit freundlicher Genehmigung von J. Klingauf).

Nach Fusion der gedockten Vesikel mit der Plasmamembran (Exozytose) werden neue Vesikel aus der Plasmamembran abgeschnürt (Endozytose). Die Kopplung von Exozytose und 
Endozytose ist zur Färbung der synaptischen Vesikel geeignet. Der Styrylfarbstoff FM 1-43 lagert sich in die Plasmamembran der Neurone ein und wird nach Stimulation der Neurone mit Aktionspotentialen, vom synaptischen Vesikel über den Prozeß der Endozytose aufgenommen:[17:is'].

Vesikel vom Boutonlumen müssen zur aktiven Zone transportiert werden. Wie dies geschieht ist noch weitgehend ungeklärt. Eine Möglichkeit ist aktiver Transport entlang von Filamenten des Cytoskeletts. Es gibt zwei wichtige Filamentypen für den aktiven Transport: Mikrotubuli und Actinfilamente.

Mikrotubuli sind steife Polymere, die aus langen, zylindrischen Strukturen zusammengesetzt sind und aus dem Protein Tubulin bestehen. Die Polymere entstehen, wenn sich GTPhaltige Tubulin-Moleküle unter Konformationsänderung an das freie Ende eines Mikrotubulus anlagern, wobei das eine Ende (plus-Ende) schneller wächst als das andere (minus-Ende). An die Mikrotubuli können Motorproteine binden, die ATP hydrolysieren und sich mit der so gewonnenen Energie an einem Mikrotubulus entlang bewegen (cf. Ā 3). Zur Familie der Motorproteine, die sich entlang der Mikrotubuli bewegen, gehören die Dyneine und die Kinesine [ $\overline{2} \overline{1} \overline{1}]$.

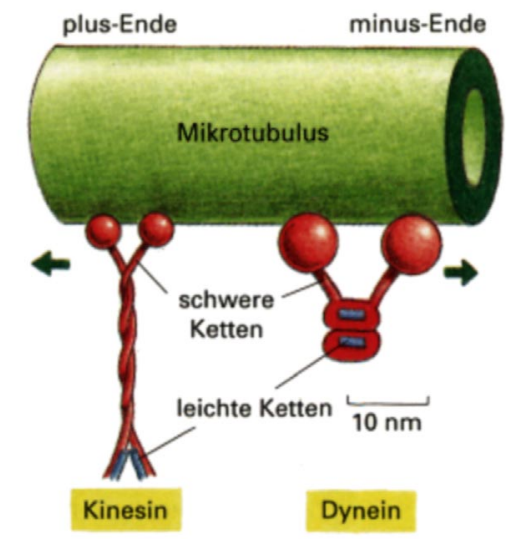

Abbildung 3: Schematische Darstellung des Kinesin-/Dynein-Transportes am Mikrotubulus (nach $[\overline{2} \overline{1}] \bar{j})$.

Actinfilamente werden aus dem Protein Actin gebildet. Das monomere ATP-haltige Actin (auch globuläres Actin oder G-Actin) steht im Gleichgewicht mit der polymeren Form, dem F-Actin. Die Motorproteinfamilie der Myosine können unter ATP-Verbrauch Bewegungen entlang von Actinfilamenten ausführen (cf. Áb̄bildung 4) [2 1 ]

Sowohl Mikrotubuli als auch Actinfilamente werden in präsynaptischen Boutons gefunden (zur Übersicht: i[22] Mikrotubuli nicht die aktive Zone erreichen. Die Actinfilamente sind nicht im direkten Kontakt mit den synaptischen Vesikeln, sondern werden über etwa $30 \mathrm{~nm}$ lange Stränge, die wahrscheinlich die Synapsine (synaptisches Protein) sind, mit den Vesikeln verbunden. Diese Stränge verbinden auch die Vesikel untereinander und mit den Fodrinsträngen (eine 
gehirnspezifische Isoform des Spektrins), die von der aktiven Zone in das präsynaptische Cytoplasma hineinragen.

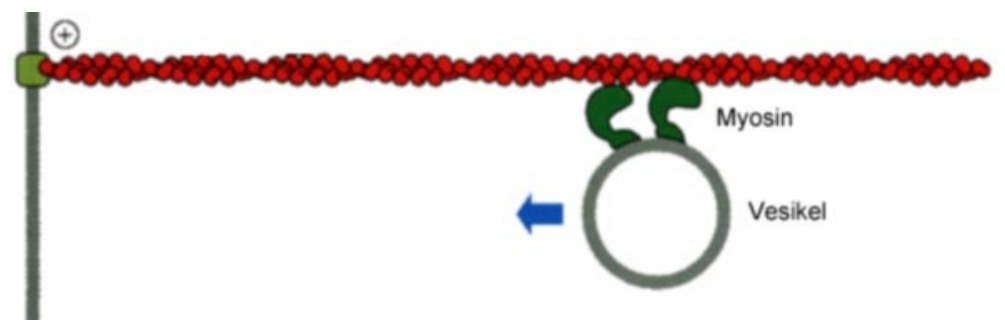

Abbildung 4: Schematische Darstellung der Vesikelbewegung am Actinstrang mit Hilfe des Motor-

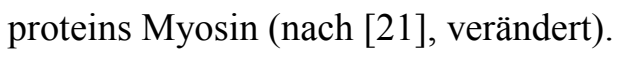

\subsection{Wirkung von Benzodiazepinen}

Ein wichtiger inhibitorischer Neurotransmitter ist die $\gamma$-Aminobuttersäure (GABA), die auf die GABA-Rezeptoren wirkt. Der $\mathrm{GABA}_{\mathrm{A}}$-Rezeptor ist ein ionotroper Rezeptor, d.h. er enthält sowohl die Bindungsstelle für den Transmitter als auch einen Ionenkanal (in diesem Fall einen Chloridkanal). Nach Bindung von GABA am GABA $_{\mathrm{A}}$-Rezeptor kommt es zum Chloridinflux in die Zelle, der also hemmend wirkt.

Diese hemmende Wirkung wird durch die Wirkstoffgruppe der Benzodiazepine verstärkt. Spezifische Rezeptoren für Benzodiazepine wurden im gesamten zentralen Nervensystem gefunden, mit besonders hoher Dichte in der frontalen und okzipitalen Hirnrinde, im Hippocampus und im Kleinhirn 131 . Die Benzodiazepin-Bindungsstelle liegt auf der $\alpha_{1}$-Untereinheit im Heteropentamer des Chloridkanals (s. Áb̄bildung 5i), wobei die zusätzliche Anwesenheit einer $\gamma_{2^{-}}$bzw. $\gamma_{3^{-}}$Untereinheit für die Vermittlung der pharmakologischen Effekte essentiell zu sein scheint Benzodiazepinbindungsstelle finden sich z.B. in $[26$ mit ihrem Rezeptor führt zu einer allosterischen Veränderung des $\mathrm{GABA}_{\mathrm{A}}$-Rezeptors, die den Ionenfluß durch den Chloridkanal erhöht Nervenzellen mit der Folge einer verminderten Erregbarkeit [31]. Der erhöhte Ionenfluß wird in vielen Neuronen durch eine Zunahme der Öffnungswahrscheinlichkeit des Chloridkanals verursacht und nur zu einem geringen Anteil durch eine längere Öffnungsdauer des Kanals [32] 36 . Auch in hippocampalen Neuronen wird fast einheitlich ein erhöhter Ionenfluß durch den Chloridkanal berichtet, wobei der genaue Mechanismus noch diskutiert wird [37.14].

Diese Wirkung der Benzodiazepine wird therapeutisch bei Unruhe, Angst- und Spannungszuständen sowie psychosomatischen Beschwerden genutzt. Neben dem Einsatz als Tranquilizer sind Benzodiazepine die derzeit wichtigsten und am häufigsten verwendeten Schlafmittel. Sie finden ebenfalls zur Behandlung von Muskelspasmen oder Muskelverspannungen, bei epileptischen Erkrankungen und als Prämedikation bei der Narkose Anwendung [3 31,141$]$. 


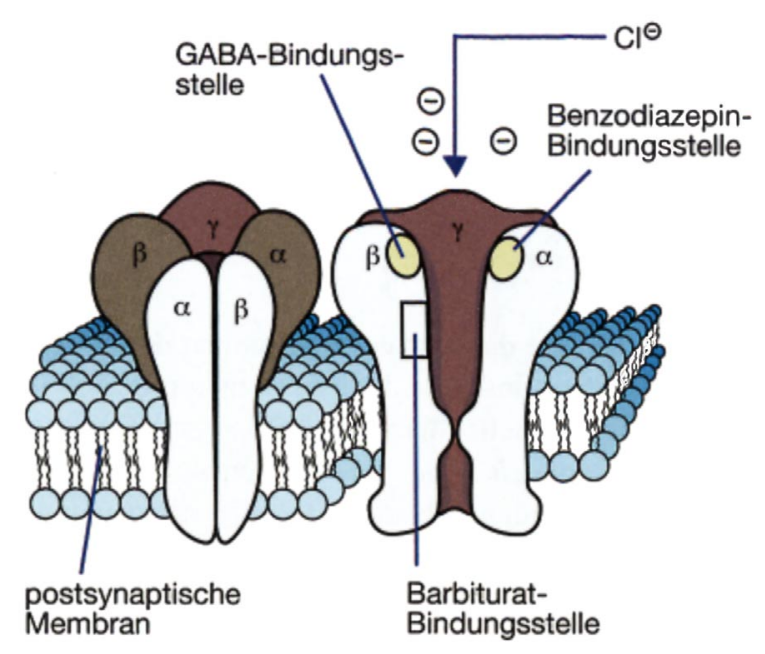

Abbildung 5: Schematische Darstellung der Benzodiazepin-Bindungsstelle (nach [프리, verändert). Die $\alpha_{1}$-Untereinheit trägt unter Beteiligung einer $\gamma_{2}$-bzw. $\gamma_{3}$-Untereinheit die Benzodiazepin-Bindungsstelle im Heteropentamer des Chloridkanalsi $[24,2 \overline{4} 5]$.

\subsection{Calciumchelatoren in Chromaffinzellen}

Chromaffinzellen aus dem Nebennierenmark gehören zur Gruppe der neuroendokrinen Zellen, die darauf spezialisiert sind Hormone in die Blutbahn abzugeben. Sie sind entwicklungsgeschichtlich gleichen Ursprungs wie Neurone und können Aktionspotentiale generieren.

Die Erhöhung der intrazellulären $\mathrm{Ca}^{2+}$-Konzentration führt zur Auslösung von Exozytose [12]. Zur Charakterisierung dieser Sekretionssteuerung durch $\mathrm{Ca}^{2+}$-Ionen ist die genaue Kenntnis der räumlich-temporalen Dynamik der intrazellulären $\mathrm{Ca}^{2+}$-Konzentration unabdingbar. Ihrer Messung erfolgt mit Calciumfarbstoffen, die in Abhängigkeit von der intrazellulären $\mathrm{Ca}^{2+}$-Konzentration $\left(\left[\mathrm{Ca}^{2+}\right]_{\mathrm{i}}\right)$ ihre Fluoreszenzeigenschaften ändern [13]. Der Bereich, in dem die $\mathrm{Ca}^{2+}$-Konzentration gemessen werden kann, hängt von der Dissoziationskonstanten $K_{\mathrm{D}}$ des Farbstoffs ab [1] cher $\mathrm{Ca}^{2+}$-Chelator in die Zelle eingebracht, der mit den endogenen $\mathrm{Ca}^{2+}$-Liganden um die $\mathrm{Ca}^{2+}$-Ionen konkurriert. Endogene Calciumbindungsstellen oder -puffer sind in hoher Konzentration vorhanden und binden nach dem $\mathrm{Ca}^{2+}$-Einstrom sofort 95-99\% der $\mathrm{Ca}^{2+}$-Ionen [14]. Sie regulieren somit entscheidend die Dynamik des in hohen Konzentrationen für die Zelle toxischen Calciums. Damit eine verläßliche Bestimmung der endogenen Pufferkapazität, d. h. der Änderung des $\mathrm{Ca}^{2+}$-Pufferkomplexes mit $\left[\mathrm{Ca}^{2+}\right]_{\mathrm{i}}$, und damit der Dynamik von $\left[\mathrm{Ca}^{2+}\right]_{i}$ erfolgen kann, ist eine ortsabhängige Kenntnis der Konzentration, der Dissoziationskonstanten und des Diffusionskoeffizienten des Farbstoffs in der Zelle von Bedeutung [1] 15$]$ ]. 


\subsection{Fragestellung und Zielsetzung}

Ziel der Arbeit war die Anwendung der Fluoreszenz-Korrelations-Spektroskopie (FCS) auf dynamische Prozesse in lebenden Zellen. Verschiedene zellphysiologisch relevante Reaktions- und Diffusionssysteme wurden ausgewählt und die Anwendbarkeit der FCS-Methode untersucht.

Zunächst war hier wichtig, das Hintergrundsignal durch die Eigenfluoreszenz endogener Zellbestandteile zu charakterisieren. Die Signalintensität und die Autokorrelation des Hintergrunds bestimmen unmittelbar die minimal einsetzbare Konzentration der zu untersuchenden Teilchen und wurden deshalb im Cytoplasma und Nucleus der Zelle bei verschiedenen Anregungswellenlängen untersucht. Weiterhin wurde die Mobilität der fluoreszierenden Zellbestandteile bestimmt, um mögliche Hintergrundsignale in FCS-Experimenten bei geringen Teilchenkonzentrationen zu erkennen.

Im einzelnen wurden exemplarisch für die verschiedenen Anwendungsbereiche der FCS folgende drei Fragestellungen bearbeitet:

1. Untersuchung von Diffusion und Kinetik von Calciumfarbstoffen:

Zur Untersuchung der Dynamik des sekundären intrazellulären Botenstoffs $\mathrm{Ca}^{2+}$ ist die genaue Kenntnis der kinetischen und Diffusionseigenschaften des als Indikator eingesetzten Calciumchelatoren unerläßlich. Ziel dieses Teilprojektes war, mittels FCS die Eigenschaften des oft verwandten Oregon Green 488 BAPTA-1 (OGB1) in situ, d.h. in Zellen bzw. Subkompartimenten davon zu bestimmen. Es ist bekannt, daß die Parameter solcher Indikatoren in lebenden Zellen erheblich von den in vitro gefundenen Werten abweichen können. Der beispielhaft herausgegriffene Farbstoff erhöht seine Fluoreszenzintensität nach der Bindung von Calciumionen. Die Fluoreszenzfluktuationen, die durch Reaktion zwischen dem calciumfreien und calciumgebundenen Farbstoff auftreten, sollten sich mit der FCS-Methode auflösen lassen und somit erlauben, die Calciumbindekinetik unterschiedlich affiner Calciumfarbstoffe zu bestimmen. Für die intrazellulären FCS-Messungen wurden Chromaffinzellen vom Rind verwendet, die ein geeignetes Modellsystem für endogene Calciumpufferung darstellen.

2. Charakterisierung der Benzodiazepin-Rezeptor-Wechselwirkung in hippocampalen Neuronen:

Als Beispiel einer Rezeptor-Liganden-Bindungskinetik sollte das Bindungsverhalten eines fluoreszenzmarkierten Benzodiazepins mit dem Benzodiazepin-Rezeptor in hippocampalen Neuronen untersucht werden. Hierzu mußte zunächst ein geeigneter Marker gefunden werden, der die Bindungsfähigkeit des mit einer molaren Masse von 334 g/mol kleinen Liganden nicht sterisch behindert. Die Bindung des Liganden sollte bei Fokussierung des Laserstrahls auf die Zellmembran hippocampaler Neurone durch eine verlangsamte Diffusion gegenüber der extrazellulären Lösung sichtbar werden. Die Spezifität der Bindung für den Rezeptor sollte durch eine Verdrängung des gebundenen farbstoffmarkierten Liganden mit 
einem Überschuß an unmarkiertem Liganden gezeigt werden können. Aus dem Zeitverlauf der Verdrängungsreaktion ließe sich sodann die Geschwindigkeitskonstante der Dissoziation ableiten.

3. Dynamik synaptischer Vesikel in hippocampalen Boutons:

In einzelnen nur einen Mikrometer messenden synaptischen Boutons sollte die Eignung der FCS-Technik zur Charakterisierung der Dynamik synaptischer Vesikel, d.h. ganzer fluoreszenzmarkierter Zellorganellen untersucht werden. Hierbei sollten durch pharmakologische Beeinflussung des Enzymhaushalts und der Cytoskelett-Architektur der Synapse die zugrundeliegenden Mechanismen der Vesikeldynamik näher untersucht werden.

Zunächst werden im Kapitel 2 dieser Arbeit die verwendeten Methoden vorgestellt. Im Kapitel 3 werden die Ergebnisse der einzelnen Projekte dargestellt und in Kapitel 4 jeweils diskutiert. Kapitel 5 gibt eine abschließende Zusammenfassung. 


\section{Material und Methoden}

\subsection{Konfokales Mikroskop}

Die konfokale Mikroskopie ist eine wichtige Methode in der Zellbiologie für Untersuchungen an lebenden Zellen. Im folgenden sollen die Grundprinzipien dieser Technik, soweit sie für das Verständnis dieser Arbeit wichtig sind, kurz skizziert werden.

Die zu untersuchende Probe wird mit einem Laserstrahl, der durch das Mikroskopobjektiv in die Probe fokussiert wird, angeregt. Das Intensitätsprofil $(I(r, z))$ des Laserstrahls im Fokus eines Objektivs ist lorentzförmig entlang der axialen (z-Achse) und gaußförmig in der radialen (lateralen) Richtung

$$
\begin{aligned}
& I(r, z)=\frac{2 P_{0}}{\pi w_{0}^{2}} \exp \left(-\frac{2 r^{2}}{w(z)^{2}}\right) \\
& w(\mathrm{z})=w_{0}\left[1+\left(\frac{\lambda z}{\pi w_{0}^{2}}\right)^{2}\right]^{1 / 2}
\end{aligned}
$$

mit $r=\sqrt{x^{2}+y^{2}} ; P_{0}:$ Gesamtleistung.

In der Nähe der Strahltaille $\left(w(z)=\sqrt{2} w_{0}\right)$ verhält sich der Laserstrahl wie ein fast pa-

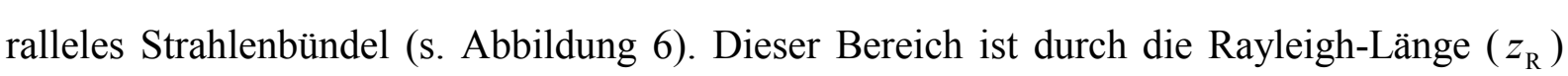
gegeben:

$$
z_{\mathrm{R}}=\frac{\pi w_{0}^{2}}{\lambda}
$$

Außerhalb der Rayleigh-Länge verhält sich der Laserstrahl wie eine sphärische Welle mit einer Quasi-Punktquelle als Ursprung und einer Divergenz von:

$$
\Theta \equiv \frac{w(z)}{z} \approx \frac{\lambda}{\pi w_{0}} \quad z>>z_{\mathrm{R}}
$$

Der $\mathrm{e}^{-2}$-Radius des Laserstrahls in der fokalen Ebene $\left(w_{0}\right)$ nach dem Durchtritt durch eine ideale Linse wird vom $\mathrm{e}^{-2}$-Radius des Laserstrahls vor der Linse $(w)$ mitbestimmt $[\overline{4} \overline{3}]$ ]:

$$
w_{0}=\frac{f \lambda}{\pi w}
$$

( $f$ : Brennweite der Linse). 


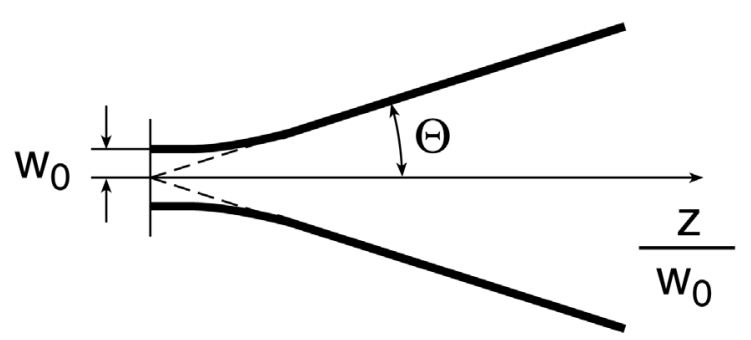

Abbildung 6: Illustration eines Laserstrahls mit dem Radius $w_{0}$ und der Divergenz $\Theta$.

Bei der Betrachtung für eine reale Linse müssen Linsenfehler, die abhängig von der Wellenlänge des verwendeten Lichtes und dem Grad der Ausleuchtung der hinteren Mikroskoppupille sind, mit berücksichtigt werden. Eine Abschätzung für eine reale Linse ergibt [43]:

$$
w_{0} \approx \frac{f \lambda}{d_{\text {Pupille }}} \approx \frac{\lambda}{2 N A}
$$

Die Messungen erfolgten entweder mit einem Wasserimmersionsobjektiv mit 40facher Vergrößerung (C-Apochromat, $1.2 \mathrm{NA}$, Deckglaskorrektur, Zeiss) oder mit 63facher Vergrößerung (Apochromat, $1.2 \mathrm{NA}$, Deckglaskorrektur, Zeiss). Mit den in Tabeelle zusammengestellten Kenngrößen der verwendeten Objektive bei voller Ausleuchtung der hinteren Mikroskoppupille und einer Anregungswellenlänge von $\lambda_{\mathrm{exc}}=488 \mathrm{~nm}$ ergibt die Abschätzung des fokussierten Laserstrahls nach Gl. $\underline{6}_{\text {bi }}^{\prime}$ 'inen Wert von ungefähr $w_{0} \approx 205 \mathrm{~nm}$.

Tabelle 1: Parameter der verwendeten Objektive.

\begin{tabular}{llll}
\hline Vergrößerung & $N A$ & Brennweite $f / \mathrm{mm}$ & $d_{\text {Pupille }} / \mathrm{mm}$ \\
\hline $40 \mathrm{x}$ & 1,2 & 4,11 & 9,5 \\
$63 \mathrm{x}$ & 1,2 & 2,61 & 6,0 \\
\hline
\end{tabular}

Nach der Anregung wird die emittierte Fluoreszenz der Probe durch das selbe Objektiv aufgefangen. Der Lichtfluß von der Fluoreszenzemission bis zur Detektion kann durch mathematische Funktionen beschrieben werden. Die Punktausbreitungsfunktion $\operatorname{PSF}\left(\boldsymbol{r}, \boldsymbol{r}^{\prime}, z\right.$ ) (point spread function) eines Mikroskops beschreibt die radiale Intensitätsverteilung des Fluoreszenzlichtes in der Bildebene $\boldsymbol{r}^{\prime}$, das von einer Punktquelle in der Probenebene (Anregungs-

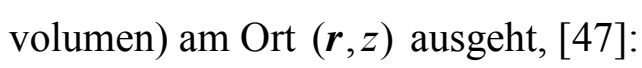

$$
\operatorname{PSF}\left(\boldsymbol{r}, \boldsymbol{r}^{\prime}, z\right)=\frac{\operatorname{circ}\left(\frac{\boldsymbol{r}-\boldsymbol{r}^{\prime}}{R(z)}\right)}{\pi R^{2}(z)}
$$

mit $\operatorname{circ}\left(\frac{\boldsymbol{r}-\boldsymbol{r}^{\prime}}{R(z)}\right)= \begin{cases}1 & \text { für }\left|\boldsymbol{r}-\boldsymbol{r}^{\prime}\right| \leq R(z) \\ 0 & \text { für }\left|\boldsymbol{r}-\boldsymbol{r}^{\prime}\right|>R(z)\end{cases}$ 
und $R^{2}(z)=R_{0}^{2}+z^{2} \tan ^{2} \alpha$

$R(z)$ : Radius des Bildpunktes einer Punktquelle im Abstand z von der fokalen Ebene

$R_{0}=0,61 \lambda / N A$ : Auflösungsvermögen des Objektivs (Radius des ersten dunklen Ringes des Airy Beugungsbildes).

$\boldsymbol{r}=(x, y)$ : Radiale Koordinate der Punktquelle in der Probenebene

$\boldsymbol{r}^{\prime}$ : Radiale Koordinate in der Bildebene

$\alpha$ : Halber Öffnungswinkel des Objektivs $(N A=n \sin \alpha)$

$n$ : Brechungsindex der Probe

Zur Reduzierung der Fluoreszenz, die außerhalb der fokalen Ebene entsteht, wird eine Lochblende verwendet. Der Effekt der Lochblende in der Bildebene kann durch die Sammeleffizienz-Funktion $\operatorname{CEF}(\boldsymbol{r}, z)$ (collection efficiency function) beschrieben werden [45]. Diese Funktion gibt den Anteil des Lichtes wieder, der die Lochblende passiert, und wird durch die gemeinsame Fläche der $\operatorname{PSF}\left(\boldsymbol{r}, \boldsymbol{r}^{\prime}, z\right)$ und der Transmissionsfunktion der Lochblende $T\left(\boldsymbol{r}^{\prime}\right)$ beschrieben $\left[\begin{array}{l}4 \\ \mathbf{4} \\ 2\end{array}\right.$

$$
\begin{aligned}
& \operatorname{CEF}(\boldsymbol{r}, z)=\frac{1}{\Delta} \int T\left(\boldsymbol{r}^{\prime}\right) \operatorname{PSF}\left(\boldsymbol{r}, \boldsymbol{r}^{\prime}, z\right) \mathrm{d} \boldsymbol{r}^{\prime} \\
& T\left(\boldsymbol{r}^{\prime}\right)=\operatorname{circ}\left(\frac{\boldsymbol{r}^{\prime}}{s_{0}}\right)
\end{aligned}
$$

mit $\Delta=\int T\left(\boldsymbol{r}^{\prime}\right) \operatorname{PSF}\left(0, \boldsymbol{r}^{\prime}, 0\right) \mathrm{d} \boldsymbol{r}^{\prime}$

und $s_{0}=\frac{r_{0}}{M}:$ In die Probenebene projizierter Lochblendenradius

$r_{0}:$ Lochblendenradius

$M$ : Vergrößerung des Objektivs

Multipliziert man die Sammeleffizienz-Funktion mit dem Intensitätsprofil des Laserstrahls

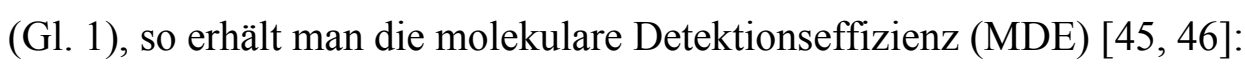

$$
\operatorname{MDE}(\boldsymbol{r}, z)=\operatorname{CEF}(\boldsymbol{r}, z) I(\boldsymbol{r}, z)
$$

Die Fluoreszenzfluktuationen $\delta F(t)$ lassen sich aus der molekularen Detektionseffizienz und den Konzentrationsfluktuationen $\delta c(\boldsymbol{r}, z, t)$ berechnen $\left[\begin{array}{c}2 \\ 2\end{array} ;\right]$

$$
\delta F(t)=g \sigma_{\mathrm{abs}} \Phi_{\mathrm{F}} \iiint \operatorname{MDE}(\boldsymbol{r}, z) \delta c(\boldsymbol{r}, z, t) \mathrm{d}^{2} \boldsymbol{r} \mathrm{d} z
$$

( $\sigma_{\text {abs }}:$ Absorptionsquerschnitt; $\Phi_{\mathrm{F}}$ : Fluoreszenzquantenausbeute und $g$ : Detektionseffizienz der Fluoreszenz (Apparatekonstante, die Fluoreszenzverluste von der Probe zur APD berücksichtigt; im konfokalen Mikroskop zwischen 1 und $3 \%$ [23] $)$. 
Beobachtet werden die Fluoreszenzfluktuationen innerhalb des Detektionsvolumens (grün in $\bar{A} \bar{b} \bar{b} \bar{b} \bar{l} \bar{d}$ ung $7 \overline{1}$, welches ohne großen Fehler als dreidimensionales Gaußvolumen angenommen werden kann, wenn man den Lochblendenradius $\left(r_{0}\right)$ entsprechend klein wählt [4 45$]$ ]. Wird der Lochblendenradius größer gewählt, wird die gemachte Näherung eines axialen gaußförmigen Profils ungenauer, und das axiale Profil nähert sich dem real vorliegenden Lorentzprofil an. Die axiale Komponente der Fluktuationen wird in der Autokorrelationsfunktion für dreidimensionale Diffusion aber nur durch einen Wurzelterm berücksichtigt (cf. G1. $38 \overline{8}$ ) und besitzt somit einen deutlich geringeren Einfluß als die radiale Komponente.

Die Autoren Qian et. al. [4]5] empfehlen einen Lochblendenradius von nicht größer als $2 M w_{0}$. Wird eine Genauigkeit von 10\% für $w(z)$ zugelassen, so schätzen Rigler et. al. die Grenzen für den Lochblendenradius folgendermaßen ab [4] $]$ ]

$$
M w_{0} \leq r_{0} \leq \frac{0,5 \tan \alpha}{\tan \delta} M w_{0}
$$

mit $\sin \alpha=\frac{N A}{n}$ und $\tan (\delta)=\frac{\lambda_{\mathrm{em}}}{n \pi w_{0}}$

( $\alpha$ : Apertur-Halbwinkel des Mikroskopobjektivs; $\delta$ : fokussierender Winkel des Laserstrahls in der Probe bei der Intensität $\mathrm{e}^{-2}$ ).

Hieraus berechnen sich die folgenden Werte für den maximalen Lochblendenradius:

nach Qian: $s_{\max }=26,5 \mu \mathrm{m}\left(M=63, w_{0}=0,21 \mu \mathrm{m}\right)$

nach Rigler: $s_{\max }=23,4 \mu \mathrm{m}\left(M=63, w_{0}=0,21 \mu \mathrm{m}, \lambda_{\mathrm{em}}=520 \mathrm{~nm}\right)$.

Ein optimales Signal-/Hintergrundverhältnis wird in konfokalen Mikroskopen bei einem Lochblendenradius $v_{\mathrm{L}}$ zwischen 2,3 bis 3,5 optischen Einheiten erreicht [49.150], wobei der Lochblendenradius $v_{\mathrm{L}}$ gemäß folgender Gleichung berechnet wird:

$$
v_{\mathrm{L}}=\left(2 \pi / \lambda_{\mathrm{em}}\right) \frac{N A}{M} r_{0}
$$

Bei dem verwendeten Objektiv $(M=63, N A=1,2)$ und einer Emissionswellenlänge $\lambda_{\mathrm{em}}=520$ $\mathrm{nm}$ ergibt sich somit ein optimaler Bereich für den Lochblendenradius von 10-15 $\mu \mathrm{m}$. Im Rahmen dieser Arbeit wurde ein minimaler Lochblendenradius von $r_{\min }=10 \mu \mathrm{m}$ (2,3 opt. E.) verwendet. Diese Einstellung wurde gewählt, wenn es auf eine möglichst kleine radiale Ausdehnung des Detektionsvolumens ankam. Die Abschneidung eines Teil des Signals durch die Lochblende wurde dabei in Kauf genommen. Bei Verwendung des minimalen Lochblendenradius $r_{\min }$ zeigten die Autokorrelationskurven für FCS-Experimente mit Rhodamin 6G keine Abweichungen vom Diffusionsmodell in einem dreidimensionalen gaußförmigen Detektionsvolumens. Ein Lochblendenradius von $r_{0}=7,5 \mu \mathrm{m}$ führte hingegen zu einer stark verrauschten Autokorrelationskurve, die durch ein reines Diffusionsmodell nicht angepaßt werden konnte. 


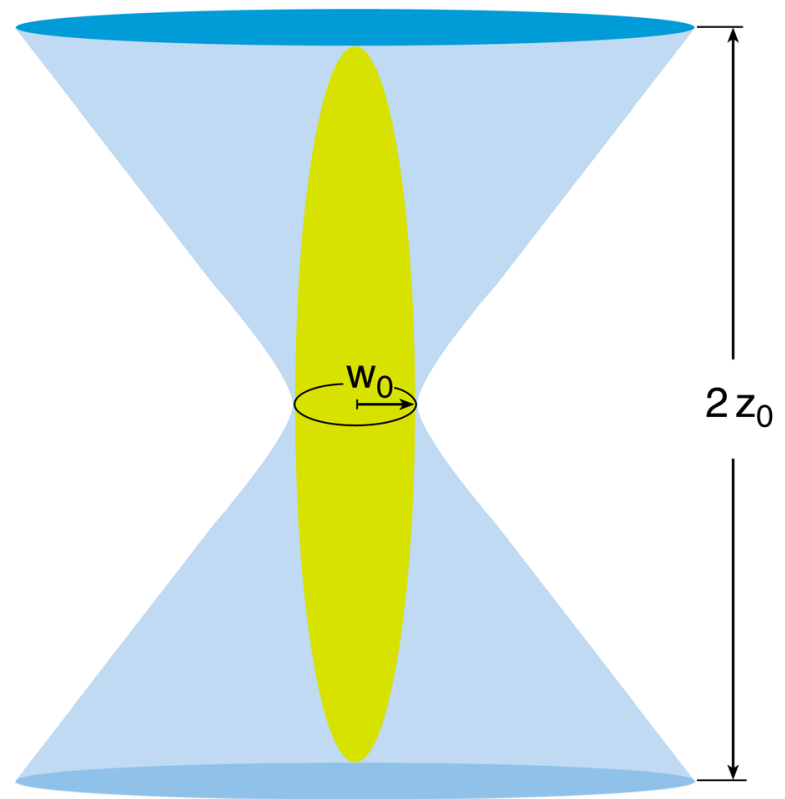

Abbildung 7: Schematische Zeichnung des Anregungs- (blau) und Detektionsvolumens (grün).

\subsection{Berechnung von Autokorrelationsfunktion und Leistungsspek- trum}

Im folgenden soll die Berechnung der Autokorrelationsfunktion und des Leistungsspektrums einer Zeitreihe mit Hilfe der Fouriertransformation skizziert werden in Anlehnung an die Darstellungen in:[1]

Zur Analyse bei der FCS wird aus den Fluoreszenz-Zeit-Daten $(h(t))$ die Autokorrelationsfunktion berechnet. Formal ist die Korrelationsfunktion zweier Funktionen $g(t)$ und $h(t)$ folgendermaßen definiert:

$$
\operatorname{Korr}(g, h)=\int_{-\infty}^{+\infty} g(t) h(t+\tau) \mathrm{d} t
$$

Korreliert man eine Funktion mit sich selbst, erhält man den Spezialfall der Autokorrelationsfunktion $(G(\tau))$ :

$$
G(\tau)=\operatorname{Korr}(h, h)=\lim _{T \rightarrow \infty} \frac{1}{T} \int_{0}^{T} h(t) h(t+\tau) \mathrm{d} t
$$

$(G(\tau)$ : Autokorrelationsfunktion; $\tau$. Autokorrelationszeit; $h(t)$ : Probe zur Zeit $t ; T$ : Beobachtungsdauer).

Eine weitere wichtige Operation zwischen zwei Funktionen ist die Faltung (ausgedrückt durch das Zeichen $\otimes)$ : 


$$
g \otimes h \equiv \int_{-\infty}^{+\infty} g(\tau) h(t-\tau) \mathrm{d} \tau
$$

Nach dem Faltungs-Theorem ist die Fouriertransformation der Faltung gleich dem Produkt der individuellen Fouriertransformierten:

$$
g \otimes h \Leftrightarrow G(f) H(f)
$$

Transformiert man die Funktion $(h(t))$ mit Hilfe der Fouriertransformation (FT) in die Frequenzebene, so erhält man eine Funktion $H(f)$, die eine Funktion der Frequenz $f$ ist. Durch inverse Fouriertransformation (iFT) erhält man wieder die ursprüngliche Funktion:

$$
h(t) \underset{\mathrm{iFT}}{\stackrel{\mathrm{FT}}{\Leftrightarrow}} H(f)
$$

Der Doppelpfeil $(\Leftrightarrow)$ drückt dabei aus, daß es sich auf beiden Seiten um Transformationspaare handelt.

Die FT und die iFT sind gemäß folgender Formeln definiert:

$$
\begin{aligned}
& \text { FT: } H(f)=\int_{-\infty}^{+\infty} h(t) e^{2 \pi i f t} \mathrm{~d} t \\
& \text { iFT: } h(t)=\int_{-\infty}^{+\infty} H(f) e^{-2 \pi i f t} \mathrm{~d} f
\end{aligned}
$$

Die Korrelationsfunktion zweier Funktionen $\operatorname{Korr}(g, h)$ stehen mit den fouriertransformierten Einzelfunktionen nach dem Korrelations-Theorem in der folgenden Beziehung zueinander:

$$
\operatorname{Korr}(g, h) \Leftrightarrow G(f) H^{*}(f)
$$

Oder in Worten ausgedrückt: Multipliziert man die Fouriertransformation einer Funktion mit der komplexkonjugierten einer zweiten Fouriertransformierten so entspricht dies der Fouriertransformation ihrer Korrelationsfunktion. Da im folgenden immer von realen Funktionen die Rede sein wird, gilt folgende Vereinfachung:

$$
H^{*}(f)=H(-f)
$$

Als Spezialfall des Korrelations-Theorems kann das Wiener-Khinchin-Theorem betrachtet werden, welches die Beziehung zwischen der Autokorrelationsfunktion und der Fouriertransformierten einer Funktion beschreibt:

$$
\operatorname{Korr}(h, h) \Leftrightarrow|H(f)|^{2}
$$


Die Gesamtenergien in der Zeit- als auch in der Frequenzebene sind gleich. Dies wird im Parseval-Theorem zwischen den Transformationspaaren $h(t)$ und $H(f)$ ausgedrückt:

$$
\text { Gesamt Energie }\left.\equiv \int_{-\infty}^{+\infty} h(t)\right|^{2} \mathrm{~d} t=\int_{-\infty}^{+\infty}|H(f)|^{2} \mathrm{~d} f
$$

Für den häufig auftretenden Fall nur positiver Frequenzen integriert man $f$ nur zwischen 0 und $+\infty$ und gelangt so zur einseitigen spektralen Verteilung (Leistungsspektrum):

$$
P_{\mathrm{h}}(f) \equiv|H(f)|^{2}+|H(-f)|^{2} \quad 0 \leq f \leq \infty
$$

bzw. im Fall einer realen Funktion $h(t)$ :

$$
P_{\mathrm{h}}(f)=2|H(f)|^{2} \quad 0 \leq f \leq \infty
$$

Berechnet man also aus einer Funktion $h(t)$ zunächst das Leistungsspektrum $P_{\mathrm{h}}(f)$ gemäß G1. 26 funktion $\operatorname{Korr}(h, h)$ berechnen.

Bei der Funktion $h(t)$ handelt es sich aber bei physikalischen Messungen häufig nicht um eine kontinuierliche Funktion, sondern die Funktion besteht meistens aus gemessenen Werten, die in konstanten Zeitintervallen $(\Delta)$ aufgenommen werden:

$$
h_{k} \equiv h\left(t_{k}\right), \quad t_{k} \equiv k \Delta, \quad k=0,1,2, \ldots, N-1
$$

Wenn die Daten mit einer Aufnahmefrequenz von (1/A) aufzeichnet wurden, lassen sich nach dem Nyquist-Theorem hiermit Prozesse mit einer maximalen Frequenz von

$$
f_{\mathrm{c}}=\frac{1}{2 \Delta}
$$

beobachten. Diese Frequenz $f_{\mathrm{c}}$ nennt man auch Nyquist-Frequenz. Man erhält hiernach die gesamten Informationen über einen beobachteten Prozeß, wenn man ihn mit Frequenz aufzeichnet, die zweimal schneller ist als die maximale Frequenz des zu untersuchenden Prozesses. Alle Prozesse, die schneller als die Nyquist-Frequenz ablaufen, führen zur Verfälschung des Leistungsspektrums.

Die Fouriertransformation einer diskret aufgezeichneten Funktion läßt sich über die diskrete Fouriertransformation (DFT, $H_{n}$ ) berechnen: 


$$
H_{n} \equiv \sum_{k=0}^{N-1} h_{k} e^{2 \pi i k n / N}
$$

Es gilt:

$$
H\left(f_{n}\right)=\int_{-\infty}^{+\infty} h(t) e^{2 \pi i f_{n} t} d t \approx \sum_{k=0}^{N-1} h_{k} e^{2 \pi i f_{n} t} \Delta=\Delta \sum_{k=0}^{N-1} h_{k} e^{2 \pi i k n / N}
$$

mit $f_{n} \equiv \frac{n}{N \Delta}, \quad n=-\frac{N}{2}, \ldots, \frac{N}{2}$

Entsprechendes gilt für die diskrete inverse Fouriertransformation, die den ursprünglichen Datensatz exakt wieder herstellt:

$$
h_{k}=\frac{1}{N} \sum_{n=0}^{N-1} H_{n} e^{-2 \pi i k n / N}
$$

Das Leistungsspektrum für diskret aufgenommene Daten wird durch das sogenannte Periodogramm angenähert:

$$
\begin{aligned}
& P(0)=P\left(f_{0}\right)=\frac{1}{N^{2}}\left|H_{0}\right|^{2} \\
& P\left(f_{n}\right)=\frac{1}{N^{2}}\left[\left|H_{n}\right|^{2}+\left|H_{N-n}\right|^{2}\right] n=1,2, \ldots,\left(\frac{N}{2}-1\right) \\
& P\left(f_{\mathrm{c}}\right)=P\left(f_{N / 2}\right)=\frac{1}{N^{2}}\left|H_{N / 2}\right|^{2}
\end{aligned}
$$

mit $f_{n} \equiv \frac{n}{N \Delta}=2 f_{\mathrm{c}} \frac{n}{N}, \quad n=0,1, . ., \frac{N}{2}$

Bei der Berechnung des Periodogramms ist zu berücksichtigen, daß man den Datensatz mit $N$ Punkten formal mit einer rechteckigen Fensterfunktion multipliziert, deren Wert außerhalb des Datensatzes 0 beträgt und sonst den Wert 1 besitzt. Die gemeinsame Fouriertransformation aus dem Datensatz multipliziert mit der Fensterfunktion ist nach dem Faltungstheorem (G1. 117) die Faltung aus der Fouriertransformation des Datensatzes mit der Fouriertransformation der Fensterfunktion $\left(w_{j}\right)$ :

$$
D_{n} \equiv \sum_{j=0}^{N-1} c_{j} w_{j} e^{2 \pi i j n / N} \quad n=0, \ldots, N-1
$$




$$
\begin{aligned}
& P(0)=P\left(f_{0}\right)=\frac{1}{W_{s s}}\left|D_{0}\right|^{2} \\
& P\left(f_{n}\right)=\frac{1}{W_{s s}}\left[\left|D_{n}\right|^{2}+\left|D_{N-n}\right|^{2}\right] \quad n=1,2, \ldots,\left(\frac{N}{2}-1\right) \\
& P\left(f_{\mathrm{c}}\right)=P\left(f_{N / 2}\right)=\frac{1}{W_{\mathrm{ss}}}\left|D_{N / 2}\right|^{2}
\end{aligned}
$$

$\operatorname{mit} W_{\mathrm{ss}} \equiv N \sum_{j=0}^{N-1} w_{j}^{2}$

Die Faltung bedeutet, daß jeder Punkt im Periodogramm $P\left(f_{n}\right)$ mit der Fouriertransformierten der Fensterfunktion multipliziert wird. Der Punkt $P\left(f_{n}\right)$ ist also eine Abschätzung der kontinuierlichen Funktion $P(f)$, die durch das Verhalten der Fensterfunktion mitbestimmt wird.

Das Problem der rechteckigen Fensterfunktion ist, daß sie am Anfang des Datensatzes sprunghaft auf 1 ansteigt, am Ende des Datensatzes genau so schnell wieder auf 0 abfällt, und deshalb die fouriertransformierte Fensterfunktion nur langsam auf Null abklingt. Dies kann aber umgangen werden, wenn man die rechteckige Fensterfunktion durch eine ersetzt, deren Anstieg und Abfall nicht so schnell ist. Hierfür gibt es eine Vielzahl von Fensterfunktionen, deren Eigenschaften z.B. in [53] diskutiert werden. Zusammenfassend geht es bei den Eigenschaften der Fensterfunktionen darum, den zentralen Peak der fouriertransformierten Fensterfunktion so schmal wie möglich zu machen und den Rest der Funktion so schnell als möglich auf Null abklingen zu lassen. Der Nachteil dieser Fensterfunktionen ist aber, daß ein großer Teil des Datensatzes mit stark verminderter Amplitude in die Berechnung des Periodogramms eingeht. Aus diesem Grund wurde zur Berechnung des Periodogramms eine Fensterfunktion gewählt, die über einen großen Bereich des Datensatzes den Wert 1 besitzt und innerhalb von $10 \%$ des Datensatzes am Rand auf Null abfällt (20\% cosine tapered window oder TukeyFenster; s. 'Ābibildung 8

Zur Elimination langsamer Trends wurden die gemessenen Fluoreszenzdaten vor der Analyse ggf. mit $0,05 \mathrm{~Hz}$ hochpassgefiltert. Dazu wurde in der Frequenzdomäne ein FIR (finite impulse response)-Filter auf der Basis eines Hamming-Fensters auf den Datensatz angewandt. Nach der Rücktransformation des Datensatzes von der Frequenz- in die Zeitdomäne fehlten die langsamen Fluktuationen des ursprünglichen (ungefilterten) Datensatzes. Allerdings wird nicht nur der Datensatz, sondern auch die Filterfunktion mit zurücktransformiert. Die Fluoreszenzdaten in der Zeitebene sind überlagert mit der inversen Fouriertransformation der verwendeten Filterfunktion. Analysiert man die gefilterten Fluoreszenzdaten mit Hilfe der Autokorrelationsfunktion, so wird die zusätzliche Komponente des Filters auch in der Autokorrelationsfunktion gefunden. Eine vernünftige Interpretation der Autokorrelationsfunktion wird dadurch erschwert. In der Frequenzdomäne liegen die Verhältnisse anders, da der Fre- 
quenzgang des Filters bekannt ist. Aus diesem Grunde wurde zur Analyse von gefilterten Fluoreszenzdaten das Leistungsspektrum verwendet.

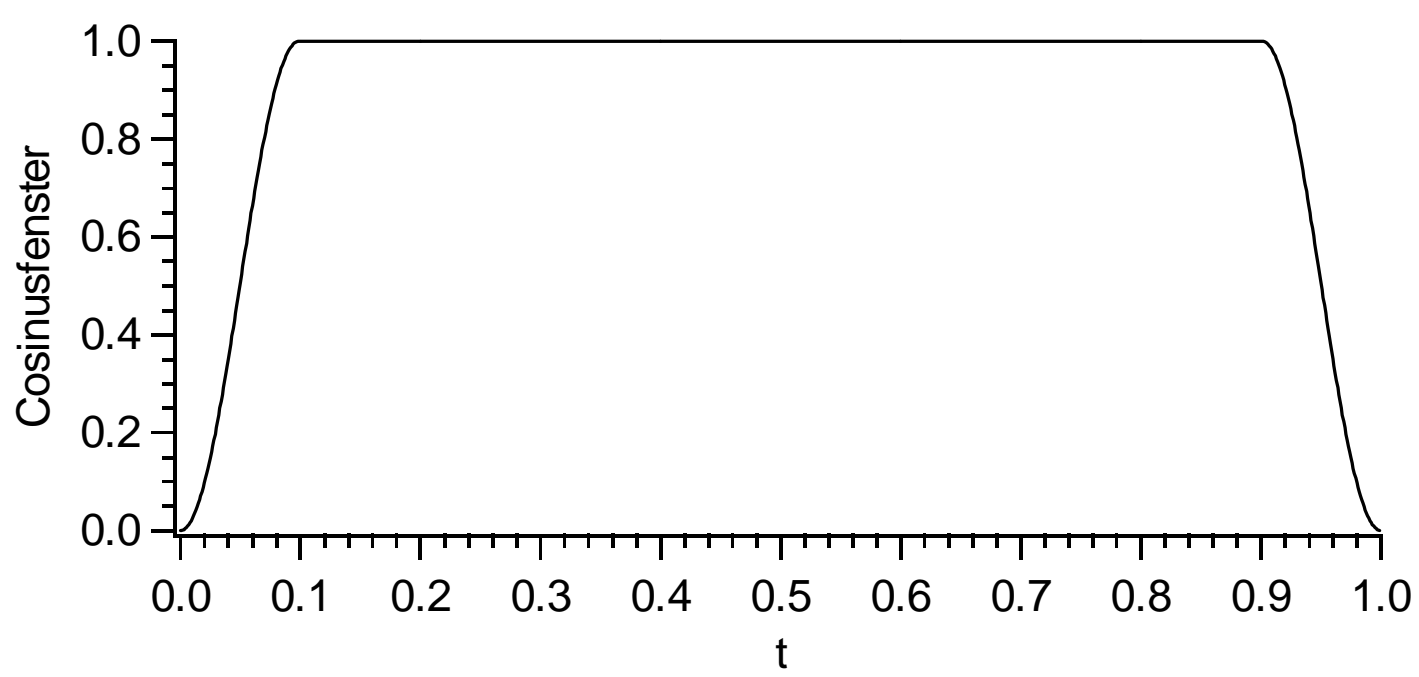

Abbildung 8: Verwendetes Cosinusfenster zur Berechnung des Periodogramms.

Die Berechnung des Leistungsspektrums eines Datensatzes erfolgte also in Anlehnung an Gl. 33 und 3 ie Autokorrelationsfunktion eines Datensatzes der Größe $N$ wurde nach folgendem Algorithmus berechnet [52]:

1) Anfügen von $N$ Nullen an den Datensatz.

2) Berechnung der DFT des Datensatzes gemäß Gl. 30.

3) Berechnung des Periodogramms (Gl. 32$)$.

4) Berechnung der inversen DFT (G1. $\underline{3}-\underline{1})^{\prime}$.

\subsection{Fluoreszenz-Korrelations-Spektroskopie (FCS)}

Die Fluoreszenz-Korrelations-Spektroskopie basiert auf der statistischen Analyse von Fluoreszenzschwankungen in einem Detektionsvolumen der Größenordnung von $10^{-15} 1$.

Die Fluoreszenz $F(t)$ wird als Funktion der Zeit $t$ aufgenommen, wobei im thermodynamischen Gleichgewicht die Fluoreszenz $F(t)$ um einen Mittelwert $\langle F(t)\rangle$ fluktuiert.

$$
\delta F(t)=F(t)-\langle F\rangle
$$

Die Fluktuationen $\delta F(t)$ der gemessenen Fluoreszenz $F(t)$ werden autokorreliert. Als Ergebnis wird die normalisierte Autokorrelationsfunktion erhalten:

$$
G(\tau)=\frac{\langle F(t) F(t+\tau)\rangle}{\langle F(t)\rangle^{2}}=\frac{\langle F(t)\rangle^{2}+\langle\delta F(t) \delta F(t+\tau)\rangle}{\langle F(t)\rangle^{2}}=1+\frac{\langle\delta F(t) \delta F(t+\tau)\rangle}{\langle F(t)\rangle^{2}}
$$


Für alle im Rahmen dieser Arbeit relevanten Prozesse werden im folgenden die theoretischen Autokorrelationsfunktionen näher erläutert.

\subsubsection{Translative Diffusion}

Befindet sich die Probe im thermodynamischen Gleichgewicht so können Konzentrationsänderungen $\delta c(\boldsymbol{r}, t)$ der anwesenden Teilchenart durch translative Diffusion auftreten, welche durch das zweite Ficksche Gesetz beschrieben werden:

$$
\frac{\mathrm{d} \delta \mathrm{c}(\boldsymbol{r}, t)}{\mathrm{d} t}=D \nabla^{2} \delta c(\boldsymbol{r}, t)
$$

(D: Diffusionskoeffizient; $\nabla^{2}=\delta^{2} / \delta x^{2}+\delta^{2} / \delta y^{2}$ ).

Unter der Annahme, daß die untersuchten Teilchen im dreidimensionalen gaußförmigen Detektionsvolumen gemäß dem Fickschen Gesetz frei und interaktionslos diffundieren, kann folgende Autokorrelationsfunktion aus den Fluoreszenzfluktuationen eines Teilchens berechnet werden $[\overline{5} \overline{5} \overline{-}]$ :

$$
\begin{aligned}
& G(\tau)=1+\frac{1}{N} \frac{1}{1+\tau / \tau_{\mathrm{D}}} \sqrt{\frac{1}{1+\left(w_{0} / z_{0}\right)^{2} \tau / \tau_{\mathrm{D}}}} \\
& \tau_{\mathrm{D}}=\frac{w_{0}^{2}}{4 D}
\end{aligned}
$$

( $w_{0}$ : Radius des Detektionsvolumens in der fokalen Ebene; $z_{0}$ : Radius des Detektionsvolumens in der axialen Richtung; $D$ : Diffusionskoeffizient; $N$ : Mittlere Zahl der Teilchen im effektiven Detektionsvolumen).

Für den Fall einer freien Diffusion in zwei Dimensionen $(z \rightarrow \infty)$ geht Gl. 3 s

$$
G(\tau)=1+\frac{1}{N} \frac{1}{1+\tau / \tau_{\mathrm{D}}}
$$

Die mittlere Anzahl fluoreszierender Teilchen $N$ ergibt sich aus dem Produkt der Konzentration des Teilchens $c$ in einem effektiven Volumen $V_{\text {eff }}[56,57,59]$

$$
N=c V_{\text {eff }}
$$

Das effektive Volumenelement wird durch die Geometrie des Detektionsvolumens bestimmt und ist definiert als:

$$
V_{\mathrm{eff}}=\frac{\left(\int I(r) d r\right)^{2}}{\int I^{2}(r) d r}
$$


Das effektive Detektionsvolumen ist einen Faktor $\sqrt{8}$ größer als das durch den Laserstrahl bestimmte Detektionsvolumen $V_{\text {det }}$, wobei letzteres sich als Integration über die dreidimensionale Gaußfunktion des Detektionsvolumens ergibt:

$$
V_{\text {eff }}=\sqrt{8} V_{\text {det }}=\sqrt{8} \int \exp \left(-2\left(x^{2}+y^{2}\right) / w_{x y}^{2}\right) \exp \left(-2 z^{2} / z_{0}^{2}\right) \mathrm{d} V=\pi^{3 / 2} w_{x y}^{2} w_{z}
$$

Für die Amplitude der Autokorrelationsfunktion ergibt sich in Anlehnung an G1. einfache Zusammenhang:

$$
G(\tau=0)=1+\frac{\left\langle\delta F(t)^{2}\right\rangle}{\langle F(t)\rangle^{2}}=1+\frac{\left\langle(F(t)-\langle F\rangle)^{2}\right\rangle}{\langle F(t)\rangle^{2}}=1+\frac{1}{N}
$$

Die Amplitude der Autokorrelationsfunktion und damit auch die mittlere Anzahl an Teilchen im effektiven Detektionsvolumen $N$ läßt sich nach G1. ${ }^{4} \overline{4} \overline{-}$ 'also auch aus dem Verhältnis von Varianz zur mittleren Fluoreszenz berechnen. Bei der Herleitung von G1. 44. ist ein rauschfreies Fluoreszenzsignal angenommen. Die gemessenen Photonenzahlen pro Zeitintervall $Z$ müssen deshalb durch die zusätzlichen Rauschkomponenten, die sich durch die Zufälligkeit der Fluoreszenzemission und der Konvertierung der Photonen in einen Photoelektronenstrom (shotnoise) ergeben, berücksichtigt werden. Wenn $Z$ die beobachtete Photonenzahl und $\Phi$ die rauschfreie Photonenzahl ist, so kann für die Zufälligkeit der Photonenemission folgendermaßen korrigiert werden [56, 58,159$]$ :

$$
\begin{aligned}
& \langle Z\rangle=\langle\Phi\rangle \\
& \langle\delta Z \delta Z\rangle=\langle\delta \Phi \delta \Phi\rangle+\langle\Phi\rangle
\end{aligned}
$$

Das aus der Konvertierung der Photonen in einen Photoelektronenstrom verursachte Rauschen kann vernachlässigt werden, wenn die Photonenausbeute pro Molekül nicht klein gegen eins ist [5]6]. Dann läßt sich die Varianz des korrigierten Signals $\langle\delta \Phi \delta \Phi\rangle$ durch einfache Subtraktion mit der mittleren gemessenen Photonenzahl $\langle Z\rangle$ erhalten.

Die Zahl der Teilchen im effektiven Detektionsvolumen ist also aus der Varianz und dem Mittelwert der Fluoreszenz bestimmbar, ohne daß eine zusätzliche Berechnung der Autokorrelationsfunktion nötig wäre.

Enthält eine ideale Lösung $n$ Komponenten, die interaktionslos im dreidimensionalen gaußförmigen Detektionsvolumen gemäß dem 2. Fickschen Gesetz diffundieren, so ist die Autokorrelationsfunktion die Summe der Autokorrelationsfunktionen der einzelnen Komponenten. Die jte Komponente wird gewichtet gemäß der Anzahl der Teilchen der jeweiligen Kompo- 
nente $\left(N_{j}\right)$ sowie dem Produkt aus Absorptionskoeffizient $\sigma_{\text {abs }_{j}}$, Fluoreszenzquantenausbeute $\Phi_{\mathrm{F}_{j}}$ und Fluoreszenzdetektionseffizienz der fluoreszierenden Komponente $g_{j}[\underline{[-2}]$ :

$$
\begin{aligned}
& G(\tau)=1+\frac{\sum_{j=1}^{n} Q_{j}^{2} N_{j}}{\left[\sum_{j=1}^{n} Q_{j} N_{j}\right]^{2}} \frac{1}{1+\tau / \tau_{\mathrm{D}_{j}}} \sqrt{\frac{1}{1+\left(w_{0} / z_{0}\right)^{2} \tau / \tau_{\mathrm{D}_{j}}}} \\
& Q_{j}=\sigma_{\mathrm{abs}_{j}} \Phi_{\mathrm{F}_{j}} g_{j}
\end{aligned}
$$

Die Fluoreszenzintensität pro Molekül, bestimmt durch die Fluoreszenzquantenausbeute $\Phi_{\mathrm{F}}$ und den Absorptionsquerschnitt $\sigma_{\text {abs }}$ des Moleküls, trägt also quadratisch zur Amplitude der Autokorrelationsfunktion bei, während die Anzahl der Moleküle $N$ nur einfach berücksichtigt wird.

Im folgenden sollen die Autokorrelationsfunktion und das Leistungsspektrum für den Fall der zweidimensionalen Diffusion einander gegenübergestellt werden.

Die Autokorrelationsfunktion für zweidimensionale Diffusion beträgt nach Gl.

$$
G(\tau)=1+\frac{1}{N} \frac{1}{1+\tau / \tau_{\mathrm{D}}}
$$

Unter Vernachlässigung des konstanten Summanden 1 kann vorstehende Gleichung folgendermaßen umgeformt werden:

$$
G(\tau)=\frac{\tau_{\mathrm{D}}}{N}\left(\frac{1}{\tau_{\mathrm{D}}+\tau}\right)
$$

Die Fouriertransformation dieser Gleichung kann analytisch gelöst werden und beträgt 48$]$ :

$$
F(y)=\frac{\tau_{D}}{N} \sqrt{\frac{2}{\pi}}\left[-\operatorname{si}\left(\tau_{D} y\right) \sin \left(\tau_{D} y\right)-\operatorname{Ci}\left(\tau_{D} y\right) \cos \left(\tau_{D} y\right)\right]
$$

mit dem Integralsinus $\operatorname{si}(y)=\int_{0}^{y} \frac{\sin (t)}{t} \mathrm{~d} t-\frac{\pi}{2}$ und dem Integralcosinus Ci $(y)=-\int_{y}^{\infty} \frac{\cos (t)}{t} \mathrm{~d} t$

In 'Ā b̄bildung 9í sind die Autokorrelationsfunktionen mit einer Diffusionszeitkonstanten von $\tau_{\mathrm{D}}=1 \mathrm{bzw} .10 \mathrm{~s}$ ihren jeweiligen Leistungsspektren (berechnet in Anlehnung an Gl. 5- 50) zum Vergleich gegenüber gestellt. In der Autokorrelationsfunktion führt eine schnellere Diffusion zu einem schnelleren Abfall der Funktion. Im Leistungsspektrum ist es gerade umgekehrt; ein langsamerer Prozeß hat einen höheren Leistungsanteil bei kleinen Frequenzen und fällt dann früher ab. 
Die theoretischen in bei der Analyse der Vesikeldynamik verwendeten Leistungsspektren nicht hochpassgefiltert. Praktisch wird also nur der Teil der Leistungsspektren ab einer Frequenz von 0,05 Hz beobachtet.
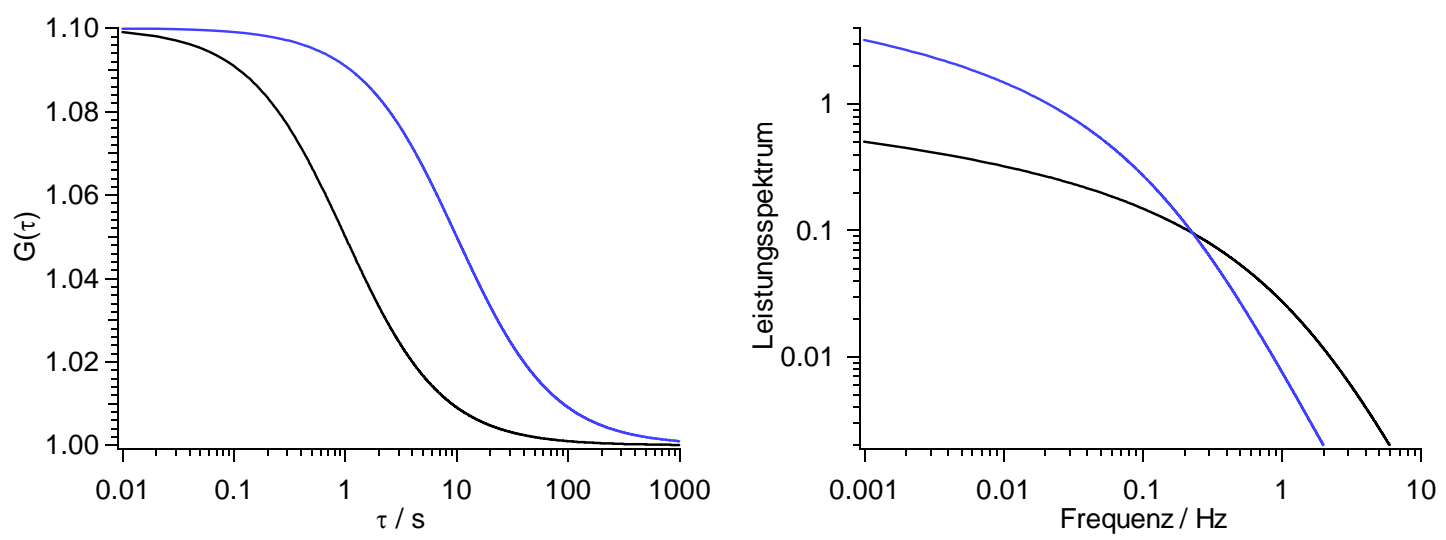

Abbildung 9: Autokorrelationsfunktion und Leistungsspektrum im Vergleich $\left(\tau_{\mathrm{D}}=1 \mathrm{~s}\right.$ bzw. $10 \mathrm{~s} ; N=$ 10).

\subsubsection{Reaktion}

Konzentrationsfluktuationen innerhalb des Beobachtungsvolumens können nicht nur durch translative Diffusion, sondern auch durch Reaktion eines Teilchens hervorgerufen werden. Bei Berücksichtigung von translativer Diffusion und Reaktion werden die Konzentrationsfluktuationen durch folgende Gleichung beschrieben [2]

$$
\frac{\mathrm{d} \delta c_{j}(\boldsymbol{r}, t)}{\mathrm{d} t}=D_{j} \nabla^{2} \delta c_{j}(\boldsymbol{r}, t)+\sum_{k=1}^{n} T_{j k} \delta c_{k}(\boldsymbol{r}, t)
$$

( $T_{j k}$ : Matrix der Geschwindigkeitskonstanten).

Damit es zu Fluoreszenzfluktuationen durch die Reaktion kommt, müssen sich die Fluoreszenzeigenschaften der reagierenden Teilchen während der Reaktion ändern. Im Fall von Gleichgewichtsreaktionen, in denen sich die Fluoreszenzeigenschaften der beteiligten Moleküle während der Reaktion ändern, führen Fluktuationen um einen Mittelwert zur zeitweisen Änderung der Teilchenzahl.

$$
A \stackrel{k_{\text {ass }}}{\frac{k_{\text {diss }}}{\rightleftharpoons}} B
$$

Haben die Teilchen A und B den gleichen Diffusionskoeffizienten, so gilt folgende Autokorrelationsfunktion für den Prozeß aus translativer Diffusion und Reaktion $\left[\begin{array}{l}2 \\ 2\end{array} 61,162\right]$

$$
G_{\mathrm{R}}(\tau)=G_{\mathrm{D}}(\tau)\left[(1-B)+B e^{-R \tau}\right]
$$

$\left(\mathrm{G}_{\mathrm{D}}(\tau)\right.$ : Autokorrelationsfunktion für translative Diffusion). 
Und unter Verwendung von:

$$
\begin{aligned}
& B=\frac{K(1-Q)^{2}}{(K+1)\left(1+Q^{2} K\right)} \\
& Q=\frac{Q_{\mathrm{B}}}{Q_{\mathrm{A}}} \\
& K=\frac{k_{\text {ass }}}{k_{\text {diss }}} \\
& R=k_{\text {ass }}+k_{\text {diss }}
\end{aligned}
$$

Die Autokorrelationsfunktion (G1. $152 j)$ der zuvor beschriebenen unimolekularen Reaktion des Teilchens A zum Reaktionsprodukt B kann auch auf den konkreten Fall der zellphysiologisch wichtigen Reaktion der Pufferung der intrazellulären Calciumkonzentration angewandt werden, sofern die Calciumkonzentration als stationär angenommen werden kann.

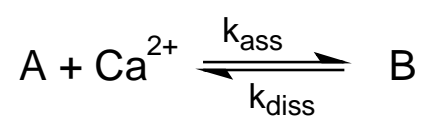

Die Variablen $B$ und $Q$ bleiben für diesen Reaktionstyp wie oben definiert, während sich die Gleichgewichtskonstante der Reaktion $K$ und die inverse Zeitkonstante für den reaktionsbedingten Abfall der Autokorrelationsfunktion $R$ wie folgt ergeben:

$$
\begin{aligned}
& K=\frac{k_{\text {eff }}}{k_{\text {diss }}}=\frac{k_{\text {ass }}\left[\mathrm{Ca}^{2+}\right]}{k_{\text {diss }}} \\
& R=k_{\text {ass }}\left[\mathrm{Ca}^{2+}\right]+k_{\text {diss }}
\end{aligned}
$$

Die Amplitude der Autokorrelationsfunktion ist abhängig von den Gleichgewichtskonzentrationen der Teilchen A $\left(c_{\mathrm{A}}\right)$ und $\mathrm{B}\left(c_{\mathrm{B}}\right)$ sowie bei gleicher Detektionseffizienz der Teilchen A und $\mathrm{B}$ von dem Produkt aus Fluoreszenzquantenausbeute und Absorptionsquerschnitt der individuellen Teilchen $Q_{\mathrm{A}}$ bzw. $Q_{\mathrm{B}}(\mathrm{Gl}$.

$$
G(\tau=0)=\frac{Q_{\mathrm{A}}^{2} c_{\mathrm{A}}+Q_{\mathrm{B}}^{2} c_{\mathrm{B}}}{\left(Q_{\mathrm{A}} c_{\mathrm{A}}+Q_{\mathrm{B}} c_{\mathrm{B}}\right)^{2}} \frac{1}{V_{\mathrm{eff}} N_{\mathrm{L}}}=\frac{c_{\mathrm{A}}+Q^{2} c_{\mathrm{B}}}{\left(c_{A}+Q c_{\mathrm{B}}\right)^{2}} \frac{1}{V_{\text {eff }} N_{\mathrm{L}}}
$$

( $c_{\text {ges }}=c_{\mathrm{A}}+c_{\mathrm{B}} ; V_{\text {eff: }}$ effektives Detektionsvolumen; $N_{\mathrm{L}}$ : Avogadrokonstante).

Aus dem Massenwirkungsgesetz folgt 


$$
c_{\mathrm{A}}=\frac{K_{\mathrm{D}} c_{\mathrm{ges}}}{K_{\mathrm{D}}+c_{\mathrm{Ca}}}
$$

Setzt man die letzte Gleichung in Gl. 's'

$$
G(\tau=0)=\frac{K_{\mathrm{D}}+c_{\mathrm{Ca}}}{V_{\mathrm{eff}} N_{\mathrm{L}} c_{\mathrm{ges}} K_{\mathrm{D}}} \frac{1+Q^{2} \frac{c_{\mathrm{Ca}}}{K_{\mathrm{D}}}}{\left(1+Q \frac{c_{\mathrm{Ca}}}{K_{\mathrm{D}}}\right)^{2}}
$$

Stellt man mit Hilfe von Calciumchelatoren unterschiedliche $\mathrm{Ca}^{2+}$-Gleichgewichtskonzentrationen $\left(c_{\mathrm{Ca}}\right)$ ein, so lassen sich aus einer Auftragung $G(\tau=0)$ gegen $c_{\mathrm{Ca}}$ bei bekanntem Volumenelement ( $\left.V_{\text {eff }}\right)$ und Einwaage an Farbstoff $\left(c_{\text {ges }}\right)$ durch nichtlineare Anpassung $K_{\mathrm{D}}$ und $Q$ bestimmen.

\subsubsection{Triplett}

Nach Anregung des Farbstoffs vom elektronischen Grundzustand $\left(\mathrm{S}_{0}\right)$ in den ersten elektronisch anregten Zustand $\left(\mathrm{S}_{1}\right)$ hat das Farbstoffmolekül entweder die Möglichkeit, unter Aussendung eines Photons in den $\mathrm{S}_{0}$-Zustand zurückzukehren oder unter Elektronenspinum-

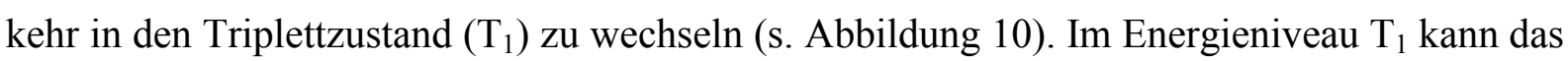
Molekül wiederum unter Spinumkehr zum elektronischen Grundzustand reagieren.

Der Übergang in das $\mathrm{T}_{1}$-Energieniveau (Interkombination, intersystem crossing) findet aufgrund des Interkombinationsverbots nicht so häufig statt.

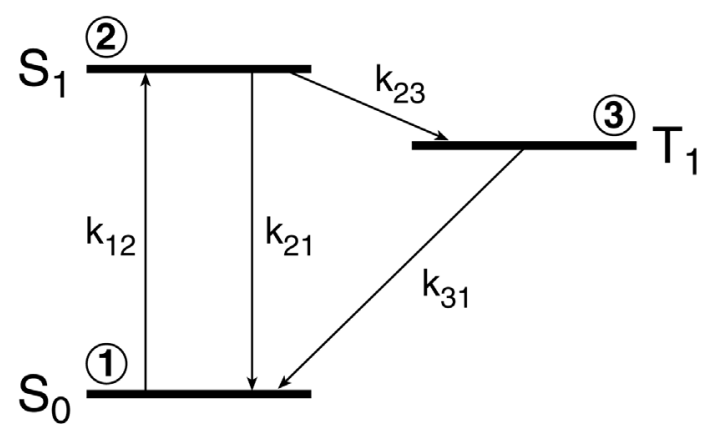

Abbildung 10: Jablonski-Diagramm mit Bezeichnung der verwendeten Geschwindigkeitskonstanten.

Die Geschwindigkeitskonstante $k_{12}$ für die Anregung des Farbstoffs vom Grundzustand $\mathrm{S}_{0}$ in den ersten elektronisch angeregten Zustand $\mathrm{S}_{1}$ ist proportional zur Laser-Anregungsleistung $P_{0}$ und dem Anregungsquerschnitt $\sigma_{\text {exc }}$ :

$$
k_{12}=\frac{\sigma_{\mathrm{exc}} P_{0} \lambda_{\mathrm{exc}}}{\pi w_{0}^{2} h c_{1}}
$$


( $\lambda_{\text {exc }}$ : Anregungswellenlänge; $h$ : Planck-Konstante; $c_{1}$ : Lichtgeschwindigkeit im Vakuum).

Unter der Annahme, daß der Zerfall aus dem $\mathrm{S}_{1}$-Niveau durch Fluoreszenz viel schneller ist als die Interkombination und der Triplettzerfall $\left(k_{21}>k_{23}, k_{31}\right)$, gibt folgende Gleichung die Besetzungswahrscheinlichkeit des $\mathrm{T}_{1}$-Energieniveaus als Funktion der Zeit nach der Photonenfreisetzung wieder [ㅜㅡㄹㅣ:

$$
T(t)=T_{\mathrm{eq}}-T_{\mathrm{eq}} \exp \left(-t / \tau_{\mathrm{T}}\right)
$$

$T_{\text {eq }}$ entspricht dem mittleren Anteil der Moleküle im Triplettzustand für den Gleichgewichtszustand $(t \rightarrow \infty)$, und $\tau_{\mathrm{T}}$ ist die Zeitkonstante für den Zerfall des Triplettzustands:

$$
\begin{aligned}
& 1 / \tau_{\mathrm{T}}=k_{31}+\frac{k_{12} k_{23}}{k_{12}+k_{21}} \\
& T_{\text {eq }}=\frac{k_{23} k_{12}}{k_{12}\left(k_{23}+k_{31}\right)+k_{31} k_{21}}=\frac{k_{23}}{k_{31}} S_{1 \mathrm{eq}}
\end{aligned}
$$

Die Aufenthaltswahrscheinlichkeiten im $\mathrm{S}_{0^{-}}$und $\mathrm{S}_{1}$-Energieniveau betragen:

$$
\begin{aligned}
& S_{0 \text { eq }}=\frac{k_{21} k_{31}}{k_{12}\left(k_{23}+k_{31}\right)+k_{21} k_{31}} \\
& S_{\text {leq }}=\frac{k_{12}}{k_{21}} S_{0 \text { eq }}
\end{aligned}
$$

Die Autokorrelationsfunktion der Fluoreszenzfluktuationen nimmt unter Berücksichtigung des Triplettanteils folgende Form an [633]:

$$
G(\tau)=1+\frac{\left(1-T_{\mathrm{eq}}+T_{\mathrm{eq}} e^{\tau / \tau_{\mathrm{T}}}\right)}{N\left(1-T_{\mathrm{eq}}\right)} \frac{1}{1+\tau / \tau_{\mathrm{D}}} \sqrt{\frac{1}{1+\left(w_{0} / z_{0}\right)^{2} \tau / \tau_{D}}}
$$

\subsubsection{Photozerstörung}

Die Photozerstörung von Farbstoffmolekülen ist eine irreversible photochemische Reaktion, in der die Moleküle ihre Fluoreszenzeigenschaften verlieren. Geschieht die Photozerstörung, während das Molekül durch das Anregungsvolumen diffundiert, so entstehen zusätzliche Fluktuationen des Fluoreszenzsignals. Durch den Einstrom neuer Farbstoffmoleküle in das Anregungsvolumen werden die zerstörten Farbstoffmoleküle z. T. ausgeglichen. Die Photozerstörung kann daher als eine Pseudo-Gleichgewichtsreaktion erster Ordnung aufgefaßt werden, die mit der effektiven Geschwindigkeitskonstanten der Photozerstörung $k_{z}$ beschrieben werden kann [6 64,65$]$. 
Die reale Geschwindigkeitskonstante der Photozerstörung $k_{z}(\mathrm{I}(x, y, z))$ ist abhängig von der eingestrahlten Laserleistung und somit eine Funktion des Ortes innerhalb des Anregungsvolumens. Eine analytische Lösung zur Berechnung dieser Autokorrelationsfunktion existiert bisher nicht. Als vereinfachende Annahme wird deshalb ein rechteckiges Anregungsprofil mit dem Radius $w_{0}$ und der Höhe $z_{0}(\pi / 8)^{1 / 2}$ verwendet. Die reale ortsabhänigige Geschwindigkeitskonstante der Photozerstörung $k_{\mathrm{z}}(I(x, y, z))$ wird so in eine räumlich konstante Photozerstörungs-Geschwindigkeitskonstante $k_{\mathrm{z}}\left(I_{0} / 2\right)$ eines Anteiles $A$ aller angeregten Moleküle umgewandelt.

Die Autokorrelationsfunktion für diesen kombinierten Prozeß aus Diffusion und Photozerstörung lautet $[6 \overline{6}, 16 \overline{6}]$ :

$$
G_{b l}(\tau)=G_{\mathrm{D}}(\tau)\left[1-A+A \exp \left(-k_{\mathrm{z}} \tau\right)\right]
$$

Die Autokorrelationsfunktion wird also aus dem Produkt der Autokorrelationsfunktion für translative Diffusion $G_{\mathrm{D}}(\tau)$ und einem zusätzlichem exponentiellen Term bestimmt, der insgesamt zu einem schnelleren Abfall der Funktion führt.

Findet die Photozerstörungsreaktion aus dem $\mathrm{S}_{1}$ - und aus dem $\mathrm{T}_{1}$-Energieniveau statt, so ist die Photozerstörungs-Geschwindigkeitskonstante $k_{\mathrm{z}}\left(I_{0} / 2\right)$ über folgende Beziehung definiert:

$$
k_{\mathrm{z}}=k_{\mathrm{bS}} S_{1 \mathrm{eq}}+k_{\mathrm{bT}} T_{\mathrm{eq}}=k_{\mathrm{b}} S_{1 \mathrm{eq}}=k_{12} S_{0 \mathrm{eq}} \phi_{\mathrm{b}}
$$

mit $k_{\mathrm{b}}=\left(k_{\mathrm{bS}}+k_{\mathrm{bT}} k_{23} / k_{31}\right)$ und $\phi_{\mathrm{b}}=($ Zahl der photozerstörten Moleküle $) /($ Zahl der absorbierten Moleküle): Quantenausbeute der Photozerstörungsreaktion.

Die mikroskopischen Photozerstörungs-Geschwindigkeitskonstanten $k_{\mathrm{bS}}$ und $k_{\mathrm{bT}}$ sind den Photozerstörungs-Reaktionen aus dem $\mathrm{S}_{1}$ - bzw. $\mathrm{T}_{1}$-Energieniveau zugeordnet (cf. Ä Āb̄bildung 11).

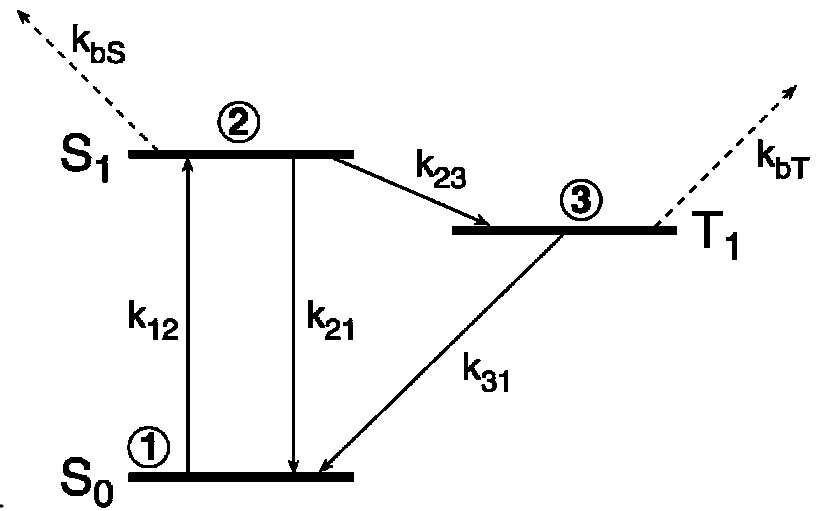

Abbildung 11: Jablonski-Diagramm unter Berücksichtigung der Photozerstörungsreaktionen aus dem $\mathrm{S}_{1}$ - und $\mathrm{T}_{1}$-Energieniveau.

Durch Analyse der Photozerstörung können also die Geschwindigkeitskonstanten der Energieniveaü̈bergänge bestimmt werden $\left[\begin{array}{l}64 \\ 1\end{array} 65\right]$. Meistens ist die Photozerstörung aber 
unerwünscht. Während der Messung in lebenden Zellen sollte die Photozerstörung idealerweise völlig vermieden werden, damit die Messung in möglichst unveränderter Umgebung stattfindet und nicht zur Schädigung der Zelle führt. Manchmal ist aber trotz massiver Reduzierung der Intensität des Anregungslichtes immer noch Photozerstörung zu beobachten, besonders wenn in lebenden Zellen gemessen wird, da sich die endogenen Zellbestandteile nicht wie Farbstoffe verhalten, die mehrere tausend mal fluoreszieren können, bevor sie zerstört werden. In anderen Fällen kann eine weitere Reduzierung der Anregungslichtintensität zur Vermeidung von Photozerstörung wegen einer möglichen Meßzeitverlängerung unerwünscht sein. Für diese Fälle soll im folgenden der Effekt der Photozerstörung auf die Autokorrelationsfunktion abgeschätzt werden

$\mathrm{Zu}$ diesem Zweck wurden Autokorrelationsfunktionen auf dem Computer simuliert, die sich aus translativer Diffusion (mit der Diffusionszeitkonstanten $\tau_{\mathrm{D} \_ \text {sim }}$ ) und Photozerstörung (mit der Photozerstörungs-Geschwindigkeitskonstanten $k_{z}$ ) gemäß Gl. '69: zusammensetzten (Zeitauflösung: $10 \mu \mathrm{s}$; Zahl der Punkte $1 \cdot 10^{5} ; z_{0} / w_{0}=7,5 ; A=0,8 ; 1 / N=0,01$ ). Diese Autokorrelationsfunktionen wurden dann durch ein Modell für reine translative Diffusion angepaßt (Gl. $3 \overline{3}$ ) $\tau_{\mathrm{D}_{\text {fit }}}$ mit der vorher simulierten Diffusionszeitkonstanten $\tau_{\mathrm{D}_{-} \text {sim }}$ verglichen. Die so erhaltenen Ergebnisse sind in Tabelle 2 izusammengestellt.

Die durch das reine Diffusionsmodell angepaßten Diffusionszeitkonstanten sind wie erwartet alle kleiner als der vorher simulierte Wert, da die Photozerstörung zu einem schnelleren Abfall der Autokorrelationsfunktion führt (cf. Gl. $6 \overline{6}$ ).

Tabelle 2: Abweichung in der Diffusionszeitkonstanten bei Verwendung eines Modells reiner translativer Diffusion auf eine ACF, die sich aus translativer Diffusion $\left(\tau_{\mathrm{D}_{\_} \text {sim }}\right)$ und Photozerstörung $\left(k_{\mathrm{z}}\right)$ zusammensetzt (weitere Details im Text).

\begin{tabular}{|c|c|c|c|c|c|}
\hline $\begin{array}{l}\tau_{\mathrm{D}_{-} \operatorname{sim}} \\
/ \mathrm{ms}\end{array}$ & $\begin{array}{l}\tau_{\mathrm{D}_{-} \mathrm{fit}} / \tau_{\mathrm{D}_{-} \operatorname{sim}} \\
\mathrm{mit} k_{\mathrm{z}}=30 \mathrm{~s}^{-1}\end{array}$ & $\begin{array}{l}\tau_{\mathrm{D}_{-} \mathrm{fit}} / \tau_{\mathrm{D}_{-} \mathrm{sim}} \\
\mathrm{mit} k_{\mathrm{z}}=10 \mathrm{~s}^{-1}\end{array}$ & $\begin{array}{l}\tau_{\mathrm{D}_{-} \mathrm{fit}} / \tau_{\mathrm{D}_{-} \mathrm{sim}} \\
\text { mit } k_{\mathrm{z}}=1 \mathrm{~s}^{-1}\end{array}$ & $\begin{array}{l}\tau_{\mathrm{D}_{-} \mathrm{fit}} / \tau_{\mathrm{D}_{-} \mathrm{sim}} \\
\text { mit } k_{\mathrm{z}}=0,3 \mathrm{~s}^{-1}\end{array}$ & $\begin{array}{l}\tau_{\mathrm{D}_{-} \mathrm{fit}} / \tau_{\mathrm{D}_{-} \operatorname{sim}} \\
\mathrm{mit} k_{\mathrm{z}}=0,1 \mathrm{~s}^{-1}\end{array}$ \\
\hline 0,1 & 0,963 & 0,987 & 0,999 & 1,000 & 1,000 \\
\hline 1 & 0,806 & 0,919 & 0,998 & 0,998 & 0,999 \\
\hline 10 & 0,464 & 0,693 & 0,971 & 0,993 & 0,998 \\
\hline 50 & - & 0,369 & 0,823 & 0,953 & 0,988 \\
\hline
\end{tabular}

Reicht der Nachstrom neuer Moleküle aus dem Reservoir nicht aus, die zerstörten Moleküle zu ersetzen, so fällt die Fluoreszenz im Laufe der Zeit exponentiell mit der effektiven Geschwindigkeitskonstanten der Photozerstörung pseudo-erster Ordnung $\left(k_{\mathrm{m}}\right) \mathrm{ab}$ :

$$
F(t)=F_{t=0} \exp \left(-k_{\mathrm{m}} t\right)
$$

Bei geringen Anregungsintensitäten kann die in Gl. 70 definierte Geschwindigkeitskonstante der Photozerstörung $k_{\mathrm{z}}$ aus der beobachteten Geschwindigkeitskonstanten des exponentiellen 
Fluoreszenzabfalls $k_{\mathrm{m}}$ bei bekanntem Detektionsvolumen $\left(V_{\mathrm{det}}\right)$ und dem Volumen des Molekülreservoirs $\left(V_{\text {ges }}\right)$ berechnet werden [6̈ 6 ]:

$$
k_{z}=\frac{V_{\mathrm{ges}}}{V_{\mathrm{det}}} k_{\mathrm{m}}
$$

Diese Gleichung gilt streng genommen für Photozerstörungsmessungen in gerührten Lösungen und geringer Anregungsintensität (Annahme: $S_{0 \mathrm{eq}}=0$ ).

Der Effekt, den der zusätzliche Trend des Fluoreszenzabfalls auf die Berechnung der Autokorrelationsfunktion hat, wurde wie folgt abgeschätzt: Der Fluoreszenz-Zeit-Verlauf mit seinem exponentiellen Abfall wurde als Summe aus einer Exponentialfunktion und den trendbereinigten Meßdaten betrachtet. Allgemein berechnet sich die Autokorrelationsfunktion der Summe zweier Prozesse, aus der Summe der Autokorrelationsfunktionen der einzelnen Prozesse plus der Kreuzkorrelation dieser zwei Prozesse; letztere wurde in diesem Beispiel als vernachlässigbar klein angenommen.

Die Autokorrelationsfunktion der trendbereinigten Meßdaten wurde durch Simulation aus

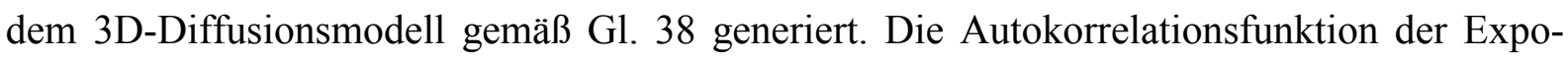
nentialfunktion wurde aus simulierten exponentiellen Zeitverläufen unterschiedlicher Abfallraten berechnet, indem die Zeitverläufe zunächst in gleich große, $50 \%$ überlappende Segmente unterteilt und daraufhin autokorreliert wurden. Die Aufteilung in kleinere Segmente bewirkte dabei einen geringeren Störeffekt der Exponentialfunktion auf die eigentlichen Meßdaten. Die Autokorrelationsfunktion des gesamten Zeitverlaufes ergab sich dann als arithmetisches Mittel der einzelnen Segment-Autokorrelogramme und wurde zur Autokorrelationsfunktion der trendbereinigten Meßdaten addiert. Die Summe aus den beiden Autokorrelationsfunktionen wurde dann mit dem Modell der trendfreien Meßdaten angepaßt (Gl. 38 ). Ábbildung 12 zeigt einige Beispiele simulierter Exponentialfunktionen und die Summe aus deren Autokorrelationsfunktionen mit der Autokorrelationsfunktion für reine translative Diffusion (letztere wurde simuliert mit den Parametern: $\tau_{\mathrm{D}}=1 \mathrm{~ms} ; 1 / N=0,01 ; z_{0} / w_{0}=7,5$; Zeitauflösung: $10 \mu \mathrm{s}$; Zahl der Punkte: 4096). Bei einer Geschwindigkeitskonstanten des Fluoreszenzabfalls von $k_{\mathrm{m}}=0,1 \mathrm{~s}^{-1}$ ergibt sich kein Unterschied in der durch Anpassung erhaltenen Diffusionszeitkonstanten im Vergleich $\mathrm{zu}$ einer trendlosen Autokorrelationsfunktion (grüne Kurve), für $k_{\mathrm{m}}=0,5 \mathrm{~s}^{-1}$ beträgt der Unterschied $3 \%$ (blaue Kurve), während für $k_{\mathrm{m}}=1,0 \mathrm{~s}^{-1}$ die Form der Autokorrelationsfunktion stark beeinträchtigt wird (rote Kurve). In Abhängigkeit von der effektiven Geschwindigkeitskonstanten der Photozerstörungsreaktion $k_{\mathrm{m}}$ und der Anzahl der Teilchen $N$ im Detektionsvolumen konnte auf diese Weise der Einfluß auf die Diffusionskonstante $\tau_{\mathrm{D}}$ bestimmt werden und die Segmentgröße bei der Berechnung der Autokorrelationsfunktion entsprechend angeglichen werden. 

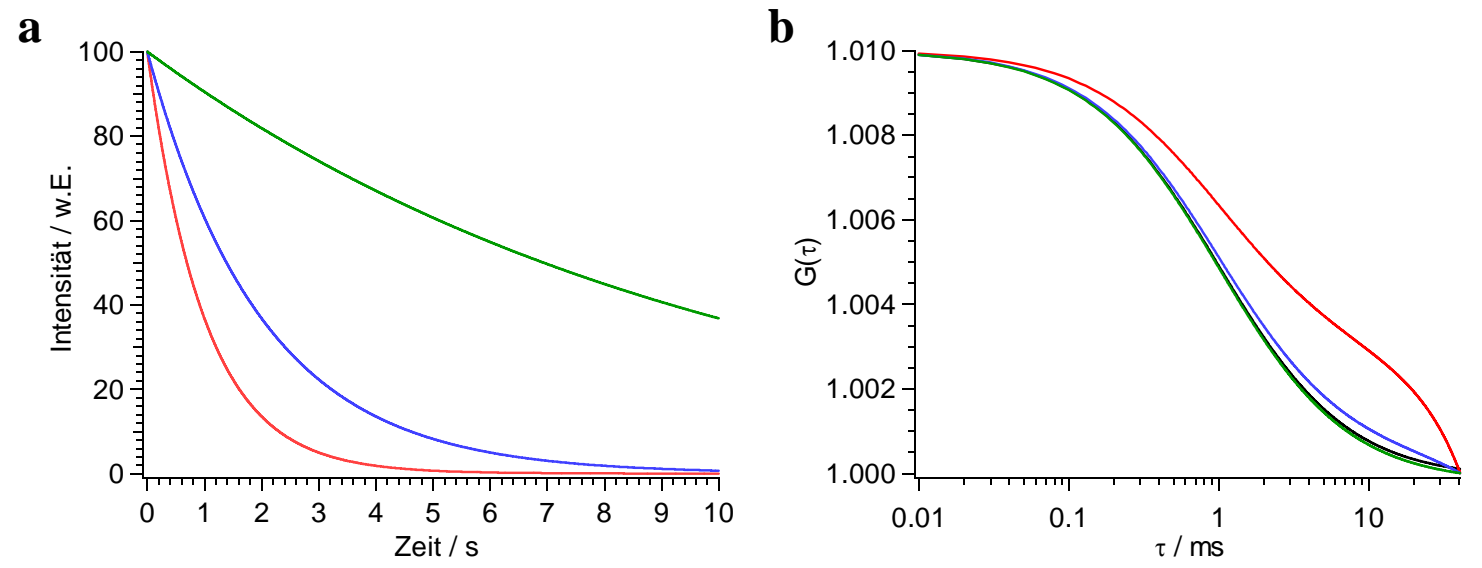

Abbildung 12: a: Simulierte, exponentielle Zeitverläufe mit den Abfallraten $1,0 \mathrm{~s}^{-1}, 0,5 \mathrm{~s}^{-1}$ und $0,1 \mathrm{~s}^{-1}$. b: Die Summe aus einer nach G1. $38_{-1}$ simulierten Autokorrelationsfunktion (Parameter: $\tau_{\mathrm{D}}=1 \mathrm{~ms} ; 1 / N$ $\left.=0,01 ; z_{0} / w_{0}=7,5\right)$ und den Autokorrelationsfunktionen der in Abbildung a dargestellten Funktionen jeweils auf eine Amplitude von 0,01 normiert (Zeitauflösung: $10 \mu \mathrm{s}$; Segmentgröße beim Autokorrelieren: 40,96 ms).

\subsubsection{Hintergrundfluoreszenz}

Besteht die gemessene Fluoreszenz zusätzlich zur Fluoreszenz der zu untersuchenden Spezies $F(t)$ noch aus Hintergrundfluoreszenz $B(t)$, so setzt sich die normalisierte Autokorrelationsfunktion der gemessenen Fluoreszenz $G(\tau)_{\mathrm{s}+\mathrm{b}}$ folgendermaßen zusammen:

$$
G(\tau)_{\mathrm{s}+\mathrm{b}}=\frac{\langle[F(t)+B(t)][F(t+\tau)+B(t+\tau)]\rangle}{\langle F(t)+B(t)\rangle^{2}}=\frac{\langle F(t)\rangle^{2}}{\langle F(t)+B(t)\rangle^{2}} \frac{\langle F(t) F(t+\tau)\rangle}{\langle F(t)\rangle^{2}}
$$

Diese Gleichung gilt unter der Annahme, daß die Hintergrundfluoreszenz nicht mit der Fluoreszenz des Signals und im betrachteten Zeitfenster auch nicht mit sich selbst korreliert 66: :67:

Die Amplitude der Autokorrelationsfunktion bei Anwesenheit einer konstanten Hintergrundfluoreszenz ist also kleiner im Vergleich zur hintergrundfreien Korrelationsfunktion. Dies täuscht eine Zunahme der Teilchenzahl im Beobachtungsvolumen vor um entsprechend

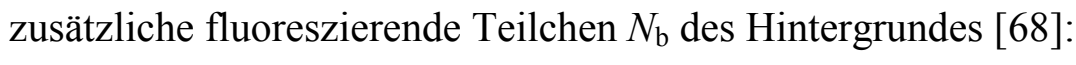

$$
G(\tau=0)=1+\frac{N_{\mathrm{s}}}{\left(N_{\mathrm{s}}+N_{\mathrm{b}}\right)^{2}}
$$

\subsection{Fluoreszenzrückkehr nach Photozerstörung (FRAP)}

Nach der Photozerstörung eines Stoffes an einem lokal begrenzten Ort entsteht eine Konzentrationssenke bzgl. dieses Stoffes, die durch die Umgebung ausgeglichen werden kann. Der Stoff kann sich im einfachsten Falle durch translative Diffusion in Richtung der Konzentrati- 
onssenke bewegen, bis sich ein Gleichgewicht zwischen dem Ort der Photozerstörung und seiner Umgebung eingestellt hat. Die Geschwindigkeit, mit der sich die Fluoreszenz erholt, ist von dem Diffusionskoeffizienten des zerstörten Stoffes abhängig. Der Zeitverlauf nach Been-

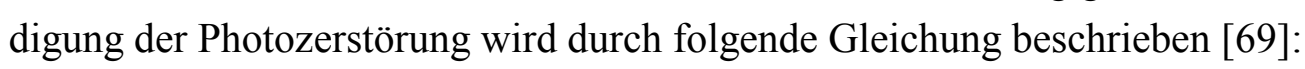

$$
F_{K}(t)=F_{\max } \sum_{n=0}^{\infty} \frac{(-K)^{n}}{n !\left(1+n\left(1+2 t / \tau_{\mathrm{D}}\right)\right.}
$$

mit $\tau_{\mathrm{D}}=\frac{w_{0}^{2}}{4 D}$

( $F_{\max }$ : Fluoreszenzintensität für $t \rightarrow \infty ; D$ : Diffusionskoeffizient; $K$ : Konstante, die von der Dauer der Photozerstörung, der Laserintensität und der Geschwindigkeitskonstanten der Bleichreaktion abhängt).

In der Praxis wurde eine Reihenentwicklung bis $n=95$ ausgeführt, die zu Ergebnissen führte, die durch das Einbeziehen zusätzlicher Summanden nicht weiter verbessert werden konnte.

\subsection{Experimenteller Aufbau}

Die experimentelle Anordnung wurde so konzipiert, daß FCS-Experimente an lebenden Zellen möglich wurden.

Ausgangspunkt war ein Standard-Meßsystem für FCS-Experimente in Lösung (ConfoCor ${ }^{\circledR}$, Zeiss/Evotec). Dieses bestand aus einem epi-illuminierten konfokalen Mikroskop und wurde durch die folgenden Komponenten erweitert: Akusto-optischer Modulator, CCD-Kamera, Laserstrahlaufweiter, Instrumente zur Durchführung von Patch-Clamp-Messungen, Zählkarte, Kontrollgeber für alle Geräte (Master 8). Eine schematische Darstellung des experimentellen Aufbaus ist in 1 b̂bildung 13 iwiedergegeben. 


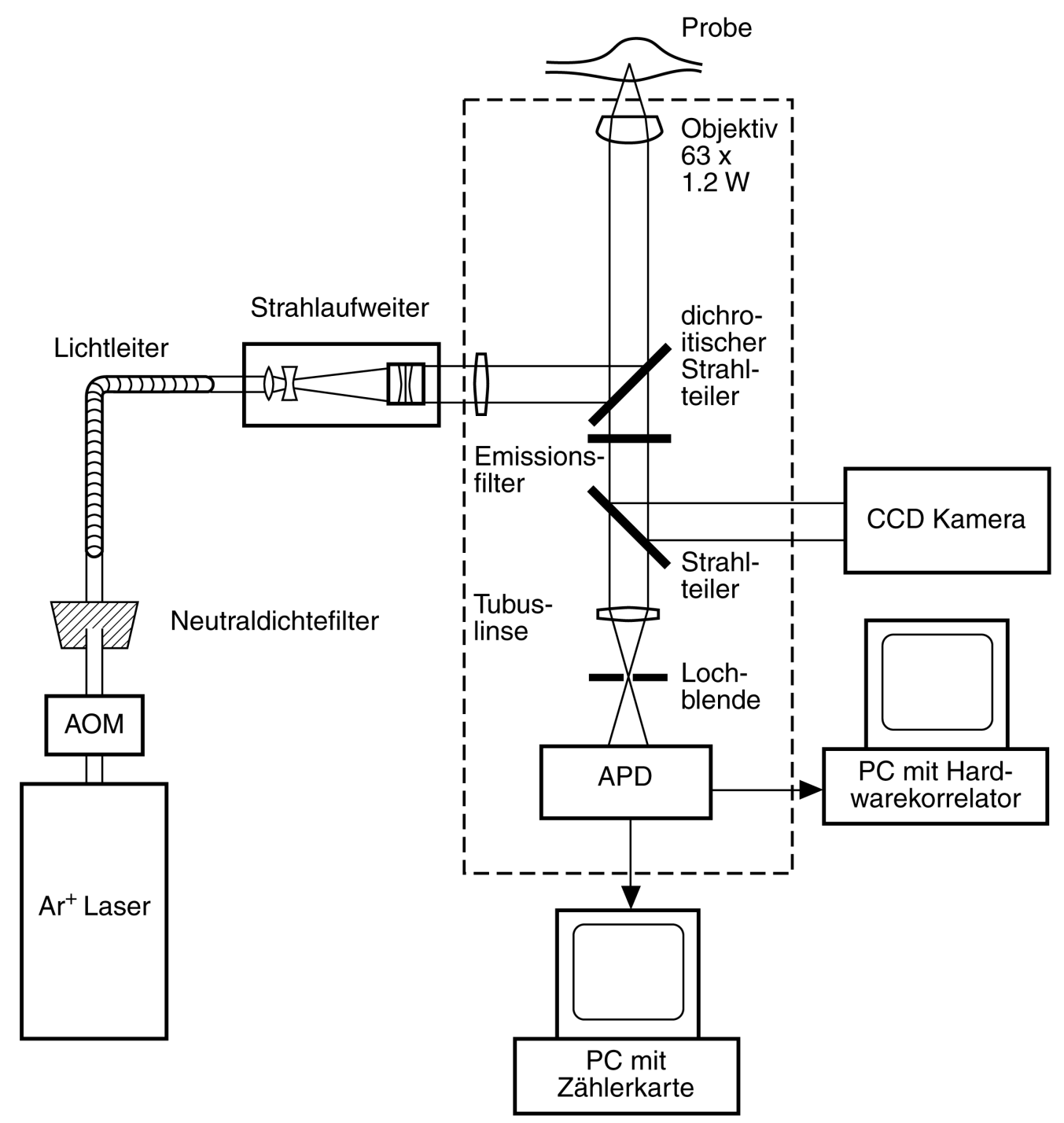

Abbildung 13: Experimenteller Aufbau.

Die Anregung der Probe bei den Wellenlängen 543 und 633 erfolgte jeweils mit einem HeNeLaser. Bei 488 und $514 \mathrm{~nm}$ diente der Strahl eines Argonionenlasers (LGK7812 ML, Zeiss) zum Anregen der Proben. Hauptsächlich emittiert der Argonionenlaser bei den zwei Wellenlängen $\lambda_{\text {exc }}=488$ und 514,5 nm, wobei auf die tiefere Wellenlänge ein Energiegehalt von 70 $\%$ fällt und bei 514,5 $\mathrm{nm}$ von ca. $30 \%$ bei einer Gesamtleistung von $20 \mathrm{~mW}$. Mindestens 95 $\%$ der Emission erfolgen in der Mode $\mathrm{TEM}_{00}$. Der linear polarisierte Laserstrahl hat am Ausgang des Lasers einen Durchmesser von $d=0,65 \mathrm{~mm}$ und ist senkrecht zur Grundplatte polarisiert mit einer Divergenz von weniger als 1,0 mrad. Nach dem Austritt aus dem Laser passiert der Strahl einen $\mathrm{AlMgF}_{2}$ beschichteten mechanischen Verschluß aus $\mathrm{CuBe}$ mit einer Apertur von 6 mm (LS6ZM2, Vincent Associates ) oder einen mit Teflon beschichteten Verschluß aus Stahl mit einer Apertur von 14 mm (VS14S2T1, Vincent Associates). Die Öffnungsdauer und -frequenz der Verschlüsse wurde von einem Treiber (UniBlitz T132, Vincent Associates) angesteuert. Die Verschlüsse brauchten eine Zeit von 0,7 bzw. 1,5 ms bis sie vollständig geöffnet sind. Das vollständige Schließen der Verschlüsse dauerte 0,8 bzw. 3 ms. 
Bei Verwendung der kleineren Blende und einer gewünschten Belichtungsdauer von $10 \mathrm{~ms}$ wird die Probe also insgesamt für 10,8 ms belichtet, während man nur 9,3 ms dieser Zeit die Probe voll beleuchtet hat. Ein weiterer Nachteil der mechanischen Verschlüsse war ihre geringe Haltbarkeit bei wiederholtem Öffnen und Schließen mit einer Frequenz von $10 \mathrm{~Hz}$ oder schneller. Diese Nachteile wurden durch Verwendung eines akusto-optischen Modulators (AOM) zur gezielten Belichtung der Probe umgangen. Eine ausführliche Darlegung der Akusto-Optik wird bei itis und $[72]$ gegeben und soll in Anlehnung daran im folgenden kurz zusammengefaßt werden.

Der AOM (AA.MTS.110/A3-VIS, A.A Opto-Electronique) besteht aus einem $\mathrm{TeO}_{2}$-Kristall, in dem eine stehende Schallwelle der Schallwellenlänge $\left(\Lambda_{\mathrm{a}}\right)$ erzeugt wird. Die Schallwelle wird durch einen elektronischen Treiber (AA.MOD.110.1W, A.A Opto-Electronique), basierend auf einem Quartzoszillator, erzeugt. Die eingestrahlte Hochfrequenz $f_{a}=110 \mathrm{MHz}$ führt zu einem gleichmäßigen Muster von Brechungsindexänderungen in dem Kristall. Trifft der Laserstrahl im Braggwinkel $\left(\Theta_{\mathrm{B}}\right)$ auf den Kristall, so ist die Intensität beim Austritt aus dem Kristall maximal und es gilt

$$
\sin \left(\Theta_{\mathrm{B}}\right)=\frac{\lambda_{\mathrm{exc}}}{2 n \Lambda_{\mathrm{a}}}
$$

mit $\Lambda_{\mathrm{a}}=\frac{v_{\mathrm{a}}}{f_{\mathrm{a}}}$

( $n$ : Brechungsindex; $v_{\mathrm{a}}$ : Schallgeschwindigkeit im Kristall (hier: $v_{\mathrm{a}}=650 \mathrm{~m} / \mathrm{s}$ ); $f_{\mathrm{a}}$ : eingestrahlte Schallfrequenz).

Das eingestrahlte Laserlicht wird bei anliegender Hochfrequenz in dem Kristall in zwei Strahlen gebrochen: Die sogenannte 0. Ordnung tritt unmoduliert durch die Bragg-Zelle, während der austretende Strahl der 1. Ordnung in einem Winkel $\Theta_{\mathrm{D}}$ von der eingestrahlten Richtung aus dem Kristall austritt.

$$
\Theta_{\mathrm{D}} \approx \frac{\lambda_{\mathrm{exc}} f_{\mathrm{a}}}{n v_{\mathrm{a}}}
$$

Die Frequenz des austretenden Laserstrahls ist um den Betrag $f_{\mathrm{a}}$ erniedrigt, und die Polarisationsebene ist um $90^{\circ}$ gegenüber dem Ausgangsstrahl gedreht.

Der Anteil der Laserleistung, die man in der 1. Ordnung findet $\left(I_{1}\right)$, im Verhältnis zur Leistung in der 0. Ordnung ohne anliegende Hochfrequenz $\left(I_{0}\right)$ läßt sich mit der applizierten Treiberleistung kontrollieren und wird durch folgende Formel beschrieben:

$$
\eta=\frac{I_{1}}{I_{0}}=\frac{\pi^{2}}{2 \lambda_{\mathrm{exc}}^{2}} M_{2}\left(\frac{L}{H}\right) P_{\mathrm{a}}
$$

(H: Akustische Wellenhöhe; $L$ : Interaktionslänge; $P_{\mathrm{a}}$ : Treiberleistung). 


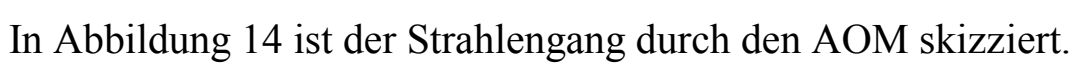

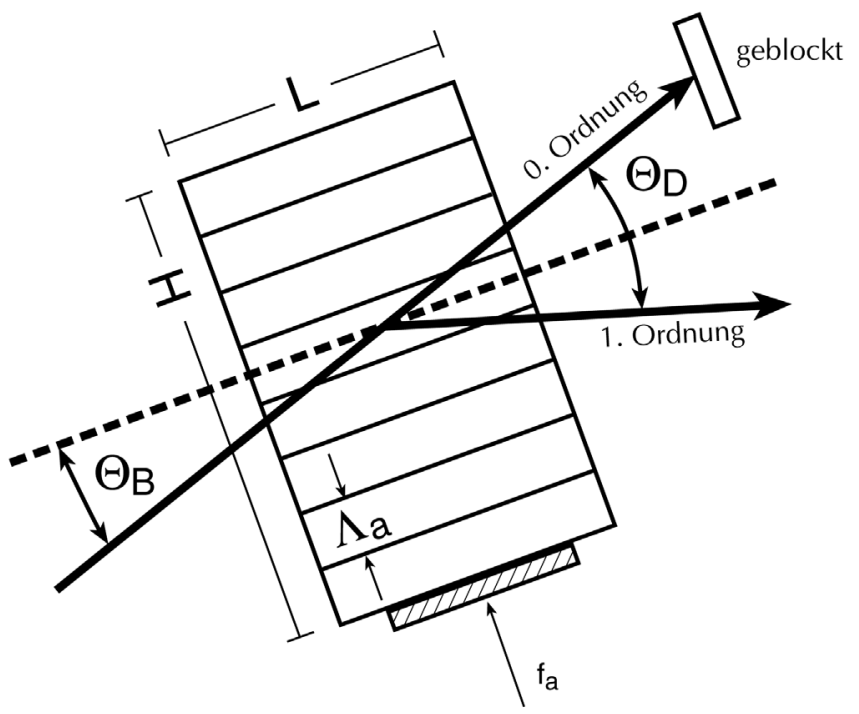

Abbildung 14: Schematische Zeichnung des Strahlenganges durch den akusto-optischen Modulator.

Wird die maximale Treiberleistung von $1 \mathrm{~W}$ auf den AOM gegeben sind $91 \%$ der eingestrahlten Laserleistung $(0,273 \mathrm{~mW})$ in der 1 . Ordnung $\mathrm{zu}$ finden, während man bei nahezu $0 \mathrm{~W}$ Treiberleistung nur $0,35 \mu \mathrm{W}$ detektiert. Die Anstiegszeit $t_{\mathrm{a}}$ (10-90\%), innerhalb der Laserstrahl in der 1. Ordnung von Null auf den Maximalwert ansteigt, berechnet sich nach

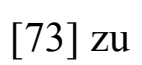

$$
t_{\mathrm{a}}=\frac{w}{1,5 \cdot v_{\mathrm{a}}}
$$

und beträgt bei der hier verwendeten Meßkonfiguration $t_{\mathrm{a}}=0,7 \mu \mathrm{s}\left(w=0,65 \mathrm{~mm}, v_{\mathrm{a}}=650\right.$ $\mathrm{m} / \mathrm{s}$ ). Die Treiberleistung wurde mit Hilfe von TTL-Pulsen zwischen den beiden Extremen variiert. Mit Hilfe des Laserstrahls der 1. Ordnung ließ sich die Probe also innerhalb von wenigen Mikrosekunden belichten.

Nach Verlassen des AOMs wurde die Polarisationsebene des Laserstrahls um $90^{\circ}$ mit Hilfe einer Rotationsplatte aus Quarz (Linos Photonics) gedreht.

Anschließend wurde der Laserstrahl in eine polarisationserhaltene Single-Mode-Faser $(\mathrm{Oz})$ mit Fokussierlinse in einem Kerndurchmesser von $d=3,5 \mu \mathrm{m}$ eingekoppelt. Die Position der Faser ließ sich sowohl entlang der drei Achsen verschieben als auch verkippen.

Über die Faser wurde der Laserstrahl in ein Linsensystem zur Laserstrahlaufweitung (Ábbildung 15i) geleitet. Innerhalb des Linsensystems konnte der Durchmesser des Laserstrahls durch gleichzeitiges Verschieben der Linsen $\mathrm{L}_{2}, \mathrm{~L}_{4}$ und $\mathrm{L}_{5}$ variiert werden. 


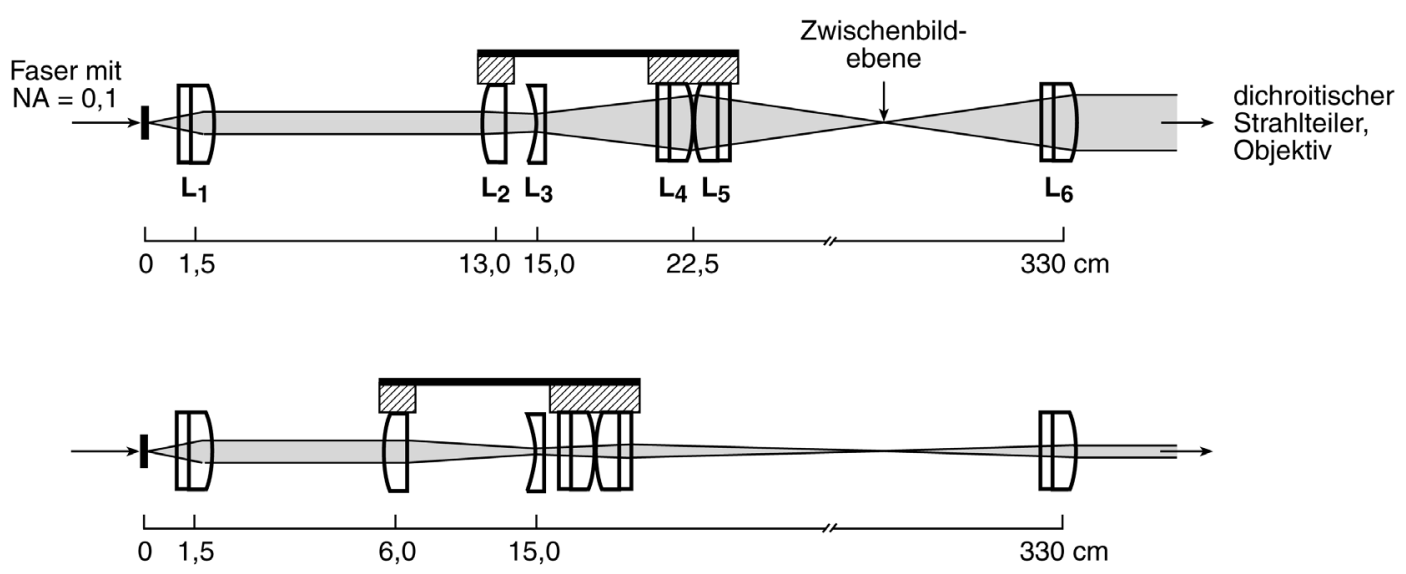

Abbildung 15: Pankratisches Linsensystem zur variablen Laserstrahlaufweitung. Die Linsen $\mathrm{L}_{2}, \mathrm{~L}_{4}$ und $\mathrm{L}_{5}$ sind miteinander verbunden ließen sich über eine Wegstrecke von $75 \mathrm{~mm}$ verschieben: $\mathrm{L}_{1}$ : Achromat $f^{\prime}=30, d=12, d_{\text {frei }}=10$ (01LAL001, Melles Griot); $\mathrm{L}_{2}$ : Plankonvexlinse $f^{\prime}=80, d=22,4$, $d_{\text {frei }}=10$ (01LPX149, Melles Griot) $\mathrm{L}_{3}$ : Plankonkavlinse $f^{\prime}=-40, d=22, d_{\text {frei }}=10$ (01LDK017, Melles Griot) $\mathrm{L}_{4} / \mathrm{L}_{5}$ : je Achromat $f^{\prime}=160, d=31,5, d_{\text {frei }}=20$ (01LAO155, Melles Griot) $\mathrm{L}_{6}$ : Achromat $f^{\prime}=$ $100, d=27$ (Melles Griot). Alle Angaben erfolgten in mm.

Nach Passieren des Linsensystems, wurde der Laserstrahl in ein konfokales Mikroskop (Axiovert 135, Zeiss) eingekoppelt. Ein dichroitischer Spiegel reflektierte den Laserstrahl Richtung Objektiv (C-Apochromat, 63x/1.2 w, Zeiss), von dem es in die zu untersuchende Probe fokussiert wurde. Die emittierte Fluoreszenz wurde mit demselben Objektiv aufgefangen, passierte den dichroitischen Spiegel sowie einen Emissionsfilter, dessen Wellencharakteristik 'Âbbildung 16u entnehmen ist. Das Emissionslicht wurde dann von einer Linse auf eine Lochblende (Pinhole) fokussiert. Die Position der Lochblende ließ sich entlang aller drei Achsen verstellen und war im Durchmesser variabel. Die Lochblende diente dazu, außerhalb der fokalen Ebene entstandene Fluoreszenz zu reduzieren.

Nach der Lochblende fokussiert eine weitere Linse das Licht auf eine Avalanche-Photodiode (APD) (SPCM-AQ-151-FS, EG\&G) im Single Photon Counting Modus. Ein auftreffendes Photon erzeugt einen lawinenartigen Strom in der APD, der nach einer Totzeit von $t_{\mathrm{d}}=$ 29 ns abgeklungen ist. Während dieser Totzeit können keine weiteren Photonen detektiert werden. Die Dauer der Totzeit der APD ist vom Hersteller als Kompromiß zwischen geringer Totzeit und geringer Nachpulswahrscheinlichkeit gewählt. Nachpulse entstehen durch aus dem Lawinenstrom eingefangene Elektronen und können einen weiteren Lawinenstrom auslösen. Die Wahrscheinlichkeit beträgt bei einer Zählrate von unter $3 \mathrm{MHz}$ etwa $0,1 \%$ und ist deshalb unter den verwendeten Meßbedingungen vernachlässigbar.

Unter der Annahme einer Poisson-verteilten Auftreffwahrscheinlichkeit der Photonen auf die APD, kann man mit folgender Formel die Wahrscheinlichkeit berechnen, daß während der Totzeit ein weiteres Photon auf die APD auftrifft:

$$
p_{k}=\frac{\lambda^{k}}{k !} e^{-\lambda}
$$


( $p_{k}$ : Wahrscheinlichkeit für das Eintreffen von $k$ Photonen; $\lambda$ : Totzeit.Zählrate).

Bei einer Zählrate von $2 \mathrm{MHz}$ werden dementsprechend $12 \%$ der ankommenden Photonen nicht detektiert. Nach einer Eichmessung lassen sich die Zählraten aber entsprechend ihrer Höhe korrigieren.

Laserlicht unterschiedlicher Wellenlänge wird von der APD mit unterschiedlichen Photonendetektionseffizienzen detektiert. Für die verwendeten Meßkonfigurationen kann der Wert aus der 'Ábbildung 16: entnommen werden. Die meisten Messungen wurden mit dem Strahlteiler bei $488 \mathrm{~nm}$ durchgeführt, bei der die APD eine Photonendetektionseffizienz von 50-60 $\%$ besitzt.

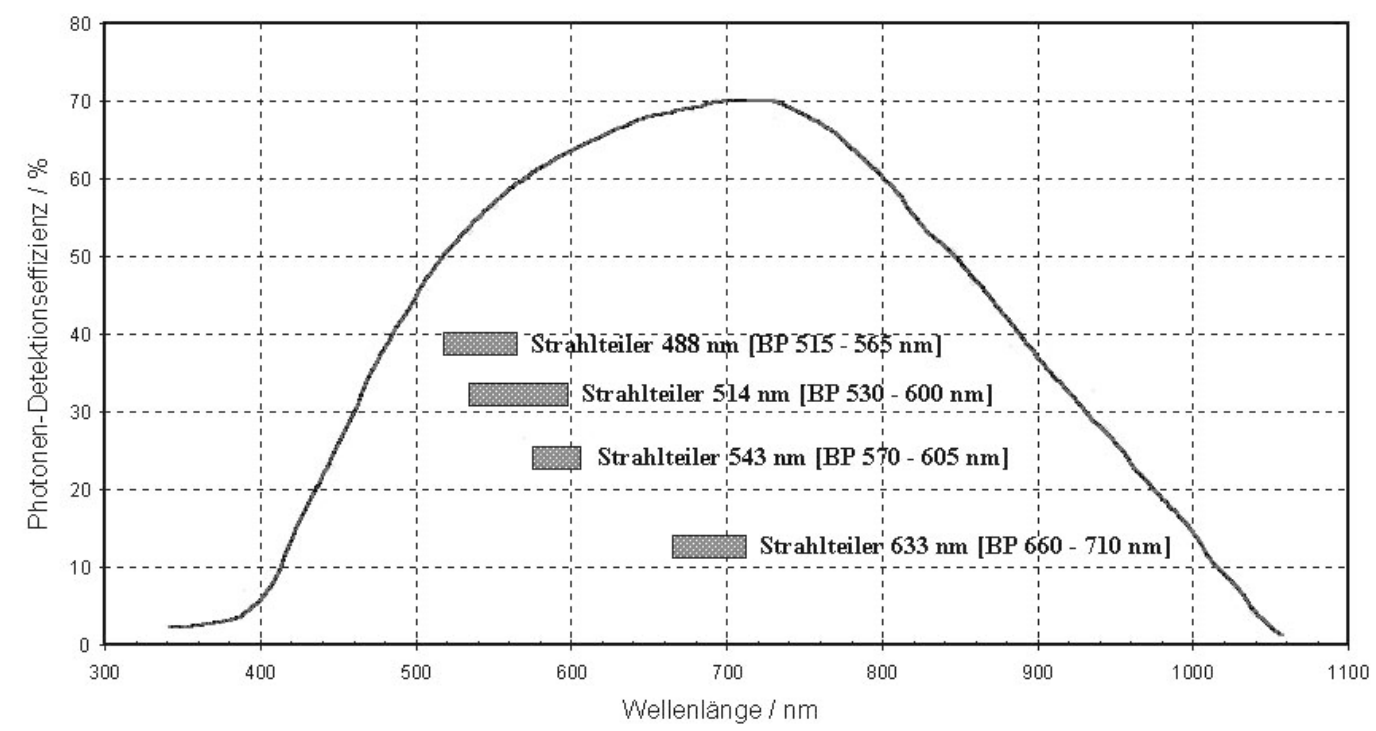

Abbildung 16: Photonen-Detektionseffizienz der APD als Funktion der Wellenlänge und Wellenlängencharakteristik der verwendeten Emissionsfilter (nach ConfoCor-Handbuch (Zeiss), verändert) .

Jedes detektierte Photon generiert in der APD einen lawinenartigen Strom, der zu einer Ausgabe eines TTL-Pulses (Amplitude $=5 \mathrm{~V}$, Länge $=9 \mathrm{~ns}$ ) führt. Die erzeugten TTL-Pulse wurden einerseits in einen Hardware-Korrelator (ALV-5000, ALV) eingespeist, der aus den ankommenden Pulsen die Autokorrelationsfunktion in Echtzeit berechnet. Andererseits wurden die TTL-Pulse in das Eingangsregister einer Zählkarte eingespeist, nachdem die Länge der TTL-Pulse auf eine Dauer von 50 ns verlängert wurde. Die Zählkarte (CIO-CTR05, ComputerBoards) zählt die Anzahl der ankommenden TTL-Pulse von der APD in vorher festgelegten Zeitintervallen und schreibt die Anzahl der TTL-Pulse für jedes Zeitintervall auf die Festplatte eines Computers. Jeder Zahlenwert besitzt eine Größe von 1 Byte, d.h. die maximale Anzahl an TTL-Pulsen pro Zeitintervall beträgt 256.

Die maximale Zeitauflösung ist $6 \mu$ s. Die Anzahl der maximal möglichen Intervalle wird durch den zur Verfügung stehenden Speicher des Computers bestimmt.

Die Rohdaten wurden dann mit selbstgeschriebenen Programmen in der Software-Umgebung von PV-Wave ${ }^{\circledR}$ (V6.0, Visual Numerics) ausgewertet. Dazu wurden Programme ge- 
schrieben, die aus den Rohdaten die Autokorrelationsfunktion bzw. das Leistungsspektrum berechneten.

Für die Experimente in lebenden Zellen wurden zur Bestimmung des Meßortes Fluoreszenzbilder aufgezeichnet. Dazu wurde eine mattierte Glasplatte in den Laserstrahlengang eingeschwenkt, die zu einem diffusen Laserstrahl und so zu einer gleichmäßigen Beleuchtung der Objektivpupille führte. Das Fluoreszenzbild wurde von einer CCD-Kamera (VarioCam, PCO Computeroptics) aufgenommen und an einen Framegrabber (PCI-1408, National Instruments) weitergeleitet. Der Framegrabber wurde mit Hilfe der Software LabVIEW (V5.1, National Instruments) kontrolliert, und die Bilder auf der Festplatte eines Computers gespeichert.

\subsection{Meßkonfiguration für patch-clamp-Messungen}

Ein $\mathrm{Ag} / \mathrm{AgCl}$-beschichteter Silberdraht innerhalb der Patch-Pipetten diente als Elektrode für die Patch-Clamp-Messungen, ein weiterer fungierte als Bezugselektrode.

Die gemessenen Ströme wurden in der „headstage“ in Spannungen umgewandelt und in einem Verstärker (EPC-9, HEKA elektronik) weiter verarbeitet. Über das Software-Programm Pulse (V 8.12, HEKA elektronik) wurden die Funktionen des Verstärkers kontrolliert, und die Daten aufgezeichnet.

Die Pipette wurde mit interner Lösung Standard befüllt, in den Pipettenhalter eingespannt und ein Überdruck von $2 \mathrm{~cm}$ Wassersäule mit Hilfe einer Multidruck-Kontrolleinheit (MPCU) appliziert. Der Überdruck sollte das Festsetzen von Verunreinigungen beim Durchtritt durch die Badlösung durch Staub oder Zellbestandteile verhindern. Nach Eintritt in die Badlösung (Zusammensetzung laut Standard externe Lösung) wurde ein Pipettenwiderstand zwischen 2 und $3 \mathrm{M} \Omega$ gemessen. Die Pipette wurde dann mit Hilfe von drei Grobtrieben in die Nähe der zu untersuchenden Zelle manövriert. Mit Hilfe eines piezoelektrischen Manipulators wurde die Pipette dann leicht auf die Zelle aufgesetzt und der Überdruck zurückgenommen. Der Widerstandswert ist dabei um mehrere Megaohm angestiegen, da der Fluß von Elektrolyten zwischen Pipettenöffnung und Badelektrode verringert wurde. Durch Anlegen eines Unterdrucks von ca. $20 \mathrm{~cm}$ Wassersäule wurde die Zelle an die Pipettenspitze angesaugt, und zeitgleich wurde das Zellmembranpotential in Richtung Ruhemembranpotential schrittweise von $0 \mathrm{mV}$ auf $-70 \mathrm{mV}$ verringert. Nachdem der Widerstand im Gigaohm-Bereich lag (Gigaseal, on-cell-Konfiguration) wurde durch ein kurzes pulsartiges Saugen der Membranbereich, der sich zwischen den Glaswänden befand, zerstört, so daß danach der Pipetteninhalt mit dem Zellinneren in Kontakt kam (whole-cell-Konfiguration) und sich ein Gleichgewicht zwischen der Pipettenlösung sowie der Zelle einstellen konnte. Die Einwaschzeit der verschiedenen Bestandteile der internen Pipettenlösung wurde anhand einer Abschätzung von Pusch und Neher [7̄̄j] bestimmt und betrug für den Farbstoff OregonGreen-BAPTA ca. 300 s. 
Verschiedene Meßorte innerhalb einer Zelle wurden durch Verschieben der Probe mit Hilfe des Mikroskoptisches erreicht. Aufgrund der unterschiedlichen Brechungsindizes zwischen Cytoplasma und Zellkern konnte klar zwischen diesen beiden Kompartimenten in der Zelle unterschieden werden.

\subsection{Zellpräparation}

\subsubsection{Neuronale Primärkulturen des Hippocampus}

Neurone aus den Regionen CA1 und CA3 (cf. 'Â̄b bildung $17 \overline{1}$ ) wurden entsprechend den Anleitungen in $\left[\begin{array}{c}75 \\ 2\end{array} ; 76\right]$ mit einigen Modifikationen kultiviert.

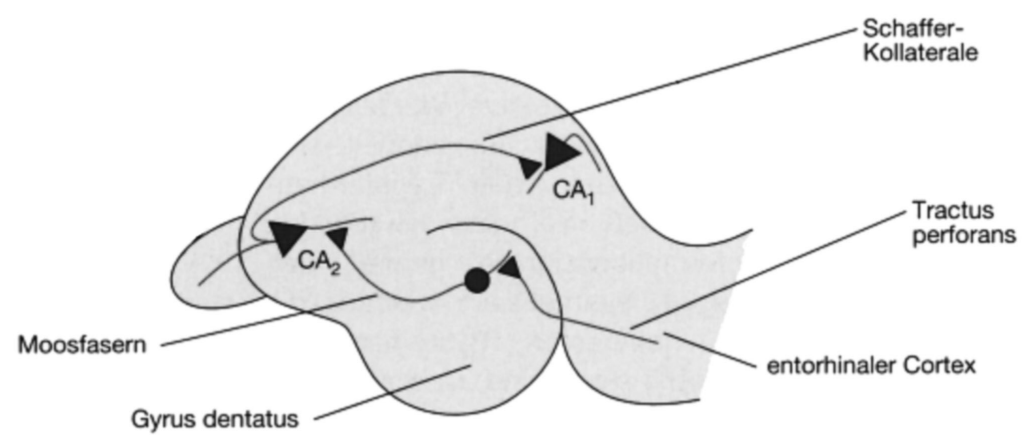

Abbildung 17: Neuronenarten im Hippocampus. Aus dem entorhinalen Cortex entspringt der Tractus perforans, der in den Körnerzellen des Gyrus dentatus endet. Die Axone der Körnerzellen sog. Moosfasern enden dann in den Pyramidenzellen der Region-CA3. Von diesen wird über die SchafferKollateralen eine Verbindung zu den CA1-Pyramidenzellen hergestellt (nach! $\left[\begin{array}{l}1 \\ 1\end{array}\right]$

Dazu wurden die Hippocampi von drei Whistar-Ratten (ein bis zwei Tage alt) steril herauspräpariert und umgebendes Gewebe vorsichtig entfernt. Anschließend wurden die Hippocampi an der Nahtstelle von CA1-Region und Gyrus dentatus beginnend entfaltet und die nicht benötigten Bereiche des Gyrus dentatus und das auf der gegenüberliegenden Seite liegende Subiculum mit einer Präparierschere weggeschnitten. Die verbleibenden CA1- und CA3-Regionen wurden in etwa 10 gleich große Würfel geschnitten, in ein Zentrifugierröhrchen gegeben und dreimal mit Hanks $+20 \%$ FBS sowie anschließend dreimal mit serumfreier Hanks-Lösung gewaschen. Zum Verdauen wurden nach der letzten Aspiration des Überstands $5 \mathrm{mg} / \mathrm{ml}$ Trypsin und $0,25 \mathrm{mg} / \mathrm{ml}$ DNase (verhindert die Polymerisation von DNA-Strängen) in Lösung I zugegeben und für $10 \mathrm{~min}$ bei $37^{\circ} \mathrm{C}$ inkubiert. Danach wurde aspiriert, mit Hanks-Lösung $+20 \%$ FBS rasch das verbleibende Trypsin neutralisiert, zweimal mit HanksLösung $+20 \%$ FBS gewaschen sowie dreimal mit serumfreier Hanks-Lösung gewaschen. Nach dem letzten Aspirieren wurden die Hippocampi in $2 \mathrm{ml}$ Lösung II und 0,25 mg/ml DNase resuspendiert und die Mischung zur mechanischen Dissoziation der Zellen durch zwei bis drei Pasteurpitten mit kleiner werdenden Öffnungsdurchmesser trituriert. Es wurde mit 3 
$\mathrm{ml}$ Hanks-Lösung + 20 FBS auf ein Volumen von $5 \mathrm{ml}$ aufgefüllt und für $10 \mathrm{~min}$ bei 1000 Upm $\left(4{ }^{\circ} \mathrm{C}\right)$ zentrifugiert. Der Überstand wurde verworfen, das Pellet in $2 \mathrm{ml}$ serumfreier Hanks-Lösung und $3 \mathrm{ml}$ Hanks-Lösung + 20 \% FBS resuspendiert und erneut unter den gleichen Bedingungen zentrifugiert. Der Überstand nach dem zweiten Zentrifugieren wurde verworfen und die Zellen in etwa $2 \mathrm{ml}$ Medium I aufgenommen. Die Zellen waren nun bereit zum Ausplattieren auf 18 mm-Deckgläser der Stärke 1 (Assistant), die sich in 12-Well-Mikrotiterplatten befanden. Zum Anwachsen der Gliazellen und der Neurone wurde vor der Präparation auf die Deckgläser $60 \mu \mathrm{l}$ Matrigel (1:50 in Medium I verdünnt) unter sterilen Bedingungen aufgetragen, für mindestens $2 \mathrm{~h}$ zur Polymerisation inkubiert, und anschließend der Überstand bis auf einen dünnen Film zur Adhäsion der Zellen aspiriert.

Auf die so vorbereiteten Deckgläser wurde jeweils 50-60 $\mu 1$ der Neuron-Suspension pipettiert und anschließend für 45-90 Minuten zum Absetzen der Zellen inkubiert. Sodann wurde zu den Zellen $1 \mathrm{ml}$ Medium I + 2 mM L-Glutamin (zur Förderung der Proliferation der Gliazellen) zugegeben. Nach zwei Tagen im Inkubator wurde das Kulturmedium fast vollständig gegen Medium II $+4 \mu \mathrm{M}$ Cytosinarabinosid (Mitoseblocker) getauscht.

Während der ersten beiden Wochen wurde die Hälfte des Kulturmediums zweimal wöchentlich und danach einmal wöchentlich gegen neues, vorher temperiertes Medium II ersetzt. Die Konzentration des Mitoseblockers wurde ab dem vierten Tag auf $2 \mu \mathrm{M}$ reduziert.

\subsubsection{Chromaffinzellenpräparation aus Nebennieren vom Rind}

Die Präparation der Chromaffinzellen vom Rind wurde in Anlehnung an [7] ausgeführt. Nach der Entnahme der Nebennieren wurden diese sofort mit 1x-Lockes-Lösung durch die Nebennierenvene aufgepumpt und bis zur Präparation so aufbewahrt.

$\mathrm{Zu}$ Beginn der Präparation wurde zunächst das umgebende Fettgewebe entfernt. Die Nebennieren wurden dann mit 1x-Lockes aufgepumpt und 5 min bei $37^{\circ} \mathrm{C}$ im Schüttelbad bewegt (bei blutigen Nebennieren wurde der Vorgang wiederholt). Anschließend wurde mit 51 Collagenase-Lösung aufgepumpt, 15 min bei $37{ }^{\circ} \mathrm{C}$ geschüttelt und diese beiden Vorgänge wiederholt. Die Nebennieren wurden dann aufgeschnitten, der helle Kern wurde herausgelöst und in einer Petrischale, gefüllt mit 1x-Lockes, mit dem Skalpell in 3-4 Stücke zerschnitten. Die Stücke wurden sodann durch einen $50 \mu \mathrm{m}$ Netzfilter gerieben, wobei immer genug 1xLockes-Lösung das Gewebe benetzte. Die so erhaltene Suspension von 30-40 ml wurde bei $700 \mathrm{Upm}$ und $20^{\circ} \mathrm{C}$ für 8 min zentrifugiert. Der Überstand wurde aspiriert, das Pellet mit 1xLockes resuspendiert und die Mischung erneut bei $700 \mathrm{Upm}$ und $20{ }^{\circ} \mathrm{C} 8 \mathrm{~min}$ zentrifugiert. Nach Aspiration des Überstands wurde das Pellet mit 14,7 ml 1x-Lockes resuspendiert und auf die Gradienten-Lösung (15,6 ml Percoll (Pharmacia LKB, Sweden) + 1,4 ml 10x-Lockes + $90 \mu 1$ 1M HCl; pH-Wert: 7,4; Osmolarität: 320 mmol/kg) gegeben. Diese wurde bei 13000 Upm, $20{ }^{\circ} \mathrm{C}$ für $20 \mathrm{~min}$ zentrifugiert. Anschließend wurden die Verunreinigungen vorsichtig verworfen, jeweils $20 \mathrm{ml}$ der Chromaffinzellfraktion mit $80 \mathrm{ml}$ 1x-Lockes verdünnt und die verdünnten Lösungen bei $700 \mathrm{Upm}, 20{ }^{\circ} \mathrm{C} 8$ min lang zentrifugiert. Nach Aspiration des 
Überstands wurde das Pellet mit 3-6 ml angereichertem DMEM-Medium resuspendiert. Die Mischung wurde dann mit einer Dichte von etwa 4400 Zellen $/ \mathrm{mm}^{2}$ auf Deckgläsern (Durchmesser: $25 \mathrm{~mm}$ ) in Multiwellplatten ausgesät. Auf die Deckgläser wurde langsam $2 \mathrm{ml}$ angereichertes DMEM-Medium zugegeben und bei $37{ }^{\circ} \mathrm{C}, 8 \% \mathrm{CO}_{2}$ und $90 \%$ Luftfeuchtigkeit im Brutschrank inkubiert.

\subsection{Verwendete Lösungen und Substanzen}

\section{Präparation der Chromaffinzellen}

- 10x-Lockes-Lösung: 1,54 mM NaCl, $56 \mathrm{mM} \mathrm{KCl,} \mathrm{8,5} \mathrm{mM} \mathrm{NaH} \mathrm{PO}_{4}, 21,5 \mathrm{mM} \mathrm{Na}_{2} \mathrm{HPO}_{4}$, 100 mM D-Glukose; pH 7,0.

- 1x-Lockes-Lösung: 10 ml 10x-Lockes +90 ml H $\mathrm{H}_{2} \mathrm{O}$; pH 7,4; Osmolarität: 300 mmol/kg.

- Collagenase (Seromed): 220-250 Einheiten $/ \mathrm{ml}(1 \mathrm{mg} / \mathrm{ml})$.

- Angereichertes DMEM Medium (Linaris): 2.2 g/1 NaHCO 3 , 4,5 g/1 D-Glukose, 1,028 g/1 L-Glutamin, $2 \mathrm{ml}$ Penicillin + Streptomycin (Seromed). Zu $100 \mathrm{ml}$ DMEM-Medium wurde $1 \mathrm{ml}$ Insulin-Transferrin-Selenium-X (ITS-X, Gibco BRL) gegeben und steril filtriert (keine Nitrozellulose-Filter, da sie Proteine absorbieren).

\section{Präparation der Hippocampusneurone}

- Medium: Minimales Essentielles Medium (MEM 51200-020 ohne Phenolrot, Gibco): Zusätze zu $500 \mathrm{ml}$ : 2,5 g Glucose, $100 \mathrm{mg} \mathrm{NaHCO}_{3}, 50 \mathrm{mg}$ Transferrin (616420, Calbiochem).

- Medium I (zur Anzucht): $100 \mathrm{ml}$ Medium enthielten $10 \% \mathrm{FBS}$, hitzeinaktiviert bei $57^{\circ} \mathrm{C}$ für $30 \mathrm{~min}, 1 \mathrm{ml}$ 0,2 M L-Glutamin-Lösung, 2,5 mg Insulin.

- Medium II (Langzeitmedium): $100 \mathrm{ml}$ Medium enthielten 5 \% FBS, hitzeinaktiviert bei $57^{\circ} \mathrm{C}$ für $30 \mathrm{~min}, 0,25 \mathrm{ml}$ 0.2 M L-Glutamin-Lösung, $2 \mathrm{ml} \mathrm{B-27-Supplement} \mathrm{(17504-010,}$ Gibco), $4 \mu \mathrm{M}$ oder $2 \mu \mathrm{M}$ Cytosinarabinosid (C6645, Sigma).

- Hank-Salzlösung: Hanks Salzlösung ohne Calcium oder Magnesium (H2387, Sigma) und zusätzlich 50mg/l $\mathrm{NaHCO}_{3}, 1$ mM HEPES; pH-Wert 7,3-7,4 (Einstellung mit NaOH).

- Hank's Salzlösung mit 20 \% FBS.

- Lösung II (zur Dissoziation der Zellen): Hanks Salzlösung + $12 \mathrm{mM} \mathrm{MgSO}_{4} \cdot 7 \mathrm{H}_{2} \mathrm{O}$

- Lösung I (zum Gewebeverdau): $137 \mathrm{mM} \mathrm{NaCl}, 5 \mathrm{mM} \mathrm{KCl}, 7 \mathrm{mM} \mathrm{Na} \mathrm{HPO}_{4}, 25 \mathrm{mM}$ HEPES; pH-Wert 7,2 (Einstellung mit $\mathrm{NaOH}$ ).

- FBS, fötales bovines Serum (Biochrom KG).

- Trypsin, Typ XI (T1005, Sigma).

- DNase Typ IV (D5025, Sigma).

- Matrigel (Beckton-Dickinson) 1:50 in Medium verdünnt.

\section{Intrazelluläre Pipettenlösung}


140 mM CsCl; 8 mM NaCl; 20 mM NaOH-HEPES; 2 mM ATP; 0,3 mM GTP; pH 7,2.

\section{Extrazelluläre Lösung für Chromaffinzellen}

$140 \mathrm{mM} \mathrm{NaCl} ; 2,8 \mathrm{mM} \mathrm{KCl} ; 2 \mathrm{mM} \mathrm{MgCl}$; $10 \mathrm{mM}$ NaoH-HEPES; $1 \mathrm{mM} \mathrm{CaCl} 2 ; \mathrm{pH}$ 7,2.

Extrazelluläre Lösung für hippocampale Neurone (modifizierte Tyrode Lösung)

$150 \mathrm{mM} \mathrm{NaCl} ; 4$ mM KCl; 2 mM MgCl $2 ; 2$ mM CaCl $2 ; 10$ mM Glukose; 10 mM HEPES; $\mathrm{pH}$ 7,4 .

Alle anderen Chemikalien wurden, sofern nicht anders angegeben, bei Sigma, Deutschland, gekauft. 


\section{Ergebnisse}

\subsection{Autofluoreszenz in Chromaffinzellen und hippocampalen Neuro- nen}

Zur Untersuchung der Fluoreszenzeigenschaften der endogenen Zellbestandteile wurden Chromaffinzellen aus dem Nebennierenmark von Rindern ( 2 Tage in Kultur) und hippocampale Neurone der Ratte (9 Tage in Kultur) bei den Anregungswellenlängen 488, 514, 543 und $633 \mathrm{~nm}$ untersucht. Die Fluoreszenz wurde $60 \mathrm{~s}$ lang mit einer Zeitauflösung von $10 \mu \mathrm{s}$ aufgenommen, wobei für jede Messung eine neue Zelle verwendet wurde. Für jeden Zelltyp erfolgte eine Unterscheidung zwischen Cytoplasma und Nucleus aufgrund ihrer unterschiedlichen Brechungsindizes. Die Laserstrahlintensität wurde durch Neutraldichtefilter auf annähernd gleiche Leistung bei den unterschiedlichen Anregungswellenlängen eingestellt. Eine Zusammenfassung der Ergebnisse ist in als Funktion der Anregungswellenlänge für Chromaffinzellen und hippocampale Neurone zeigt. Als generellen Trend für beide Zelltypen ist eine Abnahme der Fluoreszenzintensität mit höher werdender Anregungswellenlänge festzustellen sowie eine signifikant erniedrigte Autofluoreszenz des Nucleus im Vergleich zum Cytoplasma (mit einer Ausnahme bei $\lambda_{\text {exc }}=$ $543 \mathrm{~nm}$ in Chromaffinzellen).
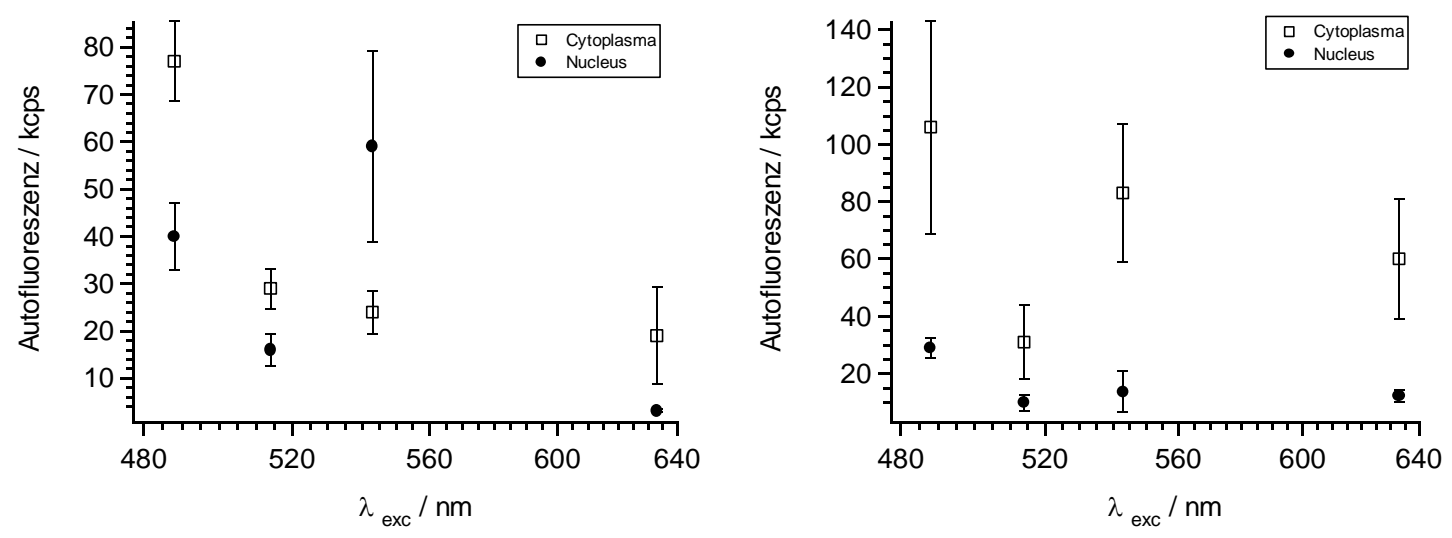

Abbildung 18: Initiale Autofluoreszenz in Abhängigkeit von der Anregungswellenlänge für Chromaffinzellen (links) und hippocampale Neurone (rechts), jeweils unterschieden für das Cytoplasma und den Nucleus (jeweils $n=9$; Leistung v.d. Objektiv: 57, 45, 44, $62 \mu \mathrm{W}(488,514,543,633 \mathrm{~nm}) A_{\text {det }} \approx$ $\left.2,0 \cdot 10^{-13} \mathrm{~m}^{2}\right)$

In allen Fluoreszenz-Zeit-Verläufen wurde nach Anschalten des Lasers ein durch Photozerstörungsreaktionen bedingter Abfall in der Fluoreszenzintensität festgestellt. Dieser konnte mit einem biexponentiellen Abfall gemäß

$$
F(t)=a_{0}+a_{1} \exp \left(-k_{1} t\right)+a_{2} \exp \left(-k_{2} t\right)
$$


beschrieben werden.

Die Berechnung der Autokorrelationsfunktion erfolgte in 81,92 ms großen Segmenten der Fluoreszenzspur, die jeweils $50 \%$ überlappten. Die Autokorrelationsfunktion der gesamten Fluoreszenzspur wurde aus dem arithmetischen Mittel der einzelnen Segmentautokorrelogramme gebildet. Die ersten $4 \mathrm{~s}$ des Fluoreszenz-Zeit-Verlaufs wurden aufgrund des hohen nichtstationären Anteils bei der Berechnung der Autokorrelationsfunktion vernachlässigt.

Bei der Betrachtung der individuellen Zeitverläufe der Autofluoreszenz und ihrer Autokorrelationsfunktionen wird ein grundsätzlicher Unterschied zwischen der Anregung bei 488 $\mathrm{nm}$ und den anderen Wellenlängen deutlich: bei $488 \mathrm{~nm}$ sind die Fluoreszenzfluktuationen nahezu unkorreliert (s. 'Ábbildung 1920' für eine Chromaffinzelle bzw. ein hippocampales Neuron), während bei den anderen Wellenlängen die Fluktuationen stark autokorrelieren (als Beispiel cf. 'Áb̄bildung 21 j. Zwischen Chromaffinzellen und hippocampalen Neuronen wurde insgesamt kein genereller Unterschied festgestellt.
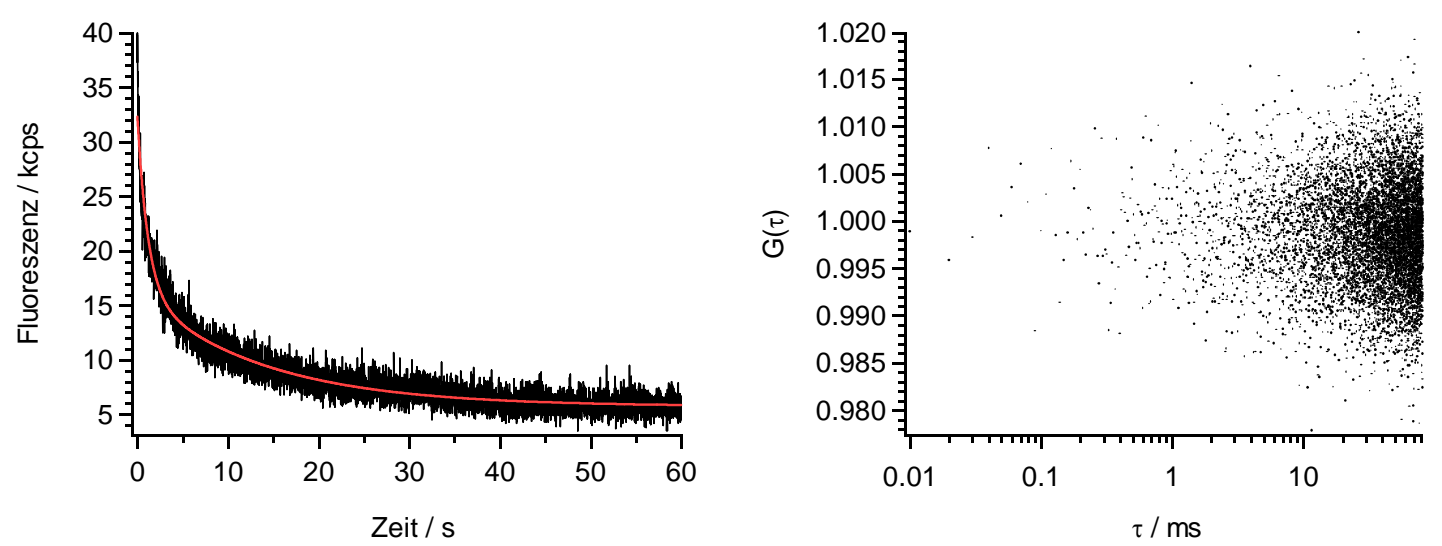

Abbildung 19: Autofluoreszenz einer Chromaffinzelle $\left(\lambda_{\mathrm{exc}}=488 \mathrm{~nm} ; P_{\mathrm{obj}}=57 \mu \mathrm{W} ; A_{\mathrm{det}} \approx 2,0 \cdot 10^{-13}\right.$ $\mathrm{m}^{2}$ ) sowie zugehörige Autokorrelationsfunktion. Der Fluoreszenz-Zeit-Verlauf wurde mit einem biexponentiellen Abfall angepaßt mit den Geschwindigkeitskonstanten u. Amplituden gemäß Gl. $a_{0}=5 \mathrm{kcps} ; k_{1}=0,86 \mathrm{~s}^{-1}(16 \mathrm{kcps})$ und $k_{2}=0,073 \mathrm{~s}^{-1}(10 \mathrm{kcps})$.

Bei der Anregungswellenlänge von $488 \mathrm{~nm}$ wurden in 21 von 23 Experimenten maximal eine Signalspitze innerhalb einer Experimentdauer von $60 \mathrm{~s}$ detektiert. In zwei Experimenten wurden 2 bzw. 3 Signalspitzen gefunden. Das häufige Auftreten der Signalspitzen, wie sie bei den anderen Wellenlängen detektiert wurde, konnte bei $488 \mathrm{~nm}$ nicht beobachtet werden. Bei der Anregungswellenlänge von $514 \mathrm{~nm}$ wurde in 16 von 24 Experimenten und bei $543 \mathrm{~nm}$ in allen 24 Experimenten zahlreich auftretende Signalspitzen beobachtet wie sie exemplarisch in Ābbildung 21 dargestellt sind. Bei $633 \mathrm{~nm}$ wurden entsprechende Signalspitzen in 12 von 24 Experimenten detektiert. 

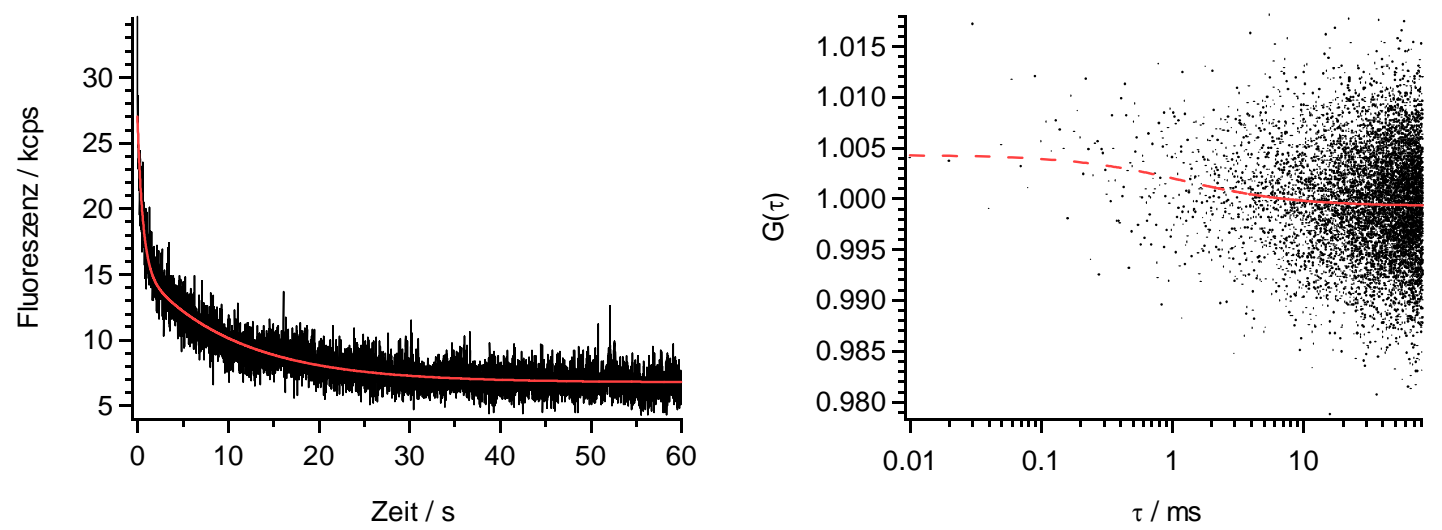

Abbildung 20: Autofluoreszenz in einem hippocampalen Neuron $\left(\lambda_{\mathrm{exc}}=488 \mathrm{~nm} ; P_{\mathrm{obj}}=57 \mu \mathrm{W} ; A_{\mathrm{det}} \approx\right.$ $2,0 \cdot 10^{-13} \mathrm{~m}^{2}$ ) und zugehörige Autokorrelationsfunktion mit Anpassung an das 3D-Diffusionsmodell $\left(\tau_{\mathrm{D}}\right.$ $\approx 1,2 \mathrm{~ms} ; N \approx 68)$. Der biexponentielle Fluoreszenzabfall wird beschrieben durch (Gl. 181$): a_{0}=6 \mathrm{kcps}$; $k_{1}=1,7 \mathrm{~s}^{-1}(11 \mathrm{kcps}) ; k_{2}=0,095 \mathrm{~s}^{-1}(8 \mathrm{kcps})$.

Die beobachteten Signalspitzen sind typisch für den Durchgang von einzelnen Molekülen durch das Detektionsvolumen (cf. Ábbildung 21 $(N=2,8)$ und Ábbildung $22:(N=1,0))$. Die Autokorrelationsamplitude ergibt folgerichtig Molekülzahlen in der Nähe von 1, wobei unkorrelierte Hintergrundfluoreszenz eine zu hohe Molekülzahl vortäuschen kann (cf. Kapitel: 2.3 .5 Hintergrundfluoreszenz).
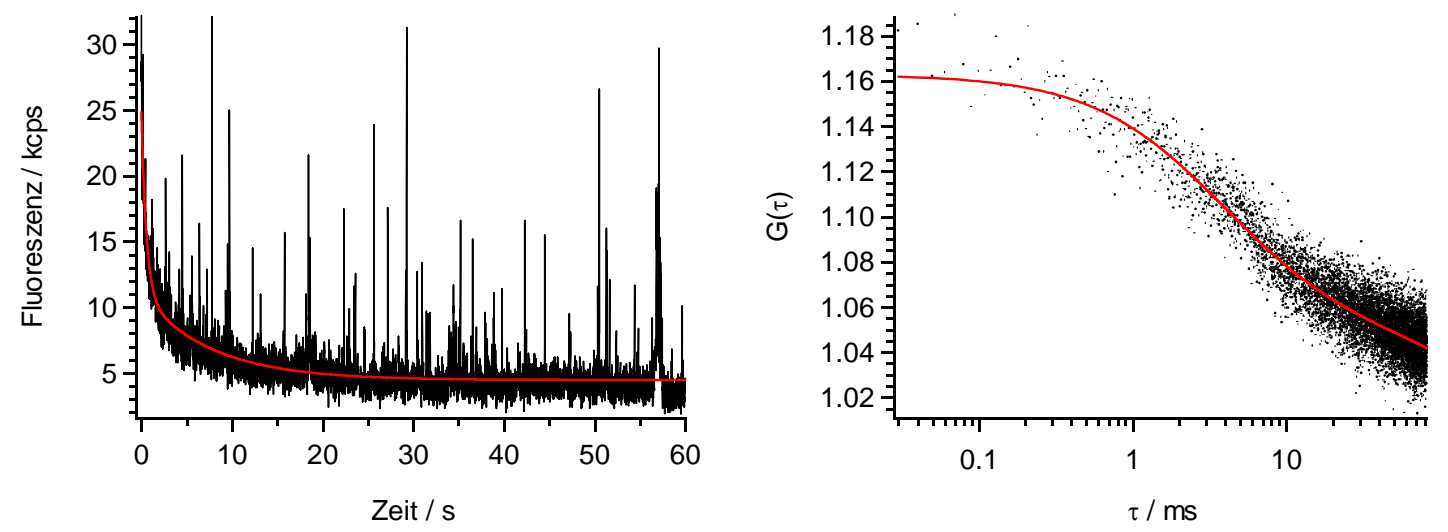

Abbildung 21: Autofluoreszenz einer Chromaffinzelle $\left(\lambda_{\mathrm{exc}}=514 \mathrm{~nm} ; P_{\mathrm{obj}}=45 \mu \mathrm{W} ; A_{\mathrm{det}} \approx 2,0 \cdot 10^{-13}\right.$ $\mathrm{m}^{2}$ ) und zugehörige Autokorrelationsfunktion mit Anpassung (Gl. $47 \mathrm{z}$ : $\tau_{\mathrm{D} 1}=3,9 \mathrm{~ms}(31 \%), \tau_{\mathrm{D} 2}=$ $1851 \mathrm{~ms} ; N=2,8$; Fluoreszenz-Zeit-Verlauf angepaßt mit G1. $181 ; a_{0}=4 \mathrm{kcps} ; k_{1}=1,8 \mathrm{~s}^{-1}(13 \mathrm{kcps})$ und $k_{2}=0,13 \mathrm{~s}^{-1}(6 \mathrm{kcps})$.

Eine Verringerung der Anregungsleistung reduzierte die Photozerstörung, hatte aber keine Auswirkungen auf das Auftreten der Signalspitzen (s. Abbildung $222 i$ gemessen bei zehnfach geringerer Anregungsleistung). Die Signalspitzen sind also nicht als Produkt von Photozerstörungsreaktionen anzusehen, sondern werden durch die Fluoreszenz endogener Zellbestandteile hervorgerufen. Aus der Analyse der Autokorrelationsfunktionen ergibt die Diffusion weniger Moleküle $N$ einen Diffusionskoeffizienten in der Größenordnung von etwa $3 \mu \mathrm{m}^{2} / \mathrm{s}$. 
Die Fluoreszenzanregung bei $\lambda_{\mathrm{exc}}=488 \mathrm{~nm}$ führte zu keiner nennenswerten Autokorrelation des Fluoreszenzsignals. Eine Bestimmung des Diffusionskoeffizienten der fluoreszierenden, endogenen Zellbestandteile bei dieser Wellenlänge wurde durch die Erholung der Fluoreszenz nach starker initialer Photozerstörung ausgeführt (FRAP-Experiment). Ein aus neun Experimenten gemittelter Zeitverlauf nach Beendigung der Photozerstörung ist in dargestellt. Die Anpassung aller FRAP-Experimente $(n=15)$ ergibt einen Diffusionskoeffizienten von insgesamt $D_{\text {autofl }}=(1,1 \pm 0,2) \cdot 10^{-3} \mu \mathrm{m}^{2} / \mathrm{s}$ (mittlerer Photozerstörungsparameter: $K$ $=4,8 \pm 0,8)$.
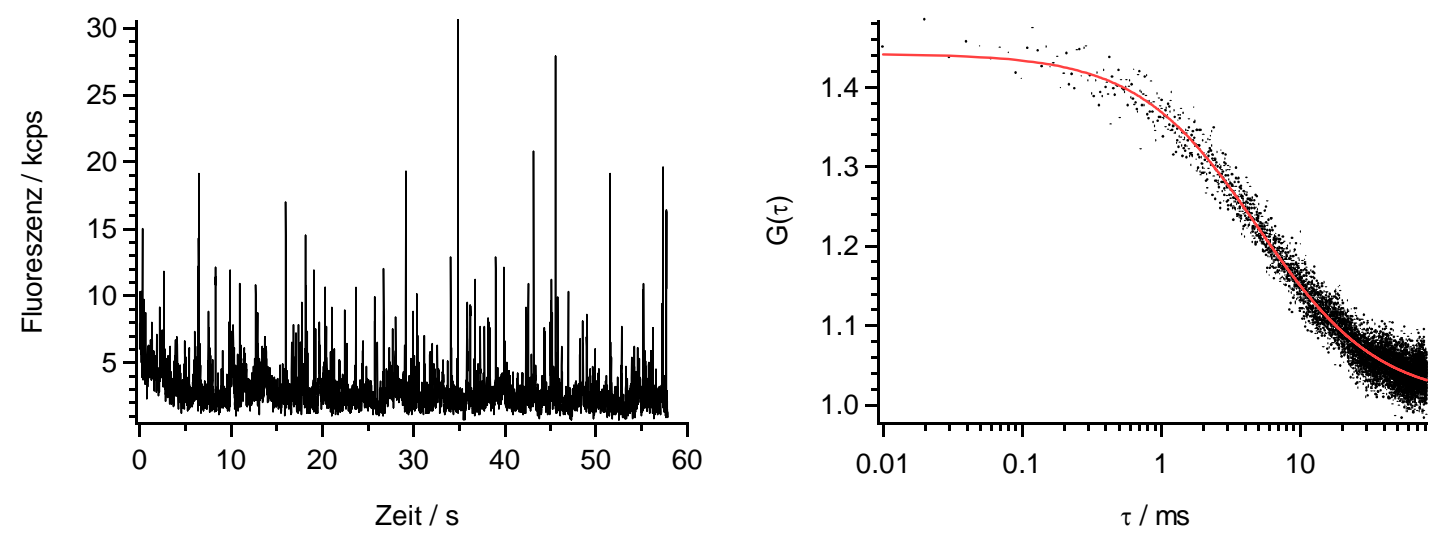

Abbildung 22: Fluoreszenz-Zeit-Verlauf in einem hippocampalen Neuron $\left(\lambda_{\text {exc }}=543 \mathrm{~nm} ; P_{\text {obj }}=4,3\right.$ $\mu \mathrm{W} ; A_{\text {det }} \approx 2,0 \cdot 10^{-13} \mathrm{~m}^{2}$ ) und zugehörige Autokorrelationsfunktion mit Anpassung an das 3D-Diffusionsmodell nach G1. $3 \underline{3}_{-1}^{i}\left(\tau_{\mathrm{D}}=5,0 \mathrm{~ms} ; N=1,0\right)$.

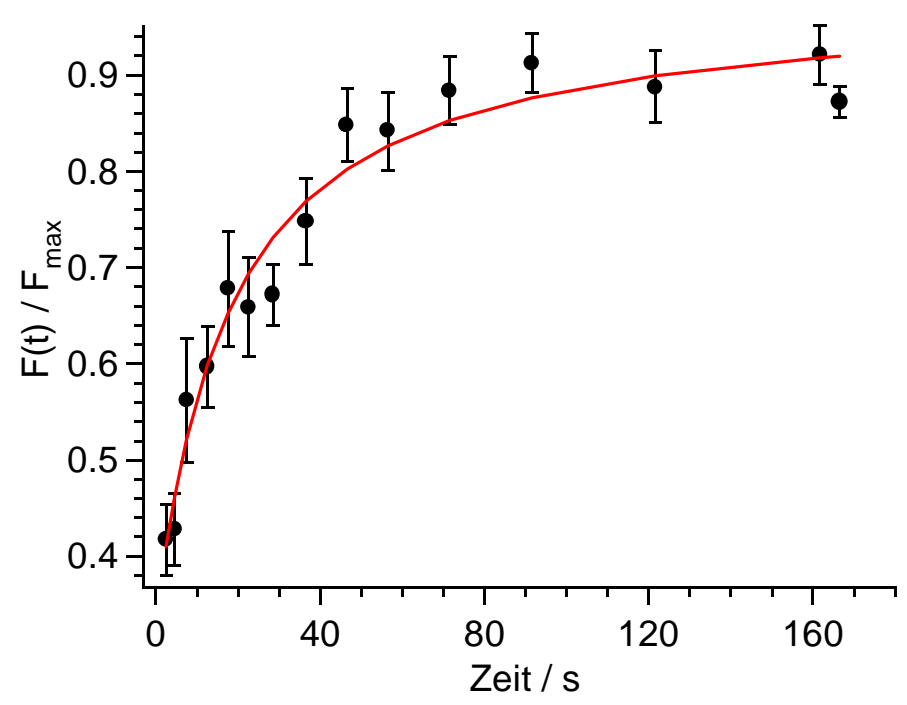

Abbildung 23: Mittlerer Fluoreszenz-Zeit-Verlauf $(n=9)$ nach Beendigung der Photozerstörung in einer Chromaffinzelle sowie Anpassung mit G1. störung wurde die ursprünglich vorhandene Fluoreszenz auf etwa $33 \%$ ihres Anfangsniveaus verringert $\left(\lambda_{\text {exc }}=488 \mathrm{~nm} ; P_{\text {bleich }}=4,3 \mathrm{~mW}\right)$. Bei $t=0$ wurde die Photozerstörung beendet und das Erholen der Fluoreszenz mit einer Leistung von $P_{\text {recov }}=10 \mu \mathrm{W}$ beobachtet. 


\subsection{Diffusion und Kinetik von Calciumfarbstoffen in einfachen Elek- trolyten und in Chromaffinzellen}

\subsubsection{Diffusion und Kinetik von Calciumfarbstoffen im Elektrolyten}

Die Farbstoffe Oregon Green 488 BAPTA-1 (OGB1) bzw. -BAPTA-2 (OGB2) erhöhen ihre Fluoreszenz nach $\mathrm{Ca}^{2+}$-Bindung und eignen sich deshalb zur Detektion von Calciumionen. Zur Detektion möglichst vieler kinetischer Fluktuationen, die durch das An- und Abbinden von Calciumionen an den Farbstoff hervorgerufen werden, wurde das Detektionsvolumen mit Hilfe des pankratischen Linsensystems (cf. Kapitel Experimenteller Aufbau) zur Variation des Laserstrahldurchmessers vergrößert, und damit die Aufenthaltsdauer des Moleküls im Detektionsvolumen erhöht. In Anstieg der Diffusionszeitkonstanten $\tau_{\mathrm{D}}$, die direkt mit dem Radius der fokalen Ebene des Detektionsvolumens verknüpft ist (Gl. $39 \overline{9})$, deutlich.
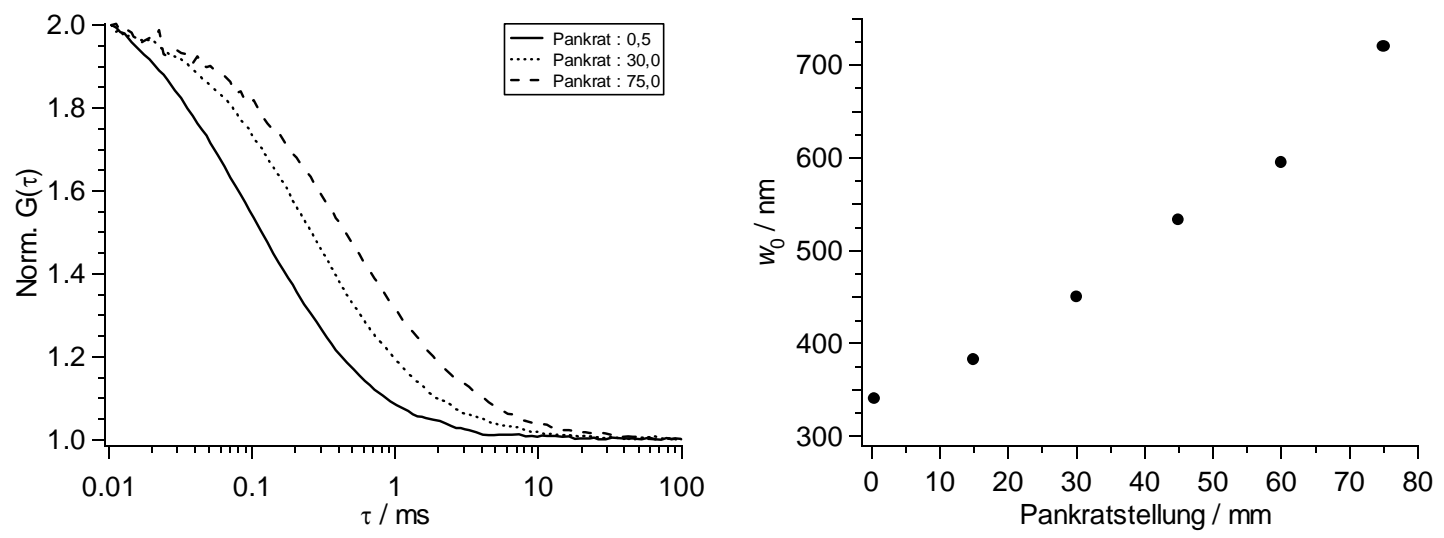

Abbildung 24: Normalisierte Autokorrelationskurven einer Lösung von $50 \mathrm{nM}$ Rh6G für verschiedene Stellungen des pankratischen Linsensystems zur Variation des Laserstrahldurchmessers (links) sowie die entsprechenden aus der Zeitkonstante $\tau_{\mathrm{D}}$ berechneten Radien des Detektionsvolumens $\left(w_{0}\right)$ in der fokalen Ebene (rechts).

Unter Verwendung des Calciumchelators BAPTA sowie unterschiedlicher Mengen an $\mathrm{CaCl}_{2}$ wurde das Reaktionsgleichgewicht zwischen $\mathrm{Ca}^{2+}$-freiem und -gebundenem Farbstoff variiert. Die Gleichgewichtskonzentration der Calciumionen $\left[\mathrm{Ca}^{2+}\right]_{\mathrm{eq}}$ in Anwesenheit von $40 \mathrm{nM}$ OGB1 bzw. OGB2 wurde mit Hilfe eines abteilungsinternen Makros von T. Xu berechnet.

Die Autokorrelationsfunktionen bei verschiedenen $\mathrm{Ca}^{2+}$-Konzentrationen wurden mit der Korrelatorkarte aus $120 \mathrm{~s}$ dauernden Messungen berechnet. 1Abbildung 25: zeigt einige Beispiele bei verschiedenen $\mathrm{Ca}^{2+}$-Gleichgewichtskonzentrationen des Farbstoffs OGB1.

Die Autokorrelationsfunktionen wurden mit Gl. ${ }_{1}^{5} 2$ Autokorrelationsfunktion $G_{\mathrm{D}}(\tau)$ wurde durch die vorher bestimmten Parameter der Diffusionszeit $\tau_{\mathrm{D}}$ und dem Verhältnis $z_{0} / w_{0}$ beschrieben, die während der Anpassung konstant gehalten wurden. Aus der Anpassung wurden für jede eingestellte $\mathrm{Ca}^{2+}$-Konzentration die 
Parameter $B$ (Anteil des Reaktionprozesses an der Autokorrelationsfunktionsamplitude), $R$ (effektive Geschwindigkeitskonstante des reaktionsbedingten Autokorrelationsabfalls) und die Autokorrelationsamplitude bestimmt. Für den Farbstoff OGB1 erfolgte eine Mittelung der Ergebnisse aus sieben Experimenten.

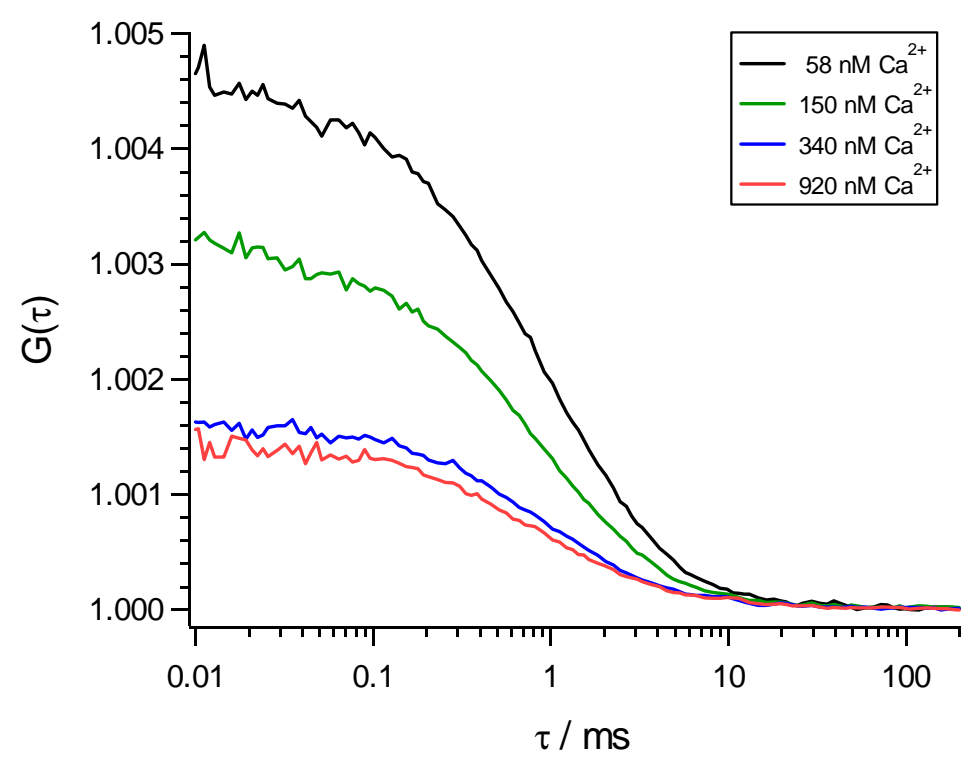

Abbildung 25: Autokorrelationskurven von 40 nM OGB1 in Anwesenheit verschiedener $\mathrm{Ca}^{2+}$-Gleichgewichtskonzentrationen.

Die Auftragung von $B$ als Funktion der eingestellten $\mathrm{Ca}^{2+}$-Konzentration ist für die Farbstoffe OGB1 und OGB2 in Ābobildung 26. dargestellt. Durch nichtlineare Kurvenanpassung mit G1. 53 w w w die Dsoziationskonstante des calciumgebundenen Farbstoffs $\left(K_{\mathrm{D}}\right)$ sowie das Verhältnis des Produktes aus Fluoreszenzquantenausbeute und Absorptionsquerschnitt der beiden Reaktionsprodukte des Farbstoffs $\left(Q=Q_{\mathrm{B}} / Q_{\mathrm{A}}\right)$ erhalten.

Ābobildung 27ì zeigt die Abhängigkeit der Geschwindigkeitskonstanten des reaktionsbedingten Autokorrelationsabfalls $R$ von der eingestellten $\mathrm{Ca}^{2+}$-Konzentration und die Anpassung von G1. $5 \overline{5}$ 'an die Punkte; hieraus ergaben sich die Geschwindigkeitskonstanten der Hinund Rückreaktion ( $k_{\text {ass }}$ bzw. $k_{\text {diss }}$ ).

Die $\left[\mathrm{Ca}^{2+}\right]_{\mathrm{eq}}$-Abhängigkeit der Autokorrelationsamplitude lieferte eine weitere Bestimmungsmöglichkeit von $K_{\mathrm{D}}$ und $Q$ durch Anpassung mit G1. 6161 und ist in 'Âbbildung 28 stellt. 

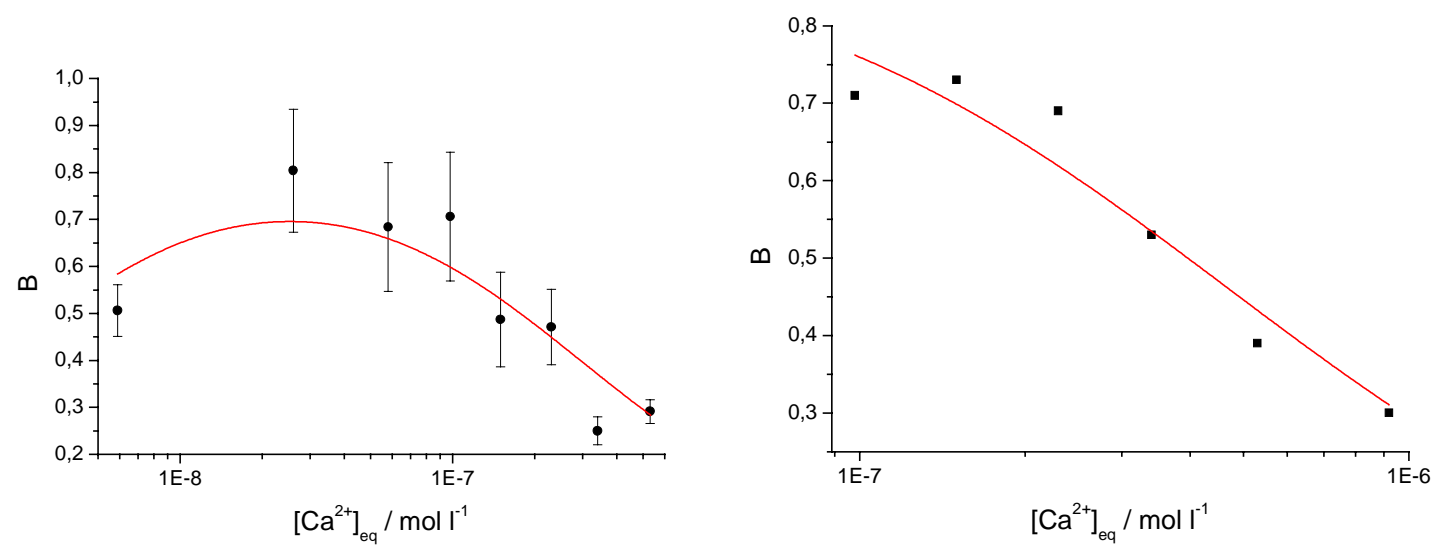

Abbildung 26: Der aus der Anpassung der Autokorrelationskurven erhaltene Parameter $B$ als Funktion der $\mathrm{Ca}^{2+}$-Gleichgewichtskonzentration für OGB1 $(\bullet)$ und OGB2 (घ). Die rot eingezeichneten Kurven zeigen die beste Anpassung der Funktionswerte in Gl. 53 imit folgenden Ergebnissen für OGB1: $K_{\mathrm{D}}=$ $(279 \pm 50) \mathrm{nM} ; Q=11 \pm 2$; und OGB2: $K_{\mathrm{D}}=(462 \pm 111) \mathrm{nM} ; Q=28 \pm 27$.
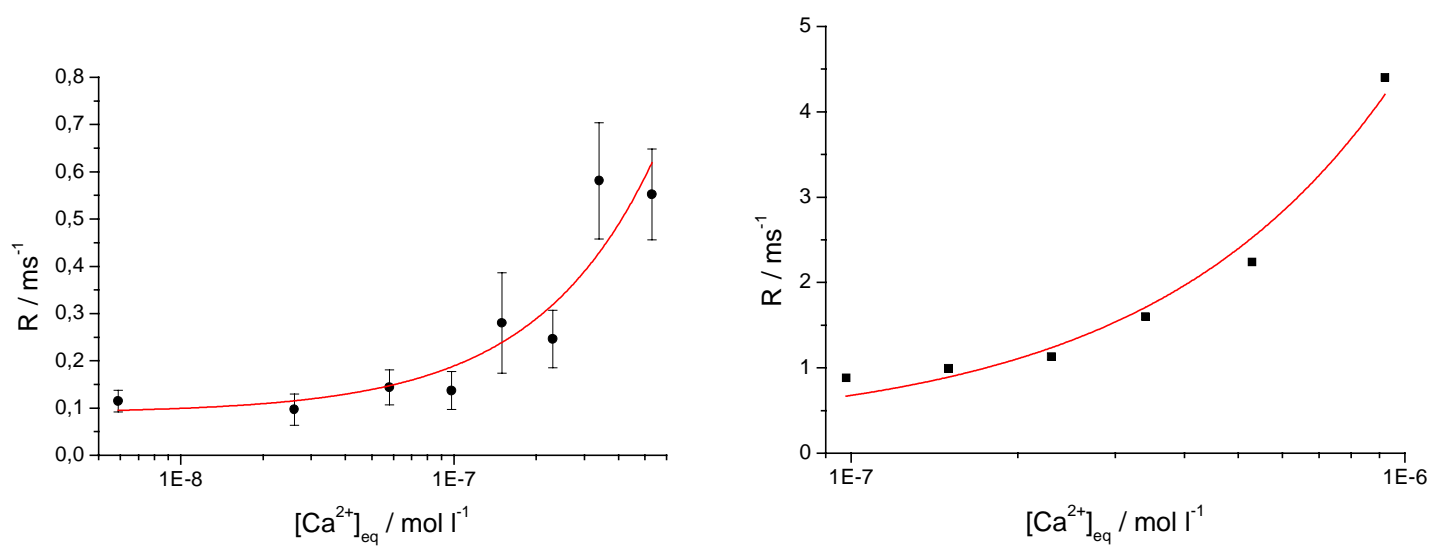

Abbildung 27: Auftragung des aus der Anpassung an die Autokorrelationskurven erhaltenen Parameters $R$ für verschiedene eingestellte $\mathrm{Ca}^{2+}$-Konzentrationen. Die Anpassungen mit Gl. $15 \overline{8}$ ergeben für OGB1 $(\bullet): k_{\text {ass }}=(1,0 \pm 0,2) \cdot 10^{9} 1 \mathrm{~mol}^{-1} \mathrm{~s}^{-1} ; k_{\text {diss }}=(89 \pm 41) \mathrm{s}^{-1} ;$ und für OGB2 $(\mathbf{\square}): k_{\text {ass }}=(4,3 \pm 0,3) \cdot 10^{9}$ $1 \mathrm{~mol}^{-1} \mathrm{~s}^{-1} ; k_{\text {diss }}=(247 \pm 153) \mathrm{s}^{-1}$. 

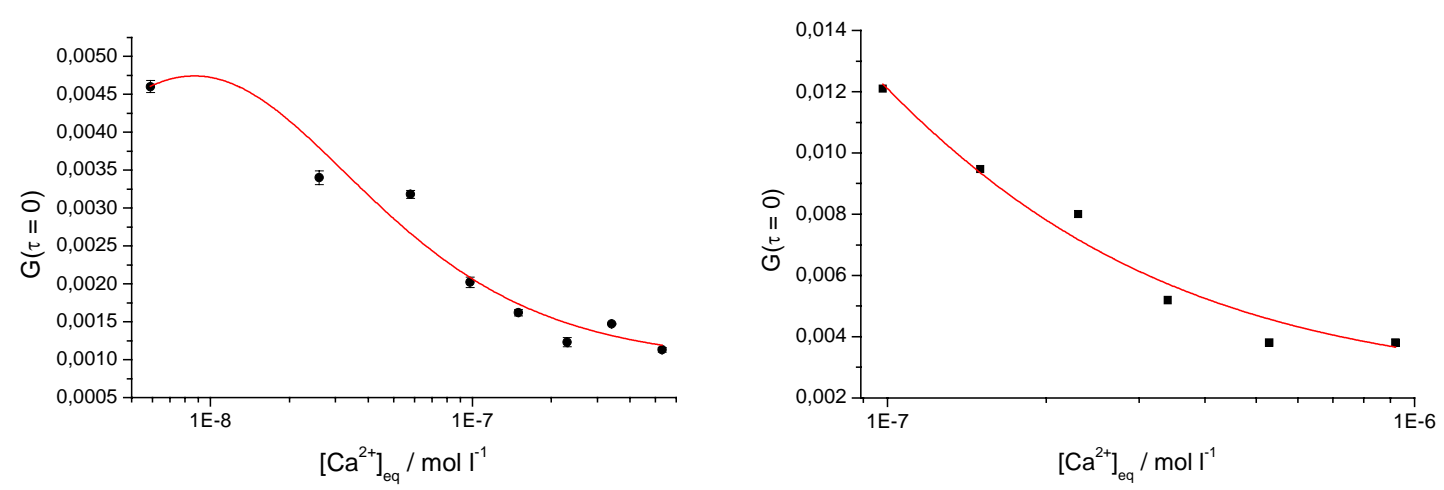

Abbildung 28: Auftragung der Autokorrelationsamplitude als Funktion der freien Calciumionenkon-

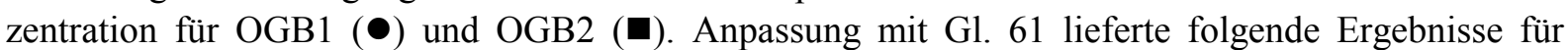
OGB1: $K_{\mathrm{D}}=(155 \pm 56) \mathrm{nM} ; Q=18 \pm 4$ und OGB2: $K_{\mathrm{D}}=(545 \pm 96) \mathrm{nM} ; Q=44 \pm 28$. Die eingesetzte Konzentration an OGB1 bzw. OGB2 (jeweils $c_{\text {ges }}=40 \mathrm{nM}$ ) sowie die Größe des Detektionsvolumens $\left(V_{\text {eff }}=1,86 \cdot 10^{-14} 1\right.$ bzw. $\left.V_{\text {eff }}=1,76 \cdot 10^{-14} 1\right)$ wurden als mit $20 \%$ fehlerbehaftet angenommen und in diesen Grenzen mitvariiert.

Die Diffusionskoeffizienten der Farbstoffe OGB1 und OGB2 jeweils im $\mathrm{Ca}^{2+}$-gebundenen und -freien Zustand wurden in Anwesenheit von $1 \mathrm{mM} \mathrm{CaCl}_{2}(n=7)$ bzw. 5 mM BAPTA ( $n$ $=7$ ) und Vergleich mit dem bekannten Diffusionskoeffizienten von Rhodamin 6G bestimmt.

Insgesamt ergeben sich für den Farbstoff OGB1 die folgenden aus sieben Experimenten gemittelten Ergebnisse (Mittelwert plus/minus Standardabweichung):

$$
\begin{aligned}
& K_{\mathrm{D}}=(241 \pm 46) \mathrm{nM} \\
& k_{\mathrm{ass}}=(9,9 \pm 1,5) \cdot 10^{8} 1 \mathrm{~mol}^{-1} \mathrm{~s}^{-1} \\
& k_{\mathrm{diss}}=(143 \pm 37) \mathrm{s}^{-1} \\
& Q=11,9 \pm 2,7 \\
& D_{\mathrm{OGB} 1}=(188 \pm 9) \mu \mathrm{m}^{2} / \mathrm{s}(5 \mathrm{mM} \mathrm{BAPTA}) \\
& D_{\mathrm{OGB} 1}=(202 \pm 10) \mu \mathrm{m}^{2} / \mathrm{s}\left(1 \mathrm{mM} \mathrm{CaCl}_{2}\right)
\end{aligned}
$$

Der Farbstoff OGB2 besitzt eine geringere Calciumaffinität und wird mit folgenden Parametern beschrieben:

$$
\begin{aligned}
& K_{\mathrm{D}}=(461 \pm 143) \mathrm{nM} \\
& k_{\text {ass }}=(3,0 \pm 1,3) \cdot 10^{9} 1 \mathrm{~mol}^{-1} \mathrm{~s}^{-1} \\
& k_{\text {diss }}=(420 \pm 135) \mathrm{s}^{-1} \\
& Q=28 \pm 24
\end{aligned}
$$




$$
\begin{aligned}
& D_{\mathrm{OGB} 2}=(225 \pm 12) \mu \mathrm{m}^{2} / \mathrm{s}(5 \mathrm{mM} \text { BAPTA }) \\
& D_{\mathrm{OGB} 2}=(239 \pm 9) \mu \mathrm{m}^{2} / \mathrm{s}\left(1 \mathrm{mM} \mathrm{CaCl}_{2}\right)
\end{aligned}
$$

\subsubsection{Farbstoffdiffusion in Chromaffinzellen}

Die Charakterisierung der Diffusionseigenschaften des calciumgebundenen und des calciumfreien Farbstoffs OGB1 in Chromaffinzellen wurde mit Hilfe der FCS-Technik untersucht. Im Unterschied zu den Experimenten in einer Lösung ohne Zellen war die optimale Position der Lochblende im Detektionsstrahlengang in einer Lösung mit Zellen eine leicht andere und wurde deshalb vor den Experimenten in der extrazellulären Lösung über den Zellen neu kalibriert. Die Ausmaße des Detektionsvolumens wurden ebenfalls in der extrazellulären Lösung über den Chromaffinzellen ermittelt durch ein FCS-Experiment des Diffusionsprozesses von Rhodamin 6G. Unter Annahme des Diffusionskoeffizienten von Rhodamin 6G von $\mathrm{D}_{\mathrm{Rh} 6 \mathrm{G}}=280 \mu \mathrm{m}^{2} / \mathrm{s}$; $[70]$ w w we der Radius des Detektionsvolumens in der fokalen Ebene $w_{0}$ und in der axialen Richtung $z_{0}$ berechnet (G1. 38 u. 139 ). Ohne die Nachjustierung der Lochblendenposition wären $w_{0}$ und $z_{0}$ ungefähr einen Faktor zwei größer gewesen.

Die Chromaffinzellen wurden mittels einer Patchpipette entweder mit dem calciumgesättigten Farbstoff (in Anwesenheit von $100 \mu \mathrm{M} \mathrm{CaCl}_{2}$ in der Pipettenlösung) oder dem calciumfreien Farbstoff (mit 1-3 mM BAPTA in der Pipettenlösung) beladen. Dazu wurden der Pipettenlösung $100 \mathrm{nM}$ OGB1 zugesetzt, und in der whole-cell-Konfiguration (nähere Details im Methodenteil) die Zelle auf ein Potential von $-70 \mathrm{mV}$ geklemmt.

Durch die Pufferung der freien Calciumionenkonzentration wurden kinetische Fluktuationen, die durch das Reaktionsgleichgewicht zwischen calciumfreiem und calciumgebundenem Farbstoff hervorgerufen werden, verringert. Die Autokorrelationsfunktion reaktionsbedingter Fluktuationen (G1. 152) wird durch die Geschwindigkeitskonstante des reaktionsbedingten Abfalls der Autokorrelationsfunktion $R$ (G1. 58 i) und der Amplitude $B$ (G1. 53 i) beschrieben. Mit den im vorherigen Kapitel bestimmten Geschwindigkeitskonstanten $k_{\text {ass }}=9,9 \cdot 10^{8} 1 \mathrm{~mol}^{-1}$ $\mathrm{s}^{-1}$ und $k_{\text {diss }}=143 \mathrm{~s}^{-1}$ beträgt die Zeitkonstante $1 / R$ im Falle des calciumfreien Farbstoff (3 mM BAPTA; $\left.\left[\mathrm{Ca}^{2+}\right]_{\mathrm{eq}}=0,05 \mathrm{nM}\right) 1 / R_{\mathrm{frei}}=7 \mathrm{~ms}$ und die Amplitude $B=0,04$. In Anwesenheit von $\left[\mathrm{Ca}^{2+}\right]=100 \mu \mathrm{M}$ betragen die Werte $1 / R_{\text {geb }}=10 \mu$ s und $\mathrm{B}=0,001$. Im Falle der Pufferung der freien Calciumionenkonzentration sind die Autokorrelationsamplituden der Reaktion mit 4 bzw. 0,1 \% gegenüber denen der Diffusion vernachlässigbar klein und spielen daher für die folgenden Diffusionsexperimente keine Rolle.

Ein Beispiel für das Einwaschen von $100 \mathrm{nM} \mathrm{Ca}^{2+}$-freiem OGB1 (3 mM BAPTA) in den Nucleus einer Chromaffinzelle vom Beginn der on-cell- $(t=0)$ über die whole-cell-Konfiguration $(t=20 \mathrm{~s})$ bis zum Gleichgewicht zwischen Zelle und Patchpipette ist in dargestellt. Die Probe wurde anschließend $10 \mathrm{~s}$ lang belichtet und das Fluoreszenzsignal mit einer Zeitauflösung von $10 \mu$ s mittels der Zählkarte aufgenommen (cf. 'Ā 
Fluoreszenz-Zeit-Verlauf wurde nach Beendigung des Experiments autokorreliert und die theoretische Autokorrelationsfunktion für translative Diffusion (Gl. 138) angepaßt (cf. Âbbildung 29. d). Während der gesamten Dauer des Experiments wurde der Strom $I$ und die

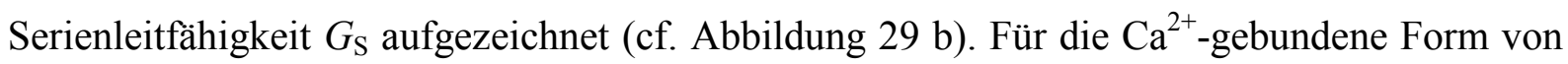
OGB1 ist ein Beispiel in Âbbildung 30izusammengestellt.

$\mathbf{a}$

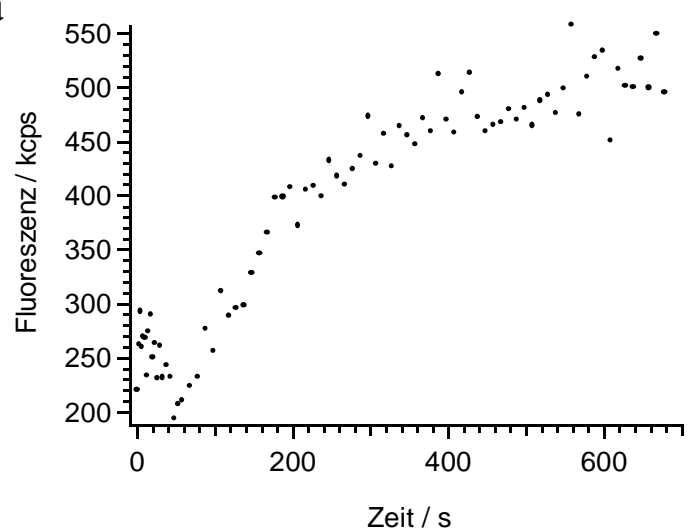

c

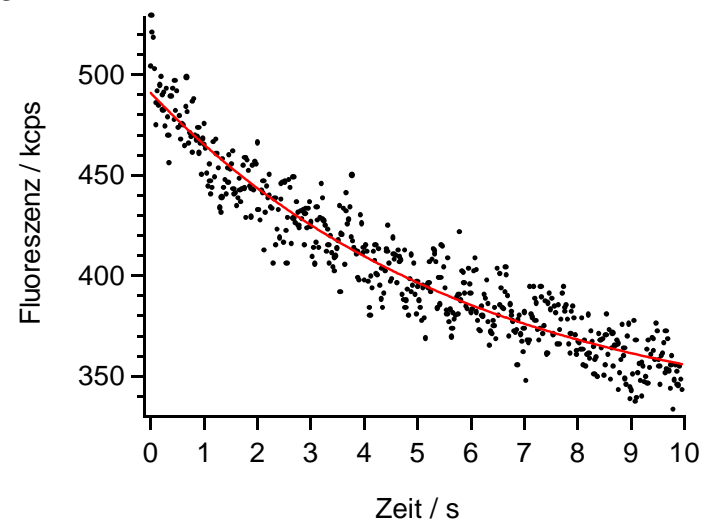

b

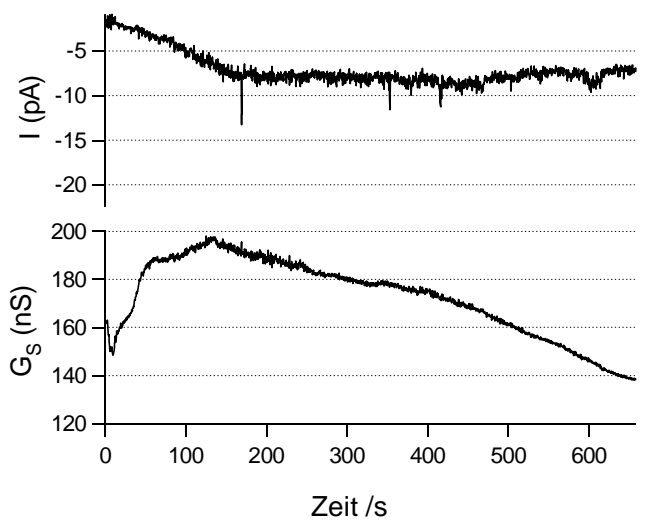

d

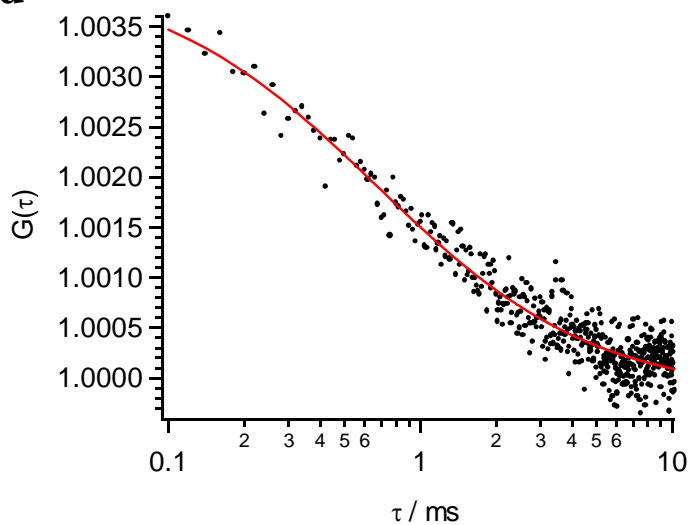

Abbildung 29 a: Einwaschkurve von 100 nM OGB1 ( 3 mM BAPTA) in den Nucleus einer Chromaffinzelle. Beginnend mit der on-cell-Konfiguration bei $t=0$ über die whole-cell-Konfiguration bei $t=$ $20 \mathrm{~s}$ wurde schließlich das Einwaschen des Farbstoffs in die Zelle erreicht. b: Der Strom $I$ und Serienleitfähigkeit $G_{\mathrm{S}}$ vom Beginn der Ganzzellableitung bis zum Ende des FCS-Experiments. c: Fluoreszenz-Zeit-Verlauf $\left(\lambda_{\text {exc }}=488 \mathrm{~nm} ; P_{\text {obj }}=50 \mu \mathrm{W}\right)$ zur Berechnung der Autokorrelationsfunktion und Anpassung mit monoexponentiellem Fluoreszenzabfall $\left(a_{0}=324 \mathrm{kcps} ; a_{1}=166 \mathrm{kcps} ; k_{1}=0,168 \mathrm{~s}^{-1}\right)$. d: Autokorrelationsfunktion und Anpassung mit dem 3D-Diffusionsmodell nach G1. $138:-\tau_{\mathrm{D}}=0,64 \mathrm{~ms}$. 
$\mathbf{a}$

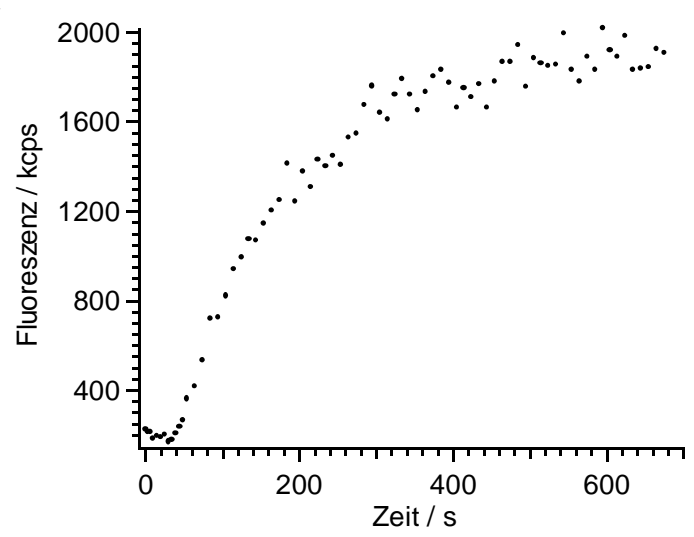

c

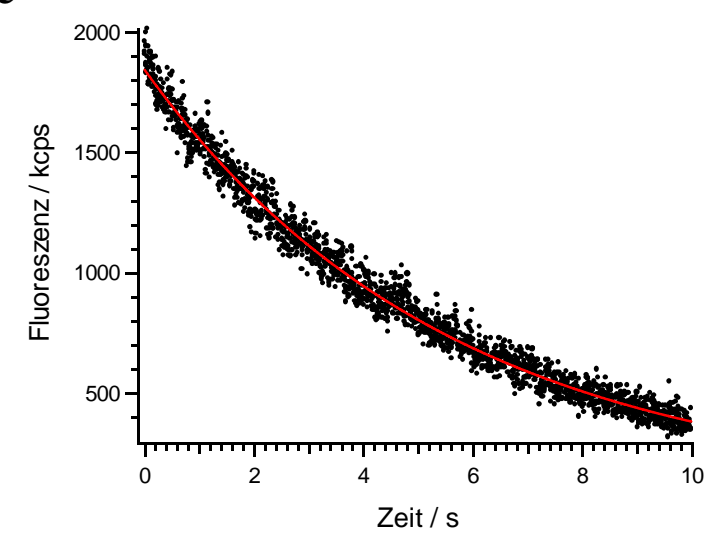

b
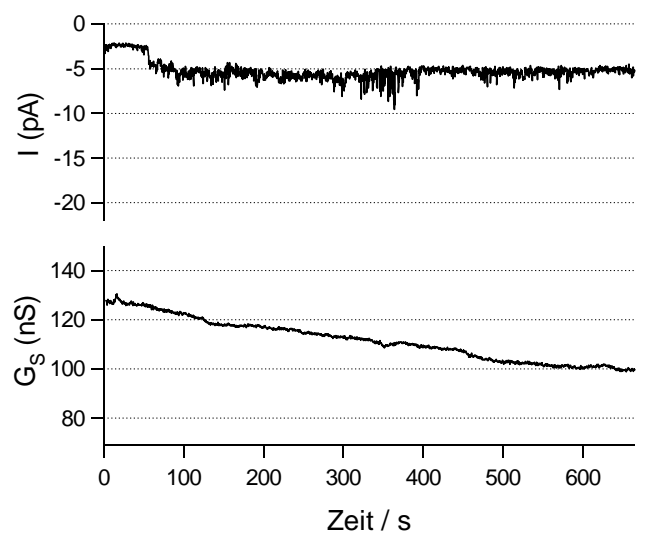

d

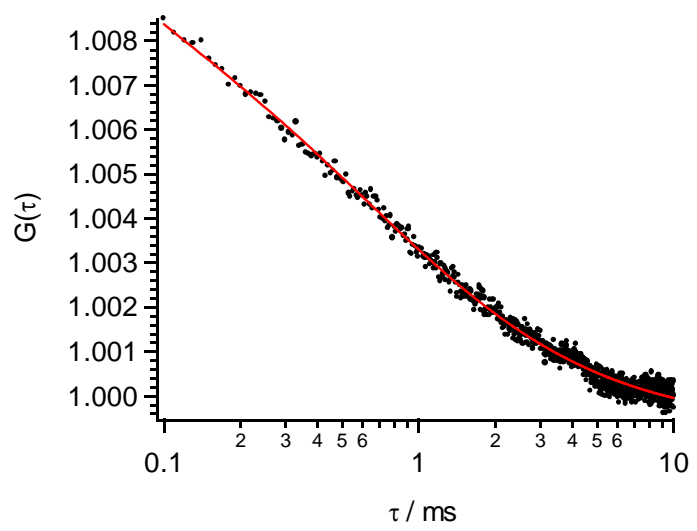

Abbildung 30: a: Einwaschkurve von $100 \mathrm{nM}$ OGB1 $\left(100 \mu \mathrm{M} \mathrm{CaCl}_{2}\right)$ in den Nucleus einer Chromaffinzelle. On-cell-Konfiguration bei $t=0$; whole-cell-Konfiguration bei $t=15 \mathrm{~s}$. b: Der Strom $I$ und Serienleitfähigkeit $G_{\mathrm{S}}$ vom Beginn der Ganzzellableitung bis zum Ende des FCS-Experimentes. c: Fluoreszenz-Zeit-Verlauf ( $\left.\lambda_{\mathrm{exc}}=488 \mathrm{~nm} ; P_{\mathrm{obj}}=50 \mu \mathrm{W}\right)$ zur Berechnung der Autokorrelationsfunktion und Anpassung mit monoexponentiellem Fluoreszenzabfall $\left(a_{0}=91 \mathrm{kcps} ; a_{1}=1762 \mathrm{kcps} ; k_{1}=\right.$ $\left.0,180 \mathrm{~s}^{-1}\right) . \mathbf{d}$ : Autokorrelationsfunktion und Anpassung mit dem 3D-Diffusionsmodell nach Gl. 3 $=0,71 \mathrm{~ms}$.

Eine weitere Abschwächung der Anregungsintensität von $P_{\mathrm{obj}}=50$ auf $12 \mu \mathrm{W}$ führte zur Verringerung der Photozerstörungsreaktionen. Der kontinuierliche Fluoreszenzabfall während der Messungen wurde dadurch vermieden. Allerdings mußte aufgrund der geringeren Photonenzahl pro Molekül die Meßdauer verlängert werden. eine Messung im Nucleus einer Chromaffinzelle in Anwesenheit von $2 \mu$ M OGB1.

Im Cytoplasma erfolgte nach Einschalten des Lasers regelmäßig zunächst ein schneller nach wenigen Sekunden abgeschlossener Fluoreszenzabfall, der bei der Berechnung Autokorrelationsfunktion aufgrund des hohen nichtstationären Fluoreszenzsignals vernachlässigt wurde. 

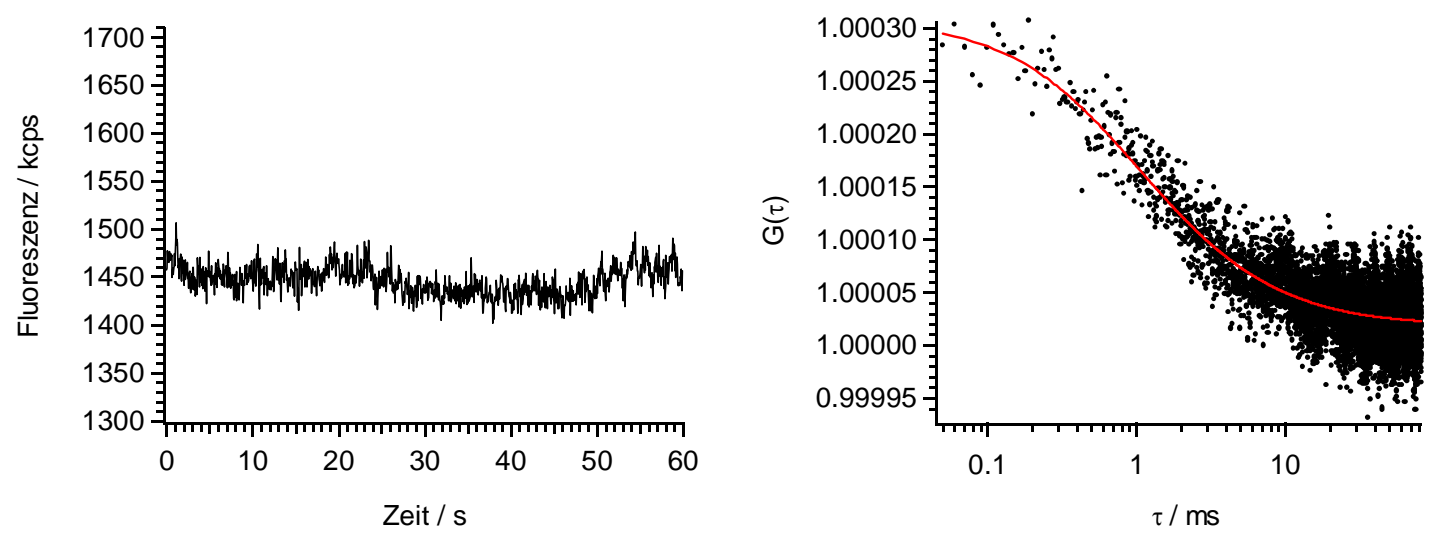

Abbildung 31: Fluoreszenz-Zeit-Verlauf im Nucleus einer Chromaffinzelle $\left(\lambda_{\mathrm{exc}}=488 \mathrm{~nm} ; P_{\mathrm{obj}}=50\right.$ $\mu \mathrm{W}$ ) in Anwesenheit von $2 \mu \mathrm{M}$ OGB1 (5 mM BAPTA) und die zugehörige Autokorrelationsfunktion $\left(\tau_{\mathrm{D} 1}=0,98 \mathrm{~ms}(91 \%), \tau_{\mathrm{D} 2}=5,6 \mathrm{~ms}(9 \%) ; N=1226\right)$
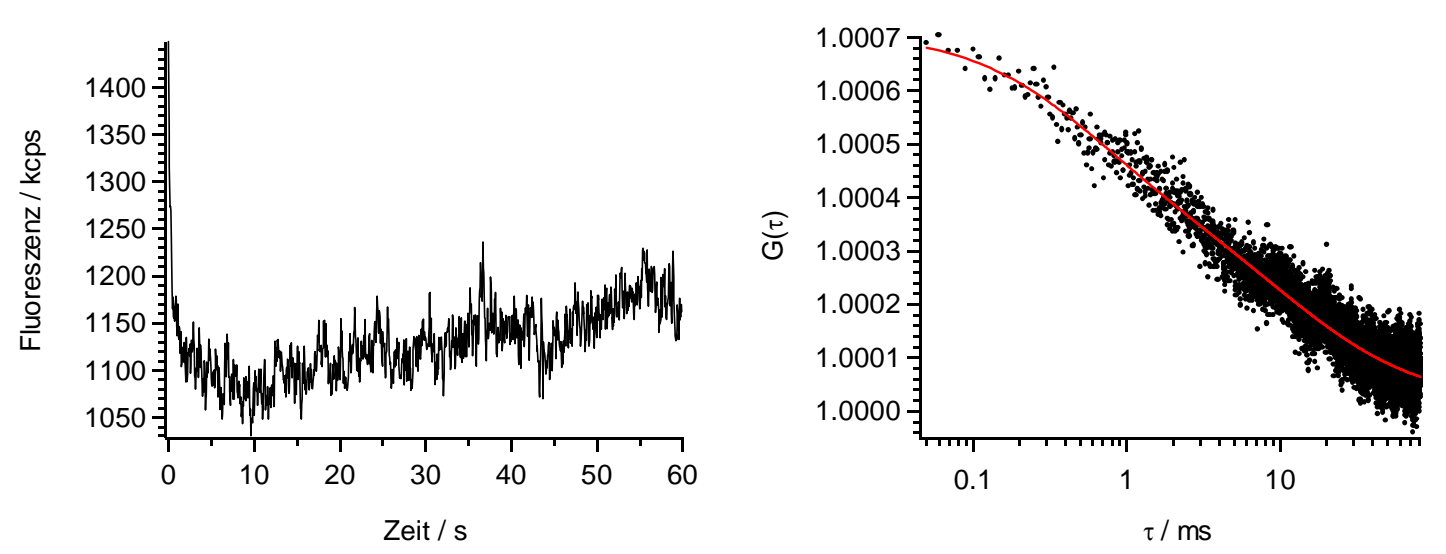

Abbildung 32: Fluoreszenz-Zeit-Verlauf im Cytoplasma einer Chromaffinzelle $\left(\lambda_{\mathrm{exc}}=488 \mathrm{~nm} ; P_{\mathrm{obj}}=\right.$ $50 \mu \mathrm{W}$ ) in Anwesenheit von $2 \mu \mathrm{M}$ OGB1 (5 mM BAPTA) und die zugehörige Autokorrelationsfunktion $\left(\tau_{\mathrm{D} 1}=0,60 \mathrm{~ms}(51 \%) ; \tau_{\mathrm{D} 2}=13,6 \mathrm{~ms}(49 \%) ; N=511\right)$.

Zusammengefaßt wurden folgende Ergebnisse für die Diffusionskoeffizienten des $\mathrm{Ca}^{2+}$-gebundenen $\left(D_{\mathrm{geb}}\right)$ und $\mathrm{Ca}^{2+}$-freien Farbstoffs $\left(D_{\text {frei }}\right)$ OGB1 in Chromaffinzellen erhalten:

Nucleus:

$$
\begin{aligned}
& D_{\text {geb }}=(99 \pm 14) \mu \mathrm{m}^{2} / \mathrm{s}(n=12) \\
& D_{\text {frei }}=(92 \pm 10) \mu \mathrm{m}^{2} / \mathrm{s}(n=12)
\end{aligned}
$$

Cytoplasma:

$$
\begin{aligned}
& D_{\text {geb }}=(51 \pm 12) \mu \mathrm{m}^{2} / \mathrm{s}(n=5) \\
& D_{\text {frei }}=(33 \pm 5) \mu \mathrm{m}^{2} / \mathrm{s}(n=8)
\end{aligned}
$$




\subsection{Benzodiazepin-Rezeptor-Wechselwirkung in der Membran hippo- campaler Neurone}

Zur Untersuchung der Wechselwirkung des Benzodiazepin-Derivates Ro 07-1986/602 mit seinem Rezeptor in der Zellmembran von hippocampalen Neuronen mußte das Benzodiazepin zunächst mit einem Farbstoff gekoppelt werden. Insgesamt wurden hierzu die vier Farbstoffe Tetramethylrhodamin (TMR), Fluorescein, Oregon-Green 488 und Alexa 532 verwendet und die Eigenschaften der einzelnen farbstoffmarkierten Liganden untersucht.

Zur Synthese der farbstoffmarkierten Benzodiazepine (im Partnerlabor) wurde der Farbstoff in aktivierter Form als Succinimidylester eingesetzt und mit der primären Amingruppe des Ro 07-1986/602 zur Reaktion gebracht (Mechanismus der Reaktion in Á Ábildung 333). Zwischen dem Benzodiazepin und dem Farbstoff wurde soweit möglich ein Spacer eingefügt, um einen denkbaren Einfluß des Farbstoffs auf das Bindungsverhalten des Benzodiazepins zu minimieren. Das entstehende Reaktionsprodukt wurde mittels HPLC unter Verfolgung des UV-Spektrums abgetrennt. Nähere Details zur Synthese und Reinheitsbestimmung sind in [7]

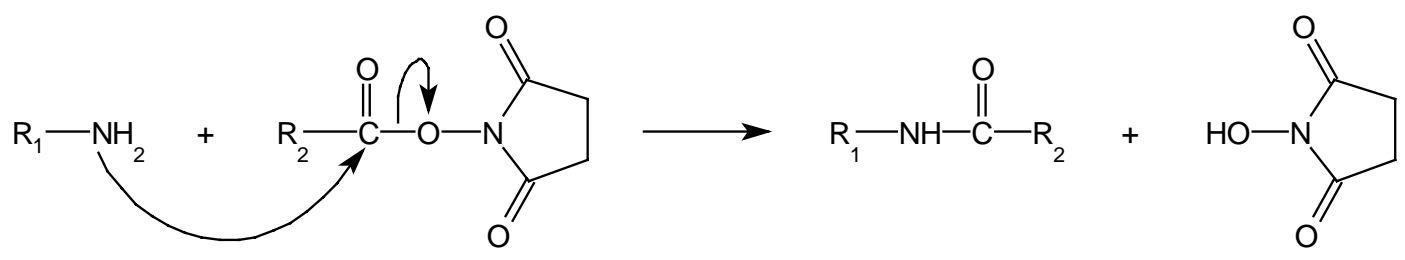

Abbildung 33: Reaktionsmechanismus zur Kopplung der primären Amingruppe des Benzodiazepins Ro 07-1986/602 $\left(\mathrm{R}_{1}\right)$ mit dem aktivierten Farbstoffmoleküls $\left(\mathrm{R}_{2}\right)$.

Die Strukturformeln der (im Partnerlabor) synthetisierten farbstoffmarkierten Liganden sind in Äbbildung 35. zusammengestellt. Da eine Beeinflussung des Farbstoffrestes auf die Benzodiazepin-Rezeptor-Bindung nicht auszuschließen war, wurde zunächst die Funktionalität der farbstoffmarkierten Liganden überprüft. Dazu wurde die Bindung des farbstoffmarkierten Liganden an einen polyklonalen Benzodiazepin-Antikörper (Nr. 11005004, Biotrend) und an den Benzodiazepin-Rezeptoren in der Zellmembran hippocampaler Neurone untersucht. Die Experimente mit dem Benzodiazepin-Antikörper hatten den Vorteil, daß sie einfach und schnell in wäßriger Lösung auszuführen waren. $\mathrm{Zu}$ dem in Lösung vorliegenden Antikörper wurden verschiedene Konzentrationen von Ro-TMR gegeben und der Anteil des am Antikörper gebundenen sowie des ungebundenen Liganden bestimmt. Beide konnten durch ihre unterschiedlichen Diffusionszeiten deutlich voneinander unterschieden werden. Eine Verdrängung des am Antikörper gebundenen Liganden wurde durch einen Überschuß an unmarkiertem Benzodiazepin vorgenommen. Dieses im Vergleich zu den Ligand-RezeptorenMessungen in der Zellmembran einfachere System konnte somit einen ersten Hinweis auf einen möglichen Funktionalitäts-Verlust des Ro 07-1986/602 durch die Kopplung mit dem Farbstoff geben [78, 79$]$. 
Der zuerst synthetisierte Ligand mit Tetramethylrhodamin als Farbstoff (Ro-TMR) zeigte eine Bindung zum Benzodiazepin-Antikörper. Mit ansteigenden Ro-TMR-Konzentrationen ließ sich die Antigen-Antikörper Bindung sättigen. Durch eine Vorinkubation mit einem unmarkierten Benzodiazepin konnte die Bindung des farbstoffmarkierten Liganden verhindert werden. Das Ro-TMR wird also durch den Antikörper spezifisch erkannt [78, 79].

Die spezifische Bindung an den Benzodiazepin-Rezeptoren in der Zellmembran hippocampaler Neurone konnte allerdings nicht nachgewiesen werden, da sich das Ro-TMR unspezifisch in hohen Konzentrationen in der Zellmembran angereichert hat. Am BenzodiazepinRezeptor gebundenes TMR-Ro konnte deshalb nicht vom vielfach höheren nichtspezifischen Bindungsanteils unterschieden werden.

Zur Vermeidung der unspezifischen Einlagerung des farbstoffmarkierten Liganden in die Zellmembran der Neurone, wurde das Ro 07-1986/602 deshalb mit dem hydrophilen Farbstoff Fluorescein gekoppelt (Strukturformel des Ro-Fluorescein in iÂbilidung 35. Ligand wies keine oder nur eine sehr geringe unspezifische Membranbindung auf, zeigte allerdings sowohl zum polyklonalen Benzodiazepin-Antikörper als auch zu den Benzodiazepin-Rezeptoren in der Zellmembran keine Bindung. Das gleiche Verhalten wurde mit Ro 071986/602 gekoppelt an das polare Farbstoffmolekül Oregon-Green 488 beobachtet [78,

Ein Vergleich der ähnlichen Strukturformeln des funktionellen Ro-TMR mit den nichtfunktionellen des Ro-Fluorescein und Ro-Oregon-Green ließen einen möglichen Einfluß der stark elektronegativen Gruppen an den Kohlenstoffatomen C-3 und C-6 des Farbstoffrestes auf das Bindungsverhalten des Benzodiazepins vermuten (Vergleich der Strukturformeln in Ábbildung 35). Darauf wurde das Ro 07-1986/602 mit dem polaren Farbstoff Alexa 532 gekoppelt. Dieser Ligand Ro-Alexa zeigte eine spezifische Bindung zum BenzodiazepinAntikörper membran hippocampaler Neurone soll im folgenden näher dargelegt werden.

Für die FCS-Experimente wurden 8 bis 15 Tage alte hippocampale Neurone verwendet. Ein einzelnes Neuron wurde durch Verschieben des Mikroskoptisches zum Ort des Laserstrahls bewegt und durch das Soma des Neurons ein Fokusscan entlang der optischen Achse ausgeführt. Wie in Âbilang 34 dargestellt (schwarze Kurve) kommt es beim Durchtritt des Laserstrahls an der Grenzfläche Deckglas/extrazelluläre Lösung zur einer Dispersion des Laserlichts, die zu einer erhöhten Fluoreszenz führt (6,206 mm). Nach dem Durchtritt durch die Grenzfläche fällt die Fluoreszenz wieder ab, und es wird die Zellautofluoreszenz des Cytoplasmas detektiert. Wird der Fokus weiter nach oben bewegt, so wird die Zelle schrittweise wieder verlassen (6,212-6,214 mm), und es folgt schließlich die Fluoreszenz der extrazellulären Lösung ( $>6,215 \mathrm{~mm}$ ). Nach Beendigung des Fokusscans wurde die fokale Ebene des Laserstrahls auf den halben Wert des Fluoreszenzabfalls der oberen Zellmembran positioniert $(6,213 \mathrm{~mm})$. Dies entspricht einer Meßkonfiguration, in der sich die fokale Ebene in der Zellmembran des Neurons befindet. Die untere Hälfte des Detektionsvolumens liegt innerhalb der Zelle und die obere Hälfte des Detektionsvolumens ragt in die extrazelluläre Lösung 
hinein. In dieser Meßkonfiguration erfolgte die Fluoreszenzdetektion für 120 Sekunden mit zeitgleicher Berechnung der Autokorrelationsfunktion durch den Hardwarekorrelator.

Ein typischer Fluoreszenz-Zeit-Verlauf mit dazugehöriger Autokorrelationskurve eines unbehandelten Neuron ist in ergibt eine stark verrauschte Autokorrelationskurve, die durch ein zweidimensionales Diffusionsmodell beschrieben werden kann (G1. 401$)$. Sowohl die Diffusionszeit $\tau_{\mathrm{D}}$ als auch die Partikelanzahl im effektiven Detektionsvolumen $N$ waren für verschiedene Neurone sehr unterschiedlich und wurden vor der Zugabe des farbstoffmarkierten Liganden für die zu untersuchende Zelle individuell bestimmt. In diesem Beispiel ergibt sich eine Diffusionszeit für die endogenen autofluoreszierenden Zellbestandteile von $\tau_{\mathrm{D}}=6,5 \mathrm{~ms}$ und eine Partikelzahl von $N=35$ bei einer mittleren Zählrate von 2,63 kcps. Die Zählrate pro Molekül beträgt damit 0,075 kcps für die Hintergrundfluoreszenz. Im Vergleich dazu wurde für Ro-Alexa eine Zählrate von 2,7 kcps / Molekül gemessen. In Anwesenheit von $5 \mathrm{nM}$ Ro-Alexa $(N=0,14)$ berechnet sich nach G1. İ_hieraus ein Anteil des Hintergrunds an der Amplitude der Autokorrelationsfunktion von $17 \%$. Dieser Hintergrundanteil verringert sich für ansteigende Konzentrationen von Ro-Alexa auf 9, 4, 2 und $<1 \%$ (für [Ro-Alexa $]_{0}=10,25,50$ und $>100 \mathrm{nM}$ ) und wurde dementsprechend berücksichtigt.

Nach Zugabe von Ro-Alexa wurde die fokale Ebene wie oben beschrieben in der oberen Zellmembran des selben Neurons positioniert sowie die Fluoreszenz aufgezeichnet und autokorreliert. Im erhaltenen Fluoreszenz-Zeit-Verlauf für $10 \mathrm{nM}$ Ro-Alexa in Ā sind Fluoreszenzspitzen zu erkennen, die während der Messung der Autofluoreszenz der Zelle (cf. ÁAbbildung 36'a) nicht aufgetreten sind und durch die Diffusion rezeptorgebundener Liganden durch das Detektionsvolumen erklärt werden können. Die dazugehörige Autokorrelationsfunktion wird gut durch ein Modell mit drei diffundierenden Komponenten beschrieben (s. Á Ábildung 36 b). Die Diffusionszeitkonstante des ungebundenen Ro-Alexa über den Neuronen $\left(\tau_{\mathrm{D} 1}=48 \mu \mathrm{s}\right)$ wurden in unabhängigen Experimenten vorher bestimmt und während Anpassung der theoretischen Autokorrelationsfunktion (G1. 40) an die Meßdaten konstant gehalten. Die freien Parameter der Anpassung waren zwei Diffusionszeitkonstanten $\tau_{\mathrm{D} 2}$ und $\tau_{\mathrm{D} 3}$ sowie die einzelnen Anteile der drei Diffusionskomponenten am Autokorrelationsabfall als auch die Anzahl der Teilchen $N$ im effektiven Detektionsvolumen.

Eine weitere Erhöhung der eingesetzten Ro-Alexa-Konzentration am selben Neuron führte zu häufiger auftretenden Fluoreszenzspitzen (s. $\mathrm{nM}$ ). Weiterhin wurde im Fokusscan durch die Zelle eine starke Anreicherung des fluoreszierenden Liganden in der Zellmembran beobachtet (AA bibildung 34 , blaue Kurve für [Ro-Alexa] $=120 \mathrm{nM})$. 


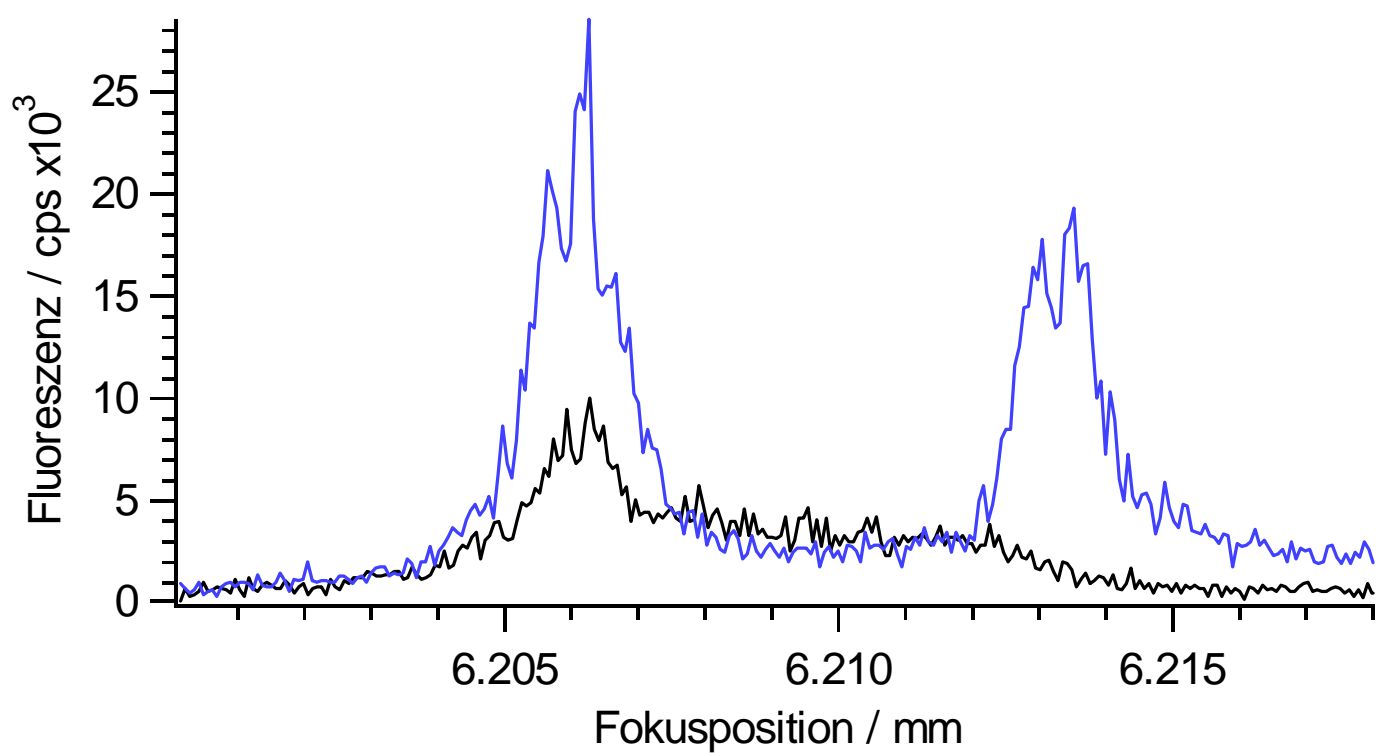

Abbildung 34: Fokusscan entlang der optischen Achse durch ein Neuron ohne Ligand (schwarz) und in Anwesenheit von $120 \mathrm{nM}$ Ro-Alexa (blau).

Die aus der Autokorrelationsanalyse erhaltenen mittleren Diffusionszeitkonstanten wurden nach G1. $\overline{3} 9$ in mittlere Diffusionskoeffizienten umgerechnet. Dabei wurden folgende Ergebnisse für den freien und den gebundenen Liganden Ro-Alexa erhalten:

$$
\begin{aligned}
& D_{\text {frei }}=(220 \pm 3) \mu \mathrm{m}^{2} / \mathrm{s}(n=25) \\
& D_{\text {geb } 1}=(1,32 \pm 0,26) \mu \mathrm{m}^{2} / \mathrm{s}(n=20) \\
& D_{\text {geb2}}=(2,63 \pm 0,63) \cdot 10^{-2} \mu \mathrm{m}^{2} / \mathrm{s}(n=22)
\end{aligned}
$$

Die absolute Anzahl an gebundenem Ligand in der Zellmembran ließ sich nicht beliebig erhöhen, sondern erreichte einen konstanten Wert, der von der Anzahl aller zur Verfügung stehenden Bindungsstellen in der gesamten Probe abhängig war. Die maximale Anzahl aller Membranbindungsstellen in der gesamten Probe ist äquivalent zur maximal erreichbaren Konzentration an sättigbar gebundenem Liganden $\left(B_{\max }\right)$. Bei Sättigung aller Bindungsstellen in der Zellmembran entspricht die Anzahl an gebundenem Liganden im Detektionsvolumen der Rezeptorendichte in der Zellmembran. Bei einer im Detektionsvolumen liegenden Membranfläche von etwa $0,134 \mu^{2}$ wurde eine mittlere Rezeptorendichte in hippocampalen Neuronen von $\rho=(14,9 \pm 2,7)$ Rezeptoren $/ \mu \mathrm{m}^{2}(n=7)$ erhalten.

Ein Reaktionsmechanismus bei dem der farbstoffmarkierte Ligand $\left(\mathrm{L}^{*}\right)$ und die Bindungsstellen in der Zellmembran (R) im Gleichgewicht mit dem gebundenen Ligand ( $\left.\mathrm{L}^{*}-\mathrm{R}\right)$ stehen, gemäß

$$
L^{*}+R \underset{\text { diss }}{\stackrel{k_{\text {ass }}}{\rightleftharpoons}} L^{*}-R
$$


führt zu folgender Abhängigkeit der gebundenen Ligandkonzentration $\left[\mathrm{L}^{*}\right]_{\mathrm{geb}}$ (umgerechnet in Teilchen/Volumen) von der insgesamt eingesetzten Ligandkonzentration $\left[\mathrm{L}^{*}\right]_{0}$ :

$$
\left[\mathrm{L}^{*}\right]_{\mathrm{geb}}=\frac{\left[\mathrm{L}^{*}\right]_{0}+B_{\text {max }}+K_{\mathrm{D}}-\sqrt{\left(\left[\mathrm{L}^{*}\right]_{0}+B_{\text {max }}+K_{\mathrm{D}}\right)^{2}-4\left[\mathrm{~L}^{*}\right]_{0} B_{\max }}}{2}
$$

mit $\left[\mathrm{L}^{*}\right]_{\text {geb }}=\left[\mathrm{L}^{*}-\mathrm{R}\right]:$ Konzentration an gebundenem Ro-Alexa und

$$
K_{\mathrm{D}}=\frac{k_{\text {diss }}}{k_{\text {ass }}}=\frac{\left(\left[\mathrm{L}^{*}\right]_{0}-\left[\mathrm{L}^{*}\right]_{\mathrm{geb}}\right)\left(B_{\mathrm{max}}-\left[\mathrm{L}^{*}\right]_{\mathrm{geb}}\right)}{\left[\mathrm{L}^{*}\right]_{\mathrm{geb}}}
$$

Die eingesetzte Menge an Ligand $\left[\mathrm{L}^{*}\right]_{0}$ kann als konstant angesehen werden, da in unabhängigen Experimenten keine wesentliche Adsorption des Liganden mit den Gefäßwandungen festgestellt wurde.

Aus der Auftragung der gebundenen Ligandkonzentration $\left[\mathrm{L}^{*}\right]_{\text {geb }}$, bestimmt durch die Analyse der Autokorrelationskurven, gegen die eingesetzte Ligandkonzentration $\left[\mathrm{L}^{*}\right]_{0}$ ließ sich durch nichtlineare Kurvenpassung mit G1. 182 für jede Zelle jeweils die Dissoziationskonstante $\left(K_{\mathrm{D}}\right)$ und die maximale Anzahl der Bindungsstellen $\left(B_{\max }\right)$ bestimmen. Eine zusammenfassende Auftragung, die sich aus dem arithmetischen Mittel von sieben Bindungskurven

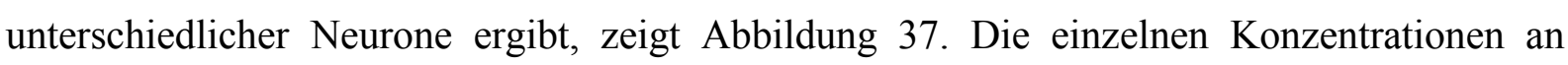
gebundenem Ligand $\left[\mathrm{L}^{*}\right]_{\text {geb }}$ wurden vor dem Zusammenfassen durch das individuelle $B_{\max }$ des einzelnen Experimentes dividiert, so daß eine Vergleichbarkeit der verschiedenen Konzentrationen in den unterschiedlichen Zellexperimenten erreicht wurde. Die gemittelten relativen Werte $\left[\mathrm{L}^{*}\right]_{\text {geb }} / B_{\max }$ wurden dann mit dem arithmetischen Mittel von $B_{\max }=(37,8 \pm 7,7)$ $\mathrm{nM}$ multipliziert und die erhaltene Auftragung $\left[\mathrm{L}^{*}\right]_{\text {geb }}$ vs. $\left[\mathrm{L}^{*}\right]_{0}$ mit G1. $B_{\max }$ konstant gesetzt wurde.

Aus der Anpassung ergibt sich eine mittlere Dissoziationskonstante von

$$
K_{\mathrm{D}}=(9,9 \pm 1,9) \mathrm{nM}(n=7)
$$

Die mittlere Anzahl an maximalen Bindungsstellen betrug $B_{\max }=(37,8 \pm 7,7) \mathrm{nM}(n=7)$. 


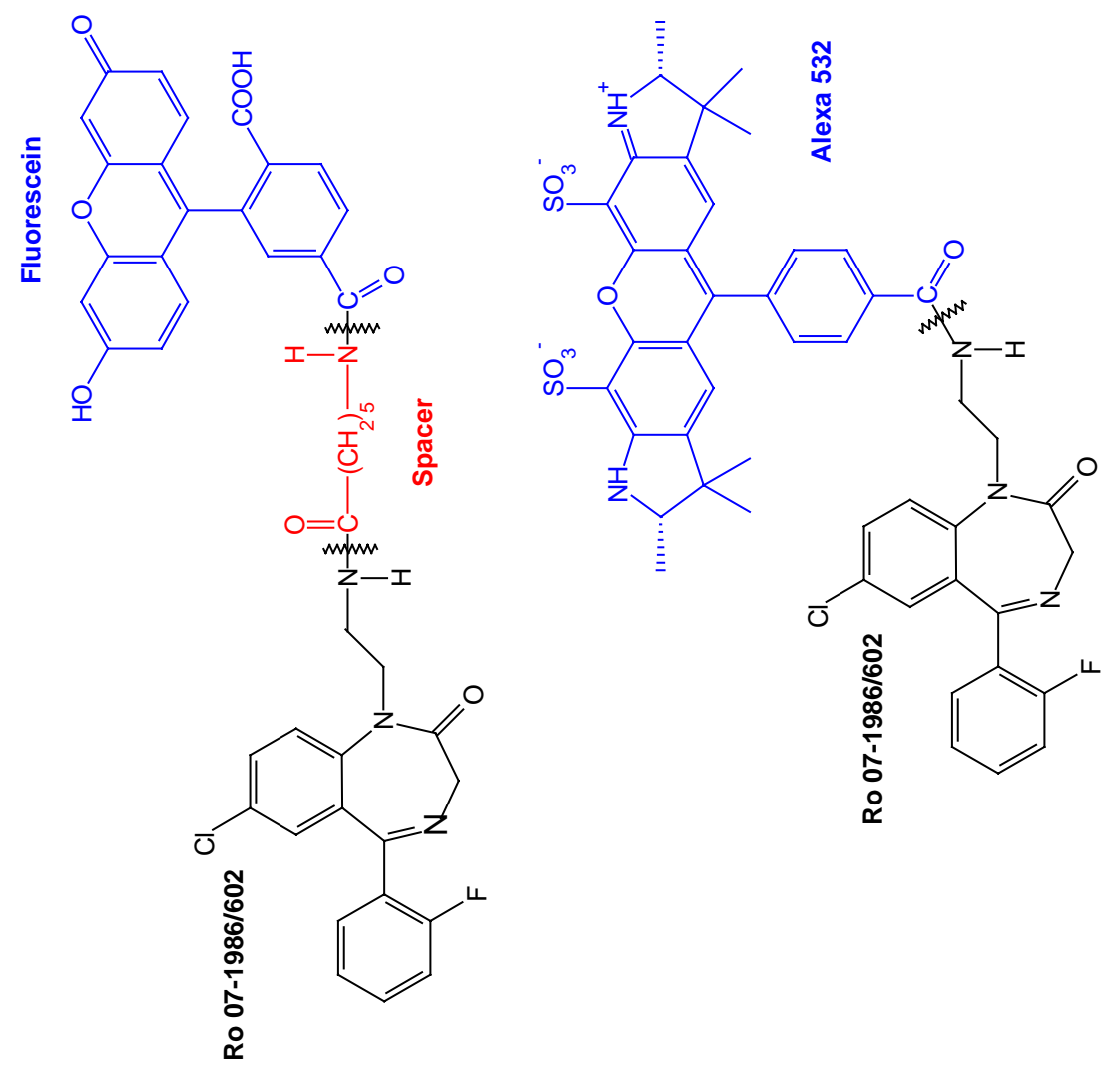

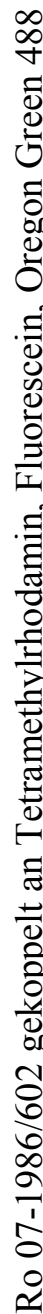
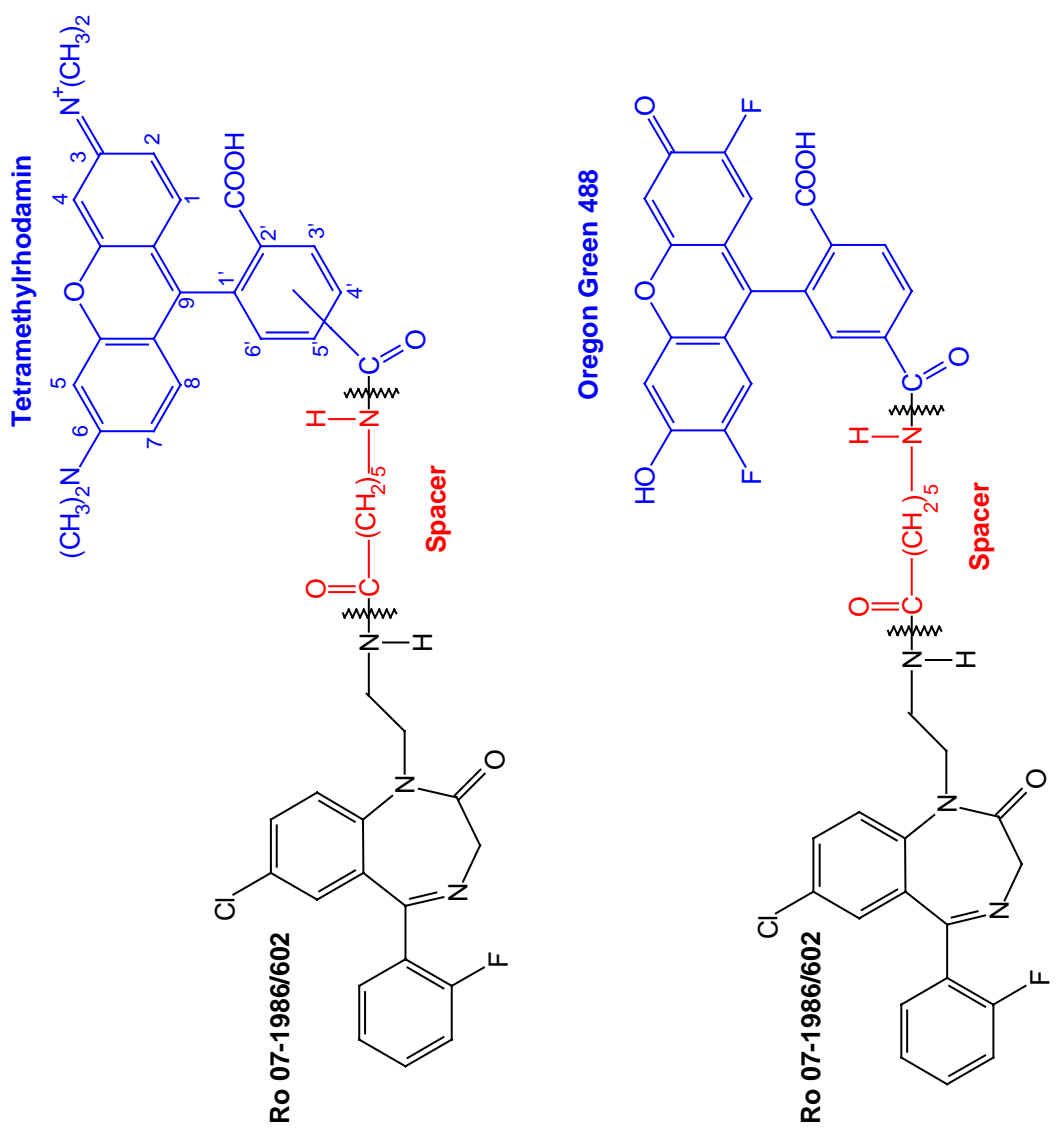

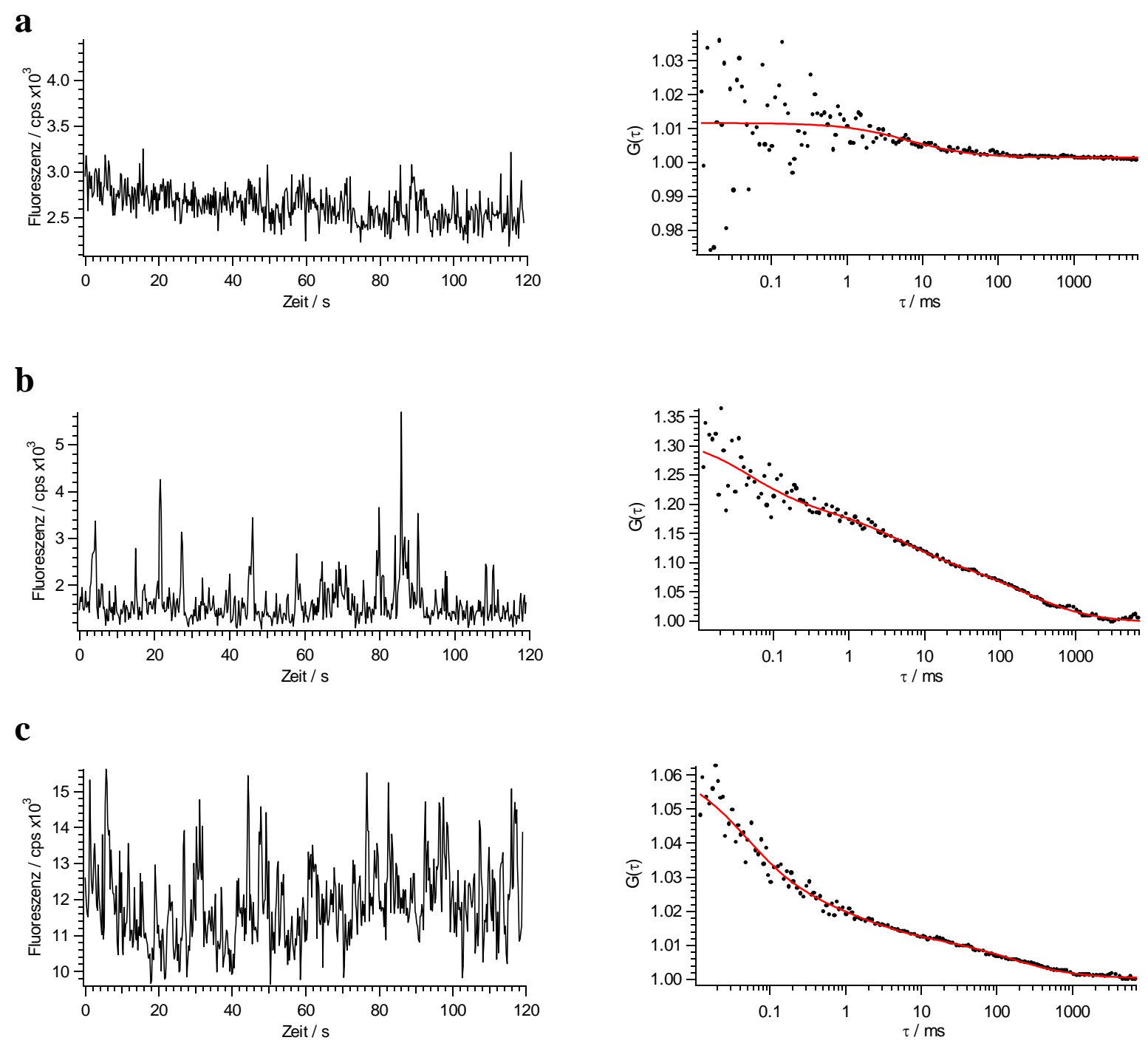

Abbildung 36: Fluoreszenz-Zeit-Verlauf mit zugehöriger Autokorrelationsfunktion der Autofluoreszenz, in Anwesenheit von $10 \mathrm{nM}$ Ro-Alexa bzw. $240 \mathrm{nM}$ Ro-Alexa $\left(P_{\text {obj }}=5 \mu \mathrm{W}, \lambda_{\text {exc }}=488 \mathrm{~nm}\right.$, nähere Details zur Anpassung im Text).

a: Autofluoreszenz: $\tau_{\mathrm{D}}=6,5 \mathrm{~ms}, N=35$.

b: $10 \mathrm{nM}$ Ro-Alexa: $\tau_{\mathrm{D} 1}=48 \mu \mathrm{s}(41 \%), \tau_{\mathrm{D} 2}=4,9 \mathrm{~ms}(30 \%), \tau_{\mathrm{D} 3}=250 \mathrm{~ms}(29 \%), N=3,1$.

c: $240 \mathrm{nM}$ Ro-Alexa: $\tau_{\mathrm{D} 1}=48 \mu \mathrm{s}(71 \%), \tau_{\mathrm{D} 2}=4,1 \mathrm{~ms}(14 \%), \tau_{\mathrm{D} 3}=220 \mathrm{~ms}(15 \%), N=15,1$. 


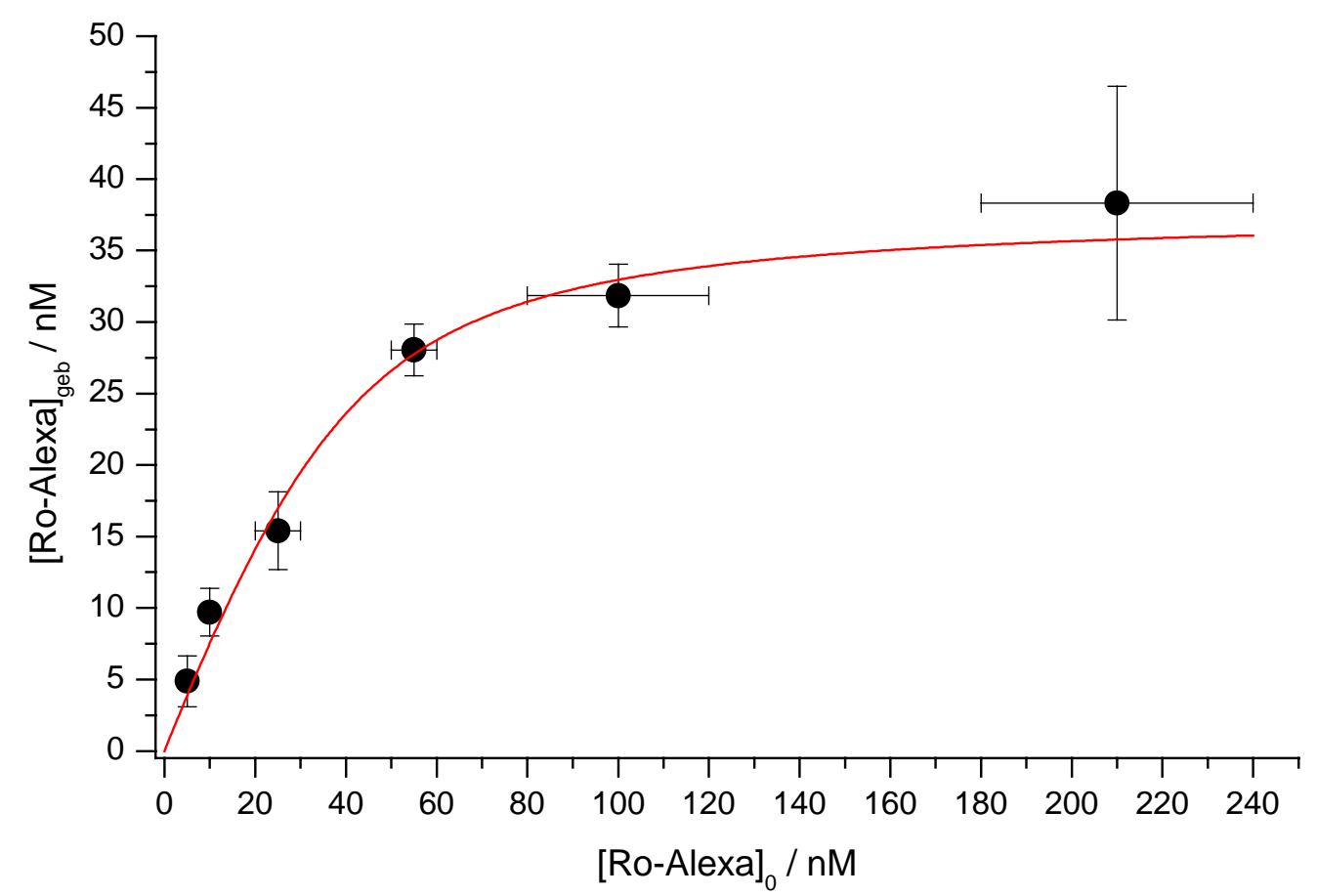

Abbildung 37: Auftragung der mittleren gebundenen Ro-Alexa-Konzenzentration (umgerechnet in Teilchen/Volumen) ( $n=7$ ) gegen die eingesetzte Konzentration sowie die Anpassung mit G1. $\overline{8} 2$;

Bei einer spezifischen Interaktion zwischen dem farbstoffmarkierten Benzodiazepin und seinem Rezeptor in der Zellmembran, sollte sich der gebundene Agonist Ro-Alexa durch einen Überschuß an unmarkiertem Agonist wieder freisetzen lassen. Die Verdrängung des gebundenen farbstoffmarkierten Liganden Ro-Alexa $\left(\left[\mathrm{L}^{*}\right]_{0}=10 \mathrm{nM}\right)$ erfolgte mit 8 bzw. $10 \mu \mathrm{M}$ Midazolam. Midazolam wurde dem Agonisten Ro 07-1986/602 vorgezogen, da Midazolam in dem benötigten Konzentrationsbereich deutlich besser wasserlöslich ist und zudem eine geringere Eigenfluoreszenz besitzt. Der Zeitverlauf der kompetitiven Verdrängung nach Zugabe von $10 \mu \mathrm{M}$ Midazolam (bei $t=0$ ) ist in und läßt sich durch einen monoexponentiellen Abfall gemäß der Gleichung

$$
\left[\mathrm{L}^{*}\right]_{\text {geb }}(t)=\left[\mathrm{L}^{*}\right]_{0} \exp \left(-k_{\text {diss }} t\right)
$$

beschreiben. In vier von sieben Experimenten erfolgte die kompetitive Verdrängung erst nach einer Zeitverzögerung von ca. 10 Minuten.

Der unspezifische Bindungsanteil, der sich nicht durch einen Agonistüberschuß verdrängen ließ, betrug im Mittel zwischen 7 und $10 \%$. Dieser Wert war unabhängig davon, ob der Zeitverlauf der Verdrängung durch wiederholte Messungen beobachtet wurde, oder nur eine einzige Messung 60 Minuten nach Applikation des Midazolamüberschusses ausgeführt wurde. Eine mögliche irreversible Änderung des Bindungsanteils durch Photozerstörung konnte deshalb ausgeschlossen werden. 


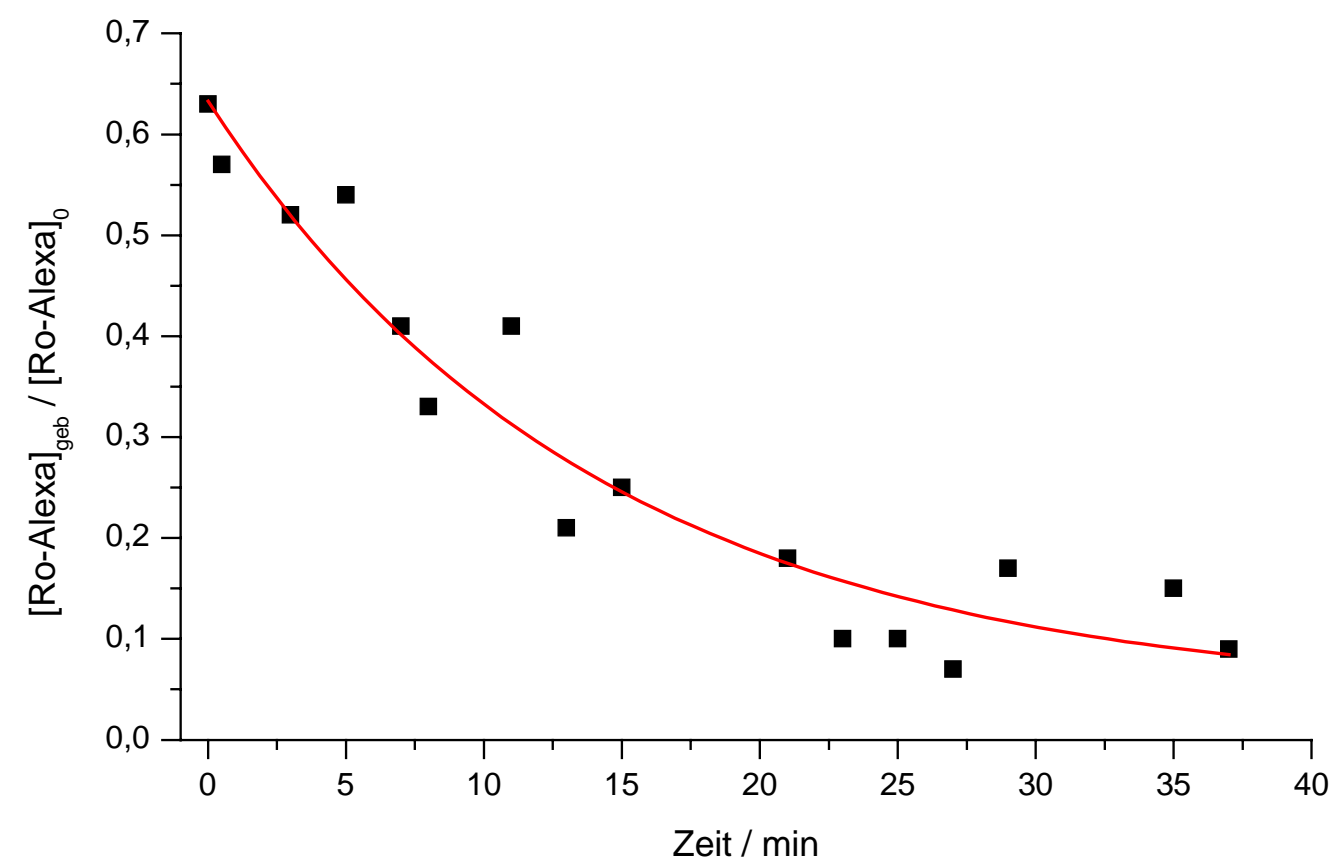

Abbildung 38: Auftragung des gebundenen Ro-Alexa-Anteils als Funktion der Zeit nach Zugabe von $10 \mu \mathrm{M}$ Midazolam bei $t=0$ sowie die Anpassung des Zeitverlaufs mit G1. $184 \overline{1}$ ([Ro-Alexa $]_{0}=10 \mathrm{nM}$; $\left.\tau_{\text {diss }}=14,1 \mathrm{~min}\right)$.

Aus den einzelnen Verdrängungskurven ergibt sich eine mittlere Geschwindigkeitskonstante für die Dissoziation des gebundenen Komplexes von

$$
k_{\text {diss }}=(1,28 \pm 0,08) \cdot 10^{-3} \mathrm{~s}^{-1}(n=5)
$$

Aus der Dissoziationskonstanten $\left(K_{\mathrm{D}}\right)$ und aus der Geschwindigkeitskonstanten der Komplexdissoziation berechnet sich eine Assoziations-Geschwindigkeitskonstante von

$$
k_{\mathrm{ass}}=(1,30 \pm 0,26) \cdot 10^{5} 1 \mathrm{~mol}^{-1} \mathrm{~s}^{-1}(n=5) .
$$

\subsection{Dynamik synaptischer Vesikel in hippocampalen Boutons}

Vor den FCS-Experimenten zur Untersuchung der Dynamik synaptischer Vesikel in hippocampalen Neuronen wurde die Größe des Detektionsvolumens in der extrazellulären Lösung über den Neuronen bestimmt. Dazu wurden $10 \mathrm{nM}$ des Farbstoffs Rhodamin 6G (Rh6G) in die extrazelluläre Lösung gegeben und 30 Sekunden lang aus den Fluoreszenzfluktuationen die zugehörige Autokorrelationskurve mit Hilfe des Hardwarekorrelators berechnet. Aus der Autokorrelationskurve wurde durch Anpassung mit Gl. $38^{1} \tau_{\mathrm{D}}$ bzw. $z_{0} / w_{0}$ erhalten und aus diesen Werten sowie unter der Annahme eines Diffusionskoeffizienten für Rh6G von $D_{\mathrm{Rh} 6 \mathrm{G}}=$ $280 \mu \mathrm{m}^{2} / \mathrm{s}[70]$ mit Hilfe von G1. 339 die Größe des Detektionsvolumens berechnet. 
Âbbildung 39i' zeigt eine typische Autokorrelationsfunktion. Die Zeitkonstante für den Diffusionsprozeß beträgt in diesem Beispiel $\tau_{\mathrm{D}}=26 \mu$ s und das Verhältnis $z_{0} / w_{0}=6,0$. Aus der Diffusionszeitkonstanten folgte ein Radius in der fokalen Ebene der konsistent zwischen 170 und $180 \mathrm{~nm}$ lag (in diesem Beispiel: $w_{0}=171 \mathrm{~nm} ; z_{0}=1,03 \mu \mathrm{m}$ ). Nach G1. 43 ist die Größe des Detektionsvolumen also etwa $V_{\text {eff }} \approx 0,06$ fl. Die relative Größe des Detektionsvolumens zum Synapsenvolumen soll im folgenden abgeschätzt werden:

Eine typisches präsynaptisches Bouton hat einen Durchmesser von etwa $1 \mu \mathrm{m}$. Bei nahezu sphärischer Gestalt ergibt das ein Volumen von etwa $V_{\text {syn }} \approx 0,5$ fl. Das Verhältnis der beiden Volumina zueinander beträgt also etwa $V_{\text {syn }} / V_{\text {eff }} \approx 9$. Hierbei ist zu berücksichtigen, daß die Ausdehnung des Detektionsvolumens in der z-Achse insgesamt einen Durchmesser von $2 z_{0} \approx 2 \mu \mathrm{m}$ besitzt, die Synapse aber nur einen Durchmesser von etwa $1 \mu \mathrm{m}$, d.h. ein Teil des Detektionsvolumens befindet sich außerhalb der Synapse. Je nach Meßkonfiguration kann der Anteil des Detektionsvolumens, der sich außerhalb der Synapse befindet, unterschiedlich sein. Das Verhältnis $V_{\text {syn }} / V_{\text {eff }}$ von ungefähr 9 ist deshalb eher als untere Grenze anzusehen.

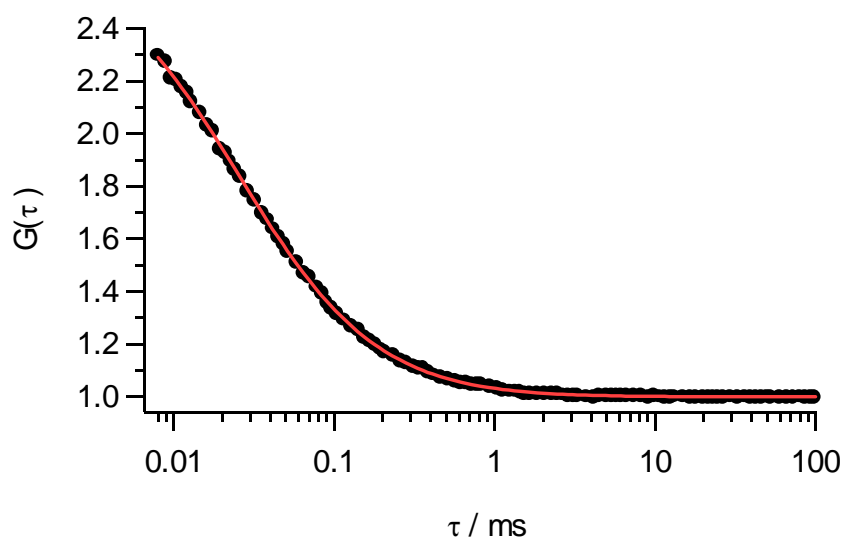

Abbildung 39: Autokorrelationsfunktion zur Bestimmung der Größe des Detektionsvolumen ausgeführt mit $10 \mathrm{nM}$ Rh6G in der extrazellulären Lösung über hippocampalen Neuronen sowie Anpassung mit dem 3D-Diffusionsmodell $\left(N=0,25, \tau_{\mathrm{D}}=26 \mu \mathrm{s}, z_{0} / w_{0}=6,0 ; \Rightarrow w_{0}=171 \mathrm{~nm}, z_{0}=1,28 \mu \mathrm{m}\right)$.

Zur Färbung der synaptischen Vesikel wurde der Styrylfarbstoffs FM 1-43 verwendet. FM 143 ist ein amphiphiles Molekül mit einem lipophilen Dibutylaminophenyl-Rest (,Schwanz“) und einem doppelt positiv geladenen Pyridinium-Rest („Kopf“) (cf. ÁAbbildung 40). Der Farbstoff läßt sich über einen großen Wellenlängenbereich anregen mit einem Absorptionsmaximum bei ca. $480 \mathrm{~nm}$ (Absorptions- und Emissionsspektrum im Anhang). Das Absorptions- und Emissionsverhalten ist dabei stark umgebungsabhängig. In Wasser wird die Fluoreszenz durch die Wassermoleküle überwiegend gelöscht. In Membranen lagert sich das Molekül mit seinem hydrophoben Schwanz in die äußere Membrandoppelschicht ein, während der hydrophile Kopfteil des Moleküls in der Lösung verbleibt. Aufgrund des amphipilen Charakters ist die Wahrscheinlichkeit des Moleküls, sich innerhalb der Membran zu drehen, sehr gering. Mit der Einlagerung in die Membran erhöht sich die Fluoreszenz gegenüber dem Löschverhalten im Wasser um 2-3 Größenordnungen [80]. Je nach Membranzusammenset- 
zung kann es zu spektralen Verschiebungen im Emissionsverhalten des Farbstoffs kommen, wobei diese wahrscheinlich auf die mikroskopische Umgebung des Farbstoffs zurückzuführen sind. Der Farbstoff ändert seine Fluoreszenz auch in Abhängigkeit vom Zellmembranpotential. Bei einer Hyperpolarisation von $100 \mathrm{mV}$ vergrößert sich die Fluoreszenz um ca. 3 \%, für eine gleich große Depolarisation der Zellmembran verringert sich die Fluoreszenz entsprechend $[80]$.

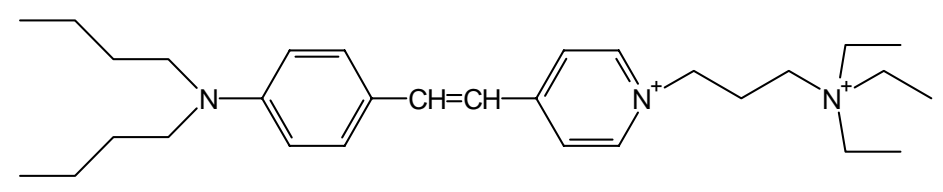

Abbildung 40: Strukturformel des amphiphilen Styrylfarbstoffs FM 1-43.

Zur Anfärbung der synaptischen Vesikel wurde zunächst der Farbstoff FM 1-43 in einer Konzentration von $[\mathrm{FM} \mathrm{1-43}]_{\mathrm{e}}=15 \mu \mathrm{M}$ in die extrazelluläre Lösung gegeben. Die hohe Farbstoffkonzentration sollte später zu einer möglichst hohen Dichte an Farbstoffmolekülen pro Vesikel führen.

Nachdem sich ein Gleichgewicht zwischen gelöstem und in die äußere Zellmembranschicht eingelagertem Farbstoff eingestellt hat, wurden Aktionspotentiale in den Neuronen generiert. Die Aktionspotentiale wurden durch Depolarisation der Plasmamembran hervorgerufen, entweder durch eine erhöhte extrazelluläre Kaliumionenkonzentration $\left(\left[\mathrm{K}^{+}\right]_{\mathrm{e}}=40 \mathrm{mM}\right)$ oder durch elektrische Feldstimulation. Bei der letzten Methode wurde mit Hilfe von zwei Platindrähten, die sich auf dem Boden des Deckglases in der extrazellulären Lösung in einem Abstand von ca. 1,0 cm voneinander befanden, ein elektrisches Feld mit einer Feldstärke von ca. $15 \mathrm{~V} / \mathrm{cm}$ erzeugt, indem durch die Platindrähte kurze Strompulse mit einer Amplitude von $I=40 \mathrm{~mA}$, einer Länge von $t=1 \mathrm{~ms}$ und einer Frequenz von $f_{\mathrm{p}}=10 \mathrm{~Hz}$ appliziert wurden. Die Anzahl der Strompulse wurde den experimentellen Bedingungen angepaßt und betrug zwischen 80 und 240. Die Depolarisation der Zellmembran wurde in Anwesenheit von $10 \mu \mathrm{M}$ NBQX (Blocker der postsynaptischen AMPA-Rezeptoren) zur Vermeidung von periodisch wiederkehrenden Aktionspotentialen ausgeführt und erfolgte, soweit nicht anders angegeben, mit Hilfe der externen Feldstimulation.

Die generierten Aktionspotentiale führten zur Verschmelzung unmarkierter Vesikel mit der Plasmamembran (Exozytose). Aufgrund der Kopplung von Exozytose und Endozytose wurde ebenfalls die Abschnürung von Vesikeln aus der Membran (Endozytose) hervorgerufen. Durch diesen Prozeß der Endozytose lagerten die Vesikel mehrere hundert Farbstoffmoleküle in ihre innere Lipidschicht ein.

50 s nach Ende der Strompulsapplikation wurde der Farbstoff aus der Neuronenmembran durch etwa zehnminütige Perfusion mit extrazellulärer Lösung herausgewaschen. Äb̄bildung _.

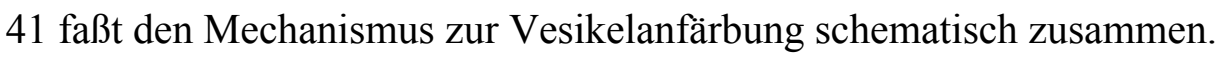

Nach dem Auswaschen des Farbstoffs aus der Plasmamembran der Neurone wurde durch gleichmäßige Beleuchtung des Mikroskopobjektivs ein Fluoreszenzbild (Laserleistung vor 
dem Objektiv $P_{\text {obj }}=1 \mu \mathrm{W}$ ) aufgenommen. Synapsen mit farbstoffmarkierten Vesikeln sind

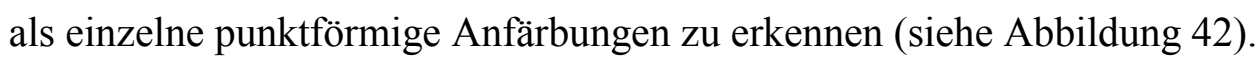

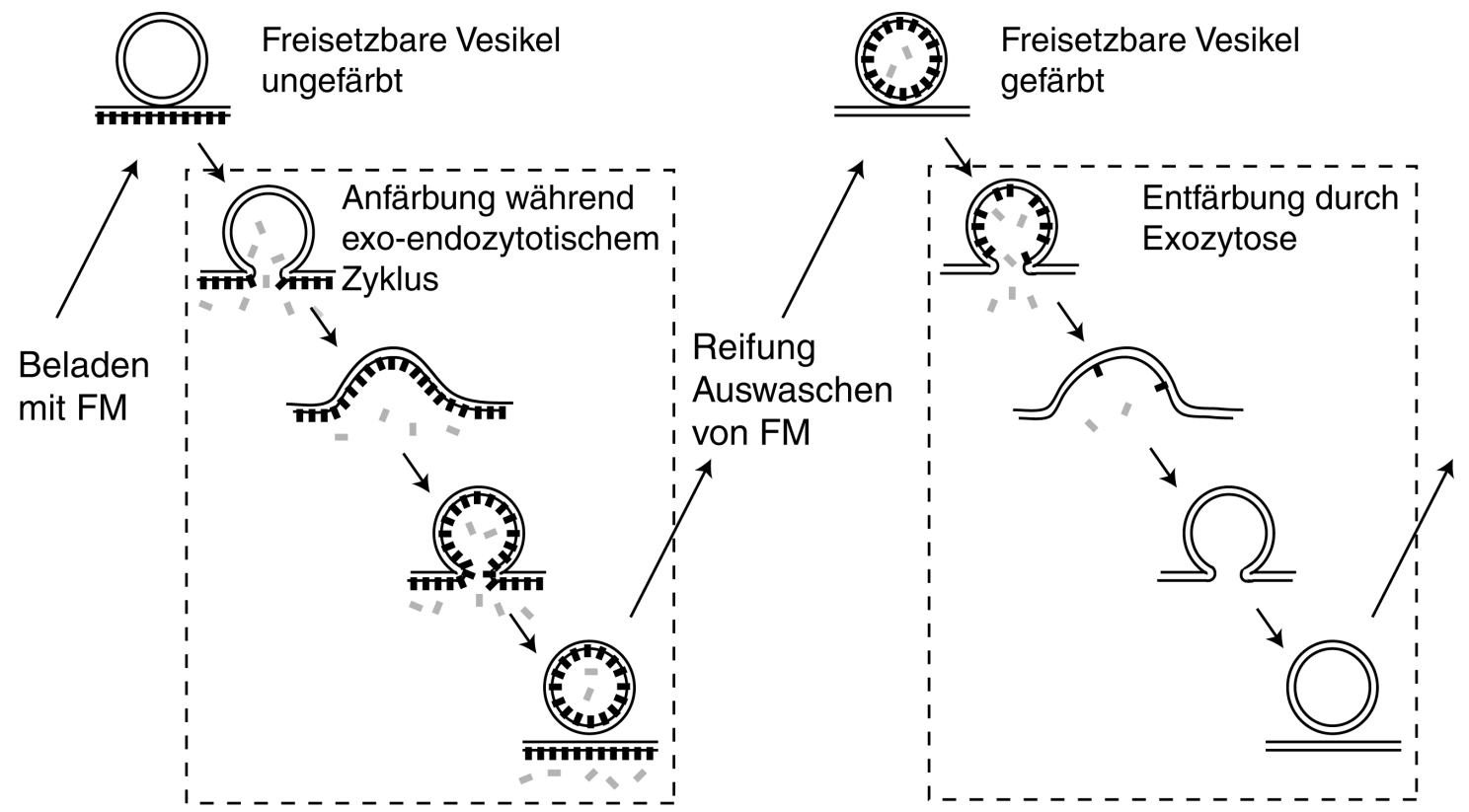

Abbildung 41: Schematische Darstellung der Anfärbung synaptischer Vesikel mit FM 1-43. Die ungefärbten Vesikel fusionieren mit der farbstoffmarkierten Plasmamembran, aus der durch den Prozeß der Endozytose gefärbte Vesikel entstehen. Diese lassen sich durch Exozytose wieder entfärben (nach [82]

Ein einzelner Fluoreszenzspot wurde herausgesucht und in das Zentrum des Laserstrahls durch Verschieben des Mikroskoptisches positioniert. Anschließend wurde das Fluoreszenzprofil der Synapse durch Scannen des Mikroskopobjektivs entlang der optischen Achse aufgenommen, und die fokale Ebene des Lasers im Maximum des Spots plaziert (cf. 'Áb̄bildung 43).

Im Maximum des Fluoreszenzspots wurde der Fluoreszenz-Zeit-Verlauf der mit farbstoffmarkierten Vesikeln beladenen Synapse mit einer Zeitauflösung von $200 \mu$ s pro Zeitintervall mit Hilfe der Zählkarte aufgezeichnet. Die Intensität des Anregungslichtes wurde mit Neutraldichtefiltern auf $P_{\mathrm{obj}}=50 \mathrm{nW}$ abgeschwächt. Trotz der geringen Leistung des Laserstrahls kam es aber bei kontinuierlicher Beleuchtung der Probe zu einer Photozerstörung.

Ein weiteres Abschwächen des Laserstrahls zur Verhinderung der Photozerstörung wurde nicht vorgenommen, da die durchschnittliche Zählrate bei vielen Experimenten nur ungefähr 10 kcps betrug und ein weiteres Abschwächen um einen Faktor 5-10 die Zählrate zu nah an die Dunkelzählrate der APD von etwa 0,2 kcps gebracht hätte. 

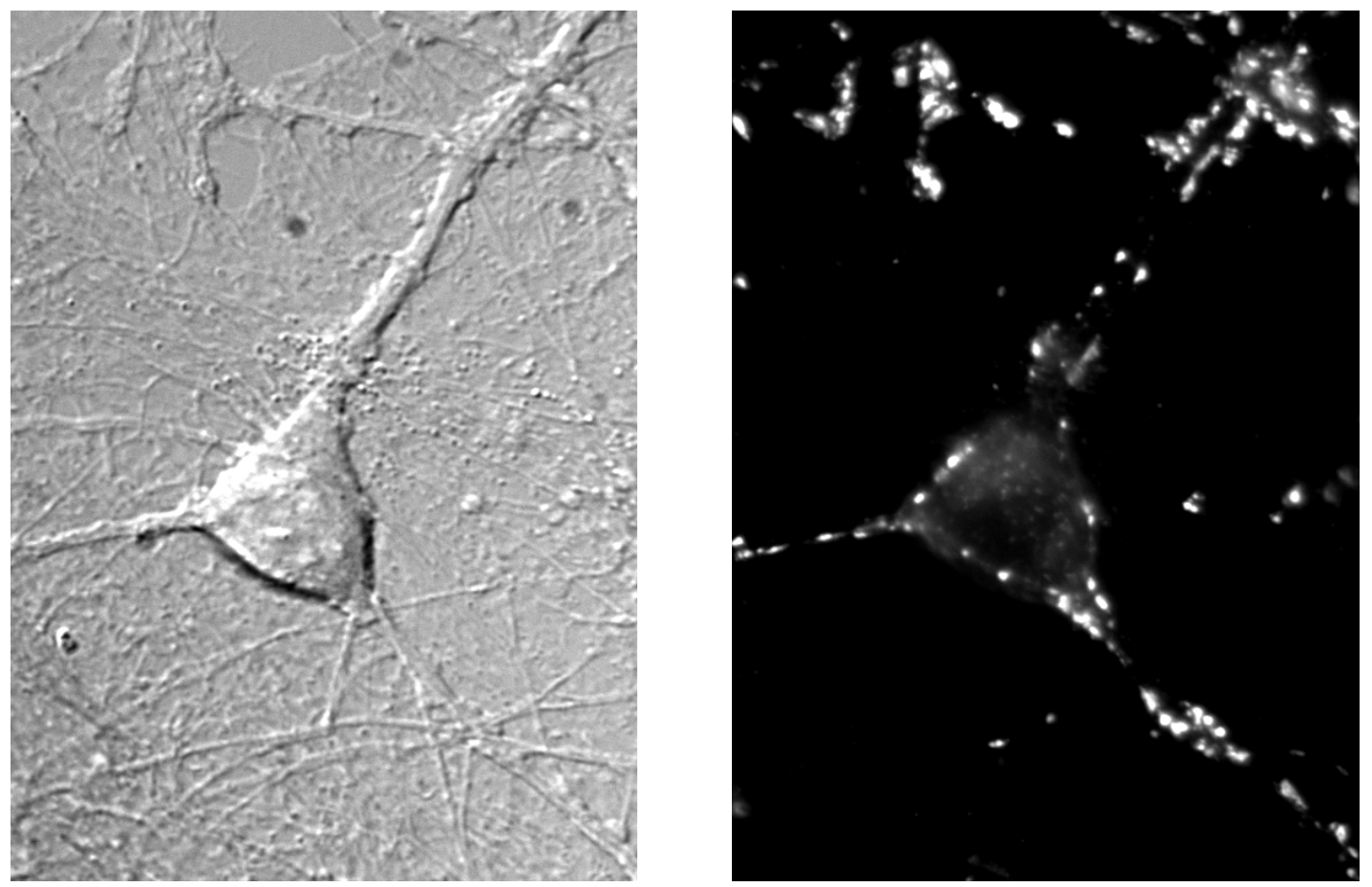

Abbildung 42: Hippocampale Nervenzelle in einer Durchlichtaufnahme (DIC, links) und nach Anfärbung synaptischer Vesikel mit $15 \mu$ M FM 1-43 (rechts).

Zur Vermeidung phototoxischer Effekte und Photozerstörung wurde die Probe vielmehr nur $10 \mathrm{~ms}$ lang pro $100 \mathrm{~ms}$ Zeitintervall mit einer Anregungsleistung von $P_{\mathrm{obj}}=50 \mathrm{nW}$ beleuchtet (10 Hz Abtastfrequenz). Dem gesamten $100 \mathrm{~ms}$ Zeitintervall wurde später das arithmetische Mittel der gesammelten Photonen aus dem $10 \mathrm{~ms}$ Belichtungs-Zeitintervall zugeordnet. Im Vergleich zur kontinuierlichen Beleuchtung der Probe konnte somit das gleiche Signal/Hintergrund-Verhältnis erreicht werden.
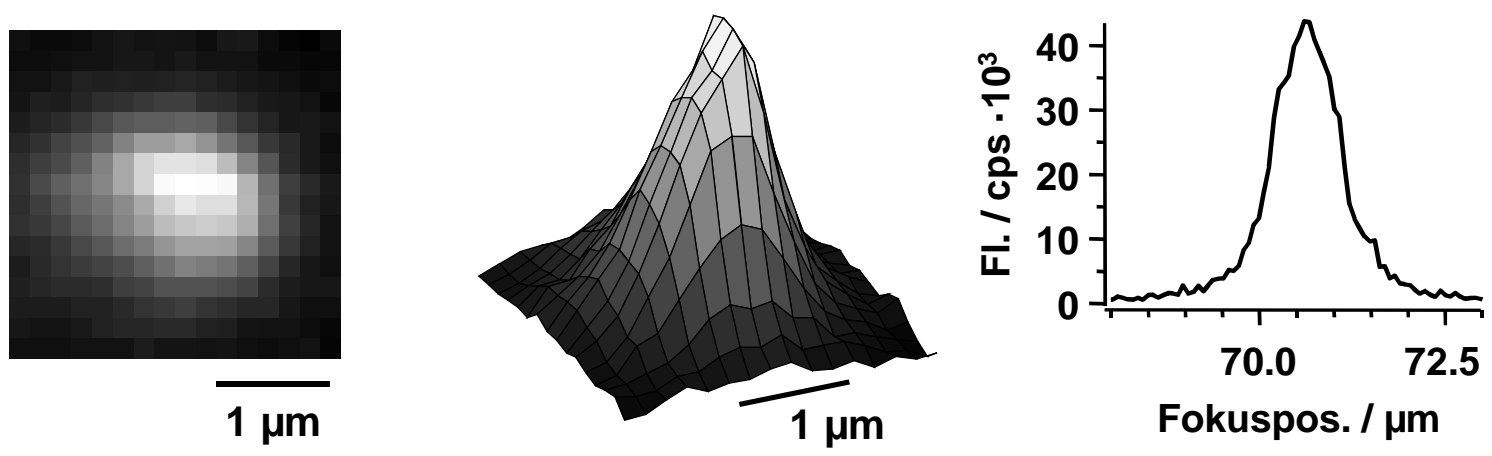

Abbildung 43: 2-D Bild einer einzelnen Synapse mit farbstoffmarkierten Vesikeln (links) mit dazugehöriger Fluoreszenz-Intensitätsverteilung (mitte) und Fokusscan entlang der optischen Achse durch das Bouton (rechts).

Ein typischer Fluoreszenz-Zeit-Verlauf einer unstimulierten Synapse ist in dargestellt. 


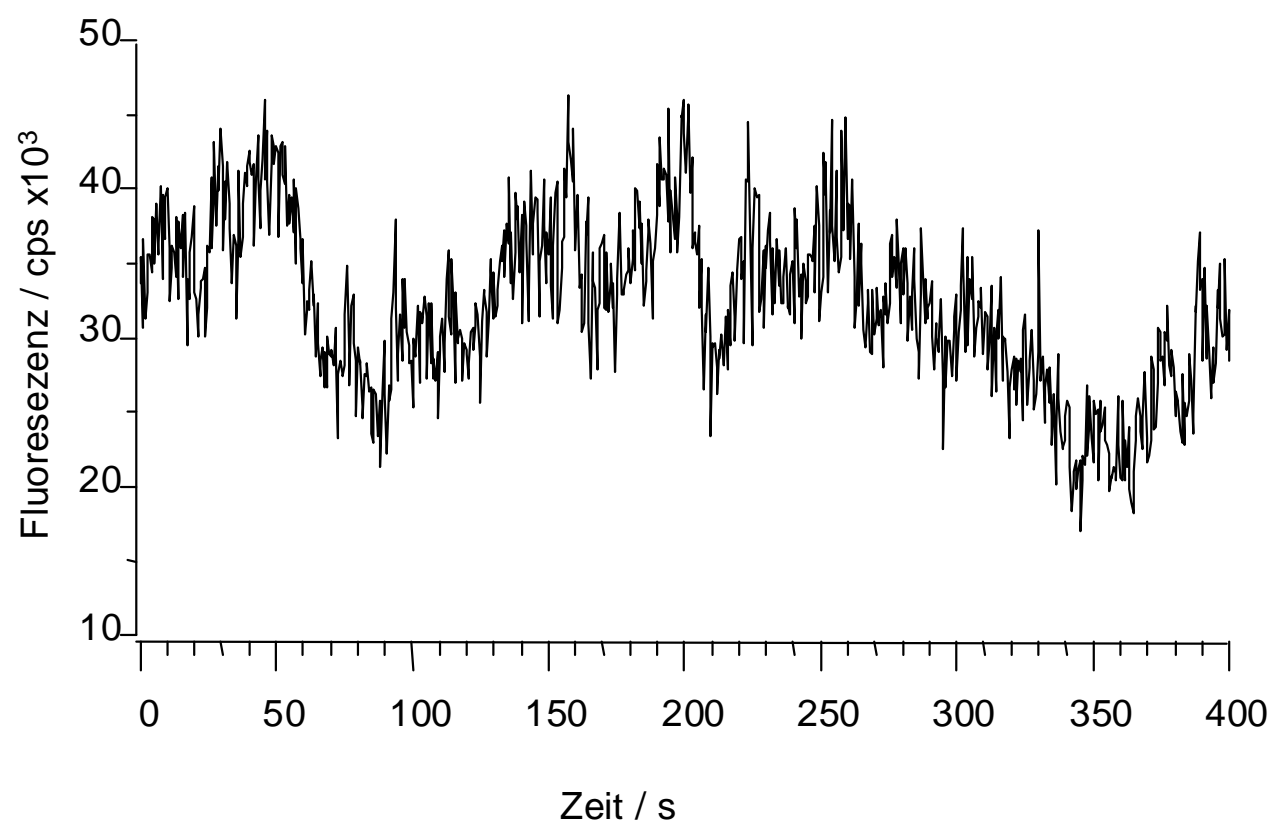

Abbildung 44: Fluoreszenz-Zeit-Verlauf einer unstimulierten Synapse mit farbstoffmarkierten Vesikeln.

Es sind schnelle Fluoreszenzfluktuationen als auch langsame im Zeitbereich von 20-100 s zu erkennen. Mögliche Ursachen für die Fluktuationen können sowohl biologisch, wie z.B. Bewegung von Vesikeln bzw. der gesamten Synapse, als auch nicht-biologisch sein, z.B. Fluktuationen der Laserstrahlintensität, Bewegung der Meßkammer bzw. des Mikroskops. Zur Abgrenzung dieser Möglichkeiten wurden die Boutons nach Vesikelfärbung mit FM 1-43 mit $4 \%$ Paraformaldehyd-Lösung fixiert. Fluktuationen, die durch einen nichtidealen Meßaufbau hervorgerufen werden, sollten nun sichtbar werden. In A- A bibildung 45 ist der Fluoreszenz-Zeit-Verlauf für ein fixiertes Bouton einige zehn Sekunden nach der Fixierung dargestellt und im Vergleich dazu im entsprechenden Maßstab für ein unbehandeltes Bouton in 'Âbbildung 46. Durch die Fixierung sind die großen relativen Fluoreszenzfluktuationen verschwunden. Nur eine leichte Drift in der Fluoreszenz mit einer Zeitkonstanten von etwa $10^{2}$ Sekunden ist erkennbar. Nichtbiologische Fluktuationsursachen können im betrachteten Zeitbereich also weitgehend ausgeschlossen werden.

Zur weiteren Analyse der Fluoreszenzfluktuationen wurden die Autokorrelationsfunktionen der fixierten und der unbehandelten Boutons berechnet (cf. ÁĀbibildung 47). Während die Fluoreszenz-Autokorrelationsfunktion des fixierten Boutons sich nahezu wie weißes Rauschen verhält, ist für eine unbehandelte Synapse eine abfallende Autokorrelationskurve erkennbar. Unterstellt man frei diffundierende, nicht interagierende Teilchen, so kann die berechnete Autokorrelationsfunktion mit G1. 38 die Anzahl der Teilchen im effektiven Detektionsvolumen $N$ erhalten, aus der Zeitkonstanten des Korrelationskurvenabfalls $\tau_{\mathrm{D}}$ und mit Hilfe von G1. $39 \mathrm{j}_{1}$ der Diffusionskoeffizient $D$. Somit ergaben sich die folgenden Werte: $N=17 ; \tau_{\mathrm{D}}=11 \mathrm{~s}, \Rightarrow D=0,75 \cdot 10^{-3} \mu \mathrm{m}^{2} / \mathrm{s}$ 


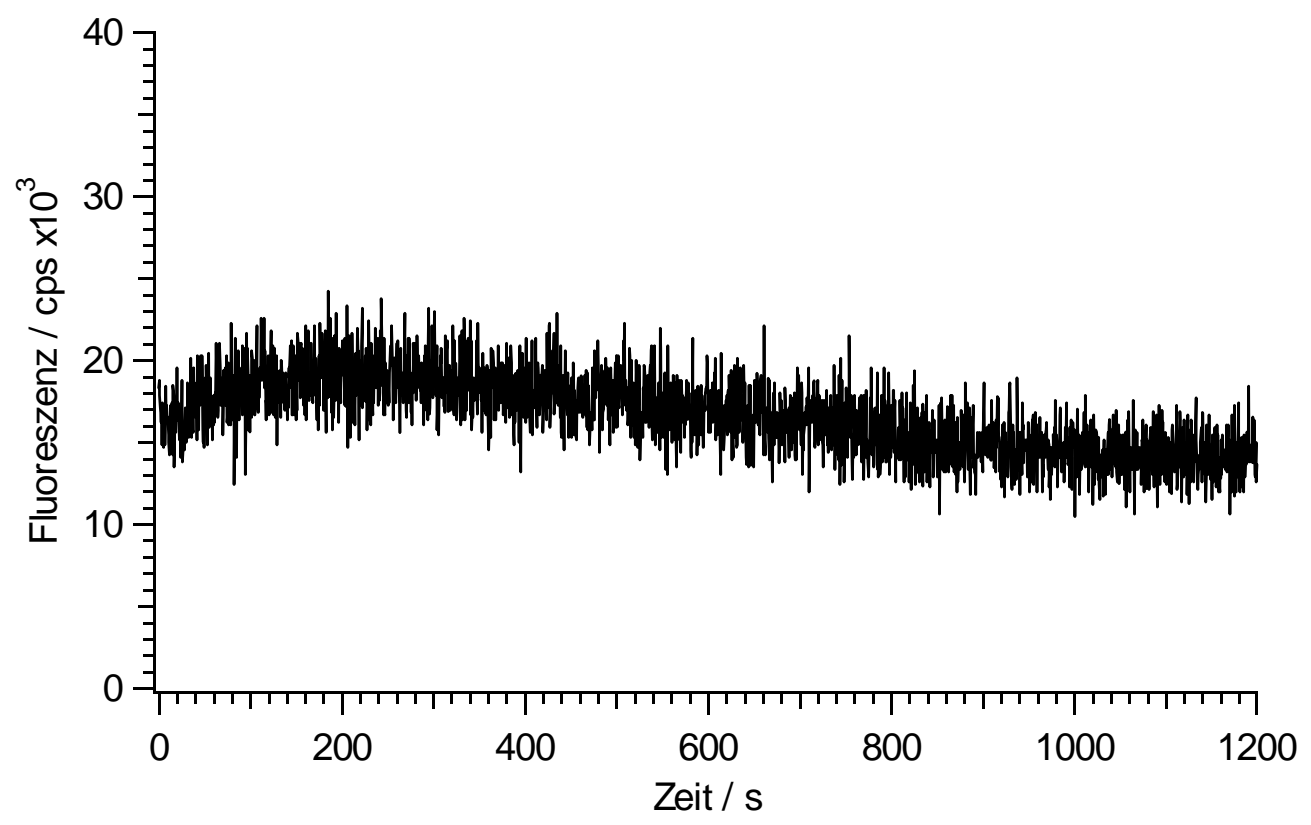

Abbildung 45: Fluoreszenz-Zeit-Verlauf einer Synapse mit farbstoffmarkierten Vesikeln nach Fixierung mit $4 \%$ Paraformaldehyd.

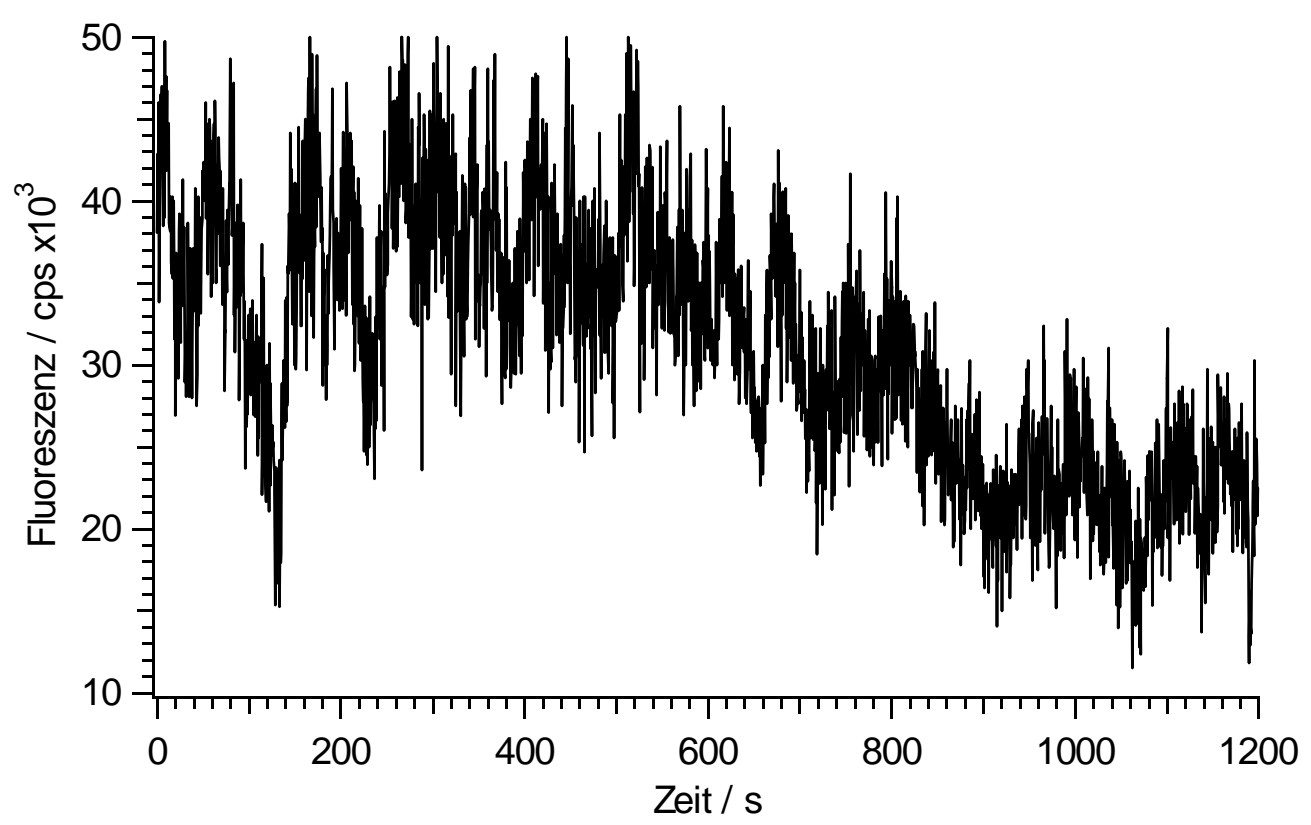

Abbildung 46: Fluoreszenz-Zeit-Verlauf einer unstimulierten Synapse mit farbstoffmarkierten Vesikeln.

Die Anpassung mit dem theoretischen Modell frei diffundierender Teilchen ist allerdings nicht adäquat. Synaptische Vesikel haben einen Durchmesser von etwa $40 \mathrm{~nm}[18]$ und können durch eine Vielzahl von Proteinen mit ihrer Umgebung interagieren. 


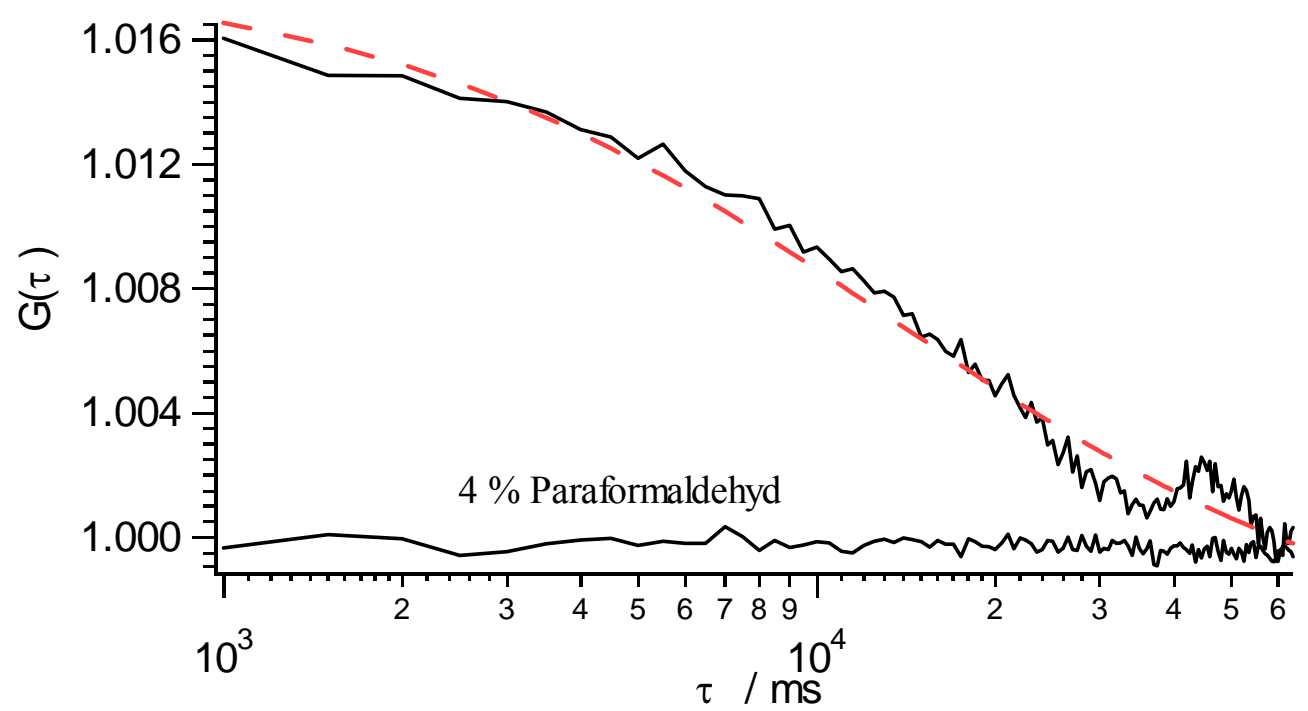

Abbildung 47: Autokorrelationsfunktionen für das fixierte und das unbehandelte Neuron aus den beiden vorherigen Abbildungen. Die Anpassung der Autokorrelationskurve mit einem dreidimensionalen Diffusionsmodell (G1. $38 \mathrm{~g}$ ) ist in rot eingezeichnet $\left(N=31 ; \tau_{\mathrm{D}}=11 \mathrm{~s}, \Rightarrow D=0,75 \cdot 10^{-3} \mu \mathrm{m}^{2} / \mathrm{s}\right.$ ).

Aus Untersuchungen ist bekannt, daß dendritische Dornen in lebenden Zellkulturen beträchtlich mobil sind und reorganisiert werden [81]. Dies wird besonders während der Zeit der Synaptogenese (Tag 0-10 nach Präparation) beobachtet, wobei nach 10 Tagen die Beweglichkeit geringer wird $[81]$. Im Rahmen dieser Arbeit wurden deshalb Neurone zwischen dem 13. und 22. Tag nach der Präparation verwendet.

Langsame Änderungen in den beobachteten Fluoreszenzverläufen müssen dennoch nicht ausschließlich von der Bewegung synaptischer Vesikel herrühren, sondern können durch eine langsame Bewegung der gesamten Synapse durch den Laserstrahl überlagert sein. Eine Positionsveränderung der Probe wurde aber selbst innerhalb der längsten Messungen von 20 Minuten Dauer nicht beobachtet, wobei mit dem Auge eine Positionsverschiebung des Meßortes um 0,5 $\mu \mathrm{m}$ erkennbar gewesen wäre. Die Positionsänderung des Meßortes betrug also maximal 0,4 nm/s. Bei einem durchschnittlichen Radius in der fokalen Ebene des Detektionsvolumens von $175 \mathrm{~nm}$ beträgt der Effekt max. 4,5\% in $20 \mathrm{~s}$.

Um eine mögliche Überlagerung der Vesikelbewegung durch die Bewegung des gesamten Meßortes zu minimieren, wurde der mittelwertsubtrahierte Fluoreszenzdatensatz vor der Analyse mit $0,05 \mathrm{~Hz}$ hochpassgefiltert, und zur Analyse der Fluoreszenzfluktuationen im weiteren das Leistungsspektrum der gefilterten Fluoreszenzdaten verwendet (cf. Kap. 2.2. Berechnung von Autokorrelationsfunktion und Leistungsspektrum).

Im folgenden soll überprüft werden, ob und ggf. in welchem Maße die Vesikelmobilität modulierbar ist. Durch systematische Applikation verschiedener Pharmaka, die regulierend in der Synapse eingreifen, sollen zunächst die Grundlagen der Vesikelbeweglichkeit in der unstimulierten Synapse verstanden werden. Die verwendeten Pharmaka wirken sowohl auf Kinasen und Phosphatasen als auch auf das Cytoskelett in der Synapse. 


\subsubsection{Kinasen-Inhibitoren}

Der zellpermeable Wirkstoff ML-7 ist ein potenter Inhibitor der Myosin-Leichtketten-Kinase $\left(K_{\mathrm{i}}=300 \mathrm{nM}\right)$, blockt aber in höheren Konzentrationen auch die Proteinkinase A $\left(K_{\mathrm{i}}=21\right.$ $\mu \mathrm{M})$ und die Proteinkinase $\mathrm{C}\left(K_{\mathrm{i}}=42 \mu \mathrm{M}\right)$. Die Myosin-Leichtketten-Kinase (myosin light chain kinase, MLCK) benötigt zur Aktivierung die Bindung eines Komplexes aus $\mathrm{Ca}^{2+}$ und Calmodulin und phosphoryliert im aktivierten Zutand die leichte Kette des Motorproteins Myosin (ÄĀbilīung 48). Durch die Phosphorylierung kann das Myosin mit einem Actinfilament in Wechselwirkung treten und sich entlang des Actinfilamentes fortbewegen. Im dephosphorylierten Zustand ist das Motorprotein jedoch inaktiv [2]

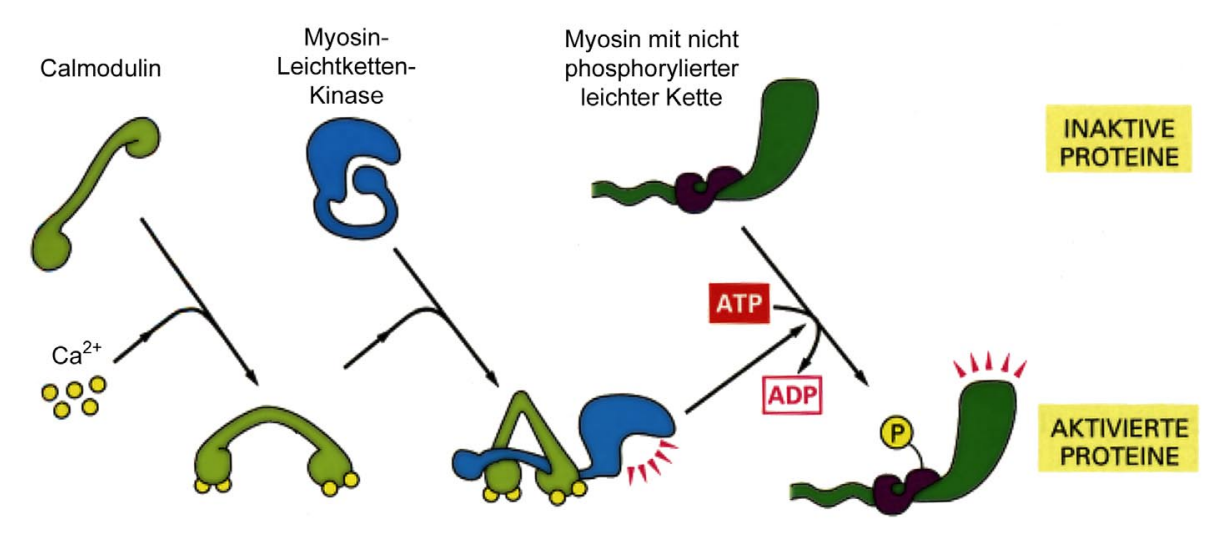

Abbildung 48: Schematische Darstellung der Aktivierungskaskade von $\mathrm{Ca}^{2+} /$ Calmodulin/MyosinLeichtketten-Kinase und Myosin (nach $\left[\begin{array}{l}2 \\ 2\end{array}\right.$

Zur Untersuchung eines Effektes der MLCK auf die Vesikelmobilität wurde nach Anfärbung der Vesikel und Auswaschen des Farbstoffs aus der Membran $15 \mu \mathrm{M}$ ML-7 der extrazellulären Lösung zugegeben, und der Fluoreszenz-Zeit-Verlauf nach einer Einwirkzeit von 10-20 Minuten gemessen. Zu Kontrollzwecken wurden die Fluoreszenzmessungen ohne die Einwirkung von ML-7 mit Neuronen der gleichen Zellpräparation wiederholt. Bei der Auswahl der Boutons für die Kontrollmessungen und unter Pharmakoneinwirkung wurde darauf geachtet, daß die Fluoreszenz-Zählraten der einzelnen Boutons vergleichbar sind, d.h. daß die Anzahl der farbstoffmarkierten Vesikel pro Bouton ungefähr gleich ist. Ein typisches Beispiel des Fluoreszenzverlaufs unter Einwirkung von ML-7 ist in gleich dazu ein repräsentatives Beispiel ohne ML-7 in 


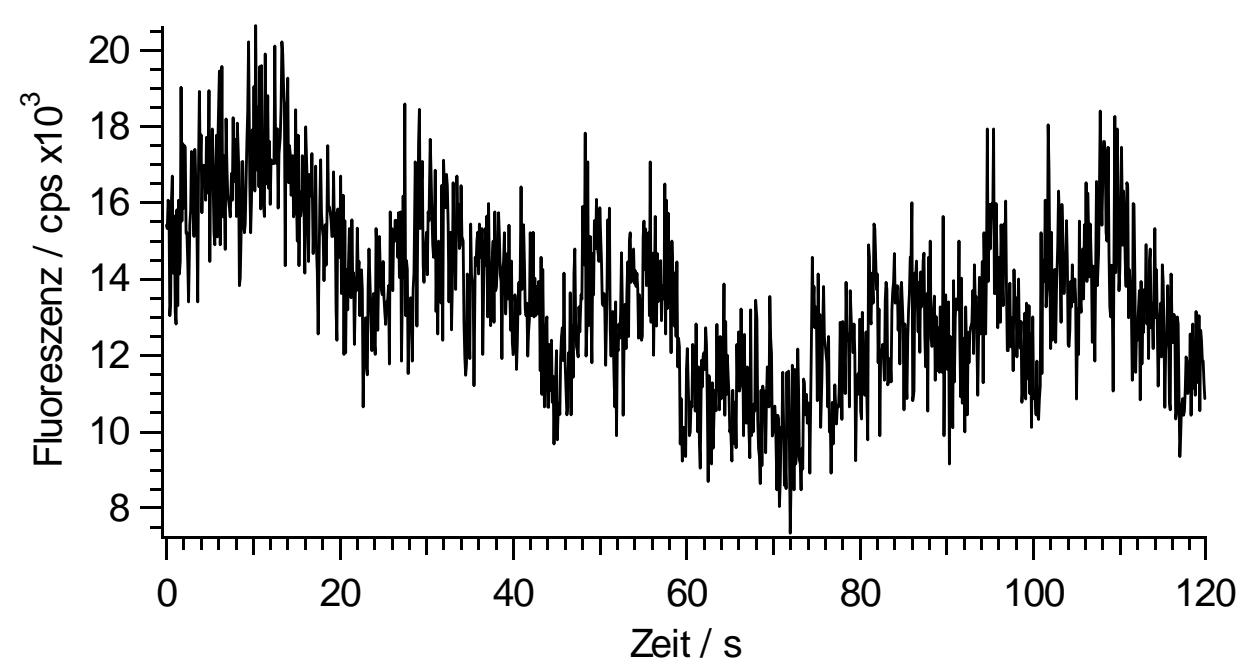

Abbildung 49: Typischer ungefilterter Fluoreszenz-Zeit-Verlauf in einem unstimulierten Bouton ohne Wirkstoffeinfluß (Kontrollbedingung).

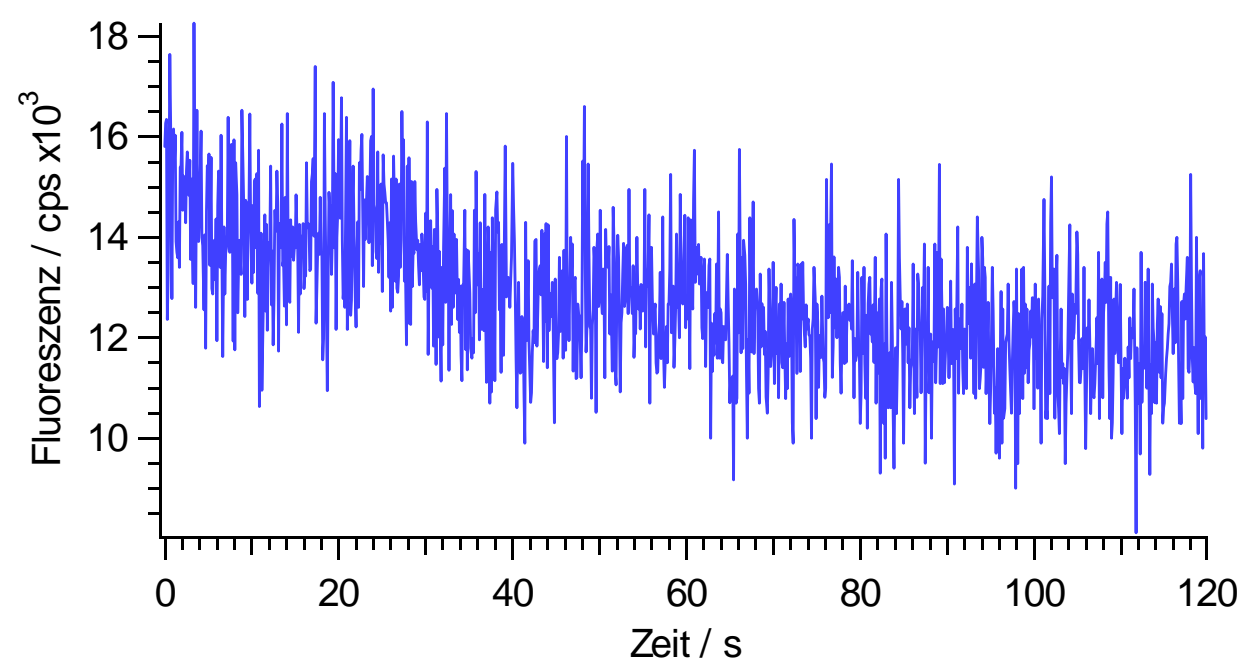

Abbildung 50: Beispiel eines ungefilterten Fluoreszenz-Zeit-Verlaufs in einem unstimulierten Bouton in Anwesenheit von $15 \mu \mathrm{M}$ ML-7.

Die Fluktuationen in Anwesenheit von $15 \mu \mathrm{M}$ ML-7 sind im Vergleich zur Kontrolle deutlich reduziert. Zur Analyse der Fluoreszenzdaten wurde von diesen zunächst der Mittelwert subtrahiert und mit $0,05 \mathrm{~Hz}$ hochpassgefiltert. filterte Fluoreszenzbeispiel ohne ML-7 Einwirkung. 


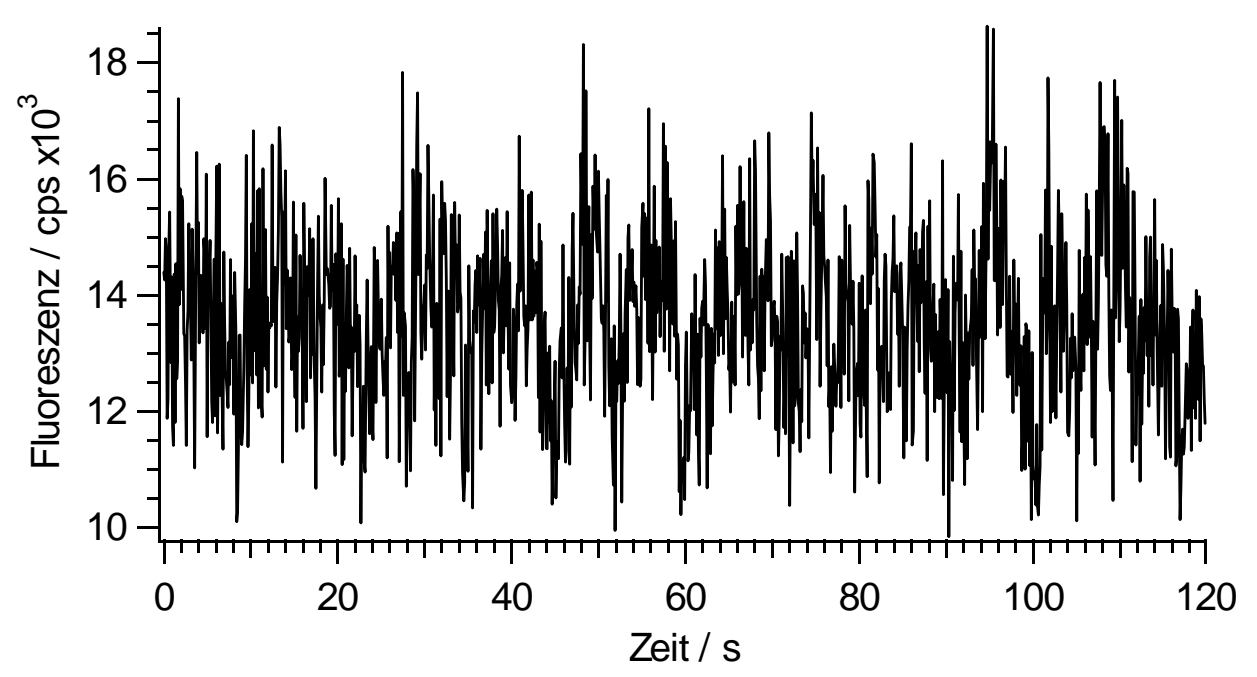

Abbildung 51: Fluoreszenz-Zeit-Verlauf aus Ầbildung 51 ĭhochpassgefiltert mit 0,05 Hz.

Aus den gefilterten absoluten Fluoreszenzfluktuationen wurde dann das Leistungsspektrum des einzelnen Datensatzes berechnet. Das Ergebnis aller Fluoreszenzmessungen unter gleichen Bedingungen ist das arithmetische Mittel der einzelnen Leistungsspektren. Für die Einwirkung von ML-7 und unter Kontrollbedingungen ist dies in Äbbildung 52 'dargestellt.

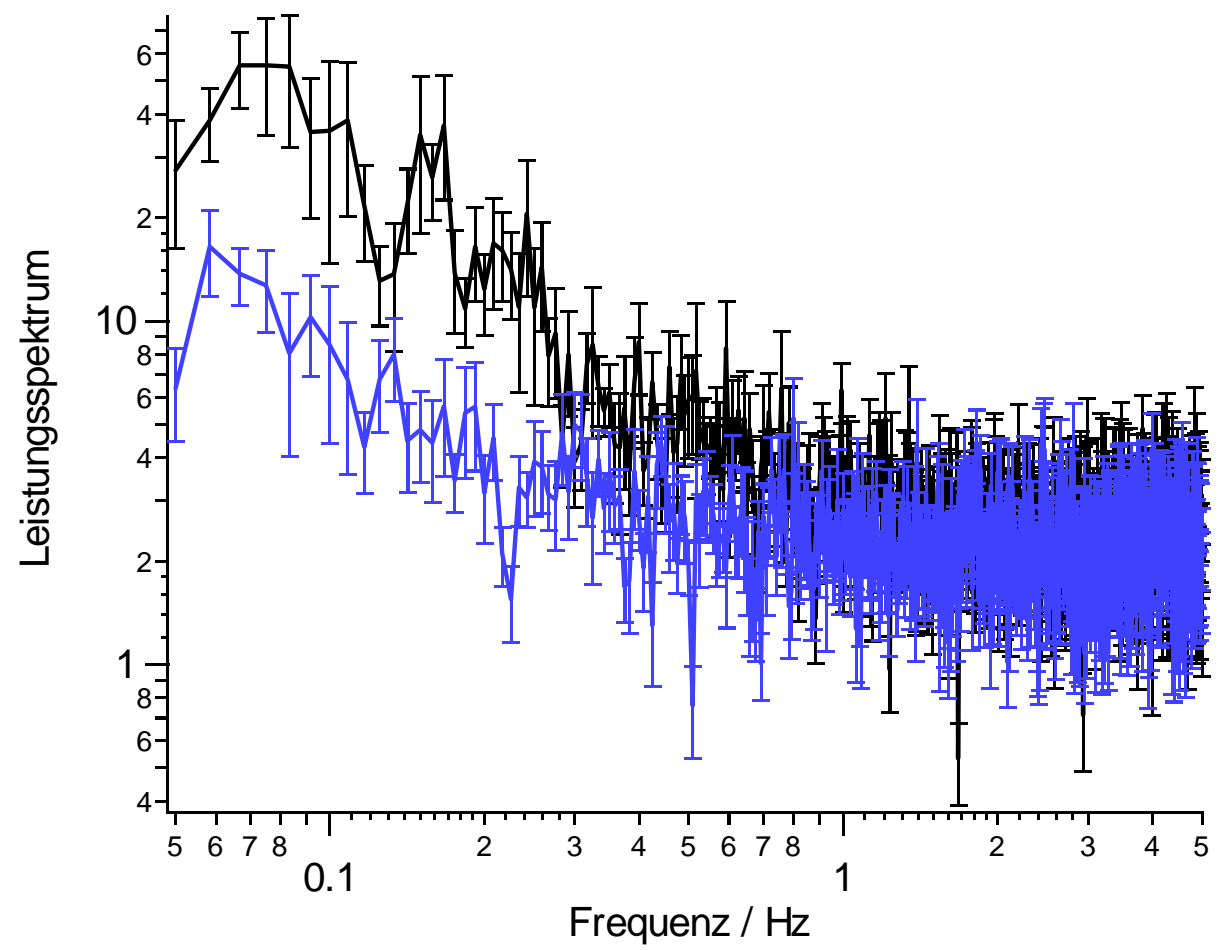

Abbildung 52: Mittleres Leistungsspektrum vor dem Zusammenfassen der Punkte: $15 \mu \mathrm{M}$ ML-7 (blau, $n=13$ ); Kontrolle (schwarz, $n=13$ );

Zur besseren Übersicht wird im folgenden die Anzahl der dargestellten Datenpunkte im Leistungsspektrum reduziert, indem nur das arithmetische Mittel in äquidistanten Zeitintervallen abgebildet wird. Die so erhaltenen Leistungsspektren der Fluoreszenzfluktuationen für ML-7 
und Kontrolle sind in spektrum für weißes Rauschen eingezeichnet.

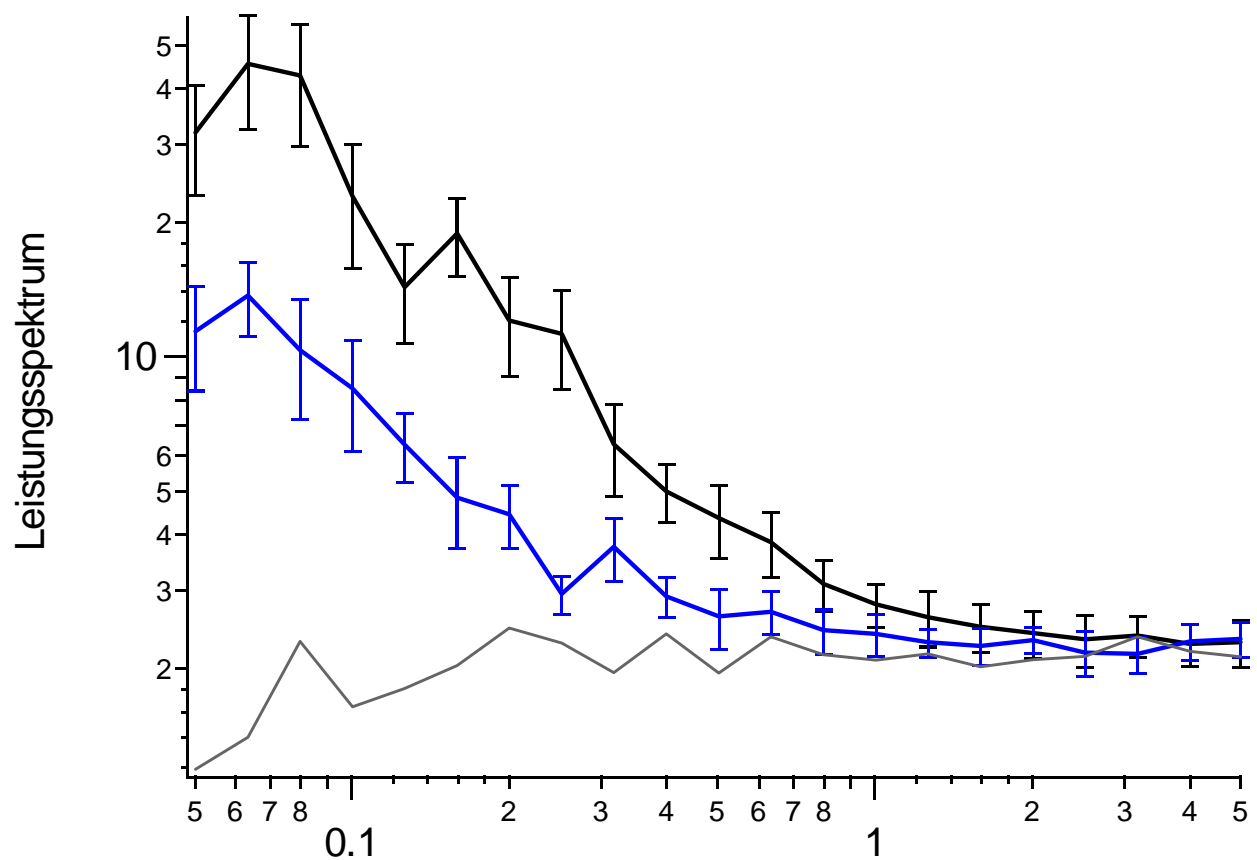

Frequenz / $\mathrm{Hz}$

Abbildung 53: Mittleres Leistungsspektrum: $15 \mu \mathrm{M}$ ML-7 (blau, $n=13$ ); Kontrolle (schwarz, $n=13$ ); weißes Rauschen (grau).

Im Vergleich zu Kontrollbedingungen sind in Anwesenheit von ML-7 die Fluktuationen im Frequenzband zwischen 0,05 und $0,6 \mathrm{~Hz}$ signifikant erniedrigt. Die Verringerung im Leistungsspektrum kann zwei mögliche Ursachen haben. Zum einen könnte sich die Anzahl der fluktuierenden Vesikel verringert haben, zum anderen ist eine geringere Mobilität der Vesikel bei unveränderter Vesikelanzahl möglich oder es könnte eine Mischung aus beiden Prozessen sein. Die Anzahl der Vesikel im Detektionsvolumen wurde über die Varianz des gefilterten Datensatzes berechnet (cf. Gl. '44). Dabei wurde sowohl für die Zufälligkeit der Fluoreszenzemission (Gl. $\bar{i} \overline{4} \bar{b})$ als auch für die Hintergrundfluoreszenz korrigiert (Gl. $\overline{7} \overline{3}$ ). Weiterhin wurde bei der Berechnung der Vesikelzahl berücksichtigt, daß das Detektionsvolumen entlang der optischen Achse in beiden Richtungen ab einem Radius von $z_{0} \approx 0,5 \mu \mathrm{m}$ aus dem Bouton herausragt (Boutondurchmesser: etwa $1 \mu \mathrm{m}$ ). Hieraus berechnet sich ein etwa 1,8 fach kleineres Detektionsvolumen im Vergleich zu einem dreidimensionalem Gaußvolumen; [83]. Die erhaltenen Ergebnisse sind in Trabelle 3 izusammengestellt.

Tabelle 3: Ergebnisse der Varianzanalyse unter ML-7-Einwirkung und Kontrollbedingungen.

\begin{tabular}{lllll}
\hline & $<F(t)>/ \mathrm{kcps}$ & $<\delta F(t)^{2}>/ \mathrm{kcps}^{2}$ & $N_{\text {total }}$ & $N_{\mathrm{im}} /\left(N_{\mathrm{im}}+N_{\mathrm{m}}\right)$ \\
\hline Kontrolle & $7,9 \pm 2,7$ & $1,91 \pm 0,78$ & $21,8 \pm 9,9$ & $0,83 \pm 0,10$ \\
$15 \mu \mathrm{M}$ ML-7 & $7,1 \pm 3,7$ & $1,23 \pm 0,43$ & $27,0 \pm 18,7$ & $0,87 \pm 0,07$ \\
\hline
\end{tabular}


Die berechnete Vesikelanzahl im Detektionsvolumen $N_{\text {total }}$ ist auffällig hoch. Aus den Stimulations-Experimenten zur Bestimmung der mittleren Zählrate pro Vesikel wurde ein Wert von $q_{v e s} \approx 2 \mathrm{kcps} /$ Vesikel erhalten (s.u.). Bei vergleichbaren mittleren Zählraten $\langle F(t)>$ von etwa 7,5 kcps in Anwesenheit von ML-7 oder unter Kontrollbedingungen würde man deshalb eine Vesikelanzahl von ca. 3 erwarten. Die aus der Varianzanalyse berechnete mittlere Vesikelzahl liegt aber zwischen 22 und 27. Die scheinbar zu hohe Vesikelanzahl kann aber mit einem Anteil immobiler Vesikel erklärt werden, die unter den experimentellen Bedingungen nicht zur Varianz der Fluoreszenz $<\delta F(t)^{2}>$, aber zur mittleren Fluoreszenz $<F(t)>$ beitragen. Dies führt zu kleineren normierten Fluoreszenzfluktuationen $\left\langle\delta F(t)^{2}>/\langle F(t)\rangle^{2}\right.$ und somit zu einer größeren Teilchenzahl $N$ (cf. Gl. '44)

Die immobilen Vesikel verhalten sich formal also wie Hintergrundfluoreszenz. Die aus der Varianzanalyse erhaltene Teilchenzahl $N_{\text {total }}$ kann also in Anlehnung an Gl. geschrieben werden:

$$
G(\tau=0)=1+\frac{1}{N_{\text {total }}}=1+\frac{N_{\mathrm{m}}}{\left(N_{\mathrm{m}}+N_{\text {im }}\right)^{2}}
$$

$\left(N_{\mathrm{m}}=\right.$ mobile Vesikelanzahl; $N_{\mathrm{im}}=$ immobile Vesikelanzahl).

Die mittlere Fluoreszenz setzt sich dementsprechend aus mobilen und immobilen Vesikeln zusammen:

$$
\langle F(t)\rangle=\left(N_{\mathrm{m}}+N_{\text {im }}\right) q_{\text {ves }}
$$

( $q_{\text {ves }} \approx 2$ kcps; mittlere Zählrate pro Vesikel bestimmt aus den Stimulations-Experimenten).

Aus den vorherigen beiden Gleichungen berechnet sich die Anzahl der mobilen Vesikel $N_{m}$ wie folgt:

$$
N_{\mathrm{m}}=\frac{\left(\langle F(t)\rangle / q_{\mathrm{ves}}\right)^{2}}{N_{\text {total }}}
$$

und somit ergibt sich der immobile Anteil der Vesikel $N_{\mathrm{im}} /\left(N_{\mathrm{im}}+N_{\mathrm{m}}\right)$ aus:

$$
\frac{N_{\mathrm{im}}}{N_{\mathrm{im}}+N_{\mathrm{m}}}=1-\frac{\langle F(t)\rangle}{q_{\mathrm{ves}} N_{\text {total }}}
$$

Der nur geringfügig höhere immobile Vesikelanteil unter ML-7 Einwirkung verglichen mit den Kontrollbedingungen legt den Schluß nahe, daß der deutliche Unterschied in den beiden Leistungsspektren überwiegend durch eine Verlangsamung der Vesikelbewegung verursacht wird. Da im Stimulationsexperiment Ereignisse geringer Intensität aufgrund des Rauschlevels nicht detektiert werden konnten, ist die mittleren Zählrate pro Vesikel möglicherweise über- 
schätzt. Es würde sich bei einem kleinerem Wert von $q_{\text {ves }}$ eine entsprechend geringerer immobiler Anteil ergeben.

Den Einfluß von Proteinkinase-A-abhängigen Prozessen wurde durch $100 \mu \mathrm{M}$ Rp-8-BrcAMPS, einem Blocker der Proteinkinase A mit Präferenz für den Subtyp I, untersucht [8 $8 \overline{4}]$. Die Proteinkinase A ist ein Enzym, das in Antwort auf eine Erhöhung an intrazellulärem zyklischem Adenosin-5'-monophosphat (cAMP) hin Zielmoleküle phosphoryliert.

Die Proteinkinase besteht in der inaktiven Form aus einem Komplex von zwei regulatorischen und zwei katalytischen Untereinheiten. An jede regulatorische Untereinheit können zwei cAMP-Moleküle binden, wobei die Bindung von zwei cAMP-Molekülen ausreicht, um aus dem tetrameren Komplex die beiden katalytischen Untereinheiten freizusetzen. Der Typ I der Proteinkinase A befindet sich überwiegend im Cytoplasma, während der Typ II über seine regulatorische Untereinheit an die Plasma- bzw. Kernmembran und Mikrotubuli gebunden ist [21].

Die mittleren Leistungsspektren unter Kontrollbedingungen und unter Wirkstoffeinfluß sind in schied zu erkennen.

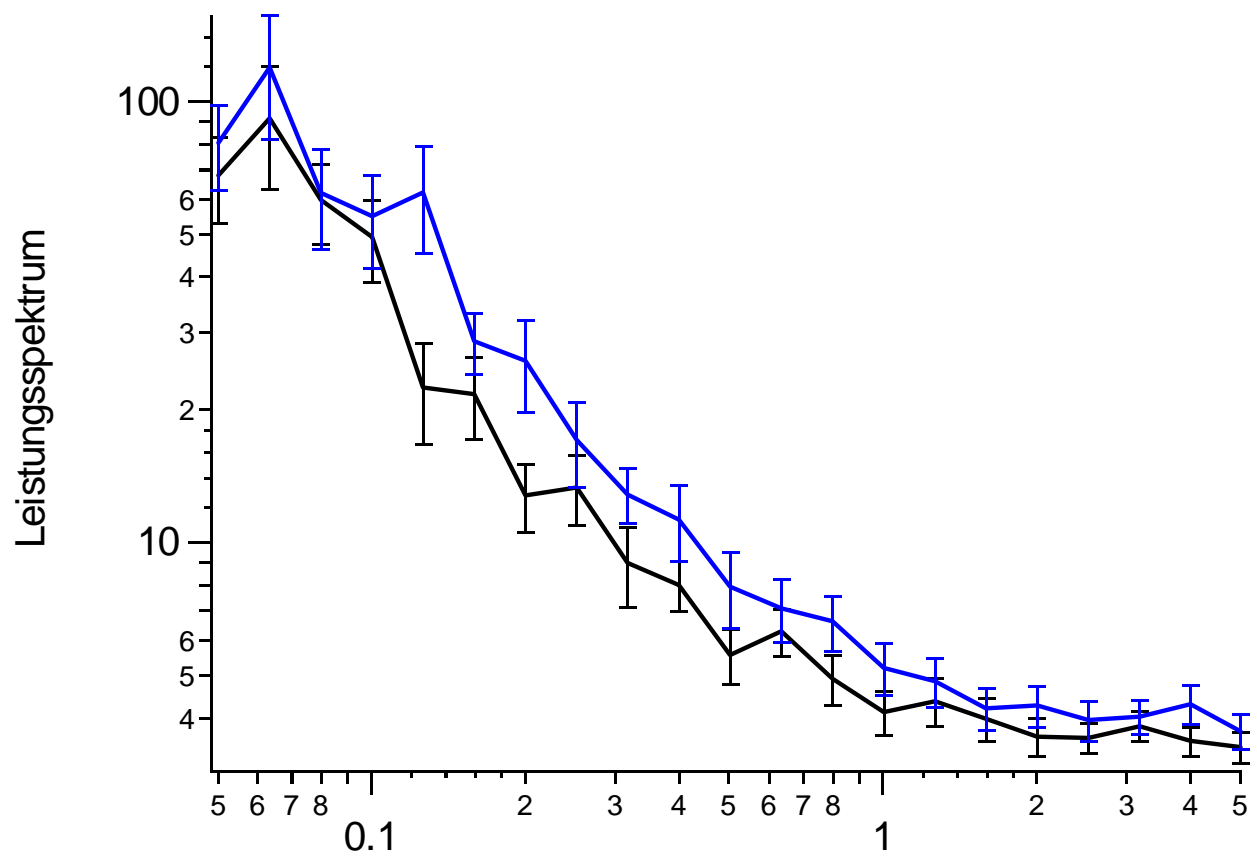

Frequenz / Hz

Abbildung 54: Mittleres Leistungsspektrum: $100 \mu \mathrm{M}$ Rp-8-Br-cAMPS (blau, $n=14)$; Kontrolle $(n=$ $15)$. 
Bisindolylmaleimid I ist ein selektiver zellpermeabler Inhibitor der Proteinkinase $\mathrm{C}\left(K_{\mathrm{i}}=10\right.$ $\mathrm{nM}$ ) und zeigt hohe Selektivität für die Isoenzyme PKC $\alpha, \beta \mathrm{I}, \beta \mathrm{II}, \gamma, \delta$ und $\varepsilon$. Bisindolylmaleimid I agiert als kompetitiver Inhibitor für die ATP-Bindungsstelle der Proteinkinase C (PKC) und blockt in höheren Konzentrationen auch die Proteinkinase A $\left(K_{\mathrm{i}}=2 \mu \mathrm{M}\right)$ [8- 25$]$. Die Funktion der Proteinkinase $C$, besteht in der Phosphorylierung von spezifischen Zielproteinen an Serin- und Threonin-Resten.

Es gibt mindestens 9 Isoformen der PKC, die alle im Nervengewebe vorkommen [1] $]$ ]. Man unterscheidet die sogenannten Hauptformen $(\alpha, \beta \mathrm{I}, \beta \mathrm{II}$ und $\gamma)$, die durch $\mathrm{Ca}^{2+}$ aktiviert werden können und alle eine $\mathrm{Ca}^{2+}$-Bindungsstelle besitzen, von den Nebenformen (z. B. $\delta, \varepsilon$ und $\zeta$ ), die $\mathrm{Ca}^{2+}$-unabhängig arbeiten. Alle Isoformen können durch Diacylglycerol oder Phorbolester aktiviert werden [21]

Inhibition der PKC durch $1 \mu \mathrm{M}$ Bisindolylmaleimid I zeigt keinen signifikanten Unterschied zu Kontrollbedingungen (Âbbildung 55).

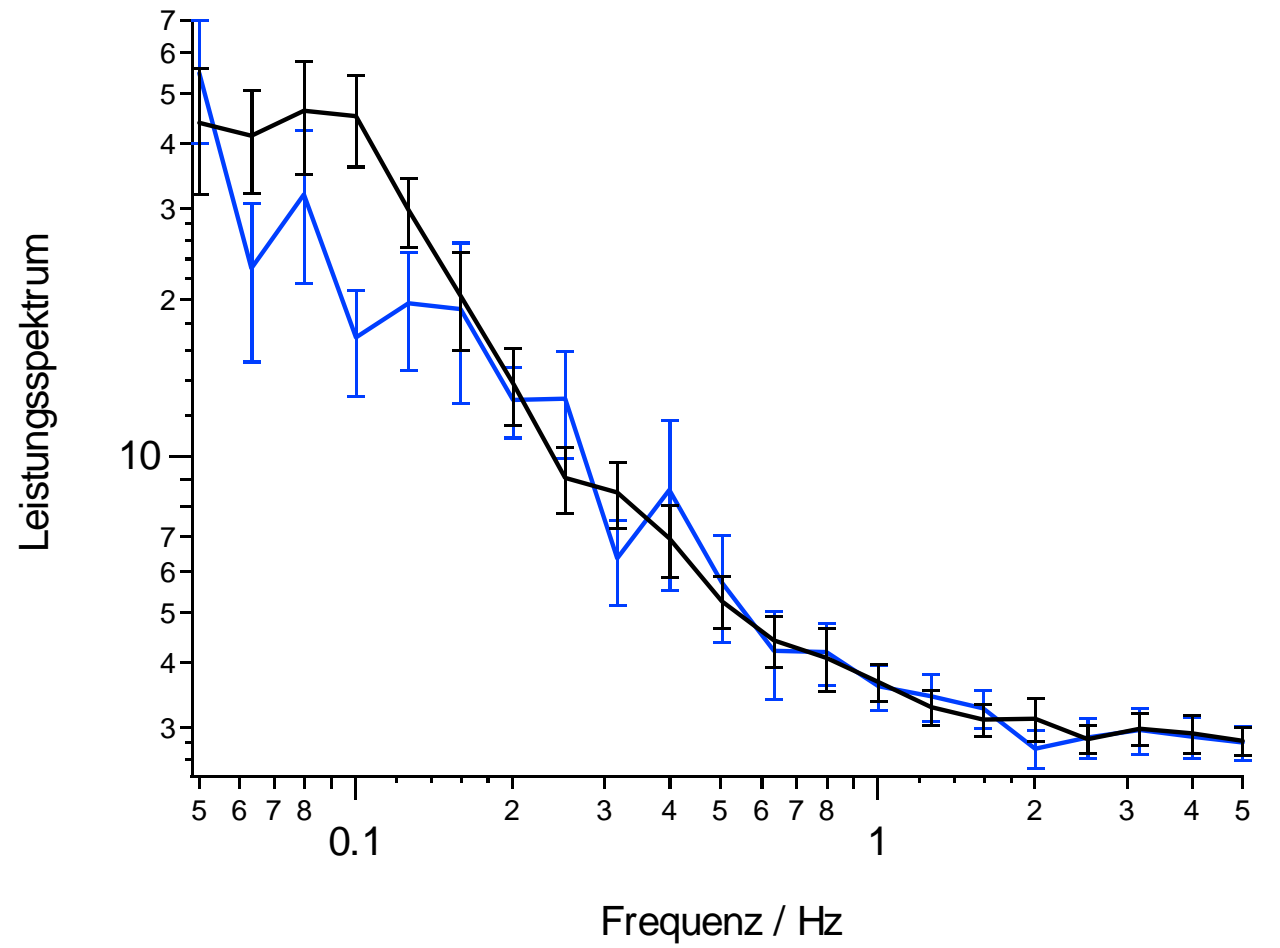

Abbildung 55: Mittleres Leistungsspektrum: $1 \mu \mathrm{M}$ Bisindolylmaleimid I $(n=7)$; Kontrolle $(n=13)$.

$\mathrm{Ca}^{2+} /$ Calmodulin-abhänigige Proteinkinasen (CaM-Kinasen) katalysieren die Phosphorylierungsreaktion an Serin- oder Threonin-Reste in Proteinen. Zur Aktivierung dieser Kinasen muß zunächst $\mathrm{Ca}^{2+}$ an das Protein Calmodulin binden. Calmodulin besitzt vier hochaffine Bindungsstellen für $\mathrm{Ca}^{2+}$ und unterliegt einer Konformationsänderung, wenn es $\mathrm{Ca}^{2+}$ gebunden hat. Im $\mathrm{Ca}^{2+}$-gebundenen Zustand kann Calmodulin dann unter erneuter Konformationsänderung an andere Proteine binden und so z.B. die CaM-Kinasen aktivieren. Zur Familie der CaM-Kinasen gehören z.B. die MLCK und die CaM-Kinase II [21]!' 
Die CaM-Kinase II ist besonders in den Synapsen von Nervenzellen angereichert und wird wie bereits erwähnt durch $\mathrm{Ca}^{2+} /$ Calmodulin aktiviert. Die CaM-Kinase II phosphoryliert aber nicht nur andere Proteine, sondern auch sich selbst (Autophosphorylierung). Dadurch bleibt das Enzym selbst dann noch aktiv, wenn $\mathrm{Ca}^{2+} / \mathrm{Calmodulin}$ entfernt ist. Erst wenn Phosphatasen die durch Autophosphorylierung initiierte Enzymaktivität übertreffen, wird das Enzym inaktivin: 1].

Zum Blocken der CaM-Kinase II wurde $4 \mu \mathrm{M}$ KN-62, ein selektiver Inhibitor der CaMKinase II in Rattenhirnen $\left(K_{\mathrm{i}}=900 \mathrm{nM}\right)$ [- $[8 \overline{6}]$, zu den Neuronen gegeben und die FluoreszenzZeit-Funktion aufgenommen. Die mittleren Leistungsspektren der Fluoreszenzfluktuationen zeigen keinen Effekt im Vergleich zu unbehandelten Neuronen (Ầbbildung 56).

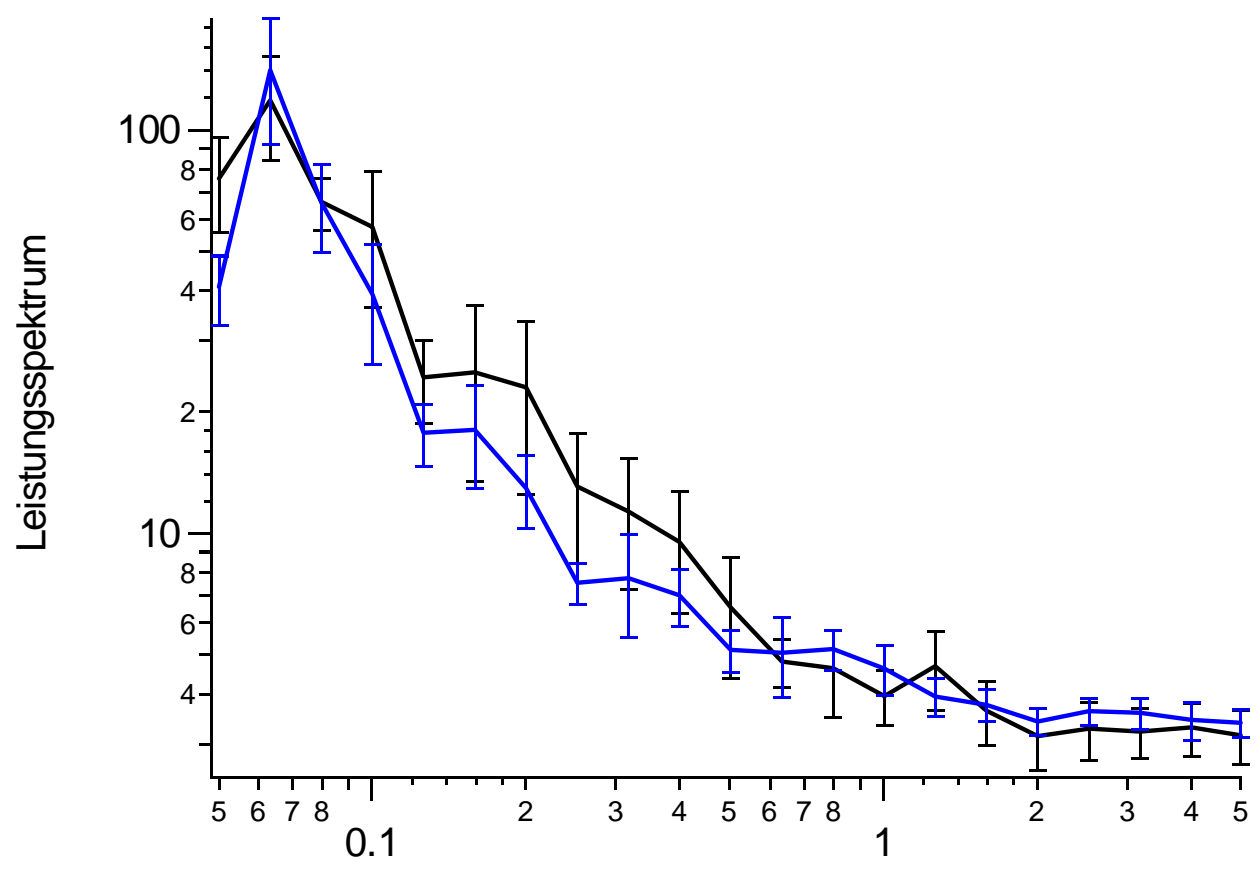

Frequenz / $\mathrm{Hz}$

Abbildung 56: Mittleres Leistungsspektrum: $4 \mu \mathrm{M} \mathrm{KN62} \mathrm{(blau,} n=8)$; Kontrolle $(n=7)$.

Die Inhibition einer einzelnen Kinasenklasse (wie z. B. der Proteinkinase A) könnte unter Umständen durch die vermehrte Aktivierung anderer Kinasenklassen kompensiert werden. Aus diesem Grunde wurden die Inhibitoren, die keinen Unterschied in der Vesikelmobilität unter Einsatz des Inhibitors und Kontrolle erkennen ließen (Rp-8-Br-cAMPS, Bisindolylmaleimid I und KN-62), gleichzeitig angewendet. Das mittlere Leistungsspektrum des Inhibitorenmixes aus $100 \mu \mathrm{M}$ Rp-8-Br-cAMPS, $1 \mu \mathrm{M}$ Bisindolylmaleimid I und $4 \mu \mathrm{M}$ KN-62 im Vergleich zu unbehandelten Neuronen ist in Abbildung 57 dargestellt. Die beiden Leistungsspektren überlappen nahezu, wobei sich bei Anwendung aller drei Inhibitoren eine leichte Erhöhung der Fluoreszenzfluktuationen zeigt. Der Effekt ist aber nicht sehr ausgeprägt. 


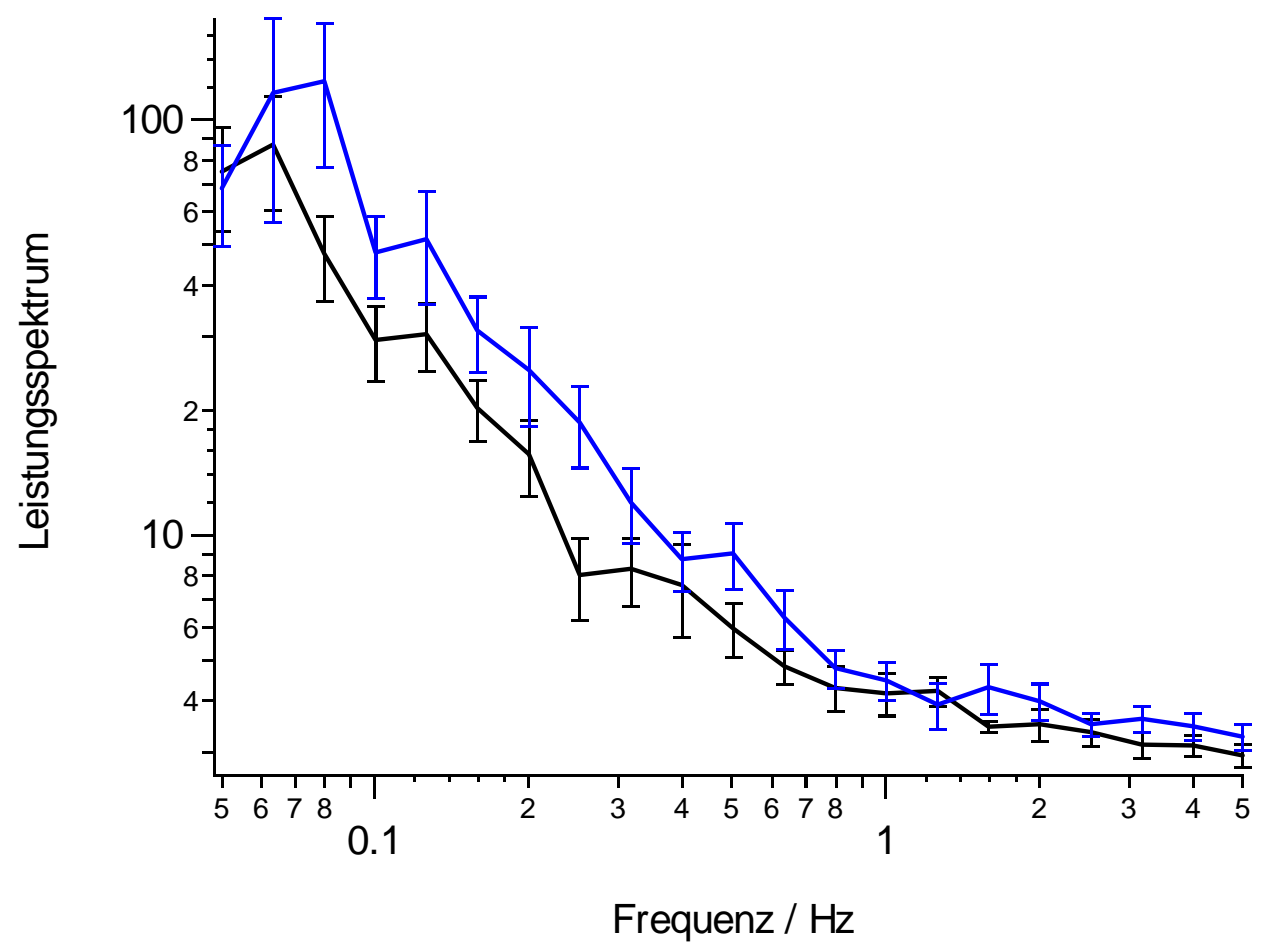

Abbildung 57: Mittleres Leistungsspektrum: $100 \mu \mathrm{M}$ Rp-8-Br-cAMPS $+1 \mu \mathrm{M}$ Bisindolylmaleimid I + $4 \mu \mathrm{M} \mathrm{KN}-62(n=13)$; Kontrolle $(n=13)$.

\subsubsection{Cytoskelett}

Zur Untersuchung einer Abhängigkeit der beobachteten Fluoreszenzfluktuationen vom Mikrotubulus, wurden die Mikrotubuli durch Inhibition der Tubulinpolymerisation mit $10 \mu \mathrm{M}$ Colchicin zerstört.

Das Bewegungsverhalten der Vesikel wurde durch diesen Prozeß nicht verändert, wie der Vergleich der Leistungsspektren mit und ohne Colchicin in Ẩb bildung 5 ìzeigt.

Die starke Mobilitätsverringerung der synaptischen Vesikel durch Inhibition der MLCK läßt die Beteiligung von Actinfilamenten vermuten, da Actin ein Bindungspartner der Myosine ist.

Das Pilzgift Cytochalasin D oder das Toxin Latrunculin B verkürzen die Actinfilamente, indem sie die weitere Addition von Action-Monomeren an das plus-Ende des Polymers bloc??ken [2]1].

Der Einfluß von Actinfilamenten auf die Beweglichkeit von synaptischen Vesikeln wurde untersucht, indem entweder Cytochalasin D oder Latrunculin B in die extrazelluläre Lösung gegeben wurde. Die Leistungsspektren in Anwesenheit von $10 \mu \mathrm{M}$ Cytochalasin D

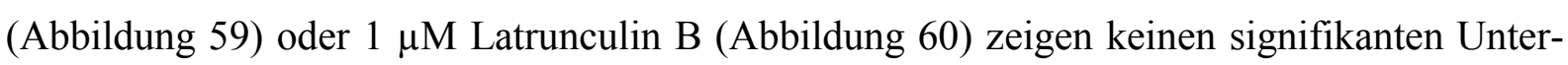
schied zu Kontrollbedingungen.

Um die Effektivität der Actinpolymerisations-Inhibition zu erhöhen, wurde die Konzentration von Latrunculin B auf $25 \mu \mathrm{M}$ erhöht und die Einwirkzeit verlängert, indem das Toxin für 70 Minuten in die extrazelluläre Lösung im Inkubator gegeben wurde. Nach dieser Zeit wurden die Neuronen mit Farbstoff beladen und nachfolgend wieder mit $25 \mu \mathrm{M}$ Latrunculin B ver- 
setzt. Auch unter diesen Bedingungen wurde keine Änderung der Vesikelmobilität beobachtet

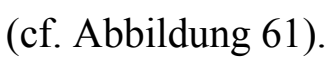

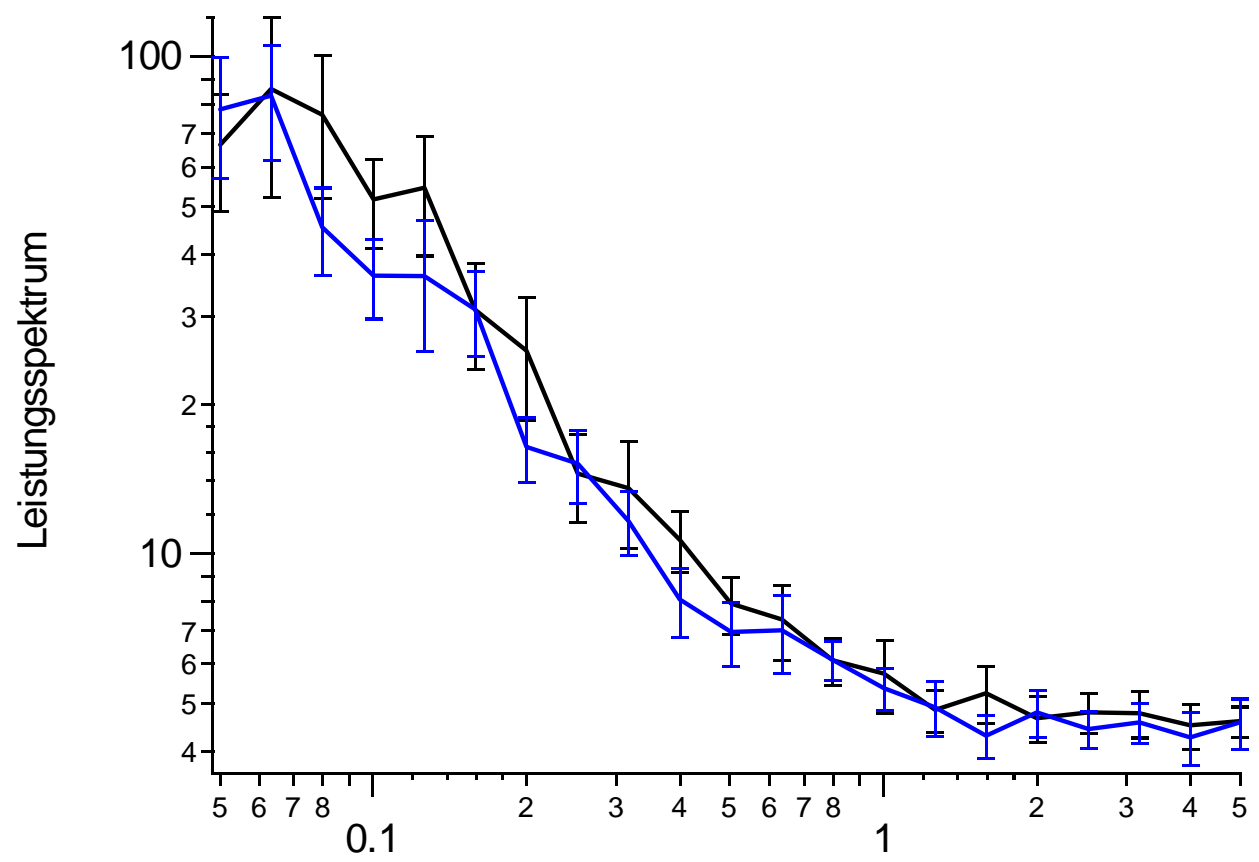

Frequenz / Hz

Abbildung 58: Mittleres Leistungsspektrum: $10 \mu \mathrm{M}$ Colchicin (blau, $n=10)$; Kontrolle $(n=12)$.

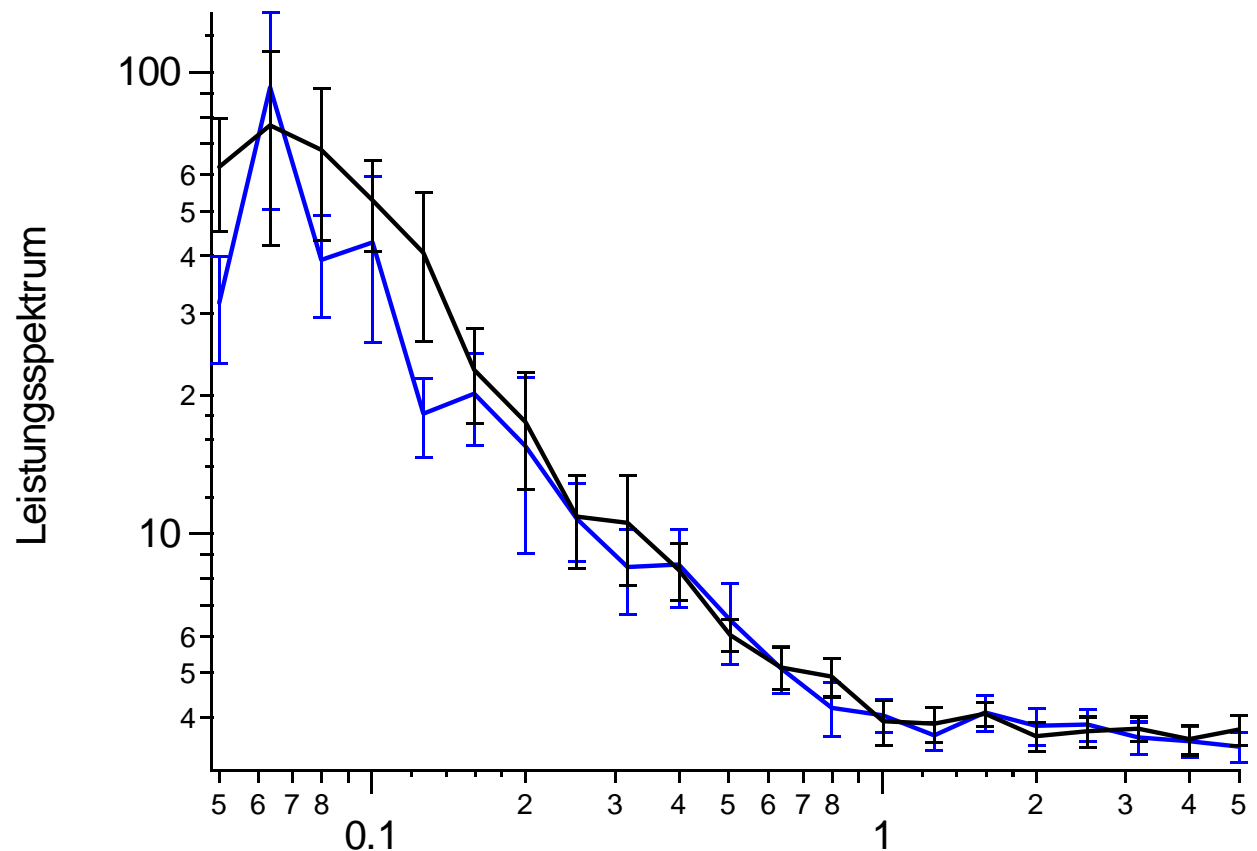

Frequenz / Hz

Abbildung 59: Mittleres Leistungsspektrum: $10 \mu \mathrm{M}$ Cytochalasin D (blau, $n=9)$; Kontrolle $(n=12)$. 


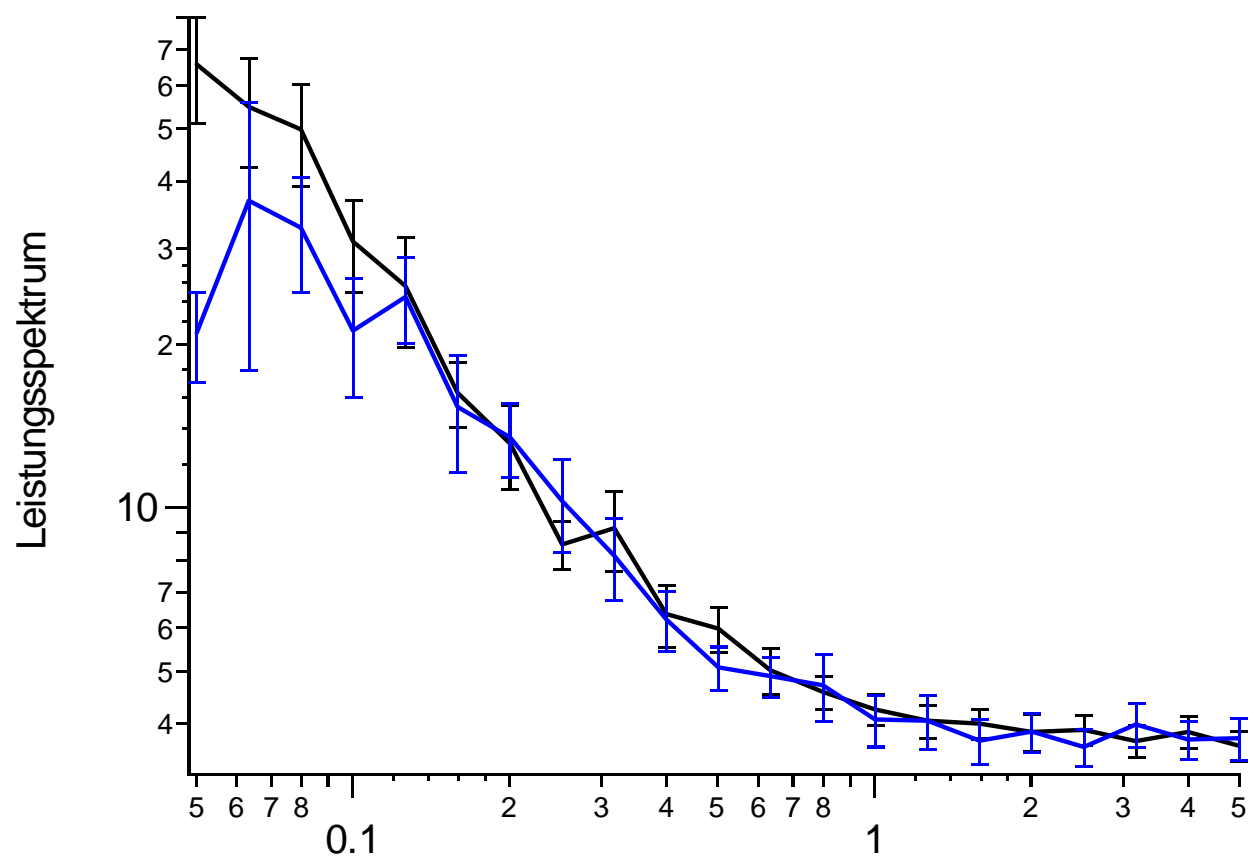

Frequenz / Hz

Abbildung 60: Mittleres Leistungsspektrum: $1 \mu \mathrm{M}$ Latrunculin B (blau, $n=14)$; Kontrolle $(n=17)$.

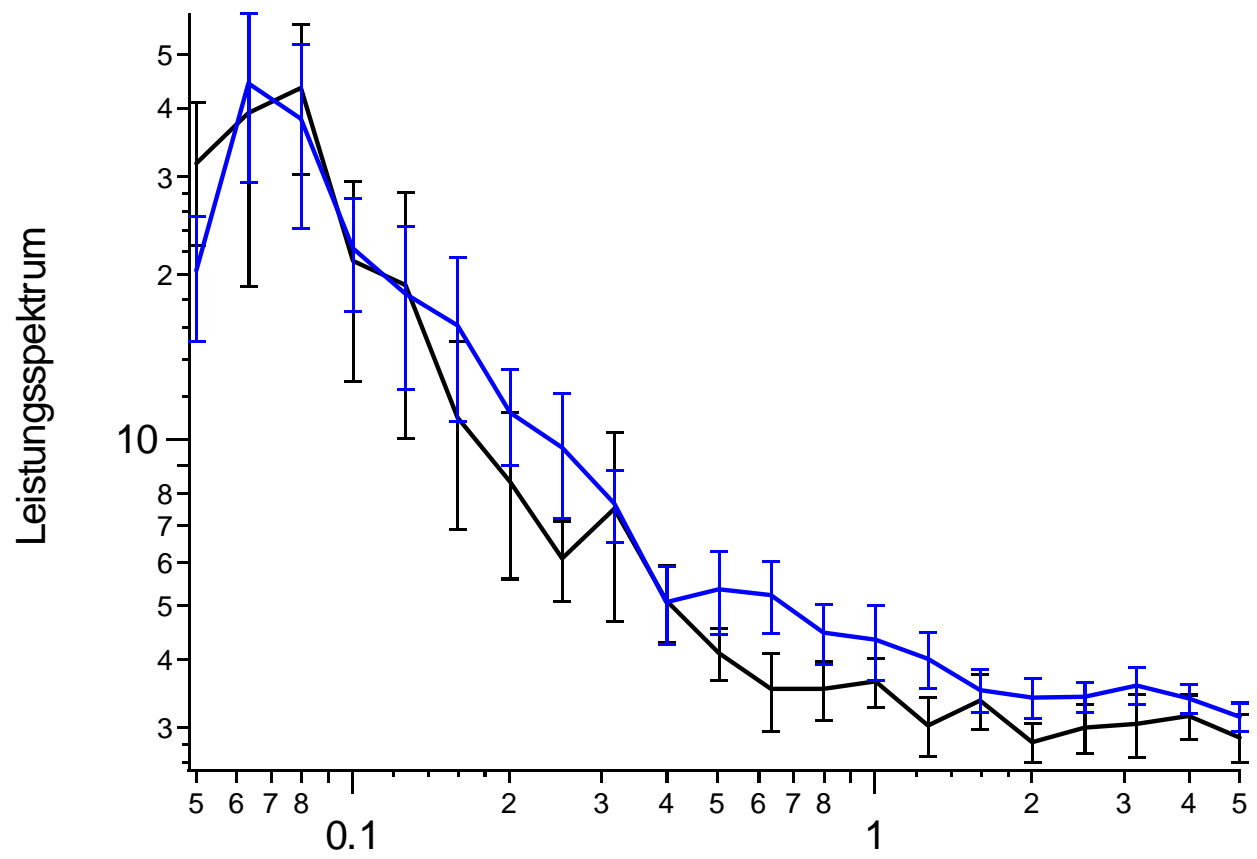

Frequenz / Hz

Abbildung 61: Mittleres Leistungsspektrum: $25 \mu \mathrm{M}$ Latrunculin B mind. 70 min vorinkubiert $(n=13)$; Kontrolle $(n=10)$. 


\subsubsection{Kinasen-Aktivatoren}

Eine Phosphoprotein-Phosphatase (oder kurz nur Phosphatase) ist ein Enzym, das eine Phosphatgruppe aus einem Protein durch Hydrolyse entfernt. Die Phosphatasen werden nach der Spezifität gegenüber ihren Zielmolekülen in zwei Hauptgruppen unterteilt: Die Serin/Threonin-Phosphatasen sowie die Tyrosin-Phosphatasen. Die Serin-/Threonin-Phosphatasen werden weiter unterteilt in die Typen 1 und 2. Während die Phosphatasen des Typs 1 durch Hitze und säurestabile Proteininhibitoren deaktiviert werden können, sind die Typ 2 Phosphatasen unempfindlich gegenüber diesen Inhibitoren. Bei den Phosphatasen des Typs 2 findet eine weitere Unterscheidung durch das Verhalten gegenüber divalenten Kationen statt: Die Phosphatase 2B benötigt $\mathrm{Ca}^{2+}$ und wird durch $\mathrm{Ca}^{2+} /$ Calmodulin reguliert; die Phosphatase $2 \mathrm{C}$ benötigt $\mathrm{Mg}^{2+}$; und die Phosphatase $2 \mathrm{~A}$ benötigt keine der beiden Kationen [187]

Okadasäure ist ein potenter Inhibitor der Phosphatase 1 und der Phosphatase 2A [88].

Ábibilung 62 zeigt einen Fluoreszenzverlauf in Anwesenheit von Okadasäure und Ábbildung 63 vergleicht die mittleren Leistungsspektren mit bzw. ohne Okadasäure. In Anwesenheit von $5 \mu \mathrm{M}$ Okadasäure ist eine deutliche Aktivitätssteigerung der Vesikel im Vergleich zu unbehandelten Neuronen zu beobachten.

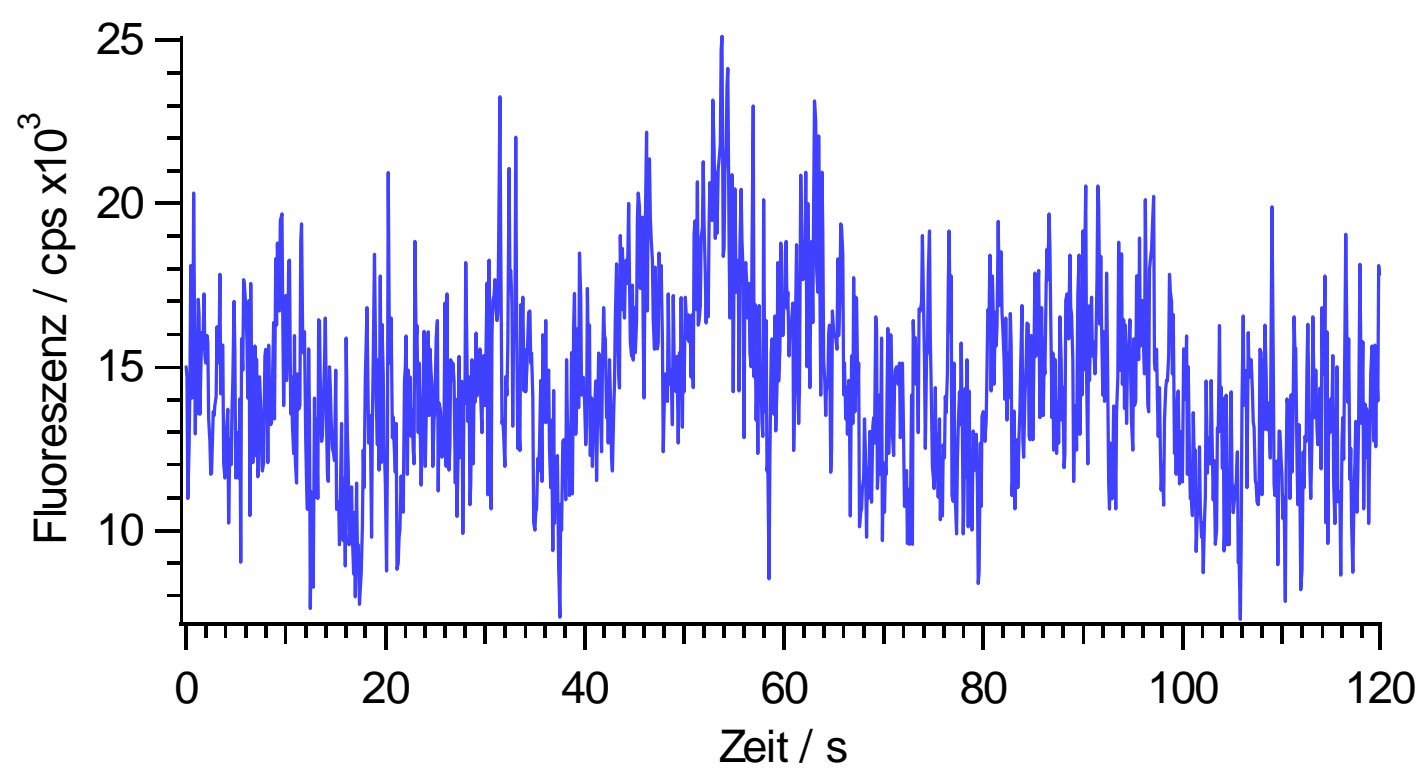

Abbildung 62: Beispiel eines ungefilterten Fluoreszenz-Zeit-Verlaufs in einem unstimulierten Bouton in Anwesenheit von $5 \mu \mathrm{M}$ Okadasäure.

Ein weiterer Unterschied im Vergleich zu den vorher gezeigten Leistungsspektren wird bei hohen Frequenzen deutlich. Während die oben gezeigten Leistungsspektren im schnellen Frequenzbereich überlappen, so ist dies unter Okadasäure im Vergleich zu unbehandelten Neuronen nicht der Fall. Eine Verschiebung des Leistungsspektrums nach oben ist bei vergleichbaren Zählraten unter beiden Bedingungen ein Indiz für eine höhere Anzahl an fluktuierenden Vesikeln. Erhöht man die Abtastrate von $10 \mathrm{~Hz}$ auf $20 \mathrm{~Hz}(5 \mathrm{~ms}$ Belichtung pro $50 \mathrm{~ms}$ 
Zeitintervall), wird die Verschiebung des Leistungsspektrums deutlicher ('Â̄bibildung 64). Die Varianzanalyse zeigt auch leicht höheren Anteil mobiler Vesikel unter Okadasäure (cf. Tabelle 4). Okadasäure führte im Unterschied zu den bisher betrachteten Pharmaka somit auch zu einer leicht erhöhten Vesikelmobilisierung.

Tabelle 4: Varianzanalyse in Anwesenheit bzw. ohne $5 \mu \mathrm{M}$ Okadasäure (OA).

\begin{tabular}{lllll}
\hline & $<F(t)>/ \mathrm{kcps}$ & $<\delta F(t)^{2}>/ \mathrm{kcps}^{2}$ & $N_{\text {total }}$ & $N_{\text {im }} /\left(N_{\mathrm{im}}+N_{\mathrm{m}}\right)$ \\
\hline Kontrolle & $11,8 \pm 3,0$ & $3,79 \pm 0,64$ & $23,8 \pm 8,5$ & $0,76 \pm 0,07$ \\
$5 \mu$ M OA & $10,9 \pm 3,4$ & $6,13 \pm 2,54$ & $14,2 \pm 8,5$ & $0,60 \pm 0,15$ \\
\hline
\end{tabular}

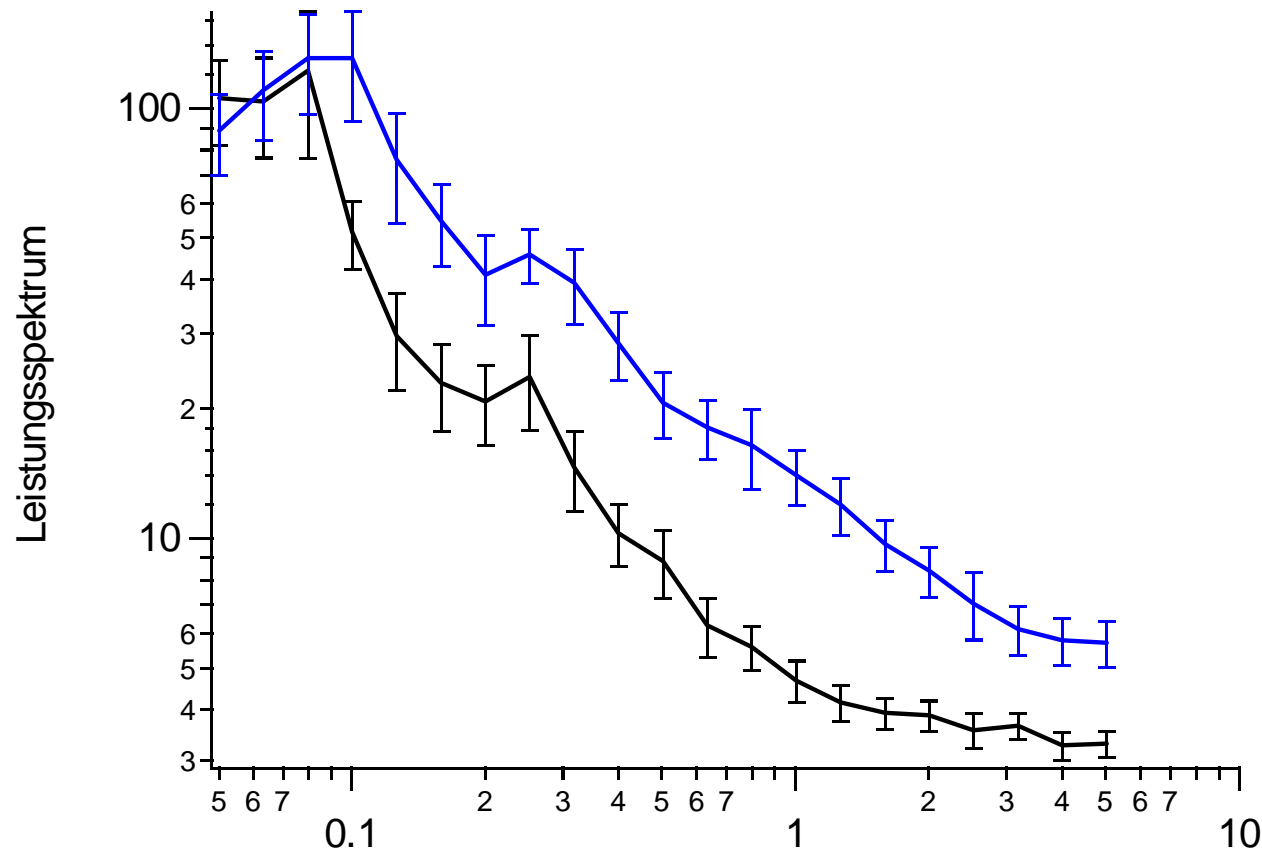

Frequenz / Hz

Abbildung 63: Mittleres Leistungsspektrum bei $10 \mathrm{~Hz}$ Abtastrate: $5 \mu \mathrm{M}$ Okadasäure (blau, $n=10$, Einwirkzeit: mind. $28 \mathrm{~min})$; Kontrolle $(n=14)$. 


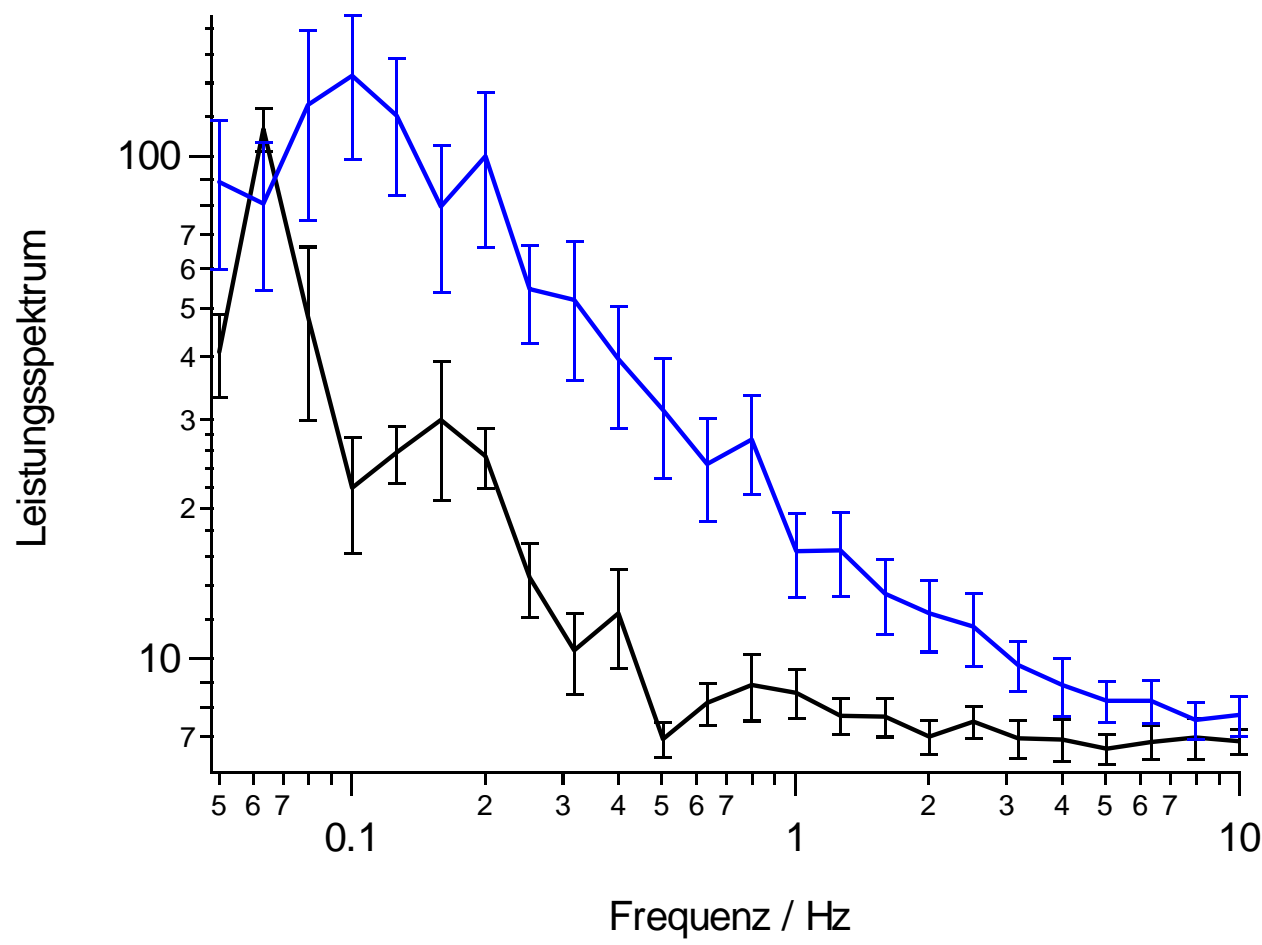

Abbildung 64: Mittleres Leistungsspektrum bei $20 \mathrm{~Hz}$ Abtastrate: $5 \mu \mathrm{M}$ Okadasäure (blau, $n=8$; mind. 25 Einwirkzeit); Kontrolle $(n=7)$.

Die Aktivierung der Proteinkinase A durch $10 \mu \mathrm{M}$ Forskolin ergab uneinheitliche Ergebnisse. In reinen hippocampalen CA3/CA1-Kulturen (d. h. solche ohne die Körnerzellen des Gyrus dentatus) allerdings wurde kein Effekt beobachtet (A A b bildung 65). Ein in ersten Experimenten beobachteter Effekt (Daten nicht gezeigt) könnte auf einen erhöhten Körnerzellen-Anteil zurückzuführen sein (cf. unten, LTP-Kapitel).

In Anwesenheit von 200 nM PMA, einem Aktivator der Proteinkinase C, werden die farbstoffmarkierten Boutons innerhalb von 30 Minuten fast vollständig entfärbt. Die Leistungsspektren in Anwesenheit von PMA und ohne Wirkstoffeinfluß sind in 'Á zusammengestellt. Unter PMA-Einwirkung ist die Kurve des Leistungsspektrums leicht nach oben verschoben.

Besitzt ein Protein Phosphorylierungsstellen für unterschiedliche Kinasen, so könnte die Aktivierung einer einzelnen Klasse von Proteinkinasen durch die Inhibition anderer Kinasenklassen zum Teil wieder kompensiert werden. Ein Effekt auf die Proteinaktivität könnte dadurch maskiert werden. Durch die gleichzeitige Aktivierung der Proteinkinasen A und C durch $10 \mu \mathrm{M}$ Forskolin und $200 \mathrm{nM}$ PMA sollte diesem Effekt vorgebeugt werden. Einen Einfluß auf die Fluoreszenzfluktuationen wurde nicht beobachtet (Abbildung 67). Wiederum zeigte sich eine starke Entfärbung der Probe, wie unter der Einwirkung von PMA allein. 


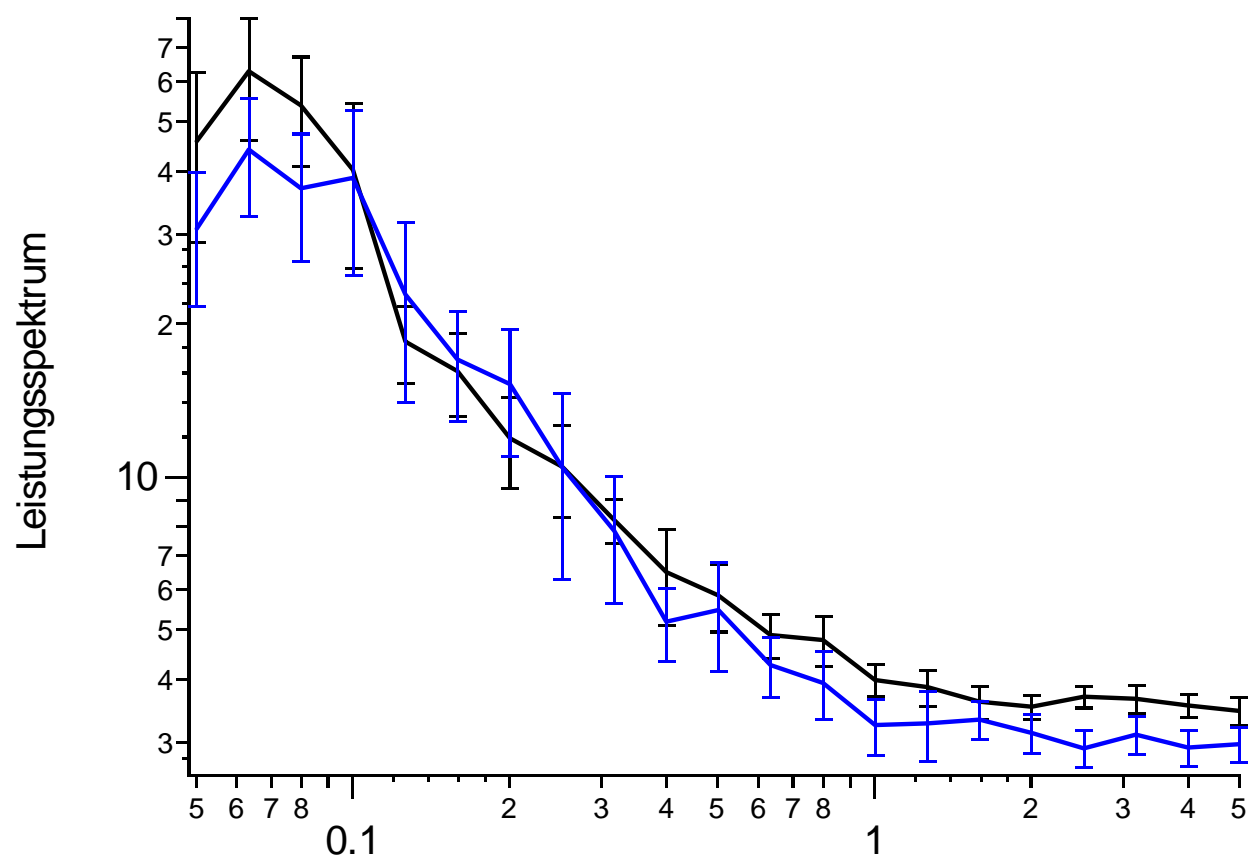

Frequenz / Hz

Abbildung 65: Mittleres Leistungsspektrum: $10 \mu \mathrm{M}$ Forskolin (blau, $n=12)$; Kontrolle $(n=15)$.

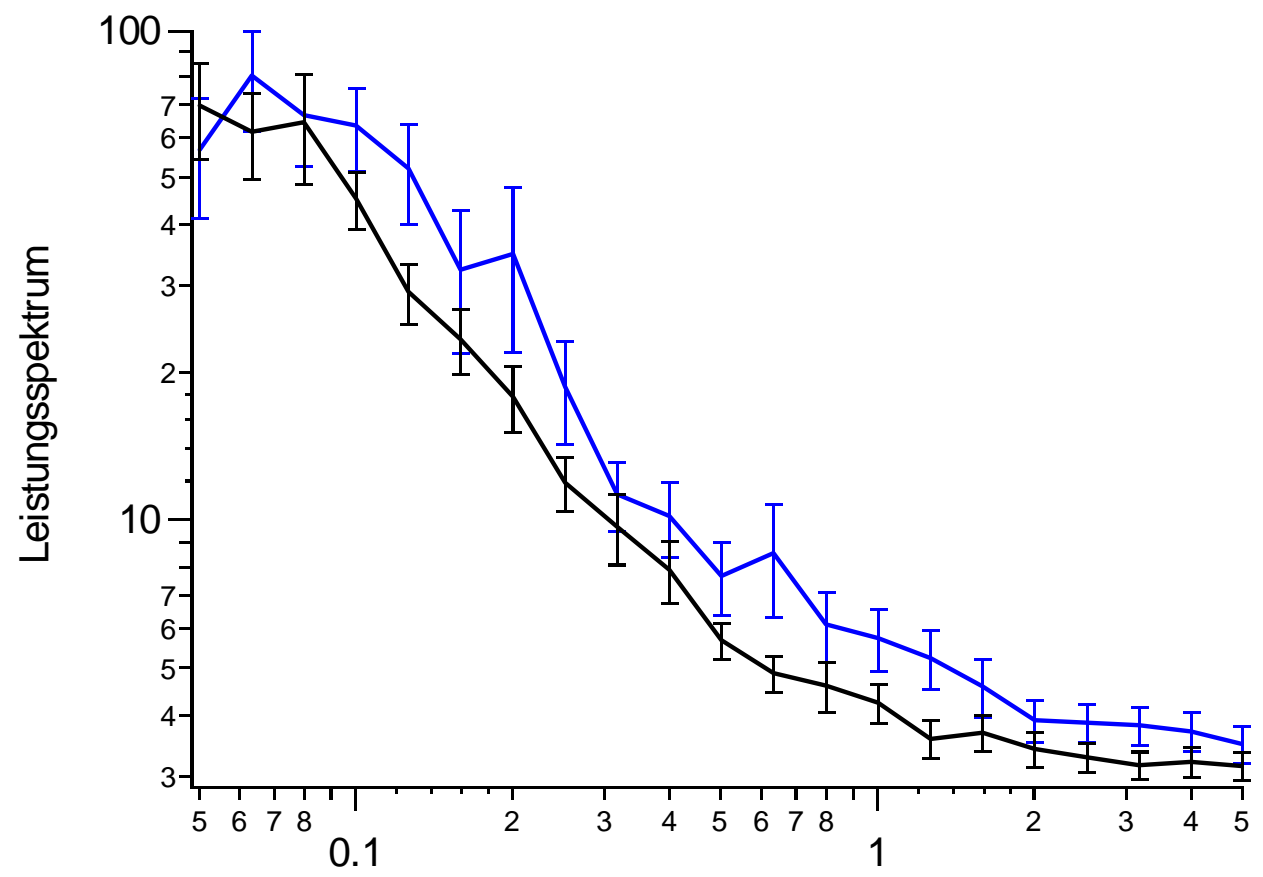

Frequenz / Hz

Abbildung 66: Mittleres Leistungsspektrum: 200 nM PMA $(n=14)$; Kontrolle $(n=24)$. 


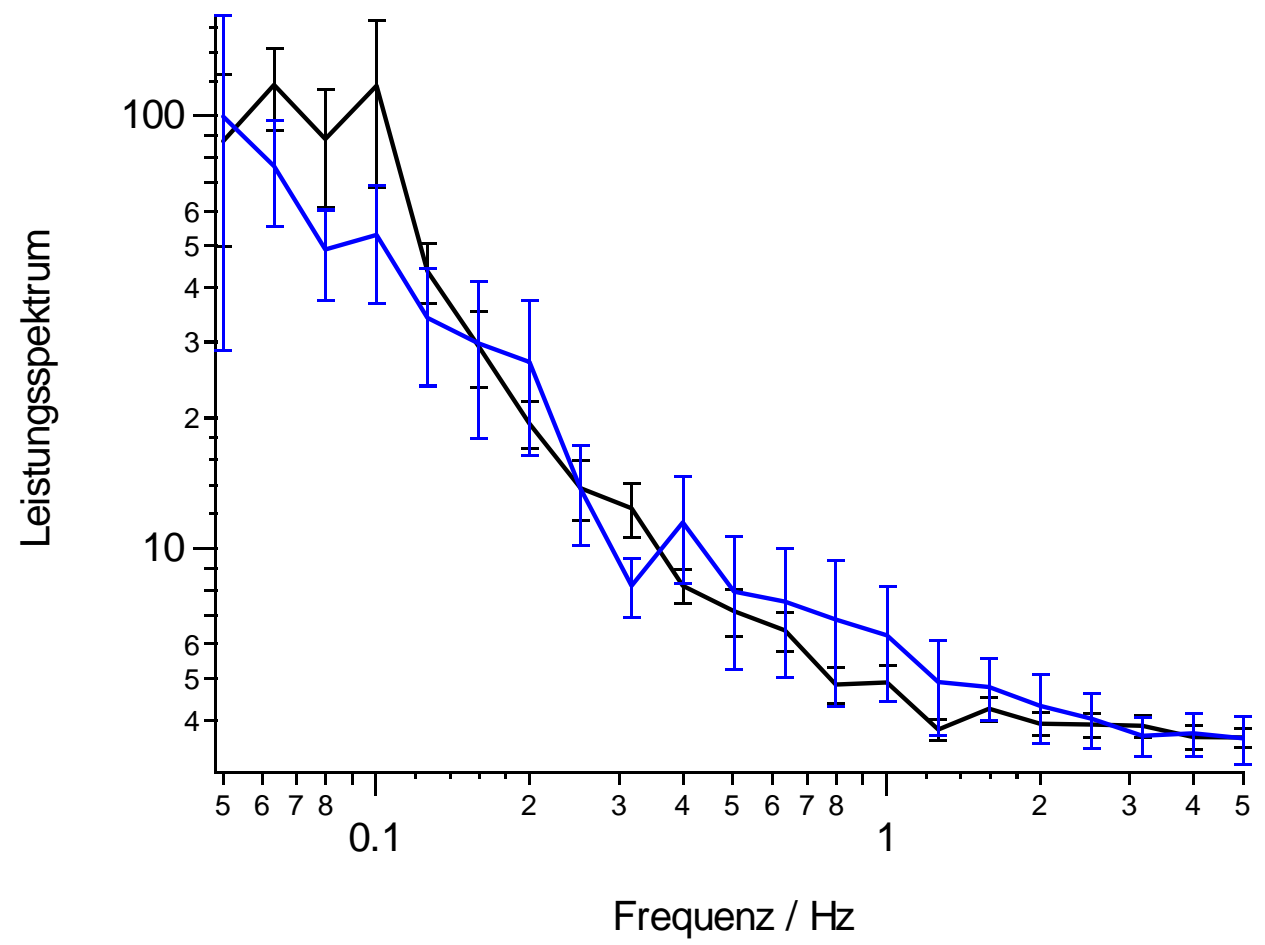

Abbildung 67: Mittleres Leistungsspektrum: $10 \mu$ M Forskolin + 200 nM PMA $(n=12)$; Kontrolle $(n=$ 16).

Ein deutlicher Effekt der Actinbeteiligung auf die Vesikelbewegung ist unter Umständen erst nach einer Aktivierung der Vesikel zu beobachten. Trotz der klaren Verringerung der Vesikelbewegung durch die Inhibition der MLCK blieben die Actinpolymerisations-Inhibitoren Cytochalasin D und Latrunculin B ohne Wirkung (s. oben). Deshalb wurde mit 1, 10 und 25 $\mu \mathrm{M}$ Latrunculin B für 60 Minuten vorinkubiert, um eine weitestgehende Depolymerisation von F-Actin sicherzustellen, und sodann in Anwesenheit von $5 \mu \mathrm{M}$ Okadasäure gemessen. Die einzelnen Leistungsspektren sind in 1 Āb bildung 68 und die Ergebnisse der Varianzanalyse in Tabelle 5 zusammengestellt. Wie bereits oben gezeigt, führten $5 \mu \mathrm{M}$ Okadasäure zu einer Vesikelmobilisierung und Mobilitätserhöhung (blaue Kurve). Die Ergebnisse wurden durch die zusätzliche Anwesenheit von $1 \mu \mathrm{M}$ Latrunculin B nicht signifikant verändert (grüne Kurve). Erst eine Konzentration von 10 bzw. $25 \mu \mathrm{M}$ Latrunculin B (beide Datensätze sind zusammengefaßt als rote Kurve) führte zu einer deutlichen Erhöhung der Fluoreszenzfluktuationen. Der immobile Vesikelanteil im Vergleich zu $5 \mu \mathrm{M}$ Okadasäure ist nahezu unverändert. Die zusätzlichen Fluktuationen sind also auf eine erhöhte Beweglichkeit der Vesikel zurückzuführen. 
Tabelle 5: Ergebnisse der Varianzanalyse in Anwesenheit von $5 \mu \mathrm{M}$ Okadasäure (OA), 1/10/25 $\mu \mathrm{M}$ Latrunculin B (LB) sowie ohne Wirkstoffeinfluß.

\begin{tabular}{lllll}
\hline & $<F(t)>/ \mathrm{kcps}$ & $<\delta F(t)^{2}>/ \mathrm{kcps}^{2}$ & $N_{\text {total }}$ & $N_{\text {im }} /\left(N_{\text {im }}+N_{\mathrm{m}}\right)$ \\
\hline Kontrolle & $11,5 \pm 3,7$ & $2,41 \pm 0,84$ & $35,6 \pm 13,3$ & $0,85 \pm 0,06$ \\
$5 \mu \mathrm{M}$ OA & $12,3 \pm 2,3$ & $3,78 \pm 1,35$ & $18,5 \pm 3,6$ & $0,74 \pm 0,15$ \\
$5 \mu \mathrm{M}$ OA $+1 \mu \mathrm{M} \mathrm{LB}$ & $10,9 \pm 2,6$ & $3,69 \pm 1,38$ & $21,6 \pm 6,9$ & $0,77 \pm 0,17$ \\
$5 \mu \mathrm{M}$ OA $+10 / 25 \mu \mathrm{M} \mathrm{LB}$ & $12,4 \pm 4,4$ & $5,41 \pm 2,85$ & $19,3 \pm 5,8$ & $0,78 \pm 0,34$ \\
\hline
\end{tabular}

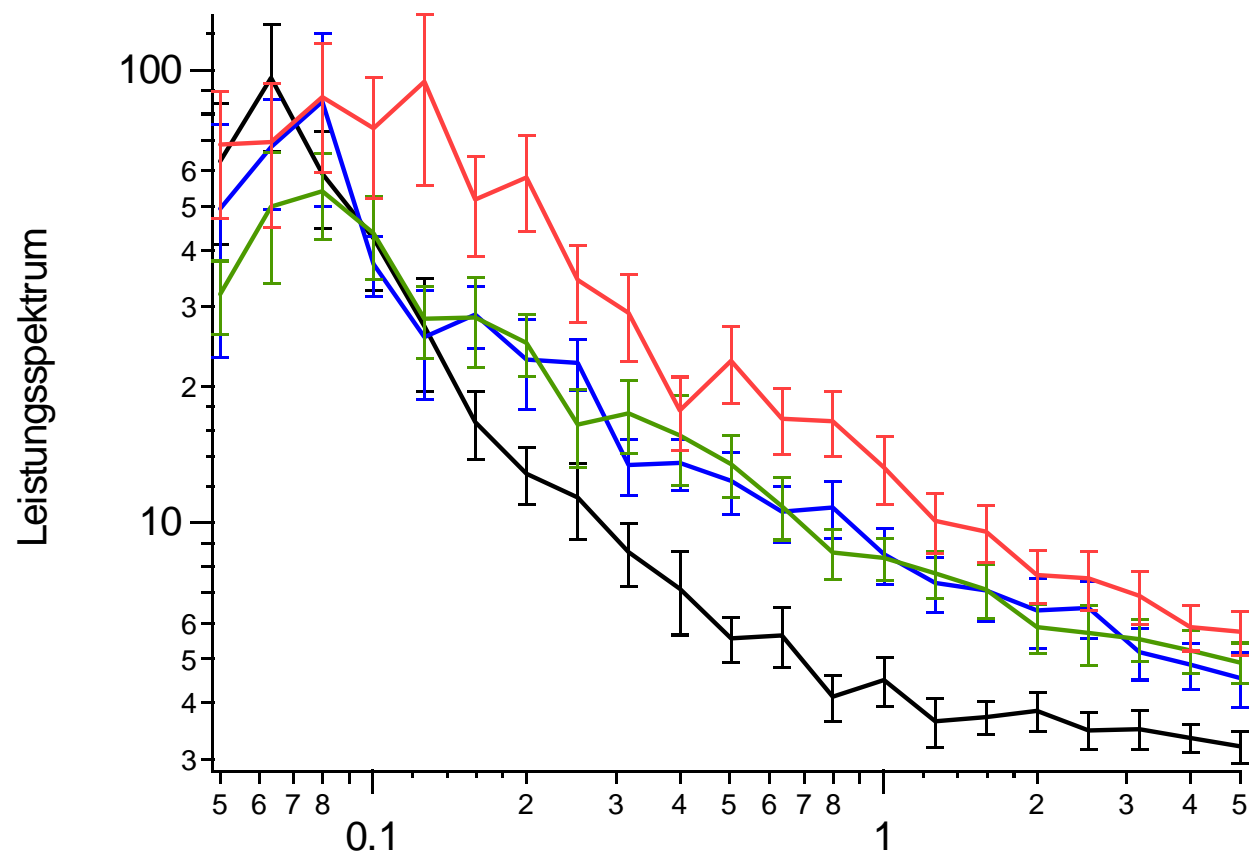

Frequenz / Hz

Abbildung 68: Mittleres Leistungsspektrum: $5 \mu \mathrm{M}$ Okadasäure (blau, $n=9$, Einwirkzeit OA: 12 min); Kontrolle $(n=11) ; 5 \mu \mathrm{M}$ Okadasäure $+1 \mu \mathrm{M}$ Latrunculin B (grün, $n=11$, LB $60-70$ min vorinkubiert); $5 \mu \mathrm{M}$ Okadasäure $+10 / 25 \mu \mathrm{M}$ Latrunculin B (rot, $n=12$, LB 60-70 min vorinkubiert,).

\subsubsection{EGTA-AM}

Der Einfluß einer verringerten internen $\mathrm{Ca}^{2+}$-Konzentration auf die Vesikelmobilität wurde durch Applikation von $10 \mu \mathrm{M}$ EGTA-AM untersucht. Zunächst wurden die Vesikel mit FM 1-43 angefärbt und der Farbstoff aus der Neuronenmembran ausgewaschen. Dann wirkte 30 Minuten lang $10 \mu \mathrm{M}$ EGTA-AM-haltige Tyrode-Lösung auf die Neuronen ein. Durch die Spaltung des Esters in der Zelle sollte sich die Konzentration an EGTA auf einige Millimolar anreichern. Anschließend wurde die EGTA-AM-haltige Lösung durch 10minütiges Auswaschen gegen normale Tyrode-Lösung ausgetauscht. Die Leistungsspektren für behandelte und unbehandelte Neurone zeigen keinen signifikanten Unterschied (s. Á Ábibildung 69 j. 


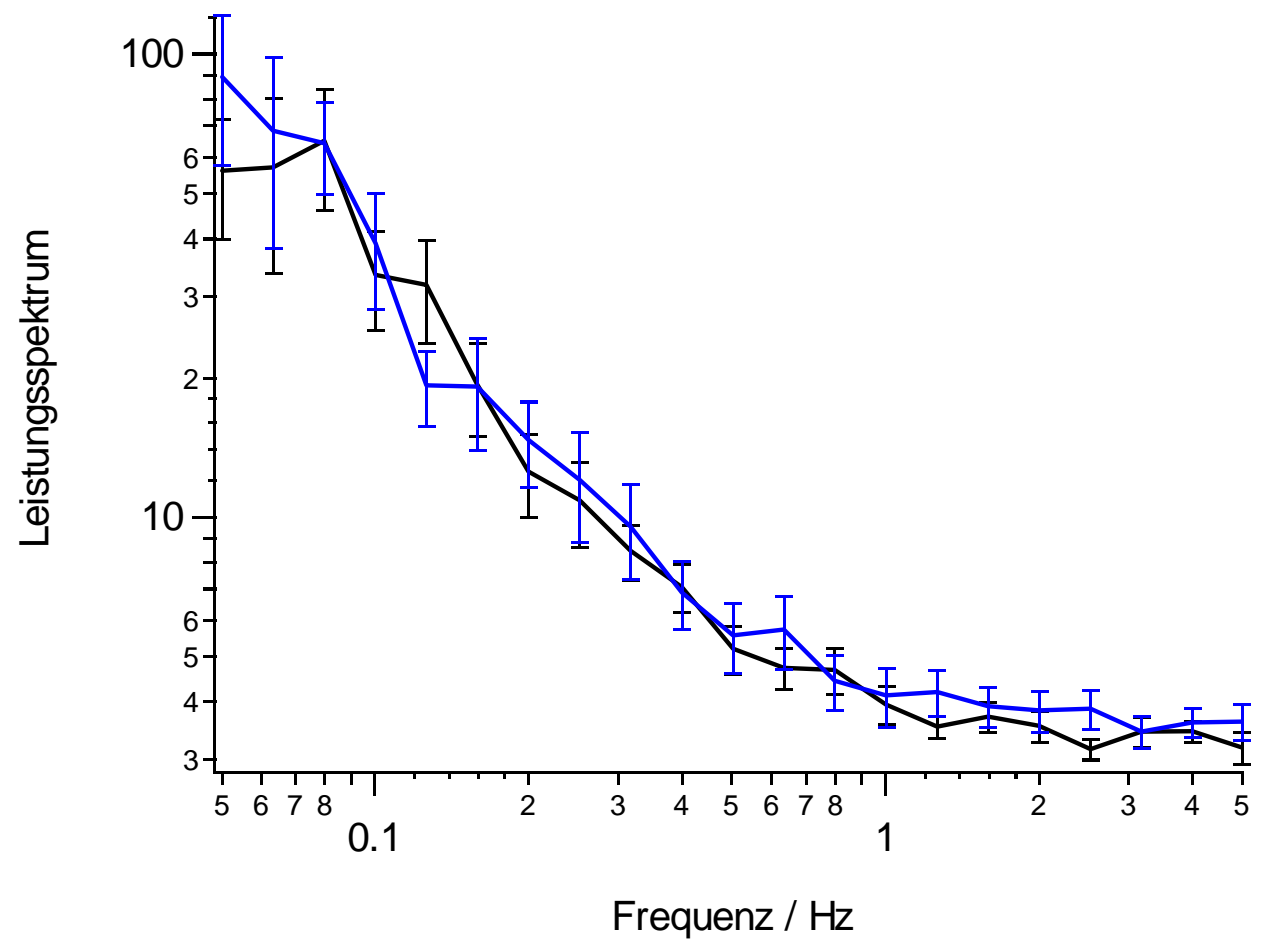

Abbildung 69: Mittleres Leistungsspektrum: $10 \mu \mathrm{M}$ EGTA-AM (Einwirkzeit: 25 min; Auswaschen mit $0,1 \mathrm{mM} \mathrm{Ca}^{2+}$ ) (blau, $\left.n=11\right)$; Kontrolle $(n=12)$.

\subsubsection{LTP}

Während alle zuvorigen Experimenten mit einer gemischten Zellkultur aus CA3- und CA1Neuronen ausgeführt wurden, sind für die folgenden Experimente Zellkulturen aus den Körnerzellen des Gyrus dentatus verwendet worden. Körnerzellen synapsieren die Pyramidalzellen der CA3-Region und bilden Synapsen mit sehr unterschiedlichen Eigenschaften. Insbesondere Forskolin führt hier zu einer Langzeitpotenzierung der synaptischen Übertragung. Inwieweit in DG/CA3-Cokulturen Forskolin auf die Vesikelmobilität wirkt, bleibt zu klären.

In diesen Kulturen führt eine starke Stimulation mit Aktionspotentialen über einen Zeitraum von 30 Sekunden (Tetanus-Stimulation) zu erhöhten postsynaptischen Stromantworten, die über Stunden hinweg noch detektiert werden können [8994. Diese erhöhte synaptische Aktivität (long term potentiation, LTP) wird als ein Mechanismus zur Gedächtnisbildung diskutiert.

Eine mögliche Beteiligung einer erhöhten Vesikelbeweglichkeit unter LTP-Bedingungen

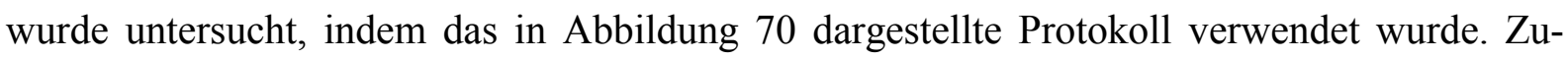
nächst wurden die Neurone 30 Sekunden lang mit Aktionspotentialen $\left(f_{\mathrm{AP}}=50 \mathrm{~Hz}\right)$ stimuliert. Sodann wurden die Vesikel wie oben beschrieben mit FM 1-43 angefärbt, und der Farbstoff aus der Neuronenmembran 10 Minuten lang durch Perfusion herausgewasschen. Nach einem variablem Zeitintervall von 15-90 Minuten wurde die Fluoreszenz mit einer Zeitauflösung von $10 \mathrm{~Hz}$ aufgenommen. 
Die gemittelten Leistungsspektren sind in Ẩbildung 71 dargestellt und die Ergebnisse der Varianzanalyse in Tabelle 6 zusammengestellt.

Das Leistungsspektrum nach Tetanus-Stimulation liegt über dem unter Kontrollbedingungen. Aus der Varianzanalyse ergibt sich ein fast unveränderter immobiler Vesikelanteil.
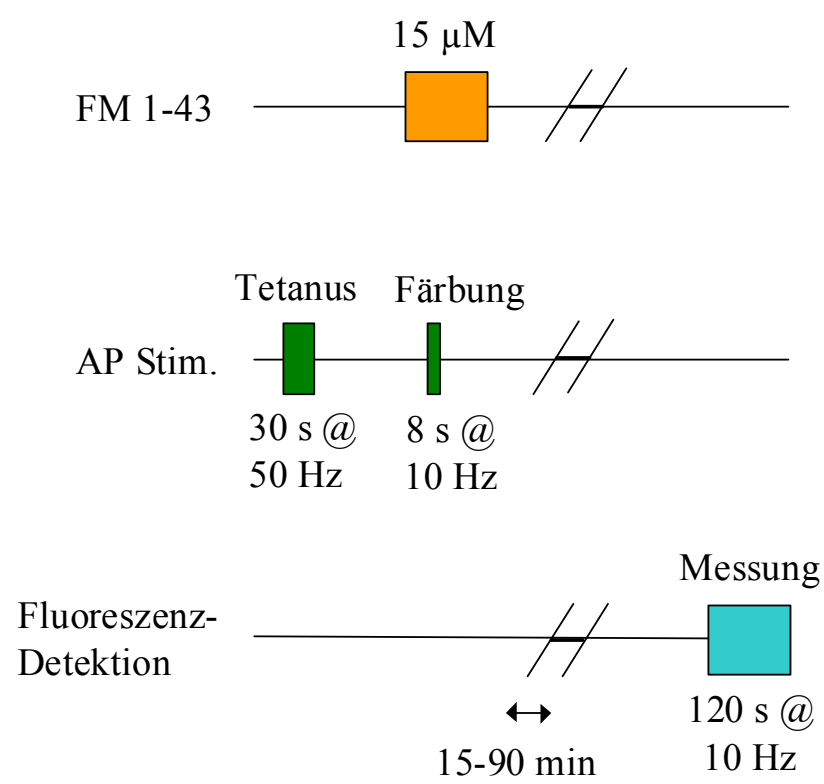

Abbildung 70: Schematische Darstellung des Protokolls zur Untersuchung der Vesikelmobilität unter LTP-Bedingungen.

Tabelle 6: Ergebnisse der Varianzanalyse ohne/mit Tetanus-Stimulation.

\begin{tabular}{lllll}
\hline & $<F(t)>/ \mathrm{kcps}$ & $<\delta F(t)^{2}>/ \mathrm{kcps}^{2}$ & $N_{\text {total }}$ & $N_{\mathrm{im}} /\left(N_{\mathrm{im}}+N_{\mathrm{m}}\right)$ \\
\hline Kontrolle & $12,7 \pm 3,2$ & $2,02 \pm 0,43$ & $52,7 \pm 21,4$ & $0,89 \pm 0,06$ \\
Tetanus & $13,7 \pm 4,0$ & $2,83 \pm 1,13$ & $43,2 \pm 11,5$ & $0,86 \pm 0,06$ \\
\hline
\end{tabular}




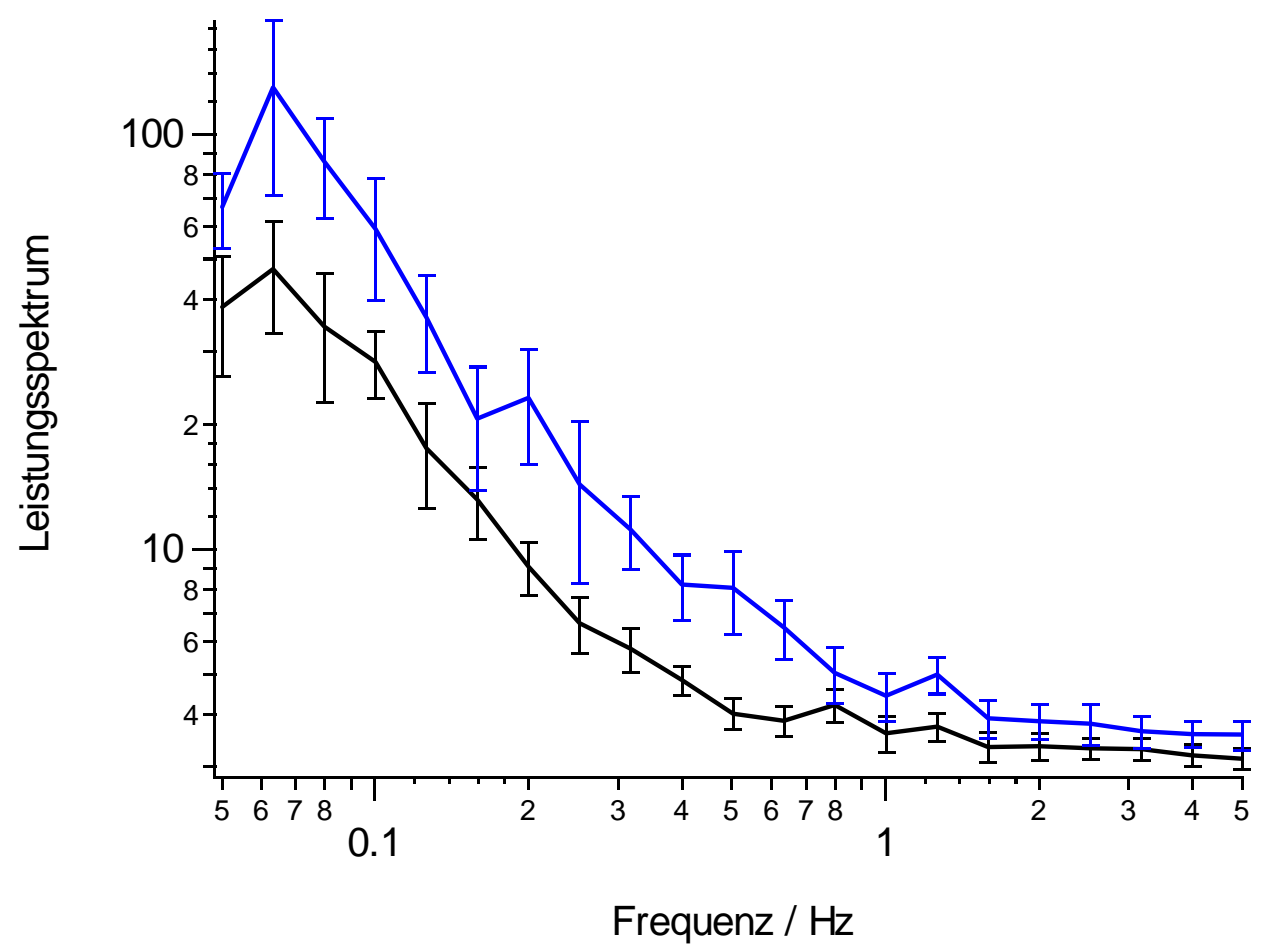

Abbildung 71: Mittleres Leistungsspektrum: LTP-Bedingungen $(n=9)$; Kontrolle $(n=13)$.

\subsubsection{AP-Stimulation}

Durch Stimulation mit einzelnen Aktionspotentialen während der Fluoreszenzdetektion in einem Bouton wurde versucht, den Fluoreszenzbeitrag eines einzelnen Vesikels zu bestimmen.

Die Vesikel wurden mit Hilfe elektrischer Feldstimulation mit Farbstoff beladen und der Farbstoff anschließend aus der Neuronenmembran 10 Minuten lang ausgewaschen. Daraufhin wurde 120 Sekunden lang die Fluoreszenz in einem einzelnen Bouton mit einer Zeitauflösung von $10 \mathrm{~Hz}$ detektiert, während mit einer Frequenz von $0,1 \mathrm{~Hz}$ jeweils ein einzelnes Aktionspotential durch elektrische Feldstimulation erzeugt wurde. Das erste Aktionspotential erfolgte 10 Sekunden nach Beginn der Fluoreszenzdetektion. Synchron mit der Stimulation werden einzelne Vesikel zur Fusion gebracht. In Folge sollte man sprunghafte Fluoreszenzänderungen beobachten entweder durch Fusion einzelner Vesikel mit der Plasmamembran oder aber durch Relokalisation eines Vesikels als Folge der Fusion eines ungefärbten oder außerhalb des Detektionsvolumens befindlichen Vesikels.

Ein Beispiel eines sehr aktiven Boutons (hohe Freisetzungswahrscheinlichkeit, d. $h$. starke FM-Entfärbung) ist in Âbildung 72 dargestellt. An den durch Pfeile markierten Punkten der Kurve ist ein starker Abfall der Fluoreszenz zu erkennen. Die Amplitude und der Zeitverlauf dieser nach Applikation einzelner Aktionspotentiale auftretender Fluoreszenzschritte soll im folgenden näher analysiert werden. 


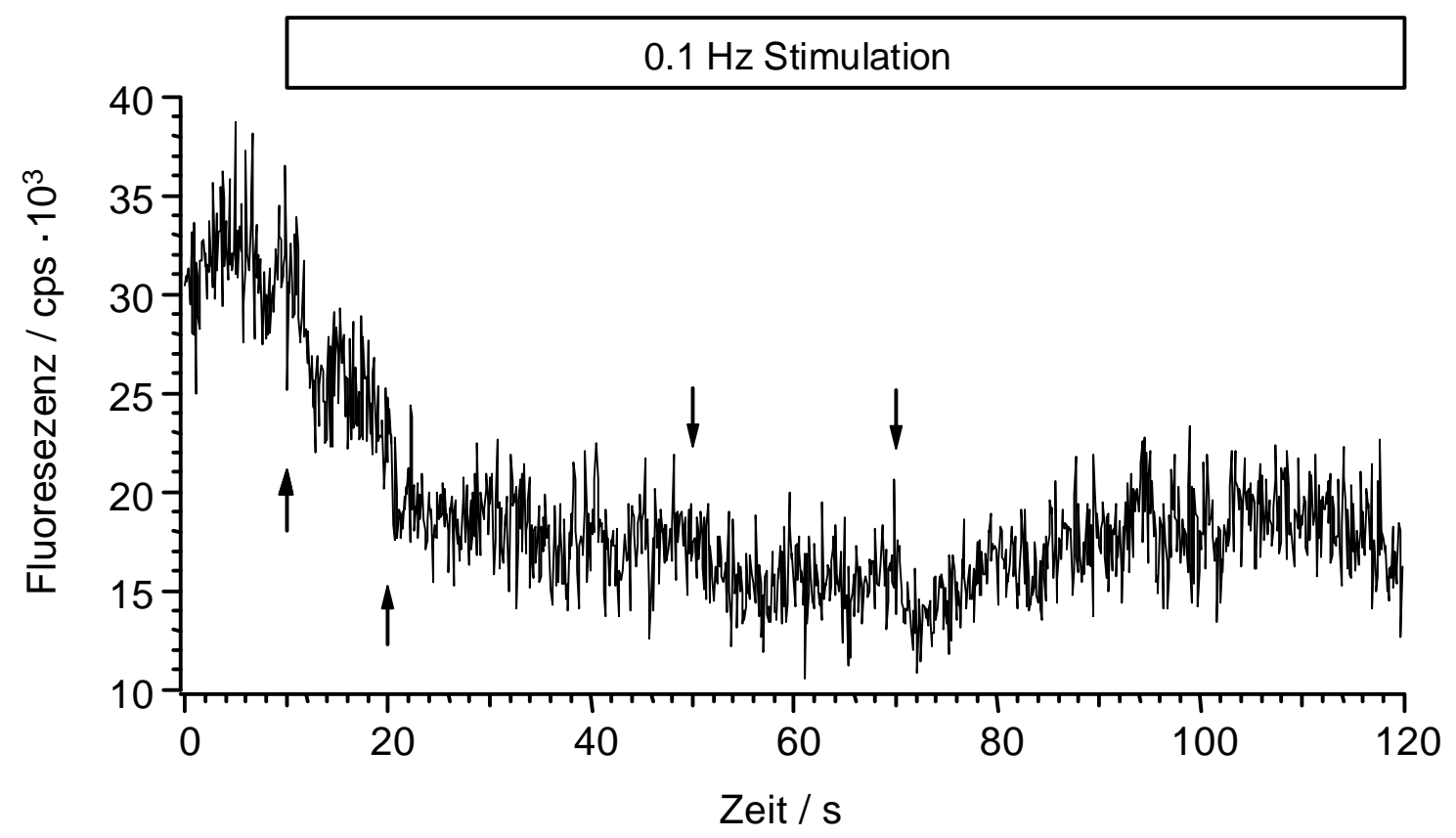

Abbildung 72: Fluoreszenz-Zeit-Verlauf während einer 0,1 Hz Stimulation mit einzelnen Aktionspotentialen $(I=40 \mathrm{pA}, t=1 \mathrm{~ms})$. Die Pfeile markieren Fluoreszenzschritte kurz nach der AP-Stimulation, hervorgerufen durch die Fusion einzelner synaptischer Vesikel mit der Plasmamembran oder durch Relokalisation eines Vesikels als Folge der Fusion eines ungefärbten oder außerhalb des Detektionsvolumens befindlichen Vesikels.

AA sierten Fluoreszschritte. Je nach Position des Vesikels im gaußförmigen Detektionsvolumen wurden Fluoreszenzschritte unterschiedlicher Amplitude detektiert. Die am häufigsten gefundenen Schrittgrößen liegen zwischen 1,5 und 2,5 kcps. Fluoreszenzschritte, die eine kleinere Amplitude als $1 \mathrm{kcps}$ hatten, konnten nicht vom Rauschlevel unterschieden werden. Insgesamt lag ein mittlerer Fluoreszenzbeitrag eines Vesikels bei etwa 2 kcps.

Der detektierte Fluoreszenzabfall kann durch unterschiedliche Prozesse hervorgerufen werden, die sowohl von der Position des Vesikels innerhalb des Boutons als auch von der Position des Detektionsvolumens im Bouton abhängen. Befindet sich die aktive Zone des Boutons außerhalb des Detektionsvolumens, so entspricht der detektierte Fluoreszenzabfall nach Ankunft eines Aktionspotentials im Bouton einer Positionsveränderung des farbstoffmarkierten Vesikel zu einem Ort geringerer Anregungsleistung. Das farbstoffmarkierte Vesikel kann dabei entweder das Detektionsvolumen verlassen oder nur innerhalb des Detektionsvolumens seinen Aufenthaltsort ändern. Der beobachtete Fluoreszenzabfall entspräche einem Prozeß der Vesikelreorganisation, der beispielsweise neue Vesikel in Richtung aktiver Zone transportiert. Schließt das Detektionsvolumen die aktive Zone mit ein, so kann der Fluoreszenzabfall zusätzlich durch das Auswaschen des Farbstoffs nach Fusion des Vesikels mit der aktiven Zone hervorgerufen werden. Der zugrundeliegende Prozeß wäre in diesem Fall die Exozytose des farbstoffmarkierten Vesikels. 
Im Falle der Vesikelreorganisation sollten nach Erreichen eines Aktionspotentials im Bouton neben abfallenden sprunghaften Fluoreszenzänderungen auch ansteigende zu beobachten sein, die durch neu in das Detektionsvolumen kommende farbstoffmarkierte Vesikel hervorgerufen werden. Es wurden aber keine sprungshaften Fluoreszenzanstiege, sondern nur langsam ansteigende, über mehrere Sekunden andauernde Fluoreszenzveränderungen beobachtet, wie z. B. nach $t=72 \mathrm{~s}$ im Beispiel der reszenzabfall und -anstieg deuten also verschiedenartige Mechanismen für diese Fluoreszenzänderungen an.

a

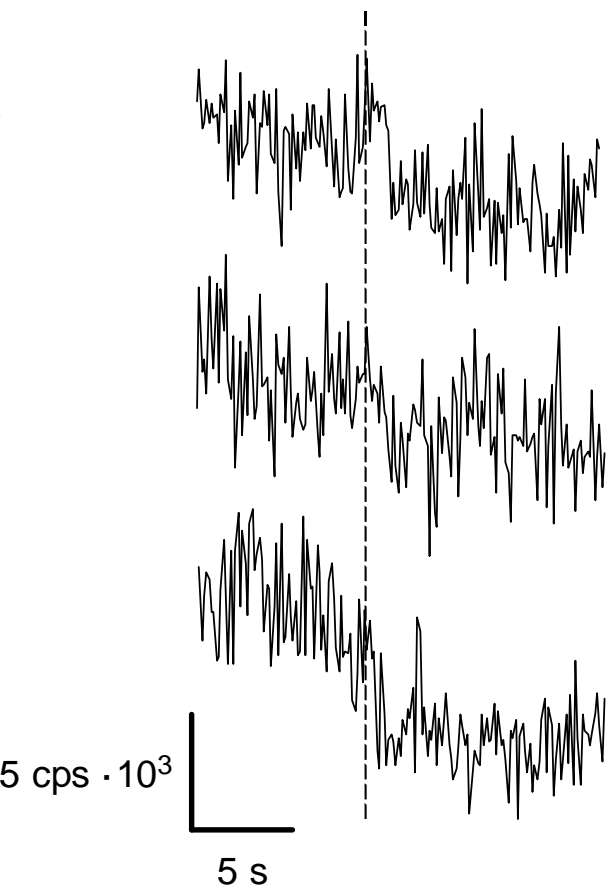

b

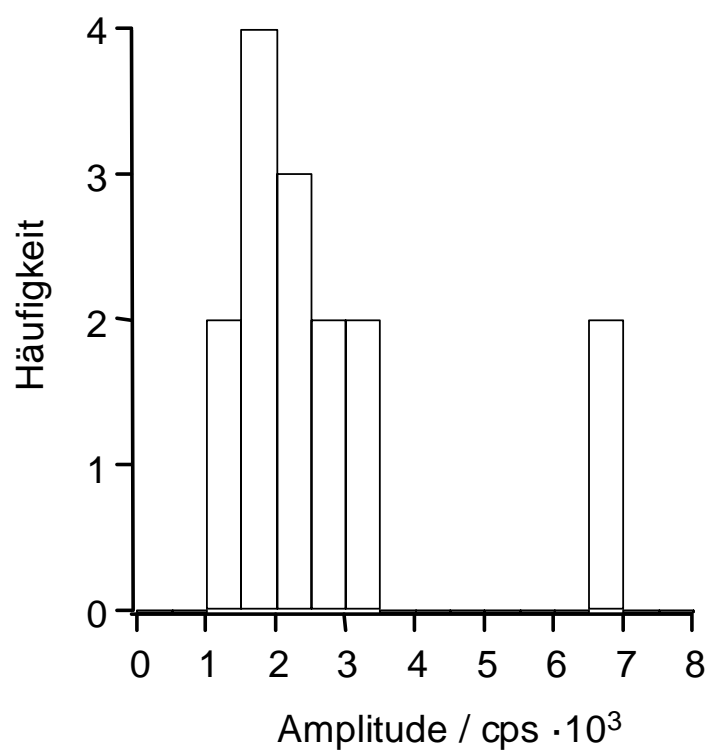

Abbildung 73: a: Einzelne Fluoreszenzbeispiele um den Zeitpunkt der AP-Stimulation (die gestrichelte Linie markiert den Zeitpunkt der Applikation eines einzelnen Aktionspotentials). b: Amplitudenhistogramm der Fluoreszenzänderung nach Stimulation mit einem Aktionspotential im Vergleich zur Fluoreszenz vorher.

Der Zeitverlauf, mit dem die Fluoreszenz nach der Applikation eines Aktionspotentials abfiel, wurde in Âbbildung 75: näher analysiert. Die einzelnen Fluoreszenzabschnitte zu jedem AP aufgenommen bei einem Radius des Detektionsvolumens in der fokalen Ebene von $w_{0}=175$ nm wurden gemittelt und danach auf eins normiert (Abb. zeigt einen Abfall der Fluoreszenz, der nach ca. $1 \mathrm{~s}$ fast vollständig auf das Endniveau Null abgefallen ist. Abbildung 1755 d zeigt das Ergebnis des Fluoreszenzverlaufs, wenn die Fluoreszenzabschnitte zwischen zwei Aktionspotentialen ( $10 \mathrm{~s}$ Intervall von -5 bis $+5 \mathrm{~s}$; $0 \mathrm{~s}$ ist der Zeitpunkt des AP; Fehler $(\Delta \mathrm{t})$ : maximal $25 \mathrm{~ms})$ gemittelt wurden. Der Wert für $t=0$ entspricht also der Zeit genau zwischen zwei Aktionspotentialen. Diese Mittelung zeigt keinen Fluoreszenzsprung und ist im Unterschied zum Ergebnis oben somit nur die Summe zufälliger Ereignisse. 
Da aus den Experimenten mit kleinem fokalen Radius $\left(w_{0}=175 \mathrm{~nm}\right)$ nicht eindeutig hervorgeht, ob die aktive Zone des Boutons innerhalb des Detektionsvolumens liegt, wurde das Detektionsvolumen vergrößert, indem die hintere Objektivpupille durch einen Laserstrahl mit einen geringerem Durchmesser nicht voll ausgeleuchtet wurde. Die verwendete Meßkonfiguration mit einem Lochblendenradius von $r_{0}=60 \mu \mathrm{m}$ führte zu einem Radius in der fokalen Ebene von $w_{0}=700 \mathrm{~nm}$. Ein typisches Bouton mit einer Durchmesser von etwa $1 \mu \mathrm{m}$ ist nun vollständig im Detektionsvolumen. Das Ergebnis ist in Âbuildung $\overline{7} \overline{5}$ b dargestellt und wird in Abb. ${ }_{7} 75$; c dem Zeitverlauf mit kleinem Detektionsvolumen gegenübergestellt. Auch bei Verwendung des aufgeweiteten Detektionsvolumens erfolgte der Fluoreszenzabfall vielfach mit einer Zeitverzögerung von etwa $0,5 \mathrm{~s}$.

\subsubsection{Injektion von Polystryrolkugeln}

Zur Simulation der Beweglichkeit eines synaptischen Vesikels in einem Neuron wurden mit farbstoffmarkierte Polystyrolkugeln mit einem Durchmesser von $50 \mathrm{~nm}$ in das Cytoplasma von Neuronen injiziert und die Fluoreszenzfluktuationen autokorreliert. Während in einfachen Elektrolyten eine durch translative Diffusion beschreibbare Autokorrelationsfunktion erhalten wurde (s. íAb bildung unkorreliert (cf. Abbildung ing). Vor der Messung wurde sichergestellt, daß sich Polystyrolkugeln im Cytoplasma des Neurons befanden, indem die Fluoreszenzintensität des Cytoplasmas mit der im Nucleus verglichen wurde.

Während sich die Polystyrolkugeln im Cytoplasma nicht bewegten, waren die Polystyrolkugeln in der Plasmamembran bzw. in ihrer unmittelbaren Nähe mobil. Dies wird in Ábbildung 77. verdeutlicht, in der die Fluoreszenzspur einer einzelnen Polystyrolkugel in unmittelbarer Nähe der Plasmamembran gezeigt wird. Die Autokorrelationsfunktion ergibt eine Diffusionszeit, die etwa 40 mal langsamer ist als im Elektrolyten.

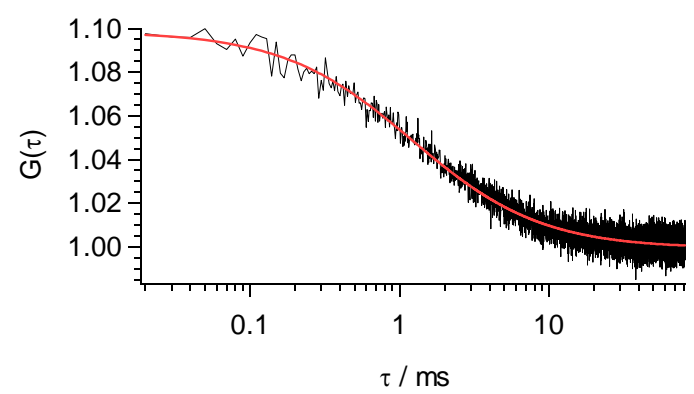

Abbildung 74: Autokorrelationsfunktion von Polystyrolkugeln im einfachen Elektrolyten sowie Anpassung mit dem 3D-Diffusionsmodell ( $\left.\tau_{\mathrm{D}}=1,5 \mathrm{~ms} ; N=3,7\right)$. 


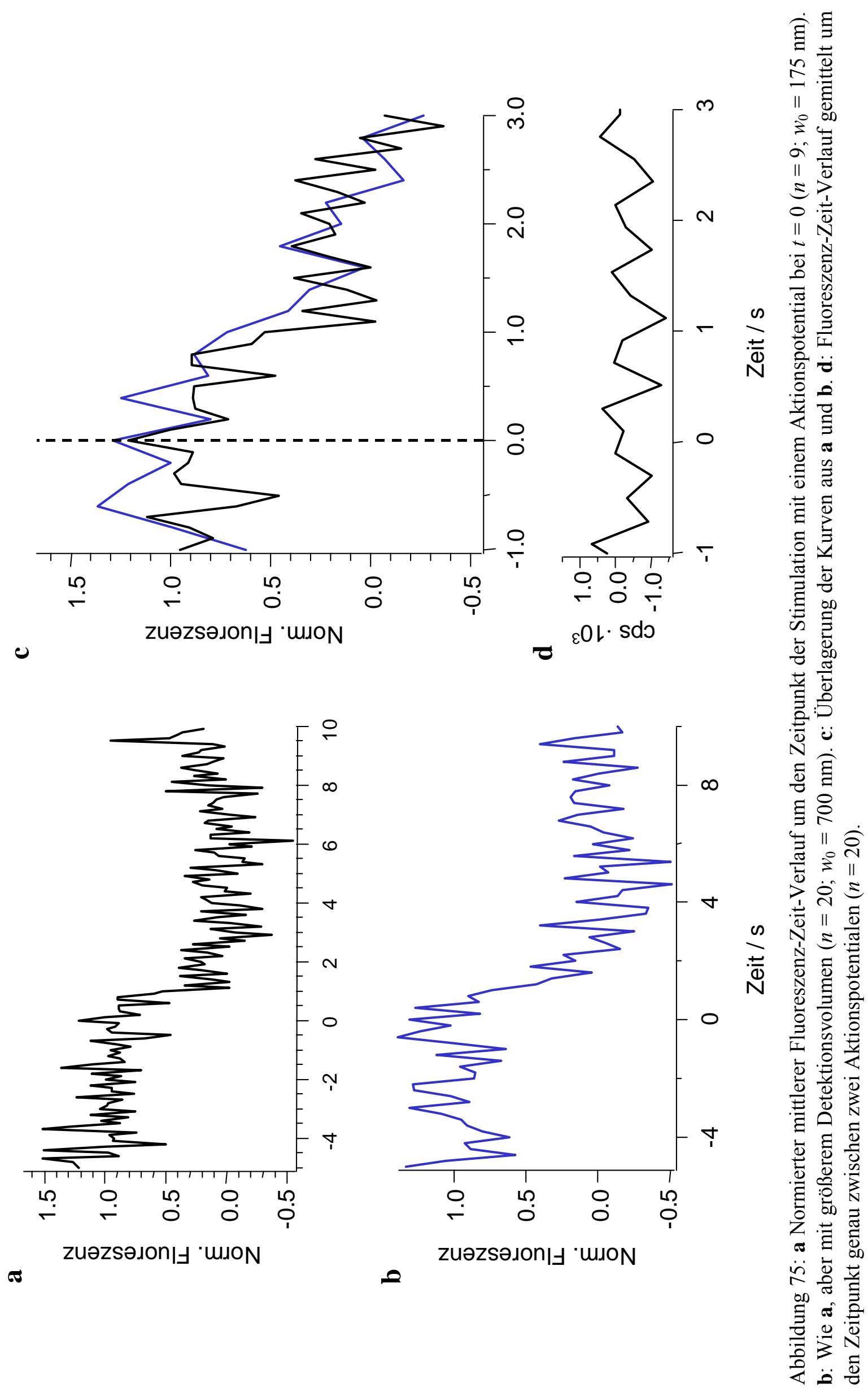



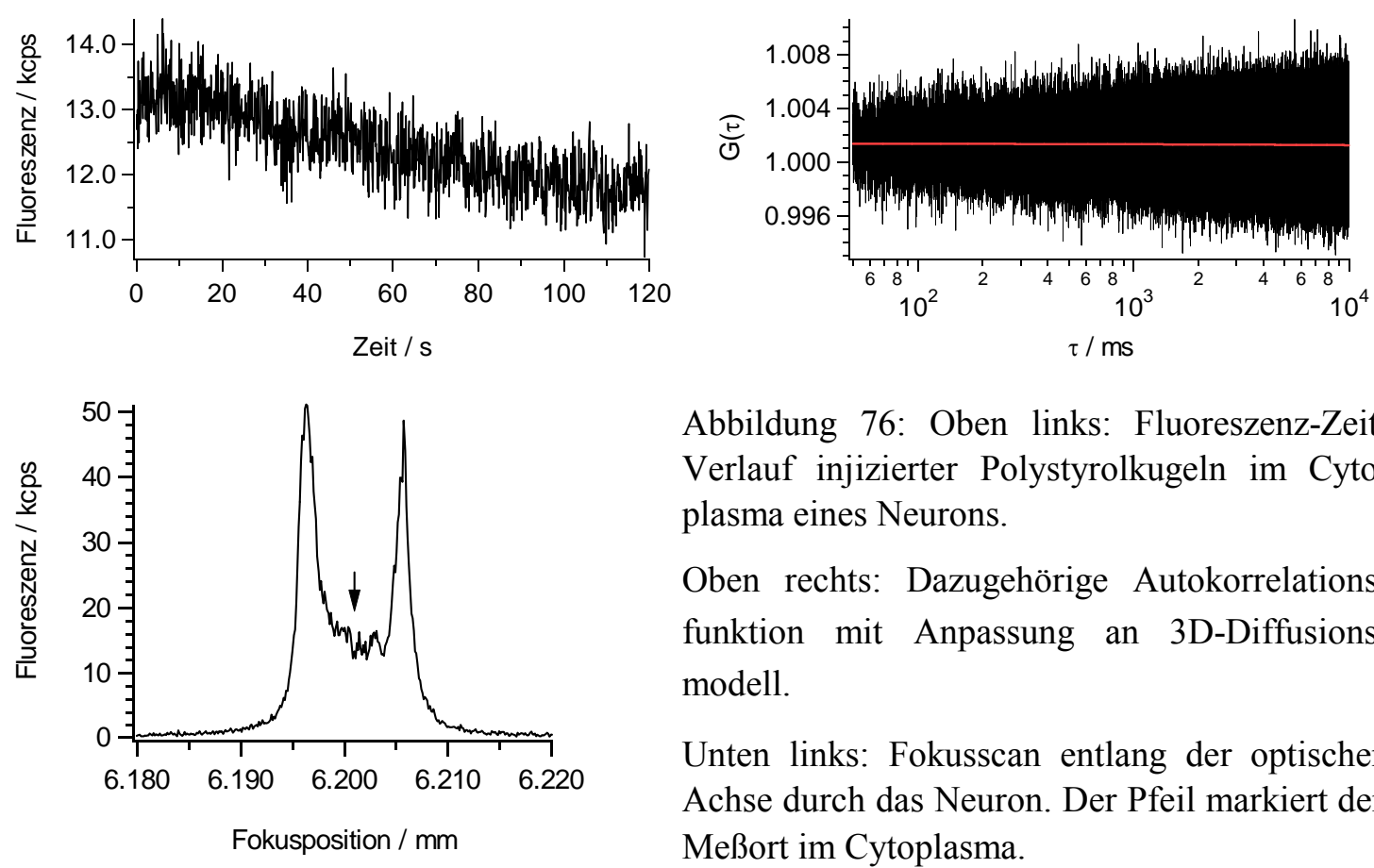

Abbildung 76: Oben links: Fluoreszenz-ZeitVerlauf injizierter Polystyrolkugeln im Cytoplasma eines Neurons.

Oben rechts: Dazugehörige Autokorrelationsfunktion mit Anpassung an 3D-Diffusionsmodell.

Unten links: Fokusscan entlang der optischen Achse durch das Neuron. Der Pfeil markiert den Meßort im Cytoplasma.
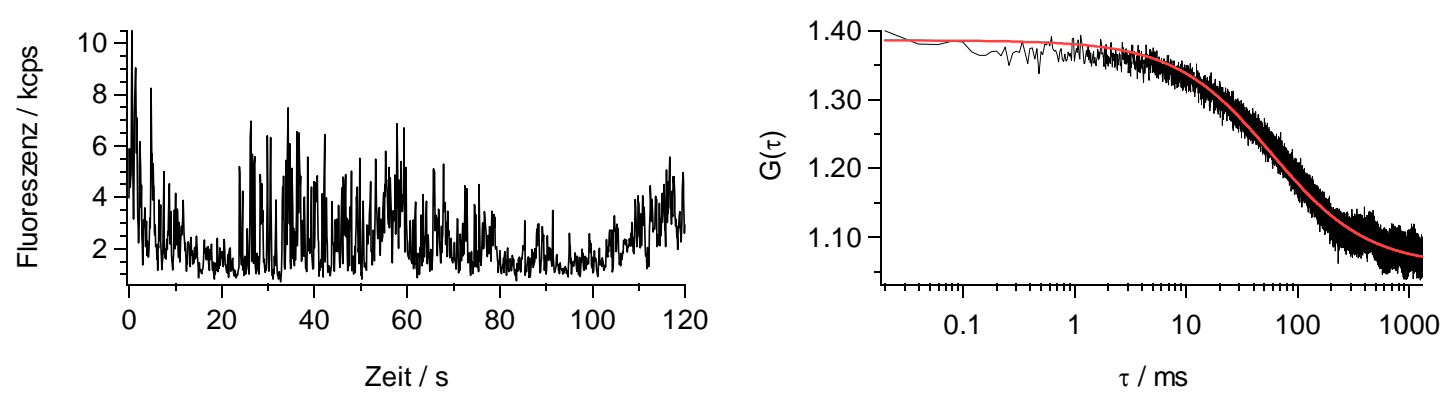

Abbildung 77: Fluoreszenz-Zeit-Verlauf einer Polystyrolkugel in der Nähe der Membran (links) sowie dazugehöriger Autokorrelationsfunktion (rechts) und Anpassung mit dem 3D-Diffusionsmodell $\left(\tau_{\mathrm{D}}=\right.$ $58,5 \mathrm{~ms} ; N=1,1)$. 


\section{Diskussion}

\subsection{Autofluoreszenz in Chromaffinzellen und hippocampalen Neuro- nen}

Die Autofluoreszenz in Chromaffinzellen und in hippocampalen Neuronen war sowohl abhängig von der Anregungswellenlänge als auch vom Meßort innerhalb der Zelle. Im Nucleus wurde fast ausnahmslos eine geringere Autofluoreszenz detektiert als im Cytoplasma. Mit höher werdender Anregungswellenlänge hat die Fluoreszenzintensität abgenommen. Im Unterschied dazu war die Autokorrelation nur bei $\lambda_{\mathrm{exc}}=488 \mathrm{~nm}$ vernachlässigbar klein, während bei den höheren Anregungswellenlängen 514, 543 und $633 \mathrm{~nm}$ eine deutliche Autokorrelation erkennbar war, hervorgerufen vom Durchgang einzelner Moleküle durch das Detektionsvolumen. Der Diffusionskoeffizient dieser Komponente lag in der Größenordnung von etwa $3 \mu \mathrm{m}^{2} / \mathrm{s}$.

Verursacht wird die Autofluoreszenz im sichtbaren Bereich höchstwahrscheinlich durch Flavine, wie z. B. Benson et. al. bei der Untersuchung der Autofluoreszenz verschiedener Zelltypen, u.a. auch Neurone, durch vergleichende Analyse von Emissionsspektren erhalten haben. Die Autofluoreszenz war auch vom metabolischen Zustand der Zelle abhängig. Ein Anstieg an Molekülen in ihrer oxidierten Form erhöhte die Autofluoreszenz [10].

Ähnliche Ergebnisse werden von Aubin berichtet [1]. Intrazelluläres NicotinamidAdenindinukleotid (NAD ${ }^{+}$; mit Fluoreszenz vor allem im UV) sowie Riboflavin und Favincoenzyme sind wichtige Komponenten der Autofluoreszenz, wie bei der Untersuchung der Autofluoreszenz durch Aufnahme von Absorptions- und Emissionsspekten in CHO-Zellen (chinese hamster ovary) festgestellt wurde. Die Fluoreszenz hatte dabei ihren Ursprung vor allem in vesikelähnlichen Regionen des Cytoplasmas, die vermutlich die Mitochondrien in der Zelle waren. Die Autofluoreszenz war abhängig von der Zellart und stieg mit der Aufenthaltsdauer der Zellen im Inkubator an [1]

Unabhängig vom genauen Ursprung der Autofluoreszenz, der im Rahmen dieser Arbeit nicht untersucht werden sollte, ergeben sich für FCS-Experimente in lebenden Zellen folgende Schlußfolgerungen.

Das Hintergrundsignal bei einer Anregungswellen von $\lambda_{\mathrm{exc}}=488 \mathrm{~nm}$ in hippocampalen Neuronen oder Chromaffinzellen wird hauptsächlich durch die Fluoreszenzsignal-Intensität bestimmt. Der mittlere Diffusionskoeffizient des Hintergrundsignals $D_{\text {autofl }}=(1,1 \pm 0,2) \cdot 10^{-3}$ $\mu \mathrm{m}^{2} / \mathrm{s}$ ist bei dieser Wellenlänge für FCS-Messungen praktisch ohne Bedeutung. Messungen im Nucleus können mit geringeren Konzentrationen an fluoreszierendem Indikator ausgeführt werden als im Cytoplasma. Bei Messungen in der Zellmembran ist auch eine Autokorrelation des Hintergrundsignals zu beachten, wie in den Experimenten zur Untersuchung der Benzodiazepin-Rezeptor Wechselwirkung gezeigt wurde. 
FCS-Experimente bei den Anregungswellenlängen 514, 543 und $633 \mathrm{~nm}$ verlangen sowohl die Kenntnis der Hintergrundsignalintensität als auch der mittleren Zählrate pro Molekül unter den jeweils gewählten experimentellen Bedingungen. Eine mögliche Interferenz mit dem Diffusionskoeffizienten der endogenen Zellbestandteile ist zu beachten.

\subsection{Diffusion und Kinetik von Calciumfarbstoffen in einfachen Elek- trolyten und in Chromaffinzellen}

Die Diffusionseigenschaften des Calciumfarbstoffs OGB1 im einfachen Elektrolyten als auch in Chromaffinzellen wurden mit Hilfe der FCS-Technik untersucht. Auch die Gewinnung von kinetischen Informationen über das Reaktionsgleichgewicht der calciumgebundenen und calciumfreien Form des Farbstoffs war im einfachen Elektrolyten bei Meßzeiten von 1-2 Minuten möglich, konnte aber in der lebenden Zelle nicht reproduziert werden, da der Autokorrelationszeitverlauf der kinetischen Fluktuationen $\left(k_{\text {diss }}=143\right.$ bzw. $\left.420 \mathrm{~s}^{-1}\right)$ durch Komponenten langsamer diffundierender Spezies bzw. mit dem durch Photozerstörungsreaktionen bedingten Funktionsabfall überlagert wurde, und von diesen nicht klar differenziert werden konnte.

Im einfachen Elektrolyten wurden für den Farbstoff OGB1 folgende Diffusionskoeffizienten erhalten

$$
\begin{aligned}
& D_{\mathrm{OGB} 1}=(188 \pm 9) \mu \mathrm{m}^{2} / \mathrm{s}(5 \mathrm{mM} \text { BAPTA }) \\
& D_{\mathrm{OGB} 1}=(202 \pm 10) \mu \mathrm{m}^{2} / \mathrm{s}\left(1 \mathrm{mM} \mathrm{CaCl}_{2}\right)
\end{aligned}
$$

und für OGB2

$$
\begin{aligned}
& D_{\mathrm{OGB} 2}=(225 \pm 12) \mu \mathrm{m}^{2} / \mathrm{s}(5 \mathrm{mM} \text { BAPTA }) \\
& D_{\mathrm{OGB} 2}=(239 \pm 9) \mu \mathrm{m}^{2} / \mathrm{s}\left(1 \mathrm{mM} \mathrm{CaCl}_{2}\right)
\end{aligned}
$$

Die calciumfreie Form (5 mM BAPTA) ist bei beiden Farbstoffen signifikant langsamer als die calciumgebundene Form $(1 \mathrm{mM} \mathrm{CaCl} 2)$, wie der zweiseitige Zweistichproben-t-Test mit der Nullhypothese $\mu_{1}=\mu_{2}$ gegen $\mu_{1} \neq \mu_{2}$ mit einer Irrtumswahrscheinlichkeit von $\alpha=5 \%$ als Ergebnis ergab. Der Unterschied beträgt nur etwa $7 \%$ und wird durch die Gegenwart des Moleküls BAPTA beeinflußt. Eine Reduktion der BAPTA-Konzentration von $5 \mathrm{mM}$ auf $1 \mathrm{mM}$ beschleunigte die Diffusion von OGB1 um etwa $20 \%$, so daß die Unterschiede in den Diffusionskoeffizienten zwischen der calciumgebundenen und calciumfreien Form der Farbstoffe vorwiegend auf das BAPTA-Molekül zurückzuführen sind.

Im Nucleus der Chromaffinzellen war die Diffusion etwa um einen Faktor 2 langsamer als im einfachen Elektrolyten, während im Cytoplasma die Diffusion 4-5 mal langsamer war. 
Dabei zeigten die Messungen an verschiedenen Orte innerhalb einer Zelle als auch zwischen unterschiedlichen Zellen z. T. eine große Streuung.

Die Diffusionskoeffizienten des calciumgebundenen $\left(D_{\mathrm{geb}}\right)$ und calciumfreien Farbstoffs $\left(D_{\text {frei }}\right)$ weisen in der Zelle keine signifikante Abweichung auf. Der zweiseitige Zweistichproben-t-Test mit der Nullhypothese $\mu_{1}=\mu_{2}$ gegen $\mu_{1} \neq \mu_{2}$ liefert mit einer Irrtumswahrscheinlichkeit von $\alpha=5 \%$ das Ergebnis, daß die $\mathrm{H}_{0}$-Hypothese nicht abgelehnt wird.

Der Effekt der Photozerstörung auf die erhaltenen Diffusionskoeffizienten wurde wie folgt abgeschätzt. Das Fluoreszenzsignal konnte mit einer monoexponentiell abfallenden Funktion im Nucleus und einer biexponentiellen im Cytoplasma beschrieben werden. Der Fluoreszenzabfall im Nucleus sowie die langsame Komponente im Cytoplasma besaßen maximal eine mittlere Geschwindigkeitskonstante von $k_{\mathrm{m}}=0,28 \mathrm{~s}^{-1}$. Unter Verwendung von G1. in der Chromaffinzelle mit dem Volumen $V_{\text {ges }} \approx 524 \mathrm{fl}$ (sphärisch mit einem Radius von ca. 5 $\mu \mathrm{m}$ ) berechnet sich hieraus eine Geschwindigkeitskonstante der Photozerstörung von $k_{\mathrm{z}} \approx 24$ $\mathrm{s}^{-1}$. Hierbei ist aber zu berücksichtigen, daß Gl. 72 der Chromaffinzelle findet aber während der Photozerstörung keine vollkommene Durchmischung mit der gesamten intrazellulären Lösung statt, womit der beobachtete Fluoreszenzabfall in der Zelle im Vergleich zur gerührten Lösung scheinbar schneller stattfindet. Bei einem langsameren Fluoreszenzabfall erniedrigt sich die Geschwindigkeitskonstante der Photozerstörung, und somit ist der Wert $k_{\mathrm{z}} \approx 24 \mathrm{~s}^{-1}$ eher als obere Grenze anzusehen. Mit der Geschwindigkeitskonstanten $k_{\mathrm{z}} \approx 24 \mathrm{~s}^{-1}$ und der Diffusionszeitkonstanten des Farbstoffs in der Zelle $\left(\tau_{\mathrm{D}} \approx 1 \mathrm{~ms}\right.$ ) wird aus TTabelle 2 eine Abweichung der gemessenen Diffusionszeitkonstanten von der photozerstörungsfreien Diffusionszeitkonstanten von ca. $20 \%$ entnommen. Die beobachteten Diffusionszeiten könnten also um ca. $20 \%$ unterschätzt worden sein, d.h. die photozerstörungsfreie Diffusion wäre dann maximal ca. $20 \%$ langsamer.

Die im Rahmen dieser Arbeit beobachtete langsamere Diffusion des Farbstoffs im Cytoplasma verglichen zum Nucleoplasma könnte durch eine mehr gehinderte Diffusion im Cytoplasma, verursacht durch dessen besondere Mikroarchitektur, erklärt werden. Die Anwesenheit von Zellorganellen, etwa den zahlreichen Sekretionsgranula in der Chromaffinzelle, oder von Filamenten des Cytoskeletts können die mittlere freie Weglänge des Farbstoffs einschränken und somit den Diffusionskoeffizienten erniedrigen.

Der Diffusionskoeffizient von OGB1 (molekulare Masse $1114 \mathrm{~g} / \mathrm{mol}$ ) in Chromaffinzellen wurde bisher noch nicht untersucht, so daß kein direkter Vergleich mit Literaturergebnissen erfolgen kann. Ein Vergleich mit den Diffusionseigenschaften des häufig verwendeten Calciumfarbstoffs Fura-2 (molekulare Masse $642 \mathrm{~g} / \mathrm{mol}$ ) ist aber möglich.

Timmerman et. al. untersuchten die Diffusion von Fura-2 sowohl in Salzlösung $(D=500$ $\left.\mu \mathrm{m}^{2} / \mathrm{s}\right)$ als auch nach Mikroinjektion des Farbstoffs in Muskelfasern der Seepocke $(D=75$ $\left.\mu \mathrm{m}^{2} / \mathrm{s}\right)[90]$. 
Durch die Mikroinjektion von Fura-2 in die Rückenmarksneurone des Neunauges und durch fluoreszenzmikroskopische Vermessung der Ausbreitung gelangten Strautman et. al. zu einem Wert von $211 \mu \mathrm{m}^{2} / \mathrm{s}$ für den Diffusionskoeffizienten [91].

Von Gabso et. al. wird ein Diffusionskoeffizient von $103 \mu \mathrm{m}^{2} / \mathrm{s}$ in den Axonen der Kiemenschnecke Aplysia californica angegeben [92].

Auch für andere Farbstoffe wird eine vergleichbare Diffusion im Zellcytoplasma gefunden.

Connor et. al. untersuchten die Diffusion der Farbstoffe Phenol-Rot und Arsenazo III im Cytoplasma von Weichtierneuronen von Archidoris monterynensis und fanden von eine wenigstens fünfmal langsamere Diffusion im Cytoplasma verglichen zu Salzlösung [일.

Insgesamt wird also von 2-7 mal langsamerer Diffusion von Farbstoffen in Zellen, verglichen mit der in einfachen Elektrolyten, berichtet. Die Werte liegen damit im gleichen Bereich wie die im Rahmen dieser Arbeit erhaltenen Ergebnisse und zeigen die Eignung der FCSMethode zur Bestimmung von Diffusionseigenschaften auch in den kleinen Zellen der Vertebraten.

\subsection{Benzodiazepin-Rezeptor-Wechselwirkung in der Membran hippo- campaler Neurone}

Die FCS-Technik wurde erfolgreich zur Untersuchung der molekularen Interaktion eines farbstoffmarkierten Benzodiazepins mit dem Rezeptor in der Zellmembran einzelner hippocampaler Neurone angewandt. Dazu wurde zunächst der Einfluß unterschiedlicher Farbstoffreste auf das Bindungsverhalten des Benzodiazepins sowie deren Eignung für Bindungsstudien in der Zellmembran von lebenden Zellen untersucht. Der schließlich verwendete Ligand, bestehend aus Ro 07-1986/602 gekoppelt an Alexa 532, zeigte geringe unspezifische Bindung an die Membran bei gleichzeitig voll erhaltener Funktionalität.

Das Spektrum der verwendbaren Liganden zur Ausführung von Bindungsstudien an lebenden Zellen mit Hilfe der FCS-Technik konnte somit auf ,kleine‘ Moleküle (molare Masse $332 \mathrm{~g} / \mathrm{mol}$ ) ausgedehnt werden, in Ergänzung zu den bisher veröffentlichten Bindungsstudien

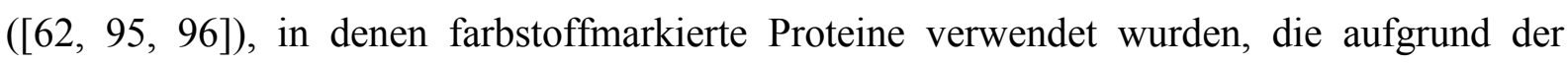
Größe der verwendeten Proteine eine Einlagerung in die Zellen nicht erwarten lassen, und bei denen der Einfluß des Farbstoffrestes auf das Bindungsverhalten eher klein sein sollte.

Nach Applikation von Ro-Alexa wurden vorher nicht vorhandene Fluoreszenzspitzen, die bei geringen Konzentrationen an Alexa-Ro von wenigen Partikeln im Fokus stammten, detektiert und eine Anreicherung des Liganden in der Zellmembran beobachtet. Neben der freien Komponente des Liganden $\left(D_{\text {frei }}=(220 \pm 3) \mu \mathrm{m}^{2} / \mathrm{s}\right)$ wurde eine schnelle $\left(D_{\text {geb } 1}=\right.$ $\left.(1,32 \pm 0,26) \mu \mathrm{m}^{2} / \mathrm{s}\right)$ und eine langsam diffundierende Komponente $\left(D_{\text {geb2 }}=(2,63 \pm 0,63) \cdot 10^{-2}\right.$ $\left.\mu \mathrm{m}^{2} / \mathrm{s}\right)$ in der Zellmembran nachgewiesen mit Diffusionskoeffizienten, wie sie in vielen Membranen beobachtet wurden und z. B. in $[97$ zusammenfassend dargestellt sind. Ein 
geringer Anteil der schneller diffundierenden gebundenen Komponente wird durch unspezifische Bindung des farbstoffmarkierten Liganden verursacht. Wie nach der kompetitiven Verdrängung des spezifisch gebundenen farbstoffmarkierten Liganden durch einen Überschuß des unmarkierten Agonisten Midazolam festgestellt wurde, verblieb ein gebundener Anteil von 7-10 \%. Die Autokorrelationsanalyse ergab, daß die langsam diffundierende Komponente vollständig verschwunden war, während von der schnellen Komponente dieser Restanteil übrig blieb.

Die zwei beobachteten Diffusionskoeffizienten in der Zellmembran werden möglicherweise durch verschiedene Formen des Ligand-Rezeptor-Komplexes hervorgerufen. Eine mögliche Clusterbildung der GABA $\mathrm{A}$-Rezeptoren, die z. B. in [98 eine langsamere Diffusionszeit erklären. Weiterhin wurde von Internalisierung der $\mathrm{GABA}_{\mathrm{A}^{-}}$ Rezeptoren berichtet, die ebenfalls zu Heterogenitäten in der Diffusionszeit führen könnten $[101,102]$.

Clusterbildung von GABA/Benzodiazepin-Rezeptoren wurde auch von Velazquez et. al. beschrieben, die in Rückenmarksneuronen der Ratte die Verteilung und Mobilität von GABA/Benzodiazepin-Rezeptoren mit NBD-markierten Benzodiazepinen durch Fluoreszenzmikroskopie bzw. FRAP-Experimente untersucht haben [103]. Sie finden eine hohe Dichte von Rezeptor-Clustern am Zellkörper der Neurone mit einen Diffusionskoeffizienten von $1,9 \cdot 10^{-2} \mu \mathrm{m}^{2} / \mathrm{s}$ und einer geschätzten Rezeptordichte von 800-1000 Rezeptoren $/ \mu \mathrm{m}^{2}$. Der Unterschied in der Rezeptorendichte $\mathrm{zu}$ dem in dieser Arbeit bestimmten Wert von $\rho=$ $(14,9 \pm 2,7)$ Rezeptoren $/ \mu \mathrm{m}^{2}$ ist wahrscheinlich auf die unterschiedlichen Zelltypen zurückzuführen. Der Diffusionskoeffizient der langsamen Komponente in dieser Arbeit stimmt gut mit dem Wert aus den FRAP-Experimenten überein.

Die bisher veröffentlichten FCS-Bindungsstudien an lebenden Zellen von Rigler et. al. [95] und Pramanik et. al. [96] zeigen, genauso wie diese Arbeit, die Anwesenheit von mindestens zwei unterschiedlich schnell diffundierenden Komponenten in der Zellmembran auf, wobei Widengren et. al. von nur einer Komponente berichten [62] ].

Rigler et. al. untersuchten die Bindung des Proinsulin C-Peptides in menschlichen Zellmembranen [ $[\overline{9} \bar{j}]$. Die Autoren ermittelten Diffusionszeitkonstanten für einen schnellen und einen langsam diffundierenden Komplex, deren Werte sich um knapp zwei Größenordnungen unterscheiden. Ein ähnliche Beobachtung wird von Pramanik et. al. berichtet, die mit Hilfe von FCS die Interaktion von TMR markiertem Galanin mit seinem Rezeptor in Rinm5FZellen untersuchten [96]. Widengren et. al. untersuchten die Wechselwirkung von TMRmarkierten EGF-Molekülen mit EGF-Rezeptoren in der Zellmembran einer BlasenkrebsZellinie der Ratte, aus denen sich ein Diffusionskoeffizient der Rezeptoren von etwa $0,7 \mu \mathrm{m}^{2}$ / $\mathrm{s}$ ergab [6- $\overline{6} \overline{-}]$.

Aus der Abhängigkeit der gebundenen Ligandkonzentration zur total eingesetzten Konzentration konnte die bisher unbekannte Dissoziationskonstante für den Ligand-RezeptorKomplex von $K_{\mathrm{D}}=(9,9 \pm 1,9) \mathrm{nM}$ bestimmt werden, wobei eine Ligand-Bindungsstelle pro 
Rezeptor angenommen wurde. Die Spezifität der Bindung wurde durch eine kompetitive Verdrängung des farbstoffmarkierten Liganden mit einem etwa tausendfachen Überschuß des unmarkierten Agonisten Midazolam nachgewiesen mit einem Restanteil von 7-10 \% der gebundenen Komponente, der nicht verdrängt werden konnte. Aus dem Zeitverlauf der Verdrängung folgte eine Geschwindigkeitskonstante für den Dissoziationsprozeß des LigandRezeptor-Komplexes von $k_{\text {diss }}=(1,28 \pm 0,08) \cdot 10^{-3} \mathrm{~s}^{-1}$. Der Dissoziationsprozeß erfolgte dabei mehrere Male mit einer Zeitverzögerung von mehreren Minuten, die durch eine gehinderte Dissoziation des gebundenen Liganden vom Rezeptor erklärt werden kann und deren genauer Mechanismus noch geklärt werden muß. Aus dem Verhältnis $k_{\text {diss }} / K_{\mathrm{D}}$ wurde die Geschwindigkeitskonstante für die Komplexassoziation berechnet $k_{\text {ass }}=(1,30 \pm 0,26) \cdot 10^{5} 1 \mathrm{~mol}^{-1} \mathrm{~s}^{-1}$.

Diese Ergebnisse sind in Übereinstimmung mit den Bindungseigenschaften anderer Benzodiazepine an ihrem Rezeptor.

Die von Mackerer et. al. untersuchte Bindung des Benzodiazepins $\left[{ }^{3} \mathrm{H}\right]$ Diazepam an homogenisierte Zellfraktionen des Rattenhirns ergab eine Bindungsstelle pro Rezeptor mit einer Dissoziationskonstanten von $K_{\mathrm{D}}=3,2 \mathrm{nM}$ und den Geschwindigkeitskonstanten $k_{\mathrm{ass}}=$ $1,13 \cdot 10^{6} 1 \mathrm{~mol}^{-1} \mathrm{~s}^{-1}$ sowie $k_{\text {diss }}=2,69 \cdot 10^{-3} \mathrm{~s}^{-1}[105]$.

Einen ähnlichen Wert für die Dissoziationskonstante wird von Walker et. al. berichtet, die für die Bindung von $\left[{ }^{3} \mathrm{H}\right]$ Diazepam an kultivierte Hippocampusneurone der fetalen Maus eine Dissoziationskonstanten $K_{\mathrm{D}}=5 \mathrm{nM}$ erhalten [106].

Die Bindung von $\left[{ }^{3} \mathrm{H}\right]$ Flunitrazepam an hippocampale synaptische Membrane, beschrieben von Fung et. al. [107], erfolgte mit einer Dissoziationskonstanten von $K_{\mathrm{D}}=1,24 \mathrm{nM}$ und war in Übereinstimmung mit der Ausbildung eines einfachen Ligand-Rezeptor-Komplexes. Die Dissoziation des Komplexes wurde mit zwei Geschwindigkeitskonstanten mit den Werten $2,0 \cdot 10^{-3} \mathrm{~s}^{-1}$ und $4,1 \cdot 10^{-4} \mathrm{~s}^{-1}$ beschrieben.

Chiu et. al. untersuchten die Bindung von $\left[{ }^{3} \mathrm{H}\right]$ Flunitrazepam an Synaptosomenmembranen vom Cortex der Ratte und fanden zwei Geschwindigkeitskonstanten mit den Werten $1,5 \cdot 10^{-3} \mathrm{~s}^{-1}$ und $4,2 \cdot 10^{-4} \mathrm{~s}^{-1}[60]$.

Insgesamt führen die FCS-Experimente also zu vergleichbaren Ergebnissen und zeigen das Potential der FCS-Technik zur Untersuchung von Ligand-Rezeptor-Wechselwirkungen in lebenden Zellen. Zusätzliche Untersuchungsmethoden können die durch die FCS-Technik erhaltenen Ergebnisse ergänzen und damit helfen, den genauen Mechanismus der Benzodiazepin-Rezeptor-Bindung aufzuklären.

\subsection{Dynamik synaptischer Vesikel in hippocampalen Boutons}

Die Dynamik synaptischer Vesikel in unstimulierten als auch in stimulierten hippocampalen Boutons wurde mit Hilfe der FCS-Technik untersucht. Hierbei konnte die Dynamik einzelner synaptischer Vesikel aufgelöst werden. 
In einem Volumenelement, das etwa 1/9 des präsynaptischen Boutonvolumens ausmachte, wurde die Fluoreszenz aufgezeichnet und analysiert. Durch systematische Applikation verschiedener Pharmaka wurde regulierend auf die Kinasen und Phosphatasen als auch das Cytoskelett in der Synapse eingewirkt.

Einen höheren Anteil mobiler Vesikel wurde durch Block der Phosphatasen 1 und 2A mit $5 \mu \mathrm{M}$ Okadasäure erreicht. Durch die Inhibition der genannten Phosphatasen scheinen also Vesikel aus dem Vesikelcluster befreit zu werden.

Dies wird unterstützt durch die in unstimulierten als auch in stimulierten motorischen Endplatten des Froschmuskels von Henkel et. al. gemachten Beobachtungen, daß nach Photozerstörung angefärbter Vesikel im Kontrollversuch keine Erholung der Fluoreszenz erfolgte, während sich dies in Anwesenheit von Okadasäure änderte [108].

Hosaka et. al. stellten nach Behandlung von Synpaptosomen mit Okadasäure eine erhöhte Phosphorylierung der A-Domäne der Synapsine fest, die eine Phosphorylierungsstelle für die Proteinkinase A und die CaM-Kinase I enthält und in allen Synapsin-Isoformen enthalten ist. Die Phosphorylierung der A-Dömane führte zur Dissoziation der Synapsine vom synaptischen Vesikel [88]. Die Befreiung der synaptischen Vesikel aus dem Cluster könnte also durch Dissoziation der Vesikel von den Synpasinen erfolgen.

Eine spezifische Aktivierung der Proteinkinase A, die ebenfalls zur Dissoziation der Synapsine von ihren Vesikeln führte ['] $[\overline{8} \overline{8}]$, hatte im Rahmen dieser Arbeit jedoch keinen Effekt auf das Fluktuationsverhalten der Vesikel. Weiterhin zeigten auch die zeitgleiche Aktivierung der Proteinkinasen A und C, als auch die Inhibition der Proteinkinasen A und C sowie der CaM-Kinase II einzeln als auch in Kombination keinen detektierbaren Effekt auf die Beweglichkeit der Vesikel.

Eine starke Verringerung der Mobilität synaptischer Vesikel wurde durch die Inhibition der Myosin-Leichtketten-Kinase (MLCK) mit $15 \mu \mathrm{M}$ ML-7 erreicht, wobei die Anzahl der mobilen Vesikel nur geringfügig abnahm. Die MLCK aktiviert in der glatten Muskulatur die Motorproteinfamilie der Myosine, die auch in präsynaptischen Boutons nachgewiesen wurden. Die Anwesenheit von Myosinen wurde beispielsweise durch eine Kolokalisation von Myosin II mit Synpatophysin gezeigt [109]. Besonders häufig ist in Nervenzellen die Isoform des Myosin V, das sowohl Bindungen zu Actinfilamenten als auch zu synaptischen Vesikeln eingehen kann [22].

Die Abnahme in der Mobilität synaptischer Vesikel ist wahrscheinlich der Grund für die Verringerung der Neurotransmitterausschüttung in Neuronen, die nach Inhibition der MLCK von Ryan und von Mochida et. al. beobachtet wurde. Ryan berichtet in hippocampalen Neuronen von einer Verringerung der Transmitterfreisetzung bei kontinuierlicher Stimulation sowie einer Reduzierung der Recycling-Poolgröße [110]. Eine aktivitätsabhängige Inhibition der Transmitterfreisetzung nach Blockierung der MLCK wurde von Mochida et. al. in cholinergen Synapsen beobachtet $[1-\overline{1}]$. Weiterhin führten Antikörper gegen Myosin II zur Inhibition der Transmitterfreisetzung [10 $10 \overline{1}$. 
Da sich die Myosine entlang von Actinfilamenten bewegen, sollten Veränderungen im Actinnetzwerk auch die Mobilität der Vesikel beeinflussen.

Eine Beteiligung der Actinfilamente auf die Vesikelmobilität wurde aber in unbehandelten Boutons nicht festgestellt. Sowohl der Block der Actinpolymerisation mit Cytochalasin D als auch mit Latrunculin B hatten selbst nach Vorinkubation von 70 min keinen Effekt auf die Vesikelmobilität. Diese Beobachtungen untermauern, daß die analysierten Fluoreszenzfluktuationen auf der Bewegung synaptischer Vesikel und nicht des gesamten Boutons basieren, da durch Cytochalasin D in Purkinjezellen und in Neuronen des Cortex die Mobilität der dendritischen Dornen inhibiert werden kann Cholchicin zeigte ebenfalls keine Auswirkung.

Erst nach Applikation von $5 \mu \mathrm{M}$ Okadasäure wurde ein dosisabhängiger Effekt von Latrunculin B festgestellt. Der Block der Actinpolymerisation durch $25 \mu \mathrm{M}$ Latrunculin B führte zu einer erhöhten Mobilität der synaptischen Vesikel. Der dosisabhängige Effekt zeigt, daß die Actinfilamente für das Toxin in geringen Konzentrationen schlecht zugänglich sind, weil möglicherweise eine starke Abschirmung der Actinfilamente durch Proteine stattfindet. Weiterhin ist denkbar, daß der aktive Transport der synaptischen Vesikel nur sekundär von den Actinfilamente abhängt, indem die Actinfilamente als Barriere oder als Verankerungssubstrat dienen.

Eine leichte Mobilitätserhöhung der synaptischen Vesikel in den Körnerzellen des Gyrus dentatus wurde nach einem Stimulationsprotokoll, das zur Ausbildung von Langzeitpotenzierung in diesen Zellen [899] führt, detektiert; hierzu sind weitere Experimente nötig.

Nach der Stimulation mit einzelnen Aktionspotentialen wurden synchron fast schrittweise abfallende Fluoreszenzsignale beobachtet, die entweder durch eine Relokalisation eines farbstoffmarkierten Vesikels innerhalb des Boutons infolge des Aktionspotentials oder durch die Fusion eines farbstoffmarkierten Vesikels mit der aktiven Zone erklärt werden können. Sprunghafte Fluoreszenzanstiege wurden auch nach Erweiterung des Detektionsvolumens auf das gesamte Bouton nicht detektiert, die aber im Falle der Vesikelreorganisation zu erwarten wären, so daß davon ausgegangen werden kann, daß in vielen Fällen die Fusion eines Vesikels mit der Membran beobachtet wurde. Aus der mittleren Fluoreszenzdifferenz vor und nach dem Aktionspotential wurde der Fluoreszenzbeitrag eines Vesikels bestimmt, der unter den in dieser Arbeit gewählten Bedingungen etwa 2 kcps betrug. Der Fluoreszenzabfall wurde vielfach mit einer Zeitverzögerung von 0,5-0,7 s beobachtet, die auch nach Erweiterung des Detektionsvolumens auf das gesamte Bouton noch vorhanden war. Weitere Experimente durch Zweiphotonenmikroskopie, die die gleichzeitige Auswertung mehrerer Pixel in der Zeit erlauben, werden im Moment zur Klärung durchgeführt. Da die Fusion eines Vesikels im Mikrosekundenbereich stattfindet, ist eine Barriere vorstellbar, die das unmittelbare Auswaschen des Farbstoffs aus der Membran der aktiven Zone verzögert und beispielsweise durch eine mit Proteinen dichtgepackte Membran oder eine Fusionspore erklärbar wären. Das verzögerte Auswaschen war nach etwa $2 \mathrm{~s}$ beendet und ist damit vergleichbar mit der von 
Klingauf et. al. erhaltenen Zeitkonstante für das Auswaschen des Farbstoffs FM1-43 aus der Zellmembran [i111]. 


\section{Zusammenfassung}

Die FCS wurde erfolgreich zur Bestimmung von Diffusionkoeffizienten im Cytoplasma und im Nucleus von Chromaffinzellen angewandt. Im Cytoplasma war der Diffusionskoeffizient des Farbstoffs OGB1 4-5 mal kleiner als im Elektrolyten im Nucleus etwa 2 mal. Zwischen der calciumgebundenen Form und der calciumfreien Form des Farbstoffs wurde kein Unterschied festgestellt.

An der Grenzfläche zwischen hippocampaler Zellmembran und extrazellulärer Lösung wurde die molekulare Interaktion des farbstoffmarkierten Benzodiazepins Ro-Alexa durch FCS direkt am Wirkort des Liganden untersucht. Verschiedene Farbstoffe wurden auf ihre Eignung für FCS-Messungen in der Zellmembran überprüft und der Effekt des Farbstoffs auf das spezifische Bindungsverhalten des Benzodiazepins charakterisiert. Der rezeptorgebundene Anteil von Ro-Alexa konnte aufgrund seiner langsameren Diffusionszeiten in der Zellmembran $\left(D_{\text {geb } 1}=(1,32 \pm 0,26) \mu \mathrm{m}^{2} \mathrm{~s}^{-1} ; D_{\text {geb } 2}=(2,63 \pm 0,63) \cdot 10^{-2} \mu \mathrm{m}^{2} \mathrm{~s}^{-1}\right)$ vom schneller diffundierenden ungebundenen Anteil $\left(D_{\text {frei }}=(220 \pm 3) \mu \mathrm{m}^{2} \mathrm{~s}^{-1}\right)$ unterschieden werden. Die FCSMethode war geeignet, die spezifische Bindung eines farbstoffmarkierten Benzodiazepins nachzuweisen. Die Affinität des Ligand-Rezeptor-Komplexes $\left(K_{\mathrm{D}}=(9,9 \pm 1,9) \mathrm{nM}\right)$ sowie die Geschwindigkeitskonstanten der Komplex-Assoziation $\left(k_{\text {ass }}=(1,30 \pm 0,26) \cdot 10^{5} 1 \mathrm{~mol}^{-1} \mathrm{~s}^{-1}\right)$ und -Dissoziation $\left(k_{\text {diss }}=(1,28 \pm 0,08) \cdot 10^{-3} \mathrm{~s}^{-1}\right)$ wurden bestimmt.

Synaptische Vesikel wurden durch FCS sowohl in unstimulierten als auch in stimulierten einzelnen hippocampalen Boutons untersucht. Hierbei konnte die Dynamik einzelner synaptischer Vesikel aufgelöst werden. Durch systematische Applikation verschiedener Pharmaka wurde die Wirkung von Kinasen, Phosphatasen und des Cytoskeletts auf die Vesikelmobilität untersucht. Ein Großteil der Bewegung ist auf aktiven Transport zurückzuführen, der durch die Myosin-Leichtketten-Kinase kontrolliert wird. Neben den beweglichen Vesikeln wurde ein immobiler Anteil detektiert, der durch Inhibition der Phosphatasen 1 und 2A in dem Bouton teilweise mobilisiert werden konnte. Nach der Mobilisierung der Vesikel führte eine Zerstörung des Actinnetzwerks zu einer erhöhten Beweglichkeit der Vesikel in dem Bouton. 


\section{Literaturverzeichnis}

[1] D. Magde, E.L. Elson, W.W. Webb, Thermodynamic Fluctuations in a Reacting System Measurement by Fluorescence Correlation Spectroscopy. Phys. Rev. Lett. 29, 705-708 (1972).

[2] E.L. Elson, D. Magde, Fluorescence Correlation Spectroscopy. I. Conceptual Basis and Theory. Biopolymers 13, 1-27 (1974).

[3] D. Magde, E.L. Elson, W.W. Webb, Fluorescence Correlation Spectroscopy II. An Experimental Realization. Biopolymers 13, 29-61 (1974).

[4] M. Ehrenberg, R. Rigler, Rotational Brownian Motion and Fluorescence Intensity Fluctuations. Chem. Phys. 4, 390-401 (1974).

[5] Ü. Mets, R. Rigler, Submillisecond Detection of Single Rhodamine Moleculs in Water. $J$. Fluorescence 4, 259-264 (1994).

[6] S. Maiti, U. Haupts, W.W. Webb, Fluorescence Correlation Spectroscopy: Diagnosis for sparse molecules. Proc. Natl. Acad. Sci. USA 94, 11753-11757 (1997).

[7] R. Rigler, J. Widengren, Ultrasensitive Detection of Single Molecules by Fluorescence Correlation Spectroscopy. Bioscience 3, B. Klinge and C. Owman (eds.), pp. 180-183 (1990).

[8] R. Rigler, W. Widengren, Ü. Mets, Interactions and Kinetics of Single Molecules as Observed by Fluorescence Correlation Spectroscopy. In: Fluorescence Spectroscopy. New Methods and Applications, O. Wolfbeis (ed.), Springer Verlag, Berlin, 13-24 (1992).

[9] R. Rigler Fluorescence Correlation, Single Molecule Detection and Large Number Screening: Applications in Biotechnology. J. Biotechnol. 4, No. 3, 259-264 (1994).

[10] R.C. Benson, R.A. Meyer, E. Zazuba, G.M. McKhann, Cellular autofluorescence - is it due to flavins? J. Histochem. Cytochem. 27 (1), 44-48 (1979).

[11] J.E. Aubin, Autofluorescence of viable cells. J. Histochem. Cytochem. 27 (1), 36-43 (1979).

[12] W.W. Douglas, Stimulus-secretion coupling: the concept and clues from chromaffin and other cells. Brit. J. Pharmacol. 34, 453-474 (1968).

[13] M. Oheim, M. Naraghi, T.H. Müller, E. Neher, Two dye two wavelength excitation calcium imaging: results from bovine adrenal chromaffin cells. Cell Calcium 24 (1), 71-84 (1998).

[14] S. Smith, R. Zucker, Aequorin responses facilitation and intracellular calcium accumulation in molluscan neurons. J. Physiol. 300, 167-196 (1980).

[15] E. Neher, Vesicle pools and $\mathrm{Ca}^{2+}$ microdomains: new tools for understanding their roles in neurotransmitter release. Neuron 20, 389-399 (1998). 
[16] E.R. Kandel, J.H. Schwartz, T.M. Jessell, Neurowissenschaften, Spektrum Akademischer Verlag Heidelberg, 1996.

[17] T.A. Ryan, H. Reuter, S.J. Stevens, Optical detection of a quantal presynaptic membrane turnover. Nature 388, 478-482 (1997).

[18] T. Schikorski, C.F. Stevens, Quantitative ultrastructural analysis of hippocampal excitatory synapses. J. Neurosci. 17 (15), 5858-67 (1997).

[19] V.N. Murthy, C.F. Stevens, Synaptic vesicles retain their identity through the endocytic cycle. Nature 392, 497-501 (1998).

[20] C.F. Stevens, T. Tsujimoto, Estimates for the pool size of releasable quanta at a single central synapse and for the time required to refill the pool. Proc. Natl. Acad. Sci. USA 92, 846-849 (1995).

[21] B. Alberts, D. Bray, J. Lewis, M. Raff, K. Roberts, J.D. Watson, Molekularbiologie der Zelle, 3. Auflage, VCH Winheim, 1995.

[22] F. Doussau, G.J. Augustine, The actin cytosceleton and neurotransmitter release: an overview. Biochimie 28, 353-363 (2000).

[23] J.B. Pawley, Handbook of confocal microscopy. 2nd edition, Plenum Press, New York, 1995.

[24] R.M. McKernan, P.J. Whiting, Which GABA $_{A}$-receptor subtypes really occur in the brain? Trend Neurosci. 19, 139-143 (1996).

[25] D.R. Burt, G.L. Kamatchi, GABA $\mathrm{A}$ receptor subtypes: from pharmacology to molecular biology. FASEB Journal 5, 2916-2923 (1991).

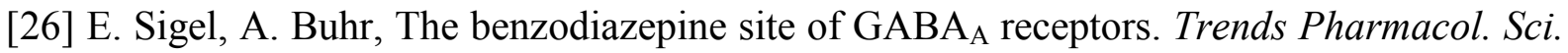
18, 425-29 (1997).

[27] E.M. Barnes jr., User-dependent regulation of $\mathrm{GABA}_{\mathrm{A}}$ receptors. Int. Rev. Neurobiol. 39, 53-76 (1996).

[28] R.L. Macdonald, R.W. Olsen, GABA A receptor channels. Annu. Rev. Neurosci. 17, 569602 (1994).

[29] D.W. Choi, D.H. Farb, G.D. Fischbach, Chlordiazepoxide selectively augments GABA action in spinal cord cell cultures. Nature 269, 342-344 (1977).

[30] R.L. Macdonald, J.L. Barker, Benzodiazepines specifically modulate GABA-mediated postsynaptic inhibition in cultured mammalian neurons. Nature 271, 563-564 (1978).

[31] E. Mutschler, Arzneimittelwirkungen. Wissenschaftliche Verlagsgesellschaft, Stuttgart, 1997. 
[32] R.E. Study, J.L. Baker, Diazepam and (-)-pentobarbital: Fluctuation analysis reveals different mechanisms for potentiation of $\gamma$-aminobutyric acid responses in cultured central neurons. Proc. Natl. Acad. Sci. USA 78, 7180-7184 (1981).

[33] J.H. Skerrit, R.L. Mc Donald, Benzodiazepine receptor ligand actions on GABA reponses. Benzodiazepines, CL 218872, zopiclone. Eur. J. Pharmacol. 101, 127-134 (1984).

[34] C.J. Rogers, R.E. Twyman, R.L. MacDonald, The benzodiazepine diazepam and the $\beta$ carboline DMCM modulate $\mathrm{GABA}_{\mathrm{A}}$ receptor single channel by opposite mechanisms. Society for Neuroscience Abstracts 15, 1150 (1989).

[35] C.J. Rogers, R.E. Twyman, R.L. MacDonald, Diazepam increases the burst frequency of GABA-activated chloride channels, Society for Neuroscience Abstracts 12, 669 (1986).

[36] C.J. Rogers, R.E. Twyman, R.L. MacDonald, Benzodiazepine and $\beta$-carboline regulation of single $\mathrm{GABA}_{\mathrm{A}}$ receptor channels of mouse spinal neurones in culture. J. Physiol. 475 (1), 69-82 (1994).

[37] Y. Sato, Y. Fujito, M. Aoki, Differential effects of a benzodiazepine on synaptic transmission in rat hippocampal neurons in vitro. Brain Research 773, 98-107 (1997).

[38] J.C. Poncer, R. Durr, B.H. Gahwiler, S.M. Thompson, Modulation of synaptic GABA A receptor function by benzodiazepines in area CA3 of rat hippocampal slice cultures. Neuropharmacology 35 (9-10), 1169-79 (1996).

[39] C. Rovira, Y. Ben-Ari, Developmental study of miniture IPSCs of CA3 hippocampal cells: modulation by midazolam. Brain Res. Dev. Brain Res. 114 (1), 79-88 (1999).

[40] T.S. Otis, I. Mody, Modulation of decay kinetics and frequency of GABA receptormediated spontaneous inhibitory postsynaptic currents in hippocampal neurons. Neuroscience 49 (1), 13-32 (1992).

[41] W. Pschyrembel, Klinisches Wörterbuch. 257. Auflage, de Gruyter Berlin, New York, 1994.

[42] O. Benkert, H. Hippius, Psychiatrische Pharmakotherapie. Springer Verlag Berlin, Heidelberg, New York.

[43] A.E. Siegman, An introduction to lasers and masers. McGraw-Hill, 1971.

[44] W. Demtröder, Laser spectroscopy. Springer, 2nd edition, 1996.

[45] D.E. Koppel, D. Axelrod, J. Schlessinger, E.L. Elson, W.W. Webb, Dynamics of fluorescence marker concentration as a probe of mobility. Biophys. J. 16, 1315-1329 (1976).

[46] H. Qian, E.L. Elson, Analysis of Confocal Laser-Microscope Optics for 3-D Fluorescence Correlation Spectroscopy. Appl. Opt. 30, 1185-1195 (1991). 
[47] R. Rigler, Ü. Mets, J. Widengren, P. Kask, Fluorescence Correlation Spectroscopy with High Count Rate and Low Background: Analysis of Translational Diffusion. Eur. Biophys. J. 22, 169-175 (1993).

[48] L.N. Bronstein, K.A. Semendjajew, Taschenbuch der Mathematik, 25. Auflage, Teubner, 1991.

[49] D.R. Sandison, R.M. Williams, K.S. Wells, J. Strickler, W.W. Webb, Quantitative fluorescence confocal laser scanning spectroscopy (CLSM). In: J.B. Pawley, Handbook of confocal microscopy. 2nd edition, Plenum Press, New York, 1995.

[50] C.J.R. Sheppard, X. Gan, M. Gu, M. Roy, Signal-to-noise in confocal microscopes. In: J.B. Pawley, Handbook of confocal microscopy, 2nd edition, Plenum Press, New York, 1995.

[51] W.H. Press, S.A. Teukolsky, W.T. Vetterling, B.P. Flannery, Numerical recipes in C, 2nd edition, Cambridge University Press, 1992.

[52] J.S. Bendat, A.G. Piersol, Random data: analysis and measurement procedures, WileyInterscience, 1971.

[53] F.J. Harris, On the use of windows for harmonic analysis with the discrete fourier transform. Proc. IEEE 66, 51-83 (1978).

[54] J.W. Tukey, An introduction to the calculation of numerical spectrum analysis. Spectral Analysis of Time Series, B. Harris, Ed., Wiley New York, 25-46, 1967.

[55] S.R. Aragón, R. Pecora, Fluorescence Correlation Spectroscopy as a Probe of Molecular Dynamics. J. Chem. Phys. 64, 1791-1803 (1976).

[56] H. Qian, E.L. Elson, Distribution of molecular aggregation by analysis of fluctuation moments. Proc. Natl. Acad. Sci. USA 87, 5479-5483 (1990).

[57] N.L. Thompson, Fluorescence Correlation Spectroscopy. Topics in Fluorescence Spectroscopy, Vol. 1, J.R. Lakowicz (ed.), Plenum Press, New York/London, 337-378, (1991).

[58] B. Saleh, Photoelectron statistics. Springer-Verlag Berlin Heidelberg New York, 1978.

[59] P. Kask, R. Günther, P. Axhausen, Statistical Accuracy in Fluorescence Fluctuation Experiments. Eur. Biophys. J. 25, 163-169 (1997).

[60] T.H. Chiu, D.M. Dryden, C. Rosenberg, Kinetics of $\left[{ }^{3} \mathrm{H}\right]$ Flunitrazepam binding to membrane-bound benzodiazepine receptors. Molec. Pharmacology 21, 57-65 (1981).

[61] A.G. Palmer, N.L. Thompson, Theory of Sample Translation in Fluorescence Correlation Spectroscopy. Biophys. J. 51, 339-343 (1987). 
[62] J. Widengren, R. Rigler, Fluorescence Correlation Spectroscopy (FCS) as a Tool to Investigate Chemical Reactions in Solutions and on Cell Surfaces. Cell Mol. Biol. 44, 857879 (1998).

[63] J. Widengren, Ü. Mets, R. Rigler, Fluorescence Correlation Spectroscopy of Triplet States in Solution: A Theoretical and Experimental Study. J. Phys. Chem. 99, 13368-13379 (1995).

[64] C. Eggeling, J. Widengren, R. Rigler, C.A.M. Seidel, Photobleaching of fluorescent dyes under conditions used for single-molecule detection: evidence of two-step photolysis. Anal. Chem. 70, 2651-2659 (1998).

[65] J. Widengren, R. Rigler, Mechanisms of photobleaching investigated by fluorescence correlation spectroscopy. Bioimaging 4, 149-157 (1996).

[66] R.D. Icenogle, E.L. Elson, Fluorescence Correlation Spectroscopy and Photobleaching Recovery of Multiple Binding Reactions. II. FPR and FCS measurements at low and high DNA concentrations. Biopolymers 22, 1949-1966 (1983).

[67] A.G. Palmer, N.L. Thompson, Molecular Aggregation Characterized by High-Order Autocorrelation in Fluorescence Correlation Spectroscopy. Biophys. J. 52, 257-270 (1987).

[68] D.E. Koppel, Statistical Accuracy in Fluorescence Correlation Spectroscopy. Phys. Rev. 10, 1938-1945 (1974).

[69] D. Axelrod, D.E. Koppel, J. Schlessinger, E. Elson, W.W. Webb, Mobility measurement by analysis of fluorescence photobleaching recovery kinetics. Biophys. J. 16, 1055-1069 (1976).

[70] J. Widengren, Ü. Mets, R. Rigler, Fluorescence Correlation Spectroscopy of Triplet States in Solution: A Theoretical and Experimental Study. J. Phys. Chem. 99, 13368-13379 (1995).

[71] I.C. Chang, Acoustooptic devices and applications., IEEE Trans. Sonics Ultrasonics, SU23, No. 1, 2-22 (1976).

[72] E.H. Young jr., S.-K. Yao, Design considerations for acousto-optic devices. Proc. of the IEEE 69, No. 1, 54-64 (1981).

[73] D. Maydan, Acousto-optical pulse modulators. IEEE J. Quantum Electron., vol. QE-6, $15-24(1970)$

[74] M. Pusch, E. Neher, Rates of diffusional exchange between small cells and a measuring patch pipette. Pflügers Arch. 411, 204-211 (1988).

[75] A. Malgaroli, R.W. Tsien, Glutamate-induced long-term potentiation of the frequency of miniature synaptic currents in cultured hippocampal neurons. Nature 357, 134-9 (1992). 
[76] G. Liu, R.W. Tsien, Properties of synaptic transmission at single hippocampal synaptic boutons. Nature 268, 1624-8 (1995).

[77] U. Ashery, A. Betz, T. Xu, N. Brose, J. Rettig, An efficient method for infection of adrenal chromaffin cells using the Semliki Forest virus gene expression system. Europ. J. Cell. Biol. 78, 525-532 (1999).

[78] O. Hegener, R. Jordan, H. Häberlein, Dye-labelled benzodiazepines: Development of small ligands for fluorescence correlation spectroscopy. Veröffentlichung in Vorbereitung.

[79] O. Hegener ${ }^{*}$, R. Jordan*, H. Häberlein, Benzodiazepine-receptor binding studies on living cells: application of small ligands for fluorescence correlation spectroscopy. ${ }^{*}$ O.H. and R.J. contributed equally to this work; Veröffentlichung in Vorbereitung.

[80] W.J. Betz, F.Mao, C.B. Smith, Imaging exocytosis and endocytosis. Curr. Opin. Neurobiol. 6, 365-71 (1996).

[81] A. Dunaevsky, A. Tashiro, A. Majewska, C. Mason, R. Yuste, Developemental regulation of spine mobility in the mammalian central nervous system. Proc. Natl. Acad. Sci. USA 96 (23), 13438-12443 (1999).

[82] T.A. Ryan, H. Reuter, B. Wendland, F.E. Schweizer, R.W. Tsien, S.J. Smith, The kinetics of synaptic vesicle recycling measured at simple presynaptic boutons. Neuron 11, 713-724 (1993).

[83] A. Gennerich, D. Schild, Fluorescence correlation spectroscopy in small cytosolic compartments depends critically on the diffusion model used. Biophys. J., Veröffentlichung in Vorbereitung.

[84] BjT. Gjertsen et. al., Novel (Rp)-cAMPS analogs as tools for inhibition of cAMP-kinase in cell culture. J. Biol. Chem. 270 (35), 20599-20607 (1995).

[85] D. Toullec, P. Pianetti, H. Coste, P. Bellevergue, T. Grand-Perret, M. Ajakane, V. Baudet, P. Boissin, E. Boursier, F. Loriolle, The bisindolylmaleimide GF 109203X is a potent and selective inhibitor of protein kinase C. J. Biol. Chem. 266 (24), 15771-81 (1991).

[86] M. Maletic-Savatic, T. Koothan, R. Malinow, Calcium-evoked dendritic exocytosis in cultured hippocampal neurons. Part II: mediation by calcium/calmodulin-dependent protein kinase II. J. Neurosci. 18 (17), 6814-21 (1998).

[87] Z.W. Hall, An introduction to molecular neurobiology. Sinauer Ass., 1992.

[88] M. Hosaka, R.E. Hammer, T.C. Südhof, A phospho-switch controls the dynamic association of synapsins with synaptic vesicles. Neuron 24, 377-387 (1999).

[89] J. C. Lopez-Garcia, O. Arancio, E.R. Kandel, D. Baranes, A presynaptic locus for longterm potentiation of elementary synaptic transmission at mossy fiber synapses in culture. Proc. Natl. Acad. Sci. USA 93, 4712-4717 (1996). 
[90] M.P. Timmermann, C.C. Ashley, Fura-2 diffusion and its use as an indicator of transient free calcium changes in single striated muscle cells. FEBS Letters 209 (1), 1-8 (1986).

[91] A.F. Strautman, R.J. Cork, K.R. Robinson, The distribution of free Calcium in transected spinal axons and its modulation by applied electrical fields. J. Neuroscience 10 (11), 3564-75 (1990).

[92] M. Gabso, E. Neher, M.E. Spira, Low mobility of the $\mathrm{Ca}^{2+}$ buffers in axons of cultured Aplysia neurons. Neuron 18, 473-481 (1997).

[93] J.A Connor, Z. Ahmed, Diffusion of ions and indicator dyes in neural cytoplasm. Cell. Molecul. Neurobiology 4 (1), 53-66 (1984).

[94] M.G. Weisskopf, P.E. Castillo, R.A. Zalutsky, R.A. Nicoll, Mediation of hippocampal mossy fiber long-term potentiation by cyclic AMP. Science 265, 1878-1882 (1994).

[95] R. Rigler, A. Pramanik, P. Jonasson, G. Kratz, O.T. Jansson, P.-A. Nygren, S. Stahl, K. Ekberg, B.-L. Johansson, S. Uhlen, M. Uhlen, H. Jörnvall, J. Wahren, Specific binding of proinsulin C-peptide to human cell membranes. Proc. Natl. Acad. Sci. USA 96 (23), 1331813323 (1999).

[96] A. Pramanik, A. Jureus, Ü. Langel, T. Bartfai, R. Rigler, Galanin receptor binding studies in the membranes of cultured cells measured by fluorescence correlation spectroscopy. Biomed. Chromatogr. 13, 119-120 (1999).

[97] D.A. Jans, The mobile receptor hypothesis: the role of membrane receptor lateral movement in signal transduction. Springer-Verlag, Heidelberg, 1997.

[98] C. Essrich, M. Lorez, J.A. Benson, J.M. Fritschy, B. Luscher, Postsynaptic clustering of major $\mathrm{GABA}_{\mathrm{A}}$ receptor subtypes requires the gamma 2 subunit and gephyrin. Nat. Neurosci. 1, 563-71 (1998).

[99] A.M. Craig, C.D. Blackstone, R.L. Huganir, G. Banker, Selektive clustering of glutamte and gamma-aminobutyric acid receptors opposite terminals releasing the corresponding neurotransmitters. Proc. Natl. Acad. Sci. USA 91 (26), 12373-7 (1994).

[100] K. Baer, C. Essrich, J.A. Benson, D. Benke, H. Bluethmann, J.M. Fritschy, B. Luscher, Postsynaptic clustering of gamma-aminobutyric acid type A receptors by gamma3 subunit in vivo. Proc. Natl. Acad. Sci. USA 96 (22), 12860-5 (1999).

[101] E.M. Barnes jr., Intracellular trafficking of $\mathrm{GABA}_{\mathrm{A}}$ receptors. Life Sciences 66 (12), 1063-70 (2000).

[102] M.H. Tehrani, E.M. Barnes jr., Agonist-dependent internalization of gammaamonibutyroc acid A/benzodiazepine receptors in chick cortical neurons. J. Neurochem. 57 (4), 1307-12 (1991). 
[103] J.L. Velazquez, C.L. Thompson, E.M. Barnes Jr., K.J. Angelides, Distribution and lateral mobility of GABA/benzodiazepine receptors on nerve cells. J. Neuroscience 9 (6), 2163-2169 (1989).

[104] H. Wang, F.K. Bedford, N.J. Brandon, S.J. Moss, R.W. Olsen, GABA A-receptorassociated protein links $\mathrm{GABA}_{\mathrm{A}}$ receptors and the cytoskeleton. Nature 397, 69-72 (1999).

[105] C.R. Mackerer, R.L. Kochman, R.A. Bierschenk, S.S. Bremner, The binding of $\left[{ }^{3} \mathrm{H}\right]$ diazepam to rat brain homogenates. J. Pharmacol. Exp. Ther. 206 (2), 405-13 (1978).

[106] C.R. Walker, J.H. Peacock, Diazepam binding of dissociated cultures from fetal mice. Brain Res. 227 (4), 565-78 (1981).

[107] S.-C. Fung, M. Fillenz, Effects of guanyl nucleotides on $\left[{ }^{3} \mathrm{H}\right]$ Flunitrazepam binding to rat hippocampal synaptic membranes: equilibrium binding and dissociation kinetics. $J$. Neurochem. 44 (1), 233-239 (1985).

[108] A.W. Henkel, L.L. Simpson, R.M.A.P. Ridge, W.J. Betz, Synaptic vesicle movement monitored by fluorescence recovery after photobleaching in nerve terminals stained with FM1-43. J. Neuroscience 16 (12), 3960-3967 (1996).

[109] L.E. Dobrunz, C.F. Stevens, Heterogeneity of release probability, fascilitation, and depletion at central synapses. Neuron 18, 995-1008 (1997).

[110] T.A. Ryan, Inhibitors of the myosin light chain kinase block synaptic vesicle pool mobilization during action potential firing. J. Neurosci. 19, 1317-1323 (1999).

[111] J. Klingauf, E.T. Kavalali, R.W. Tsien, Kinetics and regulation of fast endocytosis at hippocampal synapses. Nature 394, 581-585 (1998). 


\section{Anhang}

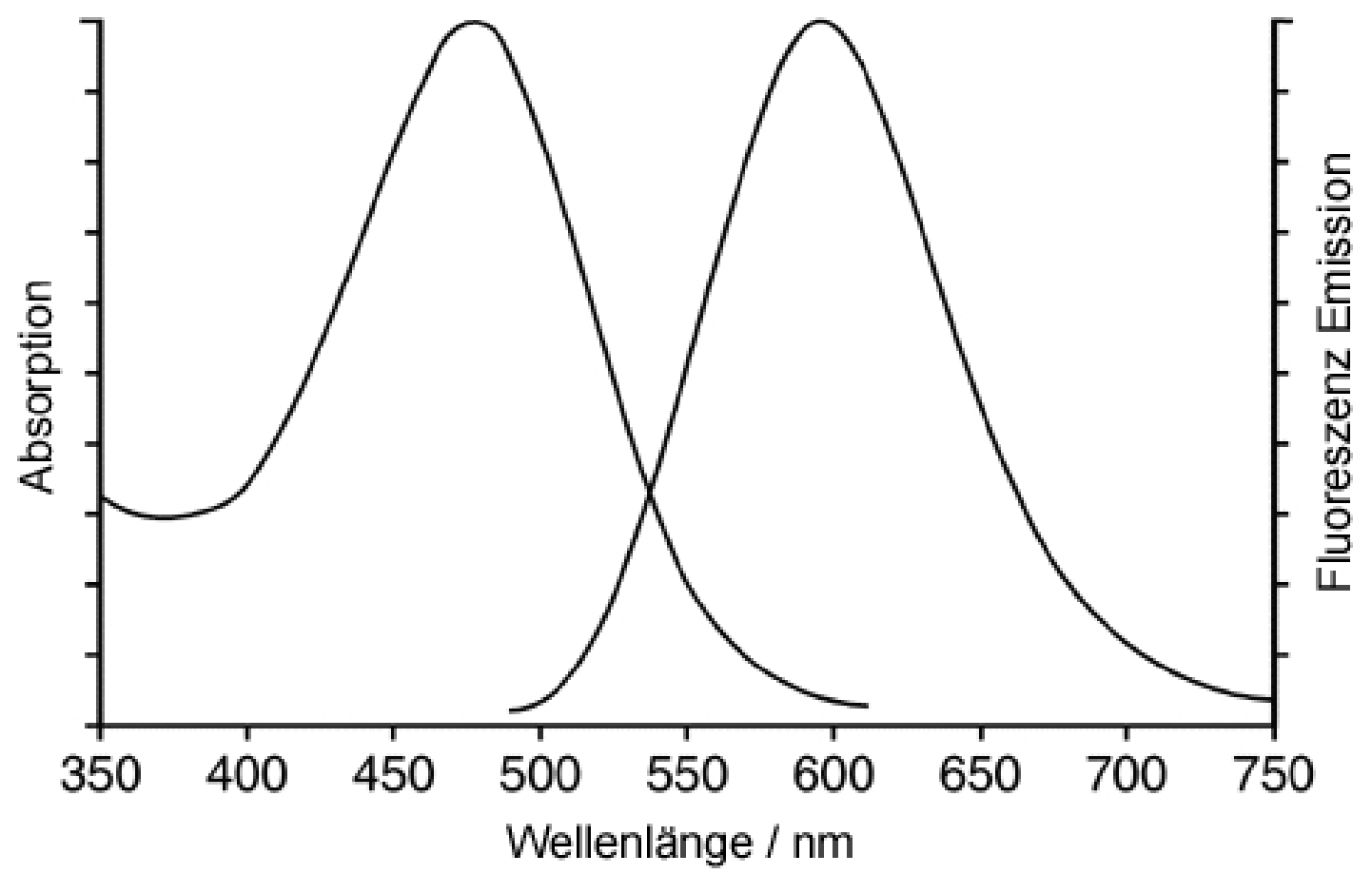

Abbildung 78: Absorptions- und Emissionsspektrum von FM 1-43 (nach Farbstoffinformation (Molecular Probes), verändert). 


\section{Danksagung}

Mein besonderer Dank gilt meinem verehrten Lehrer, Herrn Prof. Dr. E. Neher, für die Betreuung und die stete Förderung dieser Arbeit.

Herr Prof. Dr. J. Troe danke ich für die Aufsicht der Arbeit seitens der Universität Göttingen.

Dr. J. Klingauf danke ich für die zahlreichen anregenden Diskussionen und die gute Zusammenarbeit.

Herrn O. Hegener und Dr. H. Häberlein danke ich für die gute Kooperation.

Herrn F. Köhne, Herrn M. Pilot und Herrn F. Würriehausen möchte ich für ihre ständige Hilfsbereitschaft danken.

Den Mitarbeitern der Feinmechanik-Werkstatt unter der Leitung von Herrn R. Schürkötter, und allen Angehörigen der Reprostelle danke ich für die korrekten und schnellen Ausführungen der Arbeiten.

Herrn A. Gennerich danke ich für die freundliche Überlassung des Manuskripts vor der Veröffentlichung.

Weiterhin bedanke ich mich für die zahlreichen Diskussionen und das angenehme Arbeitsklima bei allen Mitarbeitern der Abteilung Membranbiophysik. 


\section{Lebenslauf}

02. März 1971:

August 1977 - Juli1981:

August 1981 - Juli 1983:

August 1983 - Mai 1990:

09. Mai 1990:

August 1990 - Oktober 1991:

Oktober 1991 - November 1996:

November 1995 - Oktober 1996:

01. November 1996:

November 1996 - Dezember 1996:

Januar 1997 - Oktober 2000:

Göttingen, 19. September 2000
Geboren in Aurich (Staatsangehörigkeit: deutsch)

Grundschule in Norden

Orientierungsstufe II in Norden

Ulrichsgymnasium in Norden

Schulabschluß: Abitur

Zivildienst im Amt für Planung und Naturschutz des Landkreises Aurich

Studium an der Georg-August-Universität zu Göttingen; Studiengang: Chemie (Diplom)

Anfertigung der Diplomarbeit „Untersuchung der Kinetik der Elementarreaktionen von $\mathrm{NH}\left(\mathrm{a}^{1} \Delta\right)$ mit $\mathrm{H}_{2} \mathrm{O}_{2}$ und $\mathrm{H}_{2} \mathrm{O}^{\text {“ }}$ am Max-Planck-Institut für Strömungsforschung (Göttingen) in der Abteilung Reaktionskinetik unter der Leitung von Prof. Dr. H. Gg. Wagner und der Betreuung von Prof. Dr. W. Hack

Hochschulabschluß: Chemie (Diplom)

Wissenschaftlicher Mitarbeiter am MPI für Strömungsforschung

Anfertigung der Doktorarbeit am Max-PlanckInstitut für biophysikalische Chemie (Göttingen) in der Abteilung Membranbiophysik unter der Betreuung von Prof. Dr. E. Neher und der Aufsicht seitens der Universität von Prof. Dr. J. Troe. 